\title{
VIETNAMESE RECEPTION OF SOFT MASCULINITIES IN KOREAN TELEVISION DRAMAS: DESIRES, IDENTIFICATIONS, AND GENDER
}

\author{
BY \\ THI GAMMON
}

\begin{abstract}
A thesis
submitted to Victoria University of Wellington

in fulfilment of the requirements for the degree of

Doctor of Philosophy
\end{abstract}

Victoria University of Wellington

2021 


\begin{abstract}
This doctoral thesis explores Vietnamese audience reception of soft masculinities, defined by the aestheticisation and romantic idealisation of male characters, in South Korean television dramas (K-dramas). Based on interview data collected in 2019, the thesis focuses on patterns of gendered desire, identification, and negotiation in viewers in their 20 s and 30s. It highlights the popularity of K-dramas in Vietnam, which have established an enduring presence there since the late 1990s, overlapping with ongoing changes in gender relations following the introduction of the 1986 Đổi Mới (reform) policy, marked by Vietnam's transition to a market economy and gradual integration into global trade. The thesis demonstrates how the spread of this "Korean Wave" is correlated with a changing local mediascape, the rise of a consumer culture, and a growing interest in exploring the self.
\end{abstract}

In this thesis, I adopt the Free Association Narrative Interview (FANI) method, which draws on the solicitation of free talk and storytelling and psychosocial attention to case studies in order to connect interview participants' biographical details with their viewing experiences. The study is influenced by Judith Butler's theoretical work on gender and performativity, as well as related material by scholars such as Michel Foucault and Pierre Bourdieu. I highlight how a nuanced understanding of the viewing experience treats it as a complex process linked to an individual's biographical details and explore how this process intertwines with larger sociocultural contexts, including local norms, Confucian values, feminism, Western gender images, notions of modernity, and globalised aesthetic ideals. The study reveals that although gendered desires and identifications are shaped by norms, they can also subvert them, and thus provides empirical evidence for Butler's theories from a Vietnamese context. It also shows that desires and identifications that result from engagement with fantasy on screen may follow viewers' personalised logics and open up multiple avenues for interpretations. Prominent themes of viewing experiences in relation to soft masculinities analysed in this thesis include escapism, parasocial interactions with characters, romantic imaginations, melancholic identification with romantic relationships on screen, desires for upward mobility, queer pleasures, ambivalence, and disidentification. The thesis thus contributes to contemporary Vietnamese studies, gender studies, psychosocial studies, media audience studies, and research on the Korean Wave. 


\section{Table of Contents}

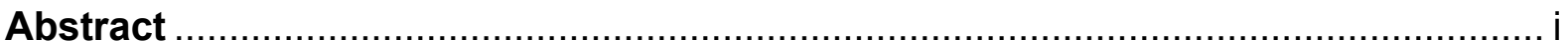

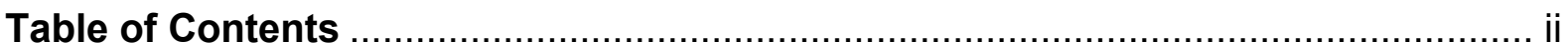

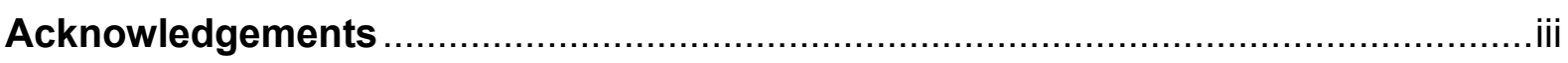

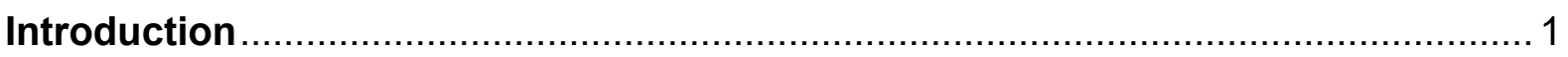

Research Questions and Psychosocial Studies ................................................... 4

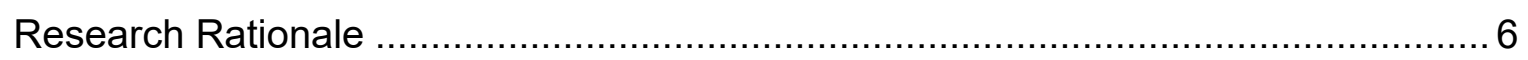

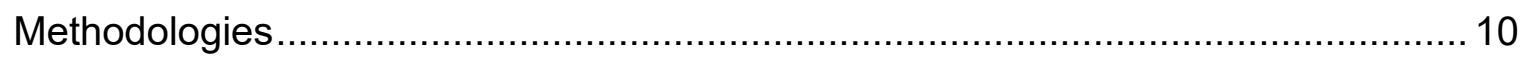

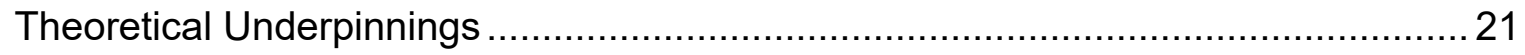

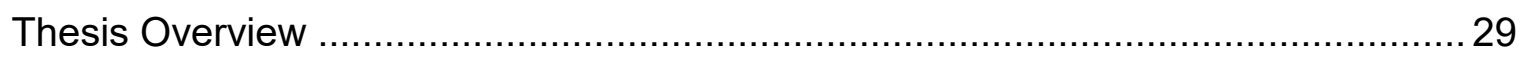

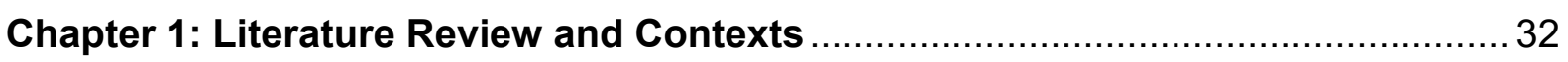

Traditional Gender Relations, Hegemonic Masculinity, and Disruptions ................... 32

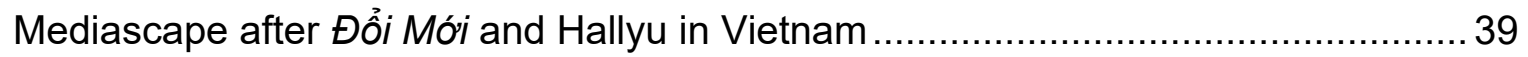

Understanding K-Drama ........................................................................... 44

The Polysemy of Soft Masculinities and Transnational Reception ..........................46

Chapter 2: A Retreat from Life: In Search of the Extraordinary............................ 56

Chapter 3: Caught in the Atmosphere of Love ............................................... 74

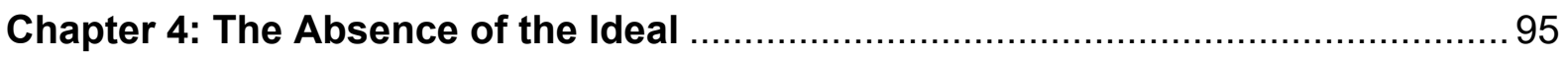

Chapter 5: Your Bodies are Our Future ....................................................... 113

Chapter 6: Resistance to Gender Threats................................................ 135

Chapter 7: Queering Korean Pop Culture ......................................................... 156

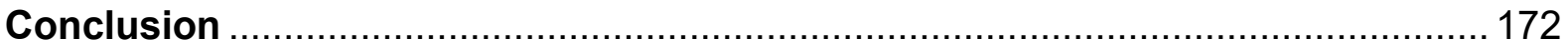

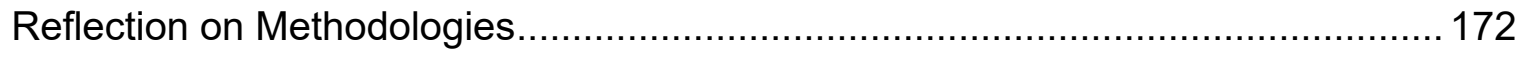

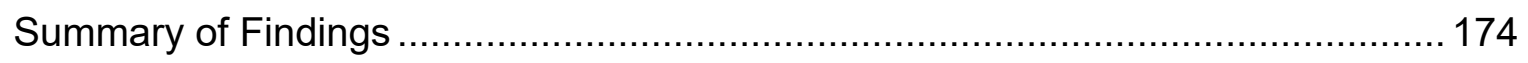

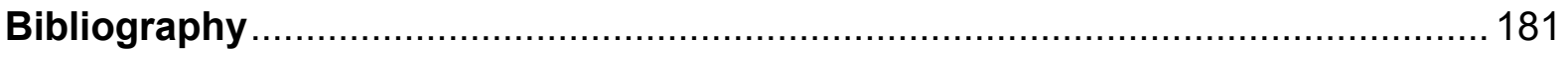

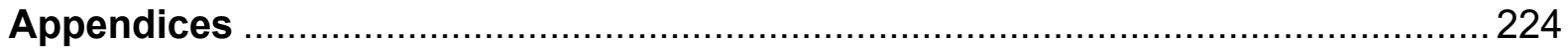

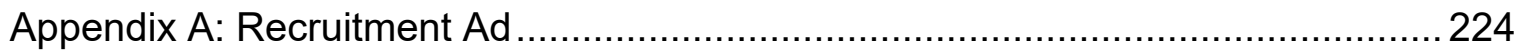

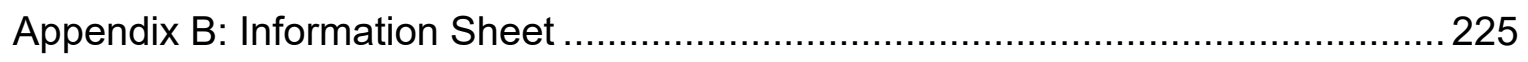

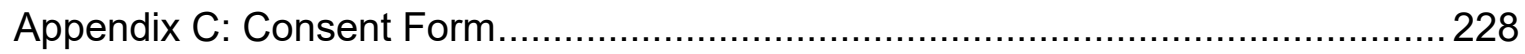

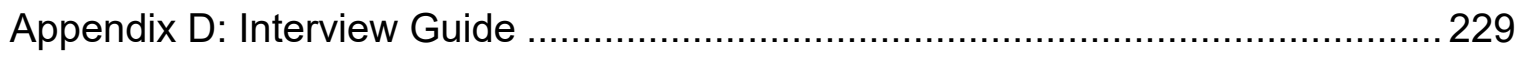




\section{Acknowledgements}

This research was made possible by the Victoria University of Wellington, which offered me a full scholarship and generous funding for data collection. I thank the university's staff for their assistance throughout my doctoral journey. I also thank the British Foreign and Commonwealth Office for having awarded me the Chevening Scholarship for my master's studies at the University of Westminster, which ultimately motivated me to pursue a PhD.

My thanks especially extend to sixteen interview participants who generously shared with me their fascinating stories, including private details of their lives. I learned as much from them as I learned from the scholars whose theories and research helped shape this study.

I am fortunate to have had three supervisors who were as encouraging as they were sharp and thoughtful in giving me constructive comments. I am greatly indebted to my primary supervisor, Associate Professor Stephen Epstein, for having helped me gain a scholarship in the first place and having offered immensely helpful guidance throughout the project. I also thank my secondary supervisors, Associate Professor Joost de Bruin and $\mathrm{Dr}$ Cherie Lacey, for their enduring encouragement and insightful advice.

I thank my parents for their ongoing support towards my studies throughout my life. It was my parents who cultivated in me a keen interest in reading, learning, and exploring. I am forever grateful for their dedication and sacrifice.

Finally, my deepest gratitude is reserved for my husband, Jack Gammon, who has more faith in my ability as a writer than I do. Coming to New Zealand to pursue a PhD. was one of the best decisions I have made because I completed my thesis with great support from many generous people here and met my partner for life. 


\section{Introduction}

My peers and I grew up and came of age amidst the emergence and growth of the Korean Wave, the ascendancy of mass culture from South Korea (hereafter Korea) in Vietnam. ${ }^{1}$ In the late 1990s and early 2000s, when I was in secondary school, Korean television (TV) dramas such as Medical Brothers (1997) and Autumn in My Heart (2000) became very popular. ${ }^{2}$ These serials brought about a Korean fashion trend, with the arrival of darkertoned lipsticks and hairstyles. Young women and men began to dye their hair, have it straightened or done in similar styles as Korean actors. By the time I reached adulthood, other forms of Korean mass culture such as K-pop, movies, and reality shows had caught up and established their steady presence in the local menu of cultural consumption. All this happened against the backdrop of a fast-changing, increasingly consumerist society transformed by the 1986 Đổi Móri (Reform) policy, defined by the country's switch to a market economy and its integration into the global economy (Turley \& Selden, 1993; Werner \& Bélanger, 2002). Vietnam, highly isolated for a decade after the war and suffering from economic and cultural impoverishment, has since been exposed to global media and embraced diversified cultural consumption.

During my school years, Korean television romances helped shape my ideal of perfect romance: all-consuming, tempestuous, and everlasting. Although my view of an ideal romance has changed over time, vivid memories of Korean romantic stories which highlight selfless devotion, spiritual compatibility, and a "love conquers all" message remain. The Korean dramas (also known as K-dramas) that have become popular in Vietnam and worldwide tend to construct a "romantic utopia" (Illouz, 1997) through the ideal of a dream man who embodies beauty, status, and wealth, combined with undying devotion to a one and only lover. Usually paired with a seemingly ordinary yet virtuous female lead, this dream man is designed to cater to women's romantic fantasy. This romantic trope, however formulaic, has not ceased to enchant Vietnamese viewers even after two decades. I have experienced rich feelings while watching romantic Korean dramas, especially when I was younger: infatuation, immersion, excitement, joy, and sorrow. I have enjoyed admiring the male leads' slim, fit bodies in perfect suits, their alluring faces, their decisive leadership at the workplace, and their acts of chivalry. Above

\footnotetext{
1 This thesis limits its discussion to South Korea only. "Korea" should be understood throughout the whole thesis as South Korea, and "Korean" as any matters pertaining to South Korea.

${ }^{2}$ All the broadcasting years used in this thesis are the initial broadcasting years in South Korea. Korean dramas in Vietnam tend to be broadcast later and re-broadcast multiple times if they become hits.
} 
all, Korean dramas showed me how a woman could be treated by a man: being offered fancy gifts, being protected and rescued, and above all, being loved and adored. I recall the excitement of watching couples' initial display of affections, often delayed by obstacles and misunderstandings. Before personally experiencing romance, I had enjoyed it vicariously through my immersion in K-dramas. I developed crushes on handsome male leads and discussed my infatuation with female friends who likewise expressed their desire for those men. Later, I realised that most of these dream men fall into the category of "soft masculinities" conceptualised most prominently by Sun Jung (2011). I should note from the outset, however, that variations occur within this overarching rubric, hence the use of a plural form throughout this thesis.

Soft masculinities in Korean dramas most stereotypically draw on a double feminisation of appearance and character in men (Maliangkay 2010; Elfving-Hwang, 2011; Jung, 2011; Khai \& Wahab, 2017). Soft masculinity icons tend to have a "pretty" face with boyish, youthful features and a tall and fit figure, and exhibit androgynous fashion marked by floral outfits and feminine-coded accessories. Such men often show polite mannerisms, unequivocal devotion in romantic relationships, and a willingness to express feelings. This trend of soft masculinities is not only observed in Korean pop culture but also in contemporary Japanese and Taiwanese cultural products, leading scholars to term the phenomenon "Pan-East Asian soft masculinity," marked by the commodification of the male body and promotion of consumerism (Jung, 2011, Louie, 2012; Maliangkay \& Song, 2015). Overall, soft masculinities are understood as feminised, romanticised, and commercialised representations of masculinities.

To Vietnamese audiences, soft masculinities are both familiar and foreign. On the one hand, these constructions reinforce the prevailing ideal of men as breadwinners and social leaders through attractive protagonists that embody wealth, privilege, and talent. These forms of masculinity have also been traced back to images of the polite male scholar in Chinese Confucian ideology (Jung, 2011), characterised by a fragile/tender appearance, good manners, and strong inner will (Louie, 2002; Song, 2004). Such constructions are known as seonbi masculinity in Korea and hình tương nho sinh in Vietnam. On the other hand, while representing the "dream men" in women's fantasy, soft masculinities belong to a fantasy world detached from reality (Maliangkay \& Song, 2015) and therefore may not be taken seriously. Furthermore, K-drama male characters' narcissistic attention to looks and wholehearted devotion to their lover may lead to them being perceived as feminine and weak in a culture that accentuates men's strength and emotional restraint (Soucy, 
1999; Nghe et al., 2003; Thanh Thi Vu³ 2020). Feminised display of male beauty in Korean pop culture has led to a backlash in local mass and social media, especially among men who find such images "unmanly" and "sissy." Vietnamese media and members of the public have described Korean soft masculinities as a negative trend that subverts a normative understanding of gender (e.g., Minh Hạo, 2018; Thanh Cao, 2018). Such a backlash can be explained by traditional perspectives on gender, which attribute beauty and the performance of beauty to women rather than men (in Vietnam, women are often called phái đẹp, or the beautiful sex while men are called phái mạnh, the strong sex) and see men fussing about their appearance as unmanly (Manh Cuong La, 2012, pp. 94-95). Nguyễn Du's poetic epic Truyện Kiều (The Tale of Kiều) describes a male villain named Sở Khanh with a hint of sarcasm and disapproval as "a meticulously groomed young man who looks glossy and gentle." ${ }^{4}$ Some Vietnamese people may see alternative gender constructions like soft masculinities as "threats" that disrupt traditional dyadic ideals of gender.

My observations of Vietnamese audiences' fascination (including my own) with soft masculinities initiated my long-time interest in exploring audiences' experience of romantic Korean dramas. Through participation in local fan forums and social media fan pages, I have noticed how many viewers, mostly women, express desires for male leads and enjoy moments of identification when they recognise themselves or imagine themselves in certain romantic situations. Vietnamese audiences of these romantic dramas come from all walks of life and are of different ages, single or married. I have come to learn, from social relationships, my master's research (Luong, 2016), and this project, that some men like watching Korean dramas too, even though they may not openly acknowledge such enjoyment. I have also realised over time that viewers go back and forth between their lived and viewing experience, i.e. their "real" life and phantasmatic world. Sometimes when they discuss a Korean drama, they refer to former lovers, current partners, or potential dates and compare romantic situations on screen with their own life. This observation has led me to question how audiences' desires, identifications, and gender ideals inform their views of Korean male characters and whether male characters help inform their ideas of masculinity. I assume, from observations of viewers' experiences, that there need not be a one-way influence here, but rather an interaction between mediated masculinities and one's views of masculinity. As O'Shaughnessy (1994) argues, media consumption reflects

\footnotetext{
${ }^{3}$ Due to the prevalence of similar last names in Korean and Vietnamese scholars, such as Kim and Nguyen, I cite and reference the full names of most Korean and Vietnamese scholars to avoid confusion.

${ }^{4}$ Một chàng vừa trạc thanh xuân/Hình dung chải chuốt, áo khăn dịu dàng
} 
us in ways that help us better understand ourselves because we all bring "emotional baggage" to our readings and may project ourselves onto characters or situations in media texts (pp. 44-46). To question the purported binary between fantasy, or more specifically fictional engagement, and "reality" as lived experience, I investigate the ways in which these worlds meet, where Vietnamese reception of Korean soft masculinities is concerned. At the same time, my observation of the backlash against soft masculinities has led me to question gender negotiations that may underlie some viewers' consumption of soft masculinities. Out of such curiosities, this doctoral research project commenced and sought to offer a space for Vietnamese audience members to share viewing experiences. To investigate the viewing of Korean dramas as both a social and personal experience, I have looked to psychosocial studies to inform my method. I explain this approach in detail in the next section and delineate how it is appropriate for addressing my research questions.

\section{Research Questions and Psychosocial Studies}

In this thesis, I endeavour to explore the following interrelated research questions:

(1) How do the gendered desires of Vietnamese viewers in their 20s and 30s interact with their experience of viewing soft masculinities in Korean television dramas?

(2) How do they (dis-)identify with soft masculinities, and what are the psychosocial meanings of such (dis-)identifications?

(3) How can those desires and (dis-)identifications be linked to negotiations of gender?

A psychosocial approach, in both empirical and interpretive terms, best serves the purpose of investigating the connection between the realms of lived and imagined experience. This increasingly influential approach, developed largely by British scholars since the 1990s (Whitehouse-Hart, 2014; The Association of Psychosocial Studies, n.d.), combines multiple disciplines in social sciences, including most typically psychology, psychoanalysis, sociology, queer studies, poststructuralist theory, and cultural studies (Frosh \& Baraitser, 2008; Frost \& McClean, 2014; Woodward, 2015). The Association of Psychosocial Studies, as of February 2021, summarises the essence of psychosocial studies as follows:

It studies the ways in which subjective experience is interwoven with social life. Psychological issues and subjective experiences cannot be abstracted from societal, cultural, and historical contexts; nor can they be deterministically reduced 
to the social. Similarly, social and cultural worlds are shaped by psychological processes and intersubjective relations. (para. 1)

Woodward (2015) explains that "psychosocial studies bring together the micro and the macro, the personal and the social, inner worlds and outer worlds, which combine in different ways" (p. 5). The approach is marked by attempts to explore both the manifest content of discourse and the latent processes behind the formation of such narratives (Whitehouse-Hart, 2014). The aim behind a psychosocial interest in these latent processes is to consider informants' anxieties, defences, and moods shown in interview contexts (Hollway \& Jefferson, 2000; Whitehouse-Hart, 2014). Applying a psychosocial approach to audience research is a means to read audience reception "symptomatically," that is, to scrutinise audiences' narratives beyond their face value and attend to the profound psychological meanings behind such narratives (Ang, 1985, p. 11).

My adoption of a psychosocial approach stems from my observation of the tendency for traditional audience research to homogenise. Addressing the viewing experience as a social rather than private experience, traditional audience research often strips viewing experiences from the context of individuals' lived experiences. Within research on the Korean Wave (also known as Hallyu ${ }^{5}$ ), even when studies explore audiences' viewing from a psychological lens, they often treat audience members' experience of such emotions as loneliness as collectively felt, despite the possibility that individuals' experience of loneliness can differ significantly. I argue that this decontextualisation of narrative cannot fully account for gendered identifications and desires, the focus of my study. As Mishler (1986) and Hollway and Jefferson (2000) contend, decontextualising narratives poses problems because doing so risks generalisation, homogenisation, and essentialism. In an era where audiences have become increasingly fragmented and viewing experience increasingly personalised due to the broader range of media on offer and proliferation of communication means, case-study research of the viewing experience such as that conducted by Johanssen (2018a; 2018b) and Whitehouse-Hart (2014) has gained currency. A psychosocial study with an orientation towards case study analysis offers an innovative way to look at individual viewing experience as both a social and private phenomenon. Such a study treats reception, as Ang (1990) urges, as "an integral part of popular cultural practices that articulate both 'subjective' and 'objective,' both 'micro' and 'macro' processes" (p. 244) and therefore

\footnotetext{
${ }^{5}$ According to Jung (2011, p.1 \& p. 174), the term Hallyu, which literally means "Korean wave" was coined in Chinese-speaking states in the late 1990s.
} 
better captures the intricacies of the viewing experience. This approach is based on the belief that a person's views and feelings about something, either conscious or unconscious, cannot be thoroughly understood without knowledge of relevant biographical facts (Hollway \& Jefferson, 2000). It is also based on the logical caution that, while people's descriptions of feelings can be similar, they can mean different things when using the same words, hence the need to examine their thoughts thoroughly by connecting these with their experiences. An obvious disadvantage of this method is that the data collected cannot be representative of a population due to its personal nature and usually small sample. Yet, larger sociological meanings can still be drawn from viewers' common patterns of viewing, as this study shall show. I elucidate the set of methods I developed to conduct this psychosocial research project in the Methodologies section.

\section{Research Rationale}

I chose to focus on romantic Korean television dramas (rather than local or other foreign cultural products) and the representations of soft masculinities in these dramas to study Vietnamese audiences' gendered viewing experience for the following main reasons:

The first is the consistent popularity of the Korean Wave in Vietnam. As in some other countries across Asia, the success of Korean dramas has brought about the penetration of other Korean cultural products such as K-pop, cinema, and reality shows. The steady presence of the Korean Wave in Vietnam and various parts of the world demonstrates itself as a global cultural phenomenon worthy of extensive academic attention. Although television shows from all over the world have joined the Vietnamese menu of mass cultural consumption during the past three decades after Đổi Mới, Korean drama remains among the genres most watched by the Vietnamese. Scholars such as Suh et al. (2006), Joong-Keun Kim (2010), and Trần and Cao (2015) have even viewed Vietnam as the centre of the Korean Wave in Southeast Asia. According to recent Google Trends annual reports, the titles of Korean dramas and Korean entertainers have been consistently present in its top searches by Vietnamese people. Recent Netflix reports also show that Korean dramas rank among the top items consumed in its Vietnamese market.

Furthermore, a link between Vietnamese consumption of Korean dramas and international marriages between Vietnamese women and Korean men has manifested itself. A survey with nearly 450 Vietnamese rural women conducted by Hong Tien Vu and Tien-Tsung Lee (2013) reveals a positive correlation between the frequency of watching Korean dramas and a tendency to view Korea as a desirable place to live and Korean men 
as attractive marriage partners. This correlation has been supported by Linh Khanh Nguyen's dissertation (2016a), which highlights how Vietnamese rural women's favourable views of Korea and of Korean men are affected by their viewing of Korean dramas. Although most research, including Linh Khanh Nguyen's (2016a), accentuates Vietnamese women's desire for a better economic standing for both themselves and their families as a primary reason for their marriage to Korean men, the role of watching Korean dramas was seen as a significant contributing factor.

Following the prevalence of Korean dramas, K-pop emerged in the mid-2000s. Its enthusiastic fandom has become a topic of heated social discourse due to the local media's tendency to pathologise and pass moral judgments on "obsessive" young K-pop fans (Bayly, 2014; Su Jeong Kim \& Eun June Kim, 2016; Duong Nguyen Hoai Phuong, 2016; Hoang $\mathrm{Ha}, 2020$ ). K-pop fandom in Vietnam is phenomenal in that it has gone beyond mundane enjoyment to become part of young fans' both private and collective intimate spaces, giving rise to considerable public debate (Phan Thanh Thanh, 2014; Duong Nguyen Hoai Phuong, 2016; Hoang Ha, 2020). Such fervent reception distinguishes K-pop fandom to fan activities associated with other genres of global media from the US, China, Japan, or Thailand, which enjoy some popularity but generally do not attract debates (Duong Nguyen Hoai Phuong, 2016; Hoang Ha, 2020). Research has also linked local fans' consumption of K-pop to their acceptance of androgyny in male entertainers (Hoang Ha, 2020).

Due to widespread consumption of Korean dramas and K-pop alike, Vietnam's most visited news websites, such as Kenh14.vn, Zing.vn, and VnExpress.net frequently report Korean showbiz events. Popular Korean dramas such as Full House (2004), She Was Pretty (2015), and Descendants of the Sun (2016) have been remade in Vietnam, while local reproductions of Korean films like Em là bà nội của anh (I'm Your Grandma) (2015) and Tháng năm rực rỡ (The Brightest Years) (2018) became box-office hits. Vietnam has also made its own versions of popular Korean reality shows such as Running Man and Dad! Where Are We Going?. Korean pop culture's aesthetic style and soft masculinities have had a considerable impact on local pop culture: Vietnamese stars such as Sơn Tùng M-TP, Soobin Hoàng Sơn, and Isaac have been viewed as exemplifying local versions of soft masculinities for their emulation of Korean entertainers' fashion and performing style.

Second, Korean dramas construct a romantic utopia in which Vietnamese viewers may indulge with a "forward-looking attitude" (Oh, 2011; Andrew Eungi Kim et al., 2013), 
characterised by the view of Korea as a more developed country and of Korean protagonists as inspirational models. They offer an aesthetic quality and emotional realism that local soap operas cannot compete with (Trần, 2020). Glamorous lifestyles and the fashions exhibited by K-drama characters-as well as scenes of highly developed cityscapes-appeal greatly to the Vietnamese audiences (Bui, 2007; Ngo, 2015; Luong, 2016). Such appeal has become more enticing as a consumer culture in urban Vietnam has developed (Thomas \& Drummond, 2003; Dang \& Pham, 2003; Nguyen Bich Thuan \& Thomas, 2004; Pham Hai Chung, 2015; Nhat Nguyen Nguyen et al. 2018; Jang et al., 2021). The emergence and rise to popularity of K-dramas have moved in tandem with the metamorphosis of Vietnamese society after Đổi Móri in the mid- and late 1990s, as I shall discuss in the next chapter. Beyond their narratives, Korean dramas as representations of Korea's modern infrastructure enable Vietnamese viewers to learn about the country's development as a "raw model" (Suh et al., 2006). The success of Korean mass culture in Vietnam can be compared to its popularity in China in the 2000s, where Korean pop culture seems to have helped satisfy audiences' demand for an alternative culture better corresponding to their increasing and dynamic economic growth and cultural development (Hyun Mee Kim, 2005). At the same time, despite the two countries' economic gap, Korea and Vietnam share significant elements of cultural proximity, such as enduring Confucian ideologies, strong social emphasis on family values, and normative views of romance that tend towards conservatism (Bui, 2007; Cohen, 2000; Joong Keun Kim, 2010; Hyejung Ju \& Soobum Lee, 2015). Such cultural proximity, which my empirical chapters shall unfold, adds to audiences' feeling of "emotional realism" as they find the texts emotionally meaningful and identifiable (Ang, 1985). The romantic dimension of the dramas has been found to mesmerise many local women and, to a lesser degree, men as well.

I argue that the aesthetic qualities and emotional realism have given Korean dramas a distinctive advantage over other Asian soap operas as well as Western TV series consumed in Vietnam and have allowed this genre to stay popular. ${ }^{6}$ These factors also help K-dramas compete with Vietnamese soap operas. Some recent popular Vietnamese TV shows such as Sống Chung Với Mẹ Chồng/Living with Mother-in-law (2017) and Về Nhà Đi Con/Come Home, Daughter (2019) deal with issues such as family affairs, intergenerational conflicts, and urban problems but fail to portray relatable love stories. This failure to compete has been attributed to a Vietnamese reticence to express romantic

\footnotetext{
${ }^{6}$ This is not to say that other foreign TV shows do not have their own appeal. Most participants in my sample consume television programmes from various countries besides Korean dramas.
} 
emotions (Đặng Thiếu Ngân, 2020), which thrive in local romantic literature but not onscreen. This transcultural emotional resonance is not uncommon, as Espiritu (2011) and Min Joo Lee (2020) find in their respective studies that Filipino and Western female audiences relate to romantic Korean dramas more than their local TV dramas.

Third, I contend that Vietnam's enthusiastic reception of soft masculinities in both K-dramas and K-pop, especially among youth, signals local demand for alternative gender representations. Globalisation and transnationalism have fostered increasing Vietnamese openness to alternative masculinities, marked by the consistent growth of international marriages. This increasing openness to alternative masculinities, including those from abroad, needs to be situated within a broader context of the local dynamic socio-economic changes, which has seen diversified consumption practices and globalised access to information. Shifting gender politics, marked by improving women's status, increasing alternative gendered practices, and the vibrancy of the contemporary LGBT movement since the $2010 s^{7}$, accounts in large part for this openness. Complex reactions to feminist values and patriarchy render a study of transnational consumption of foreign forms of masculinity worthwhile. Since Vietnam is considered one of the countries that most welcome Korean pop culture, a study of Vietnam's reception helps enrich understandings of the Korean Wave's impact across Southeast Asia while revealing elements of changing gender politics in contemporary Vietnam.

It is also important to note an observation recently highlighted by the local press regarding the lack of appeal of male characters/actors in local TV dramas and movies compared to their counterparts in foreign media, including especially male characters in Hollywood and Korean dramas (Ngọc Diệp et al., 2019; Lâm Long, 2021; Bảo Ngọc, 2021; Mi Ly, 2021). Local news websites have cited the shortage of talented and attractive actors compared to actresses and the trope of portraying men as authoritarian, adulterous, and violent to create sensational stories on local television and cinema as reasons for this situation (Ngọc Diệp et al., 2019; Lâm Long, 2021; Bảo Ngọc, 2021). The press argues that the lack of male characters that serve as exemplary models of masculinity on local screen has motivated local audiences to seek those in Hollywood and Korean dramas instead (ibid.). While I shall not delve into this situation, which merits thorough research and promises intriguing implications, I find it noteworthy to present it here as a background

\footnotetext{
${ }^{7}$ In Vietnam, the non-heterosexual community is mostly known as LGBT (lesbian, gay, bisexual, and transgender). In the society, there is little awareness of the extension of this terminology, such as LGBTQIA+. To maintain consistency with what has been going on in Vietnam, I refer to the local non-heterosexual community as LGBT in this thesis.
} 
factor that explains my focus on soft masculinities, which manage to leave a steady impression despite their foreign origins.

To date, there has been no full-length study investigating Vietnamese reception of Korean soft masculinities. My thesis, with its exploration of both women's and men's reception, including a few non-heterosexual informants, offers a holistic qualitative approach to this topic in both theoretical and methodological terms. It scrutinises Korean soft masculinities in their manifold aspects, including aesthetic and fashion styles, as well as romantic practices. In so doing, the study reveals patterns of gendered identification, desire, and negotiation among its informants as examined from a psychosocial lens, an emerging approach in audience research. Through innovative methods, my thesis, therefore, makes psychosocial contributions to the studies of media, gender, and contemporary Vietnam.

\section{Methodologies}

\section{Free Association Narrative Interview}

For data collection, I adopt the Free Association Narrative Interview (FANI) developed by Wendy Hollway and Tony Jefferson in their book Doing Qualitative Research Differently (2000). This interviewing model is based on Sigmund Freud's "free association" psychoanalytic methods and the biographical-interpretative approach developed by German sociologists Rosenthal (1993) and Schütze (1992). The psychosocial method is characterised by open-ended interviewing whereby participants are encouraged to talk freely about whatever comes to mind and by examination of the accounts of significant events that help shape their worldviews. Participants are invited to tell a story and ideally structure interviews themselves with minimal intervention from the researcher (Boydell, 2009). Due to its aim at emotionally significant data, multiple interviews with the same participant are usually conducted.

As the term "free association" suggests, this method seeks to encourage the flow of ideas that remain subconscious in the subject's mind to emerge naturally rather than following an imposed logical structure (Clarke, 2002). The method is based on the belief that strong emotions, sometimes subconscious, may be found in the links between one idea and the next (Hollway \& Jefferson, 2000) as the speaker shares what comes to their mind. While this method is traditionally used in psychoanalysis to help patients get in touch with their unconscious feelings, when used in social sciences, it aims primarily to help the 
researcher understand a subject's experience deeply. With its roots in psychoanalysis, FANI has widely been used in psychology and sociology (Frosh et al., 2003; Roseneil \& Budgeon, 2004; Roseneil, 2006; Gadd \& Jefferson, 2007; Morgan Brett, 2010; Jimenez \& Walkerdine, 2011; Arend 2014; Hickman, 2019; Aarseth, 2020;; Harris, 2020; LukacGreenwood \& Rijn, 2021). In media audience studies, however, applications of this interview method are nascent; notable examples include Cohen's (2012) research on the experience of watching a female serial killer in films, Whitehouse-Hart's (2014) investigation of viewers' relationships to their favourite media texts, and Johanssen's (2018a; 2018b) study of audience reception of the reality TV show Embarrassing Bodies. These scholars have explored the nuances of media consumers' subjective experiences that involve pleasure and anxieties. My study is similar to Cohen's and Whitehouse-Hart's in its focus on case studies and biographical significance but is less theoretically dependent on psychoanalysis in favour of grounding in a combination of psychology, sociology, and cultural studies. With its lesser dependence on psychoanalysis, my research may be more accessible to the wider public, even though scholars with a background in psychoanalysis may see my rather limited discussion of concepts such as fantasy/phantasy and lack (cf. footnote 23, p. 107) in traditional psychoanalytic terms as a drawback. My foremost reason for this narrower approach is to allow a focus on psychological and social factors in the viewing experience and the interrelation between the two and to emphasise viewing as both an individual and collective experience.

Via a free associative approach, I traced aspects of informants' biographies to understand why and how they enjoyed or did not enjoy soft masculinities. Through attempts to connect fantasy and lived experience, I examined how audience members negotiated their gender identity and ideals through viewing Korean soft masculinities. I additionally connected informants' life events with their worldviews and media consumption. For example, a person's relationship with men (their father, male relatives, male friends, romantic partners, etc.) and their media consumption help form their understanding of what it means to be an "ideal man." The aim is to connect a viewer's life experiences and their fantasies, such as their imagination of an ideal self/partner and an ideal romantic relationship, their investments in romantic TV dramas, and their identification with characters.

Interview Techniques and Practice

Following insights from previous FANI studies, I used the following key interview techniques: asking open questions such as "can you tell me about..." or "what happened?"; 
eliciting stories, avoiding "why" questions (which can result in rational, "clichéd" and intellectualised answers) and using participants' own phrasing (Hollway \& Jefferson, 2000; Clarke, 2002; Clarke, 2008; Whitehouse-hart, 2014; Woodward, 2015). I also adopted a "double interview" method, which means most participants were interviewed twice on separate occasions. The first interview should afford a preliminary reading, with attention to contradictions, inconsistencies, evasions, and nuances of emotional tone in narratives, while the second checks and further investigates information provided during the first (Hollway \& Jefferson, 1997). The second interview, which took place at least two weeks later, thus typically includes questions like "tell me more about..." or "anything else that comes to mind about...?" (Whitehouse-Hart, 2014). The time gap between interviews is intended to permit researchers to reflect on the first encounter, read through a draft transcript to get to know an informant better, and "immerse" themselves in their thoughts and feelings about the informant (Whitehouse-Hart, 2014; Gordon, 2017). It also enabled informants to reflect on the research topic and thus possibly produce richer data in the second interview. Within my project, the time gap enabled a few participants to revisit some Korean dramas or watch a new one to prepare for the next interview. Having two in-depth interviews helps ensure that research questions can be covered even if a participant strays from the main topics. Each interview lasted approximately two hours.

I added some extra steps to the interview procedure: suggestions for participants' re-watching or invitations for watching together and use of photos as visual aids. Before interviews, I asked most participants to re-watch parts of their favourite drama(s) to reengage with thoughts and feelings related to the drama(s). I occasionally replayed scenes from dramas to help participants recall feelings. In at least one interview with each participant, I showed pictures of male characters/actors in situations that exhibit soft masculinities, such as scenes of male characters showing romantic gestures towards their lover or preparing meals, photos of actors dressed in "metrosexual" or "unisex" styles or showing their bare chest and well-built bodies, and a crying scene. I only showed participants the photos after they had talked for some time, usually near the end of an interview, as early exposure might narrow their thoughts. This use of visual aids was intended to help trigger feelings and thoughts, especially regarding participants' views of the ways in which men perform masculinities. Photos also helped clarify abstract thoughts and minimise confusion, as the participants and I may have held different visualisations of what it means for a man to look manly/feminine, as the interviews confirmed. 
I prepared an interview guide (Appendix D) that shows three main areas of questioning: (1) background information about the participant (education, family, past and present life); (2) gendered experiences and opinions about gender issues and masculinity; (3) consumption of Korean dramas and soft masculinities. This guide was meant to aid interviews in case I ran out of questions, but questioning did not always follow this script, especially in instances where participants had a lot to tell on their own.

\section{Research Ethics}

Human ethics approval was granted by the Victoria University of Wellington's Human Ethics Committee in December 2018. All participants received a copy of the Information Sheet via email and were urged to read it carefully before confirming their participation. The Information Sheet specifies that questions would involve background information about family and romantic relationships. Because a narrative interview can be an anxietyladen experience, the Information Sheet warned participants about the possibility of emotional discomfort and offered information about local counselling. It also informed participants that they could stop an interview at any time, refuse to answer questions that made them uncomfortable or withdraw from the project before the data analysis process (see: Appendix B). At the beginning of the first encounter, participants were asked to go through a Consent Form (Appendix $\mathrm{C}$ ) and encouraged to ask any questions they might have about the research before signing the form. Pseudonyms are used to protect participants' privacy. Identifiable data such as institutions and locations are omitted or left vague (e.g., "a northern province" instead of its name). Participants were given compensation for their time and any travel costs in the form of shopping vouchers with Tiki, a popular Vietnamese shopping site.

\section{Recruitment, Sampling and Project Sample's Demographic Background}

My research subjects are Vietnamese men and women in their 20s and 30s. I chose this age range to make sure participants were of working age, grew up during or after the initiation of Đổi Móri, and, consequently, with the emergence and development of the Korean Wave. The radical social changes of post-Đổi Móri Vietnamese society are marked by the interplay of factors such as deeply rooted Confucian influences on gender roles and Western ideologies concerning sexual freedom and individualism. People of this age range are able to observe social changes in this transforming context (as opposed to a younger generation already exposed to prevalent Western ideas and omnipresent Korean cultural 
products since childhood). According to Grosse (2015), Vietnamese people born after 1980 tend to enjoy increased wealth and cultural diversity and demonstrate more genderequal views than older generations. Recent research (Nguyen Bich Thuan \& Thomas, 2004; Phuong An Nguyen, 2007; Martin, 2010; Earl, 2014) demonstrates that people of this generation show intricate negotiations of gender ideals due to various influencing factors. According to quantitative research by the Institute for Social Development Studies' (ISDS, 2020), members of this generation tend to hold more flexible views of gender than those of previous generations as they may benefit the most from developments after Đổi Móri and globalisation. They also fit the global group of "millennials," which includes people born between 1981 and 1996, according to the Pew research centre (Dimock, 2019). Global millennials grew up with increasing Internet penetration and the widespread use of social network sites such as Facebook and YouTube (ISDS, 2020).

Participants were also chosen for their familiarity with male television characters/actors that embody soft masculinities. Even though they may not have been aware of the concept "soft masculinity," I expected them to be able to show that they had watched some Korean dramas with characters that demonstrate soft masculinities. It was not necessary, however, that they enjoyed soft masculinities. They might have ambivalent feelings towards these representations or show disidentification. To diversify the sample, I selected married and unmarried men and women of any sexual orientation.

Interviews took place in Hanoi, Vietnam's capital with the second largest population of eight million (after Ho Chi Minh City). Interview data were collected during my three months' fieldwork between April and early July of 2019. This thesis should not, however, be considered a study of Hanoians because two-thirds of the participants were born or grew up in other parts of Vietnam, including the countryside and the south. Their lives demonstrate marked mobility: one participant was about to move out of Hanoi by the time of an interview; a few were considering emigrating abroad. Therefore, while Hanoi was the site of interviews, the research was not thematically grounded in the experience of growing up and living in Hanoi. Most interviews took place in my parents' house, where I stayed during my fieldwork. Some took place in participants' houses or locations of their choice, such as a workplace, café, and co-working space. Interviews were digitally audio recordings via my laptop through the app Video Recorder.

I recruited participants both online and offline. Offline recruitment was conducted through a one-page ad friends and acquaintances posted in cafés and their 
neighbourhoods. Online recruitment was made possible through a call for participants posted on a public Facebook page set up by me and through friends' or acquaintances' introduction. Interested men and women were asked to fill in an online application form. This form initially consisted of the following categories: name, year of birth, gender (including male, female, and "other/l do not want to answer"), email, phone number or social media page (for contact), time available for meetups, and a request for a list of Korean dramas watched and that had left a strong impression. The last item was meant to identify whether applicants watch the "right" genre, i.e. romantic Korean dramas that feature soft masculinities (they were not eligible if they only watched horror genres or movies instead of television series). Later, I added "profession" to the form out of a desire for a diversified sample and left this category optional. In the end, forty-two people applied through the online application form. Offline advertising resulted in only one additional contact. To prevent personal bias, I recruited participants who had never met me in person before the interviews. I approached one online acquaintance due to my awareness of his watching Korean dramas, and he agreed to participate. Four participants were introduced by friends or acquaintances due to their compatibility with the criteria, three of whom are male. I used this snowballing recruitment mostly due to a lack of male applicants. In the end, nine women and seven men became informants.

Class is not the focus of my study, but I acknowledge it as an important factor determining participants' perspectives. Determination of participants' socio-economic status came roughly from inquiring about their family background, lived experience, and lifestyles. More than half of my participants appear to have a working-class background, with parents who have worked as farmers, factory workers, or run a small business; the rest come from middle-class families with well-educated parents in white-collar jobs. Most participants' backgrounds show some level of social and/or spatial mobility, revealing shifts in class and migration. All of them either have obtained at least a bachelor's degree or plan to obtain one (two were students), and most exhibited middle-class lifestyles marked by broad media exposure, engagement in means of self-improvement, and participation in networks of well-educated urbanites. The fluidity of participants' social positions rendered it difficult to identify their class clearly, so I refrained from emphasising the influence of class on participants' viewing experience unless it seemed salient, as demonstrated in Chapter 5. Basic information about the participants is provided in the List of Participants below. 
Because of the limited number of participants, my sample is not representative of Vietnamese audiences. It can also be viewed as a convenience sample, as many participants share mutual friends and acquaintances with me (hence a motivation to help), and some were introduced by those mutual acquaintances. This factor fostered a selection of educated participants. However, the sample still achieves some diversity due to the varied backgrounds presented above. My empirical chapters feature case studies of fifteen participants and leave out one (Lam) because his narrative ultimately did not address my research questions well. I include him in the list of participants below because I still consider his narrative when discussing my sample as a whole.

\section{List of Participants}

\begin{tabular}{|c|c|c|c|c|c|c|}
\hline No & Pseudonym & Gender & Age & Occupation & $\begin{array}{l}\text { Education } \\
\text { level }\end{array}$ & $\begin{array}{l}\text { Relationship } \\
\text { status }\end{array}$ \\
\hline 1 & Vy $\left(2^{*}\right)$ & $\begin{array}{l}\text { Female } \\
(\mathrm{F})\end{array}$ & 30 & $\begin{array}{l}\text { Housewife, seasonal } \\
\text { freelancer }\end{array}$ & $\begin{array}{l}\text { Bachelor's } \\
\text { degree }\end{array}$ & Married \\
\hline 2 & Văn (3) & $\begin{array}{l}\text { Male } \\
(\mathrm{M})\end{array}$ & 24 & $\begin{array}{l}\text { Development officer } \\
\text { for an NGO }\end{array}$ & $\begin{array}{l}\text { Bachelor's } \\
\text { degree }\end{array}$ & Single** \\
\hline 3 & Trang (2) & $F$ & 24 & Fitness trainer & $\begin{array}{l}\text { Bachelor's } \\
\text { degree }\end{array}$ & Single \\
\hline 4 & Tài (2) & $M$ & 32 & $\begin{array}{l}\text { Language teacher, } \\
\text { translator }\end{array}$ & $\begin{array}{l}\text { Bachelor's } \\
\text { degree }\end{array}$ & Single \\
\hline 5 & Thanh (2) & $F$ & 31 & PR manager & $\begin{array}{l}\text { Bachelor's } \\
\text { degree }\end{array}$ & Married \\
\hline 6 & $\operatorname{Lam}(2)$ & $M$ & 26 & Event host & $\begin{array}{l}\text { Bachelor's } \\
\text { degree }\end{array}$ & Single \\
\hline 7 & Toàn (2) & $M$ & 23 & University student & $\begin{array}{l}\text { Bachelor's } \\
\text { degree (to } \\
\text { be obtained } \\
\text { by the year }\end{array}$ & Single \\
\hline
\end{tabular}




\begin{tabular}{|c|c|c|c|c|c|c|}
\hline & & & & & $\begin{array}{l}\text { of the } \\
\text { interview) }\end{array}$ & \\
\hline 8 & Vinh (1) & M & 37 & Business secretary & $\begin{array}{l}\text { Bachelor's } \\
\text { degree }\end{array}$ & Single \\
\hline 9 & $\operatorname{Kim}(2)$ & $\mathrm{F}$ & 25 & Event Organizer & $\begin{array}{l}\text { Bachelor's } \\
\text { degree }\end{array}$ & Single \\
\hline 10 & Minh (2) & $\mathrm{F}$ & 25 & $\begin{array}{l}\text { Media project } \\
\text { manager }\end{array}$ & $\begin{array}{l}\text { Bachelor's } \\
\text { degree }\end{array}$ & Single \\
\hline 11 & An (2) & $\mathrm{F}$ & 30 & News editor & $\begin{array}{l}\text { Master's } \\
\text { degree }\end{array}$ & Single \\
\hline 12 & Huy (2) & M & 31 & Tour operator & $\begin{array}{l}\text { Bachelor's } \\
\text { degree }\end{array}$ & Single \\
\hline 13 & Hạnh (1) & $\mathrm{F}$ & 26 & $\begin{array}{l}\text { Social activist, } \\
\text { university student }\end{array}$ & High school & Single \\
\hline 14 & Hà (2) & $\mathrm{F}$ & 34 & Government official & $\begin{array}{l}\text { Master's } \\
\text { degree }\end{array}$ & Married \\
\hline 15 & Nga (1) & $\mathrm{F}$ & 27 & $\begin{array}{l}\text { Unemployed at the } \\
\text { time of interview } \\
\text { (previously she } \\
\text { worked as an office } \\
\text { worker) }\end{array}$ & $\begin{array}{l}\text { College } \\
\text { degree }^{\star * *}\end{array}$ & Married \\
\hline 16 & Ninh (2) & M & 26 & $\begin{array}{l}\text { Tour guide, insurance } \\
\text { consultant }\end{array}$ & $\begin{array}{l}\text { Bachelor's } \\
\text { degree }\end{array}$ & Single \\
\hline
\end{tabular}

*Number of interviews conducted. As is shown in the table, twelve participants were interviewed twice, one interviewed three times as he offered to meet me for a third time 
because the second interview was cut short. Three participants were interviewed once due to their unavailability for another meeting. In total, thirty interviews were conducted.

**Single within this study means being unmarried and not living with a partner (cohabitation is still uncommon in Vietnam and sometimes seen with stigma). A single person, however, can be in a romantic relationship. I define this term from a Vietnamese perspective.

${ }^{* * *}$ After high school, Vietnamese youth interested in further studying (instead of entering the labour market) generally have three options: (1) vocational training school (trung cấp nghề), (2) college (cao đẳng), which usually requires less time than university, i.e. twothree years and which is considered of lower prestige than university; (3) university (đại họ), which requires more time than college, typically 4 or 5 years, possibly 6-7 years for medical students.

\section{Transcription}

Hollway and Jefferson (2000) propose full transcription for narrative research, warning that fragmenting data may lead to important details being missed. They recommend treating the interview data as a whole rather than only checking selected details. This is called "the Gestalt principle," which dictates that "the whole is greater than the sum of the parts" (Hollway \& Jefferson, 2000, p. 68). While I agree on the importance of observing the Gestalt principle in narrative analysis, I find the idea that only full transcripts can ensure comprehensive perspectives problematic. Riessman (1993) argues that producing a completely accurate representation of spoken language is impossible as even the most detailed transcript misses important details such as the rhythms of speech and nuances of silences. Riessman (1993) posits that "transcribing discourse, like photographing reality, is an interpretive practice" (p. 13), indicating that decisions about transcribing should be based on the particularities of each study.

I found from my own experience of transcribing lengthy interviews that doing so can be exhausting and distracting. I was at times too preoccupied with getting the words and word order right to notice important factors such as long silences or vocal tone (whether the participant sounds keen or uninterested). Transcribing the over seventy hours of talk collected on my own proved too time-consuming. The fact that I also needed to translate excerpts chosen for analysis into English and attend to particular linguistic intricacies linked to translation made it even more important to save time on technical tasks. After consulting narrative analysis studies such as Riessman (1993) and Sorsoli (2007), 
therefore, I designed a method of "strategic transcribing" as a way to reconcile the Gestalt principle with the need to avoid spending too much time on this process. Following this method, I listened to interviews from beginning to end, often several times if I needed to identify prominent themes, and then transcribed salient parts for analysis. Attentive multiple listening helped me approach narratives as a whole and connect salient features together. This method ensured that the essence of the Gestalt principle was achieved through attentive full listening, which still allowed me to immerse myself in the whole conversation. Selective transcription is, however, subjective to a certain extent. In choosing particular parts of the interviews based on my preferences, I may have missed others that struck me as irrelevant but might be salient. To minimise this risk, I wrote a summary of parts I did not transcribe and provide the time of the untranscribed parts for ease of retrieval. Transcriptions of selected segments include details such as voice tone, attitude, gestures, emphasis (words italicised), pauses (signalled by the '...'). These are aspects that Riessman (1993) stresses as important to the analysis.

\section{Interpretative method}

In terms of interpretation, I followed analytical techniques developed by Hollway and Jefferson (1997, 2000), Saville Young and Frosh (2018), and Riessman (1993), which are attentive to not only the content of the narrative but also the form, or performance of such narrative. The aim is, again, to explore both conscious and unconscious motivations behind narratives. Following this method, I begin each empirical chapter with participants' relevant life accounts and emotionally significant biographical details, then proceed to discuss their viewing experiences.

The first aspect I considered in data interpretation was the form of text alongside the content. Saville Young and Frosh (2018) note the importance of paying attention to how things are said, in addition to what is said. This requires exploring the grammatical structure and rhythms of a narrative because those contribute to meanings. For such recommendations, I reflected on the following questions:

- What are the length and speed at which the interviewee speaks? Are there notable changes in such length and speed throughout the interview?

- How is their emotional state? Do they seem nervous or calm, moody or happy, and when? 
- How loud do they speak? Are there notable changes in their volume throughout the interview?

- Do they speak with a local dialect or with a mixed accent?

- How often do they pause or remain silent?

The second aspect was the "performance" of the people involved, i.e. the interviewee and me as the interviewer. Attention to this factor, observed through selfreflections and note-taking, is to acknowledge the role of the relationship between the interviewee and interviewer in producing data. These self-reflections and notes consistently informed how I approached and analysed my data as I considered my interactions with informants.

The third aspect considered was the context of the narrative. As Saville Young and Frosh (2018) point out, an individual agency is constructed not only through relationships between individuals (a person's family and those around them) but also through their interactions with society, hence the need to place a narrative within sociocultural contexts. Attention should thus be paid to "the ways in which narrator resists or engages with dominant discourses of the social context" (Saville Young \& Frosh, 2018, p. 202). Following this stance, I situated individuals' perceptions of masculinity and their viewing experiences within the context of gender politics in Vietnam over the recent decades after Đổi Mới.

The last important aspect of the interpretive process was translation. Interviews were transcribed in Vietnamese, with salient features highlighted and selected excerpts translated into English. There are always unavoidably gaps between the Vietnamese originals and the English translation, considering significant differences between the two language systems. Researchers such as Gawlewicz (2016) call for "conscious research translation" (p. 28) in situations where interviews were conducted in one language and then translated into one another, most commonly English. Gawlewicz (2016) draws attention to narratives that include words with ambiguous or multi-layered meanings or phrases that have no exact equivalents in the research language. Following her suggestion, I provide the Vietnamese originals in cases when the English translation cannot fully articulate an informant's ideas. I also tried to offset risks by acknowledging linguistic issues regarding Vietnamese grammar, ambiguous expressions, and the local system of kinship address. 


\section{Theoretical Underpinnings}

In this section, I explain how my thesis makes use of poststructuralist philosopher Judith Butler's gender-related work as its primary theoretical toolkit, with references to my empirical chapters. Before presenting a summary of her related work and forging a connection between her work and my study, however, I find it necessary to elucidate why Butler's Western-oriented theories can be applicable to the Vietnamese context. To begin with, I am aware of arguments made by scholars such as Louie and Edwards (1994) and Taga (2004) that Asian gender studies should apply Western theories with caution or even refrain from applying these if Asian-based gender theoretical paradigms are available. I do not totally disagree, but there are issues with such reasoning. Louie and Edwards (1994) cite the example of applying the idea of a contemporary Western "macho man" to the discussion of Chinese masculinity as inappropriate because although the equivalent model of macho men in China exists, it is not prominent and co-exists with the celebrated model of a softer version of culturally cultivated men in China. Therefore, they argue, a Chinese man may be viewed as "not quite a real man" by Western standard but still regarded as desirable within the Chinese culture (ibid.). I agree with these scholars about the importance of acknowledging theoretical work that deals with local gender constructions historically and systematically. I do this by discussing at length, in both the Literature Review and Contexts chapter and the empirical chapters, how local norms and historical factors enter into contemporary constructions of masculinity. For example, I apply the Chinese dyadic model of wen and wu (Louie, 1994; 2002) to illuminate the construction of soft masculinities in dramas. I argue, however, that Louie and Edwards (1994) and Taga (2004), in foregrounding the importance of applying Asia-centric theoretical work, fail to acknowledge the increasingly intricate interplay of both Asian and Western forces in present-day constructions of gendered representations in Asian contexts amidst globalisation.

Gender constructions are complex in postcolonial, transitional societies like Vietnam, where contradictory values are increasingly at work. It is imperative to note that "modern" ideas and practices of romance and romanticism, characterised by individualistic love and self-explorations, had not really established themselves in Vietnam until French colonialism: scholars view such ideas as largely imported from the West (Cong Huyen Ton Nu Nha Trang, 1987; Jamie, 1987; Phinney, 2008). As my empirical chapters shall show, there is little evidence that "Asian" or "Vietnamese" influences are the most potent, at least within the confines of my sample. The participants, who mostly live in urban areas despite 
some participants' rural backgrounds, demonstrate the interplay of various influences in their gender ideals, such as Confucian patriarchal values and Western models of masculinity. Sometimes when my informants used the word "manly," it was not clear whether they meant "manly" by a Western or Asian standard, and clarifications became necessary; some cited Western images of men in popular culture instead of Vietnamese ones (see Chapter 7). There is no "pure" Vietnamese system of gendered values that is not inflected with multiple factors such as Confucianism, colonialism, Westernisation, and globalisation, as I discuss in the Literature Review and Contexts chapter. In considering Vietnamese ideals of masculinity in relation to local, regional and global forces, I respond to R. W. Connell's argument that local masculinities should now be considered in global terms because "what happens in localities are affected by the history of whole countries, but what happens in countries is affected by the history of the world" (1998; p. 7).

Another argument for the applicability of Butler's work to the Vietnamese context is that it is heavily theoretical and thus should not be seen as confined to a specific region. Butler discusses gender issues in patriarchal contexts in general rather than clearly stating her focus on a particular Western country, even though some of the examples she cites are grounded in the West. Mostly, Butler deals with the formation and workings of gender norms generally rather than any specific constructions of femininity and masculinity in a fixed context. The cross-regional applicability of her work has justified its application in many Asian studies, including Vietnamese gender studies such as Rydstrøm (2002), Pettus (2003), Werner (2006), and Nguyễn-võ (2008).

In what follows, I further justify my application of Butler's work to this thesis with two main reasons. First, her gender theories touch on the social and psychic phenomena of gendered identification and desire, the primary concerns of this study. Her argument that norms regulate identifications and desires and motivate gender performativity not only informs my understanding of gender but also resonates with the data I collected. Second, with her poststructuralist theorisation of subjectivity and queer theory, Butler has been acknowledged as one of the most influential names in psychosocial studies (Frosh \& Baraitser, 2008). Her theorisation of gender as socially and psychologically constructed makes it fit for a psychosocial method and has been applied in empirical psychosocial research (e.g., Walkerdine et al., 2001; Arend 2014; Vyrgioti, 2019). The following review, which traces Butler's books, papers, an interview, and a video speech, focuses on two relevant themes in her work: (1) gender norms and performativity, and (2) fantasy, (dis)identification and desire. The review also elucidates why I apply other relevant scholars' 
works, such as that by Pierre Bourdieu, Eva Illouz, and Alexander Doty, to discuss areas that Butler has not attended to, such as the dimension of class in gender performativity or the relation between gender norms and popular culture.

\section{Gender Norms and Performativity}

One of Judith Butler's most influential academic contributions is her theory of gender as performative, introduced in her article "Performative Acts and Gender Constitution" (1988) and her book Gender Trouble (1990a/2006), and further discussed in Bodies that Matter (1993/2011) and Undoing Gender (2004). Drawing on Michel Foucault's theorisation of power and Jacques Lacan's psychoanalytic framework, among others, Butler stresses the role of power in the construction of gender. For Butler, "to become gendered is partly to become gendered for others" (2004, p. 25, original emphasis), as social and symbolic norms play a significant role in regulating the ways people project gendered images. While there are individual ways for one to "do" gender, the acts of "doing gender" are not just a personal matter because gender performances are exercised in compliance with societal prohibitions and thus can be viewed as the enactments of a "strategy for cultural survival" (Butler, 1988, p. 522). Those who perform gender "well" according to social norms can be rewarded as if accomplishing something (Butler, 1990a/2006). In Gender Trouble (1990a/2006, p. 206) and Excitable Speech (1997a), Butler notes the alliance between her notion of performativity and Pierre Bourdieu's "habitus," namely the dispositions, habits, and skills embodied in individuals and influenced by their class background. Butler (1997a) views Bourdieu's theorisation of habitus as an "account of how norms become embodied, suggesting that they craft and cultivate the habitus of the body, the cultural style of gesture and bearing" (emphasis in original, p. 142). Because Butler shows little interest in the class dimension of gender, I draw on Bourdieu to supplement my analysis of working-class male viewers' reception of soft masculinities in Chapter 5.

For Butler, social norms and prohibitions are continuously maintained to direct gendered performativity and thus help shape individual gender identity. Such norms are there to preserve the notion of "intelligible genders" - that is, "those which in some sense institute and maintain relations of coherence and continuity among sex, gender, sexual practice, and desire" (Butler, 1990a/2006, p. 23). "Unintelligible" gender identities, such as homosexuality, bisexuality, and transsexuality, are therefore perceived as threats because they are "incoherent" and "discontinuous," disrupting "mundane" understandings of gender 
(ibid.). The influences of norms on individuals and their resistance to non-normative gender images, such as soft masculinities, as threats are prominent themes in my thesis.

While stressing that social norms and sanctions play a vital role in regulating gender performativity, Butler (1993/2011) objects to the essentialist view that insists on the "naturalness" of gender and instead proposes that "being a man" and "being a woman" are unstable positions. For Butler (1990a/2006), the insistence that individuals possess an inherent and fixed gender is an illusion produced through reiterated performances of gender and perpetuated by the structuring of reproductive heterosexuality. As Butler does not believe in any "truth" to sex or gender, she refutes a monolithic gender status for both heterosexuality and homosexuality. Emphasising that gender is fiction, Butler (1990/2006) asserts that gender would not exist without the various acts of doing gender. An important note that Butler (1993/2011) underscores, however, is that gender performativity can never be "complete" and that bodies never fully comply with gender rules. The fact that norms require repeated acts points to instabilities, and through such instabilities, "the regulatory law can be turned against itself to spawn rearticulation that calls into question the hegemonic force of that very regulatory law" (Butler, 1993/2011, p. xii). Because of such unpredictability, the exercise of gender norms is "where something queer can happen, where the norm is refused or revised, or where new formulations of gender begin" (Butler, 2016 , p. 18). Butler's influential work opens up avenues for queer readings of texts and analyses around non-normative gender representations such as those in Korean pop culture (Oleszczuk \& Waszkiewicz, 2020). Yet, she has not expanded her theories to discussion of cultural representations and audiences. I explore evidence for this argument via examples of how some participants assumed contradictory and/or flexible, ambiguous views of "doing masculinity" in discussions, even if they insist on a hegemonic ideal of masculinity (Chapter 2 and 3). In Chapter 7, I connect this line of thinking with Alexander Doty's (1993) idea about the prevalence of queerness in mass culture, which argues for the potential of gender representations to activate uncategorisable responses from audiences of various sexual identification.

It is worth drawing attention to a common misunderstanding of Butler's theory of gender performativity, which Butler (1995, pp. 133-136; 2011) warns against: the reading of gender performativity as a form of acting, or theatrical performance. She explains on the YouTube channel Big Think (Butler, 2011, 0:01-0:23): 
It's one thing to say that gender is performed, and that's a little different from saying gender is performative. When we say gender is performed, we usually mean that we've taken on a role, we're acting in some way, and that our acting or our role playing is crucial to the gender that we are, and the gender that we present to the world.

Unlike staged acting, a gendered performative, Butler clarifies, is often not based on the actor's deliberate intention; it is rather a recitation of gendered conventions (Butler, 1995, p. 134). Gender performativity should be distinguished from gender performance because the latter implies "an autonomous agent" who willingly conform to or resist a trope (Phillips \& Knowles, 2012, p. 420) while the former implies a general lack of intention. Gender performativity, as enacted in everyday life, tends to be the result of forceful norms imposed on people since birth, because "there is no possibility of standing outside of the discursive conventions by which "we" are constituted, but only the possibility of reworking the very conventions by which we are enabled" (Butler, 1995, p. 136). A clear understanding of this distinction is recommended here because my study deals with both gender performances, i.e. the acting of gender in Korean dramas, and everyday gender performativity, manifested in participants' behaviours in interviews, which at times can be re-enactments of social conventions. For example, the ways a participant reacted to soft masculinities, whether positively, negatively, or ambivalently, can be seen as forms of gender performativity that is usually unintentionally exercised. There are, however, often interactions between mediated gender performances (scripted acts that appear on the media) and everyday gender performativity (not scripted), as my study shall show.

Butler rallies against reductive tendencies to suggest a rigid correlation or causal relation between gender identity and sexual orientation. She warns against viewing gender identity as the cause of sexual orientation or connecting sexuality to a prior gender identity (2004, p. 79). To reinforce this argument, Butler cites complex examples of "queer crossing" within heterosexual relationships, such as the case when a feminised heterosexual man desires a feminised woman in order to enjoy the union of "us girls together," or when a "masculine" heterosexual woman wishes her lovers to behave as both boys and girls for her. Butler $(1993 / 2011 ; 2004)$ points out that similar queer crossings also occur in homosexual relationships and that crossings of heterosexual and homosexual desires can work at the same time. These manifestations of gender crossings show that restrictive views can be avoided for the understanding of complex concepts such as gender identity and gender orientation. Butler further argues that in some cases, it is 
precisely the lack of connection between gender identity and sexual orientation that enables some to take pleasure from relationships. She notes that the continued existence and ever more salient growth of "non-conforming" gender identities, despite a continuous history of social sanctions, has unwrapped the confines of the intelligible gender matrix and its governing purpose (Butler, 1990).

Butler calls the defence against alternative gender possibilities "gender anxiety," which emerges in everyday life in different forms (1997b, p. 136). For example, a woman may guard against homosexual desire because she is afraid of losing her femininity and of feeling no longer "a proper woman" or of being "like a man." Likewise, a man may fear homosexual desire because he does not want to be seen as "feminine" and no longer "a proper man" or a "failed man" (1997b, p. 136). Butler's argument could explain the backlash shown towards non-conforming gender images-for example, a woman exhibiting traits linked with traditional masculinity, or a man showing traits associated with stereotypically perceived femininity—such as the images of metrosexuality, "the new man," or "soft masculinity" addressed in this study. I explore these phenomena of defensiveness and backlash most prominently in Chapter 6 about three viewers' resistance to soft masculinities.

\section{Fantasy, (Dis-)Identification and Desire}

While Butler does not systematically work on the concept of fantasy (known as phantasy in psychoanalysis), her occasional psychoanalytically inflected discussion of phantasmatic indulgence and imagination is helpful to audience studies where it is not often applied. Her discussion of fantasy addresses the intricacies of identification and desire, germane to this research.

Butler pursues a view that does not deny multiple possibilities for gendered identifications in addition to particular identification(s) someone is conscious of. That is because identification, after all, belongs to the realm of imagination and can never be complete: "Identification is constantly figured as a desired event or accomplishment, but one which finally is never achieved; identification is the phantasmatic staging of the event" (Butler, 1993/2011, p. 68). She further articulates her thoughts about the connection between identification and fantasy in Undoing Gender (2004a) and her article "The Force of Fantasy" (1990b). Following a psychoanalytic view of fantasy inspired by Lacanian 
psychoanalytic theorists Jean Laplanche and Jean-Bertrand Pontalis (1985), Butler objects to the commonplace distinction between fantasy and reality:

Fantasy is not the opposite of reality; it is what reality forecloses, and, as a result, it defines the limits of reality, constituting it as its constitutive outside. The critical promise of fantasy, when and where it exists, is to challenge the contingent limits of what will and will not be called reality. Fantasy is what allows us to imagine ourselves and others otherwise; it establishes the possible in excess of the real; it points elsewhere, and when it is embodied, it brings the elsewhere home. (2004a, pp. 28-29)

For Butler (1992), fantasy can simultaneously reinforce and challenge existing power relations. One may thus argue that indulgence in popular culture-as a form of fantasy-exposes not only the (hegemonic) regulatory ideals of gender but also complicates them. My empirical chapters shall help expose such complications through their investigation of K-drama viewers' complex and contradictory responses to soft masculinities and the interplay of multiple influences, including traditional, modern, and global factors, on such responses.

Another critical argument Butler makes is her opposition to the common idea that desire and identification are mutually exclusive. She asserts: "Insofar as a number of such fantasies can come to constitute and saturate a site of desire, it follows that we are not in the position of either identifying with a given sex or desiring someone else of that sex" (1993/2011, p. 63). In her 1992 interview with Liz Kotz, Butler warns against the tendency to assume that women watching Marilyn Monroe would either identify with her or experience alienation by engaging with "the male gaze," describing this tendency as a "heterosexist assumption" (1992, p. 88). I show evidence of Butler's argument that desire and identification are not necessarily mutually exclusive in participants' narratives, most especially in Chapter 2. Viewers may identify with a character because they recognise either elements of themselves in the character or aspects of an ideal they themselves want to reach; at the same time, they desire such character as an Other they can never be or cannot reach. The line between identification and desire can be blurred because they are both phantasmatic phenomena that sometimes become inexplicable or ambiguous to the individual herself.

In a similar vein, Butler questions the distinction between identification and disidentification in her rarely cited article "Theatrical Machines" (2015) concerning the 
experience of attending a theatrical play. She argues that identification involves a process of disidentification in the sense that one is always aware that one cannot be that character on the stage even when one recognises oneself/sense of self in (that is, one identifies with) such character: "I am, yet I am not that character" (Butler, 2015. p. 27). Disidentification, for Butler, also involves undergoing "the lure of identification," i.e. moments of selfrecognition that are difficult to resist (ibid). The result, as Butler posits, is that "I become double to myself as a process of simultaneous identification and disidentification" (ibid). Butler (2015) explains that, within the context of the theatrical encounter, the theatre encourages simultaneous "identification within the scenes acted out and for forms of critique based on disidentification with those very scenes (p. 29)," asserting the fluidity of identification. This experience of a doubled self illustrates how denegation, which Butler defines as "a form of dissociation that allows me to believe and not believe at the same time," is at work (ibid.). To put it another way, for Butler, immersion in fantasy/the imaginary may entail the necessary willing "suspension of disbelief" 8 (Holland, 1968/1975; Ferri, 2007), but such a process can never be absolute. There can be frequent oscillations between self-alienated identification and self-awareness or the critical self. This illuminating perspective can be applicable to audiences' encounters with other cultural forms, such as cinema and television. Television studies have shown, for instance, how audiences reported experiencing simultaneous identification with and distancing from characters or situations (Chua, 2012; Chan \& Wang, 2011). I discuss this subjective experience specifically in Chapters 4 and 5 , which show how viewers display both elements of identification with K-drama characters and alienation from those characters.

In applying Butler's theorisation of fantasy to my study, I focus on specific forms of fantasy or subjective engagements with pop culture (in this case, Korean dramas) and thus need to consult additional work relevant to this particular form. As a result, I make use of Alexander Doty's theorisation of queer pleasure, as mentioned earlier, and Eva Illouz's $(1997 ; 2012)$ work on the influence of romantic pop culture on everyday life. As a sociologist, Illouz sees popular romantic texts as spreading normative ideologies of gender and love across cultures and focuses on such ideologies as enforcing universal norms, namely a common-sense understanding of love. While Illouz's work does not share with Butler a similar theoretical base, it goes along the same line of exploring how ideologies

\footnotetext{
8 This phrase is originally coined by the poet and philosopher Samuel Taylor Coleridge in 1817 in his discussion of literary reading (See: Holland, 1968/1975; Ferri, 2007).
} 
enforce power in everyday life. I make use of Illouz's work for Chapter 3, which focuses on women's emotional engagements with romantic Korean dramas.

\section{Thesis Overview}

Before the main discussion of my data, presented in Chapters 2 to 7, I provide in chapter 1 (Literature Review and Contexts) background information about contemporary Vietnam after Đổi Móii, explanations of key concepts such as K-drama and soft masculinities, and a review of extant research addressing transnational reception of soft masculinities. While the background information and explanations are intended to facilitate an understanding of the sociocultural contexts in which the narratives of research participants can be located, the review also discusses research that my study builds upon, as well as the gaps that it seeks to fill.

My empirical chapters are shaped by case studies of patterns of identifications. These include parasocial interactions with characters and desire for extraordinary men (Chapter 2); romantic identification and desires (Chapter 3); resistance to soft masculinities as romanticised and commercialised constructions (Chapter 4); engagement with masculine embodiments of wealth, and power in icons of soft masculinities (chapter 5); the change of attitudes from identification to disidentification and alienation in relation to soft masculinities (chapter 6); and queer pleasures (Chapter 7). All chapters are discussed in a storytelling style and sometimes mix interview narratives with drama content analysis. When considered in unison, the chapters paint a broader picture of how media reception is linked to a variety of psychosocial factors, including lived experiences, the phase of life a viewer was at by the time of the narrative, and their social positions. The chapters illustrate the interplay of various forces in viewers' construction of gender ideals, including local gender norms and globalised aesthetic trends, and suggest that such construction is ongoing, always in the process of being constructed and re-constructed. In the end, taken as a whole, they show how identification may never be a complete accomplishment due to its position in the realm of imagination (Butler, 1993/2011).

Chapter 2, A Retreat from Life: In Search of the Extraordinary, follows An's immersive consumption of Korean dramas as she actively seeks intense engagements with extraordinary male characters, whose conspicuous appearance and power contrast with her own internalised feeling of powerlessness and invisibility. The chapter shows how her gendered desires have largely been formed through her adoption of gender norms and 
how such desires nevertheless exceed the regulation of such norms at times, proving that "sexuality is never fully captured by any regulation" (Butler, 2004, p. 15).

Chapter 3, Caught in the Atmosphere of Love, explores three women's experience of "imagining having emotions" (Feagin, 1988, p. 493) via Korean dramas, following Eva Illouz's ideal of how love fantasies shape romantic imaginations (Illouz, 1997; 2012). The chapter highlights how informants' engagement with attractive men on screen feeds their heterosexual desires that remained unfulfilled in real life. This chapter is closely connected with chapter 2 in that it also recalls Radway's (1984/1991) idea of fictional romantic stories as serving a "compensatory" function for female audiences. The informants' narratives show fantasy as "the setting of desire" (Laplanche \& Pontalis, 1985, p. 26-27; Butler, $1990 b)$ in which they engaged with not only mediated scenarios meant to prompt romantic feelings but also their own imaginations and desires vis-à-vis men.

Chapter 4, The Absence of the Ideal, discusses the viewing experiences of three pragmatic, feminist-inclined women who, while enjoying Korean dramas, resist the interpellation towards becoming willing "dreamers" in response to commercially packaged constructions of romantic narratives and masculinities (Fang-Chih Irene Yang, 2008a). Unlike those in previous chapters, the informants in this chapter refused to fully embrace romanticised ideals and hyper-performances of masculinities. Acknowledging the male leads in K-dramas as "dream men" all women (except themselves) wish for, these informants showed how they refused to suspend disbelief, overcame "the lure of identification" (Butler, 2005, p. 27), and hold on to pragmatic views of romance and gender.

In Chapter 5, Your Bodies are our Future, I focus on the class dimension of masculinities in Korean dramas: how repetitive representations of dream men embodying masculine privileges are received. The chapter explores how three working-class male migrants engage with K-dramas as a "technology of the self" (Foucault, 1988) that introduces techniques of self-actualisation through male characters' performances of authenticity and autonomy and their display of status and wealth. Through its analysis of the male informants' reception of these techniques of the self, the chapter explores how they envisaged being transformed, improved, and enhanced, as well as transforming others while watching Korean dramas.

Chapter 6, Resistance to Gender Threats, discusses the narratives of three middleclass participants, a man and two women in their early 30s, whose views of Korean dramas and soft masculinities have shifted from fandom to disidentifications. They all enjoyed the 
phenomenal romantic drama Winter Sonata (2002) and idolised its male lead Bae Yong Joon when they were teenagers and then changed attitudes as they matured. Their experiences are situated against the backdrop of local and international backlash against soft masculinities that sees such constructions as threats to traditional masculinity.

Chapter 7, Queering Korean Pop Culture, shows how social norms exerted contradictory effects on two non-heterosexual male informants: one wishes to break free from the heteronormative mould and therefore celebrates alternative gender, while the other partly conforms to the norms and therefore finds it difficult to embrace soft masculinities. Despite such differences, watching romantic Korean dramas allowed both men to enjoy elements of queer pleasures, including the pleasure of looking at attractive men, of enjoying certain performances of masculinity, and of engaging with romantic situations.

To conclude the thesis, I present my reflections on the thesis' methodological contributions and limitations, and then provide a summary of its main findings in relation to the primary research questions. My reflections highlight both the methodological strengths of the study and the difficulties I encountered, while the summary of findings points to how the study's primary themes of gendered identification, desire and negotiation have been addressed. 


\section{Chapter 1: Literature Review and Contexts}

This chapter provides important background for my study by focusing on four main

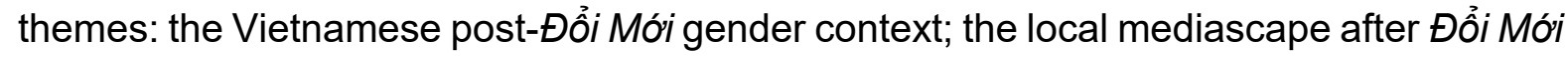
and the emergence and development of the Korean Wave in Vietnam; a conventional understanding of Korean drama as a genre; and last, Korean soft masculinities and a review of research addressing transnational reception of soft masculinities. By bringing together interrelated research encompassing multiple disciplines, including Vietnamese studies, gender studies, genre studies, and Hallyu research, I hope to draw a broader picture of the social and cultural contexts in which my research is situated.

The purpose of this chapter is twofold. First, I provide a summary and critique of the literature concerning my primary themes and offer reference points to key concepts, such as Đổi Móri, Korean Wave, K-drama, trendy/idol drama, Vietnamese hegemonic masculinity, soft masculinities, kkonminam, aegyo. Second, I present what is available in the germane literature and suggest how my research can build upon and enrich it by filling gaps. I review mostly academic publications but also media sources where backup evidence is not covered by academic literature. All my sources are in either English or Vietnamese.

\section{Traditional Gender Relations, Hegemonic Masculinity, and Disruptions}

In this section, I first discuss research into traditional ideals of gender relations and masculinities as well as how these ideals are upheld and enacted in contemporary Vietnam. I then review resistance and disruptions to these ideals, enforced by emergent and growing phenomena such as reversed gender roles in families, alternative dating practices, international marriages, and the LGBT movement. Via this review, I suggest that contemporary Vietnamese society has shown increasing ambivalence towards traditional gender ideals and growing flexibility that can be linked to the emergence and development of alternative masculinities, including Korean soft masculinities.

Over the course of Vietnam's history, factors such as Confucianism, colonialism, communism, and modernisation have shaped and reshaped its gender politics (Khuat, 2004; Schuler et al., 2006; Scott \& Truong, 2007; Grosse, 2015; Minh. T. N. Nguyen, 2018). Under the influence of these factors, men and women have been subject to the regulation of hegemonic gender ideals. Traditionally, men are expected to continue the family line and be trụ cột gia đình (roof and pillar of the family), or "head of the household" 
(Soucy, 1999; Nghe et al., 2003; Tran Ngoc Angie, 2004; Rydstrøm \& Drummond, 2004; Nguyen \& Simkin, 2017). They are supposed to act as their family's breadwinners and decision-makers while demonstrating self-determination and technical, managerial, and leadership skills (Tran Ngoc Angie, 2004). Women are, on the other hand, expected to serve as the primary caregiver (Hy V. Luong, 2003; Drummond, 2004) and "keeper of morality" (Khanh Linh Nguyen \& Harris, 2009) in the family. Corresponding to these ideals, business and affairs external to the household are traditionally seen as masculine spaces, while the home remains primarily women's province (Nguyen Thi Thuy Hanh, 2009; Werner, 2009; Schafer, 2010). Although men and women are assigned complementary roles, men's external activities tend to enjoy greater prestige than domestic service (Soucy, 2001). Like femininity, masculinity is linked to heterosexuality by default, as all men are expected to marry and have children (Soucy, 1999; Nguyen Thi Thuy Hanh, 2009; Horton \& Rydstrom, 2011; Manh Cuong La, 2012; Minh T. N. Nguyen, 2018a). Under the Vietnamese patriarchal framework, men are also expected to exhibit sexual and financial prowess, restrain "vulnerable" emotions, and demonstrate determination (Soucy, 1999; Nghe et al., 2003; Phinney, 2009; Horton \& Rydstrom, 2011; Avieli, 2019).

Significant changes have occurred following the implementation of the 1986 Đổi Mới (Reform) policy, which has marked the transition from central planning under the state's strict management to a "socialist-oriented market economy" that has fostered Vietnam's integration into global networks (Forbes et al., 1991; Turley \& Selden, 1993; Werner \& Bélanger, 2002; Hayton, 2010), and a more relaxed, flexible social life, especially in cities (Phuong An Nguyen, 2007; Martin, 2013). Scholars have termed contemporary Vietnam a "post-socialist" country for its embrace of capitalism and neoliberal values, characterised by the state's transfer of welfare issues to the market and non-state actors and its promotion of citizen self-responsibility (e.g., Thomas, 2004; Higgins, 2008; Karis, 2013a; Hai Thiem Bui, 2015; Taylor, 2016, Nguyen-Thu, 2016; Minh T. N. Nguyen, 2018b). Since Đổi Mới, a combination of factors, including the Communist party's endorsement of gender equality in political and social participation, rapid industrialisation, and globalisation, has exerted contrasting influences on men and women against the continued imposition of traditional gender ideals (Nguyen Bich Thuan \& Thomas, 2004; Khanh Linh Nguyen \& Harris, 2009). Since the 1990s, Vietnam has seen an ever-increasing flow of imported goods from the West, together with rapid economic growth and the rise of a consumer class (Karis, 2013a; Minh T. N. Nguyen, 2015; World Bank, 2018). Vietnamese people today have been found to adhere to both 
traditional and modern values (Thi Tuyet Mai Nguyen et al., 2009; Phuong An Nguyen, 2003; Allen Tran, 2015; Warren, 2017).

After Đổi Móri, although the notion of gender equality has become accepted in principle, everyday practices that exhibit men's dominance over women persist (Soucy, 2001). Essentialist ideals of gender roles, which see men and women as differently able, continue to be enacted in various spheres, including labour in the garment industry (Angie Ngoc Tran, 2004), Buddhist practices in Hanoi (Soucy, 2012), petty trade in a Saigon market (Leshkowich, 2014), learning environments at high schools (Mai Thi Thuy Dung, 2015), farming in a northern village (Bergstedt, 2016), career choice among young people nationwide (Zharkevich et al., 2016), junk trade in northern Vietnam (Minh T. N. Nguyen, 2018a; 2019) and policing in northern Vietnam (Jardine, 2019). Research has underscored how women are socially regarded as more suited for "small," meticulous work and men more suited to "big," heavy, or technical work, even if the notions of "big work" (việc lớn) and "small work" (việc nhỏ) are contested (Leshkowich, 2014; Bergstedt, 2016; Minh T. N. Nguyen, 2019). The perpetuation of such essentialist views in Vietnam, which inform everyday gender practices and relations, exemplifies Butler's argument about how mundane, repetitive performances of gender create "the illusion of a prior substantiality," or "a core gendered self" (Butler, 2000, p. 29). Nowadays, while more women are motivated to pursue higher education and professional ambitions (Phuong An Nguyen, 2004; Earl, 2014; Maheshwari \& Nayak, 2020), they still earn considerably less than men and are less likely to hold leadership positions (Chowdhury et al., 2018; Hong Tien Vu et al., 2019; Khanh-Van Phan, 2020). Furthermore, their success in leadership has been overshadowed by men's and has typically only been celebrated alongside their expected performance of the roles as good wives and mothers (Ngoc Lan Thi Dang, 2017; Hong Tien Vu et al., 2019; Hong Tien Vu, 2020; Maheshwari \& Nayak, 2020).

From childhood, men are usually taught to be active and strong, and women to be passive and submissive (Nguyen \& Harris, 2009; Rydstrøm, 2004). In local mass media, stereotypical depictions of boys and girls describe adolescent girls as "the sentimental sex" (phe mít ướt), "the graceful sex" (yểu điệu thục nữ) and "the weaker sex" (phái yếu), while adolescent boys receive such nicknames as "Mr Stubborn," or "Mr Mischievous" (Huong Nguyen, 2015a, p. 185). Women often describe themselves as the weak sex, who needs to rely on men's strength and wisdom to achieve happiness (Schafer, 2010; Nguyen Thi Thu Ha 2011). In marriage, Vietnamese men tend to prioritise their role as breadwinner over emotional work, i.e. being romantic and expressive (Thanh Thi $\mathrm{Vu}$, $2015 ; 2020)$. Persistent male entitlement has led to relative tolerance of men's risk-taking 
or "inappropriate" practices such as extramarital sex, gambling, drinking, and domestic violence (Nghe et al., 2003; Nguyễn-võ, 2008; Phinney, 2009; Nguyen \& Harris, 2009; Schafer, 2010; Horton \& Rydstrom, 2011; K. K. Hoang, 2011; Manh Cuong La, 2012; Nguyen \& Simkin, 2017; Minh T. N. Nguyen, 2018a; Murru, 2018; Avieli, 2009; JamesHawkins et al., 2019; Kwiatkowski, 2019). Nguyễn-võ (2008), Phinney (2009), and Murru (2018) contend that the government's neoliberal approach after Đổi Mới has led to the increasing commercialisation and sexualisation of leisure space, facilitating men's easy access to a growing sex industry. In addition, due to men's supposedly lesser aptitude for the domestic sphere, their lesser involvement in housework in both rural and urban areas has been highlighted (Ngo Thi Ngan Binh, 2004; Werner, 2009; Khuat et al., 2013; Higgins, 2015).

In the twenty-first century, men are still subject to social pressure to fulfil their roles as "provider" and "protector" of their family (Hung Cam Thai, 2008; Khanh Linh Nguyen \& Harris, 2009; Lan Anh Hoang, 2011; Manh Cuong La, 2012; Thi Quynh Trang Nguyen, 2015; Thi Quynh Trang Nguyen \& Simkin, 2017; Hien Thi Nguyen \& Lan Anh Hoang, 2019). Le Minh Giang (2012) finds that the notion of serving as trụ cột remains a desirable ideal for socially marginalised men, including migrant labourers, drug addicts, and sex workers, who fail or struggle to achieve hegemonic masculinity. Manh Cuong La (2012) shows that similar ideals of hegemonic masculinity persist among younger middle-class married men in Hanoi. A recent survey of more than 2,500 people of various generations by the Vietnamese Institute for Social Development Studies (ISDS) finds that Vietnamese men are still under considerable pressure to appear "strong" and be trụ cột (ISDS, 2020). The institute, however, notes a trend among younger and urban Vietnamese towards more flexible views of gender roles (ibid.).

Despite the prevalence of gender inequality, scholars such as Earl (2015) and Martin (2013) have noted the gap between ideals and practices of masculinity, especially among younger generations. As a retired government official interviewed by Phuong An Nguyen (2003) remarks, "there is a great discrepancy between what they [younger people] think, what they say, and what they do" (p. 232). According to Earl (2015), discourse and action in Vietnam after Đổi Móri may not align due to increasing flexibility in local gender practices. Earl observes that neo-Confucian patriarchal values persist, but new ways of living that challenge traditional gender ideals have also taken shape (ibid.). Earl's observation echoes Martin's (2013) note on the gap between discourses that generalise gender ideals and men's gender practices. According to Martin (2013), while Hanoi-based young men born immediately before or after Đổi Móri may retain some 
traditional expectations of gender relations, which emphasise a sense of masculine entitlement in relationships with women, the ways they live show flexibility that may render these traditional ideals irrelevant. Exposing the influences of multiple value systems in his informants' ambivalence towards ideals of masculinity, Martin (2013; 2018) warns against a tendency to essentialise gender relations in research on Vietnam. Advancing this line of critique, Minh T. N. Nguyen (2018a) further argues that research on hegemonic masculinity and alternative constructions of masculinity may fail to address competing constructions of masculinity within not only the same groups of men but also within the same man. As a case study example, Minh Nguyen shows how young men's practices of masculinity can change over time: his informants, urban junk traders in northern Vietnam, engaged in risk-taking practices before marriage but change to a more responsible life afterwards. Minh Nguyen asserts that there exist "multiple ideas about what it means to be a man in Vietnam today, both as desiring and as desirable subjects" and that contemporary society now sees "a masculinity framework that is not only shifting and relational but also increasingly hybrid" (p. 116).

It is no less important to note that class and location also play an important role in the practice of gender ideologies, with more privileged segments of the population, i.e. urban educated middle-class younger people, enjoying a more relaxed, flexible life (Phuong An Nguyen, 2003; Higgins, 2008; Locke et al., 2014; Nguyen Bich Thuan \& Thomas, 2004). For example, domestic helpers enable some married middle-class women to maintain a work-life balance while consolidating their husbands' masculine privilege, i.e. detachment from domestic duties (Minh, T. N. Nguyen, 2015). Greater tolerance toward social practices such as divorce, which is stigmatised in the countryside, has also been observed in urban areas (Bland, 2011; Locke et al., 2014).

A burgeoning number of studies of contemporary Vietnam have investigated alternative gender practices, revealing women's growing power and the corresponding corrosion of traditional ideals of masculinity. One prominent topic is the reversal of gender roles: the trend of women becoming their family's breadwinners due to their labour migration to cities (Truong, 2009; Vu \& Agergaard, 2012; Bich Ha Dao, 2015), labour migration overseas (Hoang \& Yeoh, 2011; Nguyễn Hữu Minh \& Nguyễn Thị Thanh Tâm, 2014), and involvement in petty trade (Horat, 2018). By virtue of such evolving arrangements, stay-at-home husbands in these studies report feelings of ambivalence, accepting their wives' growing power because of the family's economic gain while experiencing embarrassment (ibid.). Bich Ha Dao (2015), who explores how female migrants and their left-behind husbands have shown willingness to exchange traditional 
roles (the women become primary breadwinners while their partners take domestic duties), contends that Vietnamese society does not conform to Confucian values as fully as is usually assumed. Research has also found new gendered practices such as multiple, non-committed dating relationships and online dating among urban youth (Phuong An Nguyen, 2003; 2005; 2007), as well as growing trends for women to divorce and become single mothers. Divorce has increased after Đổi Móri as women have gained higher status and become more liberal in their marital decisions (Tran Thi Minh Thi, 2021). Dang et al.'s (2017) analysis of the Vietnam Population and Housing Census between 1999 and 2009 finds that single motherhood had risen from 5.63 to 6.41 per cent during this period. Murru (2020) and Lê Minh Tiến (2020) both see single motherhood as evidence of women's greater autonomy and of resistance to social expectations and the state's propaganda message of the "Happy Family." 9 Further, some women beyond socially prescribed "marriageable age" have chosen to remain unmarried and childless, asserting their prioritisation of personal happiness and freedom over marital life and social pressure (Bélanger \& Khuất, 2002; Bélanger, 2004).

Another notable phenomenon that disrupts traditional ideals of heterosexual relations and challenges Vietnamese masculinities is increasing openness to alternative masculinities, marked by the consistent growth of international marriages. In recent years, tens of thousands of Vietnamese women married foreign nationals, including Vietnamese overseas each year (International Organisation for Migration, 2017). Vietnamese women account for at least 85 per cent of Vietnamese marriages that involve foreign nationals, who mostly come from the US, Australia, South Korea, Taiwan, and China (ibid.). The trend of women marrying East Asian men has caused shortages of brides in some rural communities where marrying a Korean or Taiwanese man became a trend (Hoang $\mathrm{Ba}$ Thinh, 2013; Bélanger, 2016; Linh Khanh Nguyen, 2016a \& 2016b). Studies about Vietnamese brides' marriages to Asian men overseas, such as Yeoh et al. (2014), Linh Khanh Nguyen (2016a; 2016b), and Bélanger (2016), note brides' desire for economic gain for themselves and their family as foremost in their marital decision, but also cite their higher expectations of a husband and dissatisfaction with local men as contributing factors. Vietnamese brides' familiarity with East Asian culture via the viewing of Korean or Taiwanese TV dramas also enters into their desire to try their luck with foreigners (Hong Tien Vu \& Tien-Tsung Lee, 2013; Linh Khanh Nguyen, 2016a). Urban women as well have increasingly sought relationships with Vietnamese men living in the West (Việt

\footnotetext{
9 See: Pashigian (2002), Pettus (2003), Phinney (2008) and Murru (2018) for thorough discussions of the government's the "Happy Family" campaigns.
} 
kiều) and Western men, signalling the fading appeal of local men as those capable of making women happy (Nguyen Bich Thuan \& Thomas, 2004; Phuong An Nguyen, 2005; Higgins, 2008; Kimberly Kay Hoang, 2010; 2011). Scholarship concerned with this phenomenon has pointed out several reasons for this trend beyond the desire for upward mobility. Hung Cam Thai (2003; 2008) reveals a quiet "feminist revolt" that sees some educated Vietnamese women delay marriage to find the best option for a modern marriage and turn to Việt kiều or Western white men who supposedly make more respectful partners. This growing interest in foreign nationals as romantic options has also been asserted by urban educated female informants in studies by Nguyen Phuong An (2003; 2005), Nguyen Bich Thuan and Thomas (2004), Higgins (2008), and Earl (2014). ${ }^{10}$ Such research opens an important avenue for considering contemporary women's resistance to patriarchy and their desire for alternatives.

Many younger Vietnamese people have grown tired of expectations for selfsacrifice (Schafer, 2010; Nguyen Bich Thuan \& Thomas, 2004). The gap between traditional gender ideals and a yearning for alternative identities may help explain why foreign gender images such as soft masculinities from Korean pop culture and foreign men as marital options have gained considerable popularity in Vietnam. O'Harrow (1995) suggests that many Vietnamese women, trapped by pressures to fulfil the responsibilities of wife and mother, yearn for private space and fantasise about an ideal man different from traditional Vietnamese men. O'Harrow goes as far as suggesting that the ideal man in Vietnamese women's fantasies has feminine qualities, perhaps to contrast the patriarchal manners that women might not appreciate in men around them. This preference for "softened" masculinities has been noticed by Earl (2014) in a more recent study of Saigon lifestyles. Earl finds that at certain workplaces, men are expected to "feminise" their behaviour to gain respect and approval from women. Earl argues that men may need to suppress perceived masculine characteristics (such as aggression, or mischievous and unrestrained behaviour, as suggested by Rydstrom, 2004) to become more passive and flexible in the workplace. This change represents a new way for men to gain power in their relationships with female colleagues. Zharkevich et al. (2016) reveal that young women born in the mid-1990s and early 2000s stress kindness, compassion, and attention to the family as ideal qualities in a future partner. This result is notable because those desired qualities are the same as the "nurturing" qualities young men in this same research seek in a prospective significant other. Zharkevich et al. suggest that

\footnotetext{
10 Women's turn to Western men for marital options due to an aversion to patriarchy has been noted in other Confucian-influenced countries such as China (Sandy To, 2015).
} 
these criteria may reflect young women's resistance to the traditional patriarchal model of Vietnamese family, which subordinates women to men.

Last but not least, one should not ignore the substantial role of the local LGBT movement, which has become vibrant in the 2010s, in challenging the rigidity of gender ideals. Thanks to continuous activism enacted by the LGBT community and local civil society, present-day Vietnam is now recognised as one of the most accepting countries in Asia towards LGBT issues (Maresca, 2013; Ives, 2018). The government decriminalised same-sex marriage in 2013, legalised gender confirmation surgeries (locally termed "sex-alteration surgeries") the following year, and has begun discussing ways to better protect LGBT rights (see: Huong Thu Nguyen, 2016; Mai, 2017; Horton \& Rydstrom, 2019; Horton, 2019; Human Rights Watch 2020). Same-sex weddings, condemned by government officials twenty years ago (Aronson, 1999), now receive growing media coverage and attain approval from many. According to a 2013 survey by the Institute for Studies of Society, Economy and Environment (iSEE) of over 5,300 people across Vietnam, 33.7 per cent approve of legalising same-sex marriage, with the proportion among those aged 18-29 higher, at 52.3 per cent. Civil society has embraced these changes while noting existing discrimination against LGBT people and the lack of institutionalised rights for this community (Human Rights Watch, 2020). Meanwhile, some youth have begun consuming Japanese and Chinese "boys love" fiction and celebrating homosexual romance (Nguyễn Thị Kiều Anh \& Nguyễn Thị Thanh, 2018; Trịnh \& Nguyễn, 2020).

To sum up, traditionally inflected and essentialist views of gender relations have remained common in present-day Vietnam, but there are gaps between ideals and performances. Such gaps are demonstrated in not only increasingly flexible views of gender, especially among the younger generations, but also growing alternative practices. My study fits into this emergent trend of Vietnamese gender research that points to contradictory, ambiguous, and ambivalent attitudes towards traditional ideals of masculinity and gender relations.

\section{Mediascape after Đổi Móri and Hallyu in Vietnam}

In the early years after Đổi Móri, local audiences enjoyed an increasing number of media products produced within the country and imported from overseas (Marr \& Rosen, 1998; Carruthers, 2001; Nguyen-Thu, 2019). While the publishing industry saw a boom due to an "insatiable public appetite to read anything new" (Ungar, 1991, p. 50), foreign 
imported dramas from Mexico, Japan, and South Korea became popular (Nguyen-Thu, 2019). Nguyen-Thu (2019) notes local eager reception in this period as reflecting "a cultural hunger" following years of deprivation under the communist regime's ideological oppression. Templer (1998), Thomas (2004), and Nguyen-Thu (2019) argue that enthusiastic consumption of global mass culture then reflects local people's desire for the outside world where greater creativity and freedom is possible. Foreign popular culture and icons began to play a significant role in promoting values from which younger audiences construct their own identities (Thomas, 2004; Huong Nguyen, 2015b). The emergence of new values forged through such influences has also overlapped with the rise of consumerism in Southeast Asia (Chung Peichi, 2013).

Since Đổi Móri, while the state has retained its extensive control by maintaining ownership of the mass media, it also has relaxed censorship (Ungar, 1991; Pelzer, 1993; Heng, 2001; Tran Huu Phuc Tien, 2002; Dixon, 2004; Kraevskaia, 2009). A remarkable growth in television content and newspaper advertising has taken place alongside the proliferation of such cultural activities as exhibitions, fashion shows, and beauty pageants (Hoang Ngoc Nguyen, 1991). Meanwhile, global flows of consumer and cultural products have contributed to the "cosmopolitanisation" of Vietnam (Carruthers, 2001). In the early 1990s, national television coverage was achieved in Vietnam (Forrester, 1998; NguyenThu, 2019). Furthermore, since the early 2000s, digitalisation has enabled Vietnamese people, especially younger urbanites, to access foreign TV programmes and movies on international and local streaming websites. At present, Vietnam, with approximately 64 million accounts, makes up three per cent of Facebook accounts worldwide and has become the world's seventh-largest user of the platform (Ha Phuong, 2017).

Scholars have credited global media with playing a substantial role in helping construct gender views in Vietnam. Access to diversifying media has allowed local youth to experience alternative worlds, both mediated and "real," beyond their everyday life (Nilan, 1999). Ngo et al. (2008) find that global media, in addition to local discourses, have affected young urbanites' ambivalence towards hegemonic femininity and masculinity and that the internet has offered a free space in which they learn about others' gendered experience, enact their romantic practices, and discuss once-taboo subjects such as sexuality. Exposure to foreign culture and a more relaxed social life have therefore contributed to greater acceptance of premarital sex, which was previously stigmatised (Dinh \& van Teijlingen, 2019). 
Local media production has also changed following the State's weakening ideological imposition and external influences from global media and the Vietnamese diaspora (Carruthers, 2001; Huong Le, 2008; Kraevskaia, 2009). Since the 1990s, the country has seen the rise of provocative visual arts, including queer projects that challenge traditional ideals of gender and promote alternative gender identities (Lenzi, 2015; Nualart, 2016). Equally notable is the emergence of feminist art, which challenges norms and raises women's issues, albeit as a "marginal practice" (Nualart, 2018). Meanwhile, post-Đổi Móri literature has witnessed "a turn to the ordinary and the private," with prominent younger writers focusing on everyday life and inner experiences, a switch from the focus on "the extraordinary and the public" and heroic themes during wartime and the post-war period (Collins, 2015, p. 88). Local literature has increasingly dealt with day-to-day conflicts, the individual pursuit of happiness and romantic love (Phan Thi Vang Anh \& Pham Thu Thuy, 2003; Rato, 2007) while accentuating a need to reflect on and talk about the self (Doan, 2021). Contemporary female writers' novels have also projected feminist ideals by highlighting women's greater self-awareness and sexual pleasures (Healy, 2013; Nguyễn Thị Ngân, 2019). During the 2000s, along with the proliferation of women's magazines (Drummond, 2004), lifestyle magazines for men also appeared, providing men with instructions about how to become desirable and "modern" (Martin, 2013).

Although global media have been credited as a significant force in transforming ideologies and ways of living and being in contemporary Vietnam, the manner in which forms of global media have worked in exerting their influence remain under-researched. Foreign media products tend to be generalised under the rubrics of "Western media" or "East Asian pop culture" (Thomas, 2004) without being scrutinised in terms of genre and reception. My study, with its focus on Vietnamese consumption of Korean dramas, seeks to partly address such gaps.

Vietnam and the Republic of Korea established diplomatic ties in 1992, following a period of disruption in the two countries' relations due to the latter's support of the US during the Vietnam War (1955 - 1975) and Vietnam's isolation from the international community between its reunification in 1975 and Đổi Móri. Eyeing Vietnam as a potential market, Korea has made considerable efforts to forge its soft power there. While the Korean government consistently offered Vietnam foreign aid from 1991 to 2002 (Mi-Sook Park, 2017), its powerful business conglomerates (Chaebol), such as LG, Hyundai, and Samsung, began to open factories in Vietnam and sponsored broadcasts of Korean 
television dramas (Cohen, 2000; Shim, 2006; Mi-Sook Park, 2017). Local media institutions have also played a significant role as they allocated considerable broadcasting hours to Korean dramas (Chung Peichi, 2013). Considering the Vietnamese State's monopoly of the media in the earlier years after Đổi Mới, Nguyen \& ÖzçağlarToulouse (2021) contend that the state has permitted Korean cultural products to circulate for its own purposes, such as promoting Confucian values and encouraging local creative industries to learn from Korean counterparts. As Korea has forged a presence in Vietnam since the 1990s, its cultural products have also swept across both developing countries in Southeast Asia and wealthier East Asia. This ongoing regional (and now global) phenomenon known as the Korean Wave, or Hallyu (Chua \& Iwabuchi, 2008; Youna Kim, 2013; Do Kyun Kim \& Min-Sun Kim, 2011; Tae-Jin Yoon \& Dal Yong Jin, 2017), has often been seen as a result of the Korean government's policy to promote Korea as a "dream economy of icons and aesthetic experience" (Dator \& Seo, 2004, p. 37; Nguyen \& Özçağlar-Toulouse, 2021). The spread of Korean television dramas and other Korean cultural products has benefited a great deal from increasing internet penetration and digitalisation worldwide (Dator \& Seo, 2004; Chung Peichi, 2013). Today, Vietnamese audiences can easily find Korean dramas on international and local streaming websites with English or Vietnamese subtitles or download pirated copies online. A preliminary study conducted by Luong and Evans (2021) finds that an overwhelming proportion of videos translated into Vietnamese by local fans on YouTube are connected to Korean Wave products, further affirming the hegemony of Korean pop culture in Vietnam. The study highlights how those videos outnumber those originating from English media texts, despite the relative popularity of the latter.

Popular culture has turned out to be the best ambassador for Korea in Vietnam (Cohen, 2000). Korean dramas have been at the forefront of Hallyu in Vietnam and have led to audiences' interest in K-pop and other Korean products such as films, food, fashion, and cosmetics (Cohen, 2000; Phuong An Nguyen, 2003; Trần \& Cao, 2015; Mi-Sook Park 2017; Nguyen Tu, 2019). In the early years after Đổi Móri, Korean dramas offered local audiences "an enticing glimpse of the outside world" (Visser, 2002, para. 7). Along with some other foreign popular soap operas, earlier hit Korean dramas such as First Love (1996) and Autumn in My Heart (2000), often watched in family gatherings, remind Vietnamese audiences of shared cultural enjoyment after Đổi Mói (Nguyen-Thu, 2019). Scholars have noted how Korean mass culture has swept "a wave of romanticism" (Nghiem Lien Huong, 2006, p. 337) across Vietnam and have contributed to the 
increasing use of "emotion" (cảm xúc) to define the self among its people (Allen Tran, 2015).

Furthermore, the impact of aesthetic standards imposed by contemporary Korean pop culture in Vietnam is palpable. Nguyen Tu (2019) notes how images of Korean entertainers pervade public sites in Vietnam, decorating advertising billboards, department stores, and beauty salons. Such is the domination that phrases such as long lanh như phim Hàn (beautiful as Korean dramas), or trắng như Hàn Quốc (white as Koreans - used to approvingly describe skin colour) have entered everyday public discourses (Nguyen-Tu, 2019). The popularity of many things Korean, including food, mobile phones, and cosmetic brands, reflect a general forward-looking attitude (Oh, 2011; Andrew Eungi Kim et al., 2013) that views Korea as a modern and intriguing culture (Phan Thanh Thanh, 2014; Nguyen Tu, 2019; Jang et al., 2021). Considering the recency of Korea's economic dominance and the popularity of its mass culture in Asia as well as the cultural similarities shared by two countries, many Vietnamese view Korea as a desirable future that someday Vietnam could achieve (Nguyen Tu, 2019). As Nguyen-Tu (2019, p. 30) comments, "to many [Vietnamese people], Koreanness looks, feels, and in many ways is modernity."

The popularity of Korean dramas and K-pop has led to concerns among both government officials and the public, who raised charges of a "Korean deluge" or "cultural invasion" (Cohen, 2000; Thomas, 2004; Duong Nguyen Hoai Phuong, 2016; Nguyen \& Özçağlar-Toulouse, 2021). K-pop fandom, which has become part of the local youth culture since the mid-2000s, has triggered heated social debates and given rise to moral panic among the general public and local press alike (Bayly, 2014; Duong Nguyen Hoai Phuong, 2016; Hoang Ha, 2020). Teenagers' zealous K-pop fandom even featured in the 2012 national university entrance exam in a question for the subject of literature, which asks students to comment on the statement, Ngương mộ thần tượng là một nét đẹp văn hóa, nhưng mê muôi thần tượng là một thảm họa (Admiring idols is a good culture, but getting crazy about idols is a disaster). An anti-Korean Wave discourse, which focuses mostly on Korean dramas and K-pop and views the local attention to Korean mass culture as undeserving due to these genres' perceived problematic quality, emerged in the $2010 \mathrm{~s}$ (Su Jeong Kim \& Eun June Kim, 2016). However, the local backlash has never erupted into strong protests, such as those seen in China and Japan (Trần \& Cao, 2014; Chen, 2016; Hyangjin Lee, 2017; Ahn \& Yoon, 2020). 


\section{Understanding K-Drama}

This section confines its discussion to contemporary Korean TV dramas consumed by Vietnamese people since the late 1990s. These dramas, produced between the 1990s and the 2010s, belong to the profit-driven period of the Korean broadcasting industry, distinguishing themselves from those produced between 1961 and 1992 when local television was subject to stricter state control (Berg, 2018). ${ }^{11}$ Although Korean dramas in the aggregate have become increasingly diverse in genre and format due to the proliferation of channels in Korea and growing investment from streaming platforms such as Netflix (Hyejung Ju, 2017; Song Sooho, 2020), my thesis concentrates on what one might term K-dramas, that is, those that have played the greatest roles in furthering the Korean Wave worldwide with a focus on romance (Hyunji Lee, 2018; Min Joo Lee, 2020; dos Santos, 2020). These popular dramas are sometimes also called "Korean Wave trendy dramas" or "Hallyu dramas" (Jeongmee Kim, 2012; Min Joo Lee, 2020), marking themselves from other non-romantic sub-genres of Korean dramas, such as horror, crime, or long-running family and period dramas. They are usually prime-time mini-series that broadcast two episodes a week and require higher production costs than other dramas (Hae Joo Kim, 2015).

K-dramas have been known as belonging to the genre of melodrama, being influenced by Japanese TV dramas, and sometimes are called "soap operas." I shall address the association between Korean dramas and each of these media forms to facilitate an understanding of Korean dramas as a genre. First, K-dramas are generally classified as melodrama by virtue of their emotional excesses and exaggerated representations of conflicts (Baldacchino, 2014; Artz, 2015; Yi, 2018; Min Joo Lee, 2020). Through emphasised display of emotions induced by tragic events or unexpected scenarios, the dramas give audiences "the pleasure of being touched and giving way to tears" (Diderot, 1965, as cited in Neale, 1986, p. 6). Second, K-dramas share common features with soap operas-another genre of melodrama-such as closeup shots and repetition of information marked by excessive flashbacks. In K-dramas, close-up shots are exploited to direct attention to actors' beauty and performance and help construct an intimate relationship with audiences (Ma, 2007a; Yi, 2018), promoting indulgence in desire and identification. Repetition of information, common in Western soap operas, is also typical of conventional K-dramas. Unlike serialised American soap operas that may

\footnotetext{
${ }^{11}$ For information about the development of Korean television industry, see Russell (2008) and Ju (2017).
} 
run for years or even decades without offering a conclusion (Artz, 2015), however, primetime K-dramas tend to have only one season of 16 to 24 episodes, run for several months, and come to a closure (Shim, 2004; Russell, 2008; Hyunji Lee, 2018; Keller, 2019). ${ }^{12}$ Third, K-dramas are regarded to be influenced by Japanese TV productions in content and format (Shim, 2006; Russell, 2008; Creighton, 2009), with one noticeable difference being the former's greater emphasis on family values (Jeongmee Kim, 2012; Creighton, 2009). Modern Korean and Japanese dramas popular among the youth are termed "trendy dramas" and "idol dramas" (Hu, 2008; Artz, 2015; Wan-shuan Lin, 2019), which appeal to fashion-conscious and aspiring young audiences. These trendy dramas often feature glamorous male and female celebrities and are promoted through activities involving their stars (Youjeong Oh, 2014; Artz, 2015). Trendy dramas are known for portraying younger people's struggles, addressing contemporary social issues and spreading motivational messages (Hu, 2008; Artz, 2015; Wan-shuan Lin, 2019).

In terms of content, K-dramas and Western TV series differ in the amount of sexuality and violence; the former programmes are more conservative with less explicit sex scenes and less violence (Jeongmee Kim, 2012; Hyunji Lee, 2018). Known for being formulaic and predictable, many K-dramas repeat the Cinderella theme, where a poor girl meets a rich guy, and emphasise women's sacrifice and virtue (Russell, 2008; Choi, 2012). Most portray ideal love, the "one and only," "forever and ever," and "sacred" kind (Ma, 2007b; Espiritu, 2011; Jeongmee Lee, 2012). Many pursue a "pure love" theme (Lin \& Tong, 2007; Jeongmee Kim, 2012), the story of a couple who fall in love for the first time, keep pure feelings for each other despite the passage of time and overcome obstacles to be together eventually. This theme, known as junai (pure love) in Japan, is also common in Japanese anime and films. The deliberate use of pop music and romantic settings are often exploited to promote this theme of pure love to create what Ma (2007a) calls an "atmosphere of amour" (Ma, 2007a, p. 116; Cagle, 2014; Keller, 2019). Love in K-dramas, as Jeongmee Kim (2012) puts it, is "spiritual, transcendental and still childishly innocent" (p. 113). The lack of explicit sexuality in K-dramas runs counter to the dynamics of sexual practices among young couples in contemporary Korea (Jeongmee Kim, 2012). These dramas, therefore, represent a romanticised, conservative ideal of love rather than realistic portrayals of modern Korean romantic relationships (Baldacchino 2008; Jeongmee Kim, 2012). The prevalence of idealised, platonic romance in K-dramas shows

\footnotetext{
${ }^{12}$ Recent development in global television production, however, complicates the conventional understanding of K-dramas, as some popular K-dramas, such as Hospital Playlist (2020-2021) (circulated by Netflix), have begun to follow American season-based production style.
} 
how "desire for a sincere heart and pure love is commodified, advertised, packaged, distributed, and consumed" (Ma, 2007b, p. 134). This theme of pure love remains popular, even though more dramas such as My Name is Kim Sam Soon (2005) and Coffee Prince (2007) have challenged the traditional expectation of female chastity.

\section{The Polysemy of Soft Masculinities and Transnational Reception}

\section{Understanding Soft Masculinities}

This section primarily aims to offer an understanding of "soft masculinities" by discussing their typical features and the contexts in which they appear. Its secondary aim, through a review of the germane literature, is to argue that soft masculinities can be both progressive and oppressive. Understanding the complexity and fluidity of soft masculinities, including their political implications, is crucial to understanding my participants' viewing experiences.

As noted in the Introduction, soft masculinities in Korean dramas demonstrate a double feminisation of men's appearance and character. Soft masculinities icons often possess youthful looks and fit bodies. They may dress in androgynous fashion through feminine-coded (pink or floral) outfits and well-cared-for hair and sometimes exhibit an extravagant lifestyle. By virtue of such traits, they are often called kkonminam in Korean, literally "flower pretty man" (In-Sook Lim, 2008; Jung, 2011). Soft masculinities are also linked to ideals of male "purity" marked by a lack of profanity and sexual aggressiveness, polite mannerisms and chivalry, and sometimes filial piety (Maliangkay, 2010; Jung, 2011; Min Joo Lee, 2020). Some of the cited attributes, which demonstrate signs of what patriarchal societies would view as femininity, can be found in the male leads of popular Korean dramas such as Winter Sonata (2002), I Hear Your Voice (2013), or My Love from the Star (2013-2014). Similar characteristics can also be observed in the stage performance and public appearances of K-pop idols, some of whom, such as Rain, Jung Yong Hwa, or Kim Hyun Joong, juggle acting and singing. As a relatively new phenomenon that emerged and became popular in the early 2000s, soft masculinities distinguish themselves from other forms of masculinities common in Korean popular media, such as militarised masculinities (Seungsook Moon, 2005; Woori Han et al., 2016; Yezi Yeo, 2017) and hyper-masculine representations (Kyung Hyun Kim, 2004; Aramchan Lee, 2017). 
Korean soft masculinities have been linked to the influence of popular Korean manhwa (Korean comics) and Japanese manga and anime (Jung, 2011; Holliday \& Elfving-Hwang, 2012; Maliangkay, 2013). They have also been associated with Western metrosexual trends accompanying the rise of a consumer culture (Jung, 2011). Korean entertainers who embody soft masculinities have influenced their fans' perception about ideals of masculinity by fostering a model of consumerist masculinity linked to cosmetic surgery and a glamorous fashion style (Maliangkay \& Song, 2015). The spread of soft masculinities in both entertainment and everyday life is part of a growing trend in which, since the 1990s, young Asian men's bodies have become the target of interconnected global and local beauty industries (Hsing-Chen Yang, 2014).

Scholars have traced soft masculinities to traditional influences, such as images of the polite male scholar/official in Chinese Confucian ideology (Jung, 2011), known as seonbi masculinity in Korea. Accentuating "gentle and cultured mentality" over "strong, physical achievement" (Jung, 2011, p. 28), seonbi masculinity embodies the Confucian concept of wen, as opposed to the concept of $w u$, which highlights men's physical attainment. This conceptual pair of wen-wu depicts the complementarity of civil and military forces within the feudal government (Louie \& Edwards, 1994; Louie, 2002). Vietnam, also influenced by Chinese Confucian ideologies, has been familiar with the ideal of the polite scholar (hình tương nho sinh) (Ngo, 2015). Some characters in Vietnamese movies, such as the kind teacher in Bao Giờ Cho Đến Tháng Mười (1984) (When the Tenth Month Comes), the romantic and selfless doctor in the box-office hit $V i$ Đắng Tình Yêu (1990) (The Bitter Taste of Love), or the erudite poet Nguyễn Trãi in Long Thành Cầm Giả Ca (2010) (The Musician at the Dragon Citadel) project this scholar ideal. Furthermore, as Edwards (2016) reminds us, techniques of beautification were adopted by privileged Chinese men in the past to assert their superior status, as seen in Ji Baoyu, the protagonist of the classic novel Honglou meng (Dream of the Red Chamber). Ji Baoyu is familiar to Vietnamese audiences by the name of Giả Bảo Ngọc, and the novel itself, known in Vietnam as Hồng Lâu Mộng, is viewed by many Vietnamese as a classic example of Chinese literature.

A further noticeable attribute of soft masculinities is the exhibitionistic display of eroticised male bodies (Epstein \& Joo, 2012) and male self-awareness of, or even narcissistic obsession with appearance, as shown in scenes of men grooming and gazing at themselves or enjoying others' gaze (Elfving-Hwang, 2011). Social celebration of this bodily display reflects a trend known in Korea as the momjjang syndrome, which might 
best be translated as "body master" and which underscores Korean desires for a fit body (Jung, 2011, p. 65). Many recent Korean dramas display idealised male bodies in "innocent" contexts, such as a man baring his chest while showering, playing sports or fighting, or in neatly dressed suits. Such bodily display seems to foster a kind of "consumer fetish," inviting both the gaze and the desire to possess (Epstein \& Joo, 2012). Some scholars contend that soft masculinities not only cater to the female gaze but also pressure men to invest care in their appearance (In-Sook Lim, 2008; Epstein \& Joo, 2012; Maliangkay, 2013; Maliangkay \& Song, 2015).

Soft masculinities also involve the emotionalisation of male characters. Examples in K-dramas include male characters showing vulnerability by weeping and seeking women's comfort, and reference to a tragic life history. A common scenario is that a female character sees those vulnerabilities, usually hidden from others, and successfully "cures" the men of emotional pain. The presence of a fundamental lack suffered by a perfect male character, often linked to childhood trauma and parental loss, facilitates the development of romance, as his lover is supposed to fill such lack (Sooyeon Lee, 2012). K-drama male protagonists also tend to be very romantic: they demonstrate unconditional, unequivocal devotion to their lover and a willingness to express feelings. According to Louie (2012) and Ainslie (2017), as women gain more power in East Asia, new representations of female-friendly masculinities such as mild-mannered and emotionally expressive male protagonists emerge. Yates (2007) links media representations of men's emotional vulnerabilities to what she terms the "emotionalisation" of society (p. 9), arguing that such representations challenge the traditional imbalanced "emotional labour" gender division whereby women are expected to be more emotional.

Performance of cuteness is another distinctive feature of soft masculinities. This behaviour of "acting cute" is known as aegyo, enacted through a childish voice, cute facial expressions, or "sweet" and childlike gestures such as forming a heart with one's hands (Manietta, 2015; Han, 2016; Puzar \& Hong, 2018). Both male and female Korean young entertainers are expected to perform aegyo to express affection to fans and please them. According to Ae Jin Han (2016), aegyo in men should be viewed as a unique manufactured aesthetic style and is not associated with the aesthetics of gay, bisexual or transgendered presentations. Korean male entertainers' performances of aegyo are intended to achieve such purposes as showing friendliness and gentleness, playing the role of a younger member in a group, pleasing senior colleagues, and entertaining 
audiences (Manietta, 2015; Han, 2016). Male stars tend to combine aegyo with traditionally masculine performances such as acting "macho" and "cool" to project a versatile image (ibid.). In Korea, aegyo may be observed not just in the entertainment industry but also in everyday life (Han, 2016).

Although soft masculinities appear to challenge binary gender oppositions, they do not necessarily stray far from patriarchy. Icons of soft masculinities often combine feminised traits with stereotypically masculine attributes to reaffirm their "manliness" (Shiau, 2017). While promoting capitalist, postmodern masculinities, most K-dramas show major male characters as wealthier and better educated than their female counterparts, according to Lee and Park's (2015) analysis of 100 popular dramas broadcast between 2003 and 2012. Male characters often save female characters from danger or economic breakdown and sometimes show controlling, manipulative characteristics along with their softer side. The Cinderella theme, in which a wealthy man falls in love with a girl from an underprivileged background, is common. Baldacchino (2008) argues that these dramas portray the Cinderella-like character as a "passive object of the man's power" (p. 113). Jackson (2017) links the portrayal of authoritative men in Korean dramas to the figure of "superior gentleman" in Confucianism: a decision-maker not only for himself but for others, i.e. the people he "rules" and his family. While this ideal of masculinity is supposed to promote men's self-cultivation and self-sacrifice, it also champions men's authoritarianism (Jackson, 2017). Considering these narrative contexts, one may argue that soft masculinities may simply be a new reconstitution of hegemonic masculinity, in which a man oscillates between "soft" and "hard" signifiers of masculinities (Elfving-Hwang, 2011). Louie (2012) notes that both Western metrosexual icons and Pan-East Asian icons of soft masculinities inspired by the Chinese "fragile scholar" ideal are "winners" in patriarchal systems because their typical features such as alluring looks and comfortable life can only be achieved by the well-off. Most protagonists in Korean dramas, as Sooyeon Lee (2012) points out, incarnate the ego ideal of modern Korean culture: possessing economic power and good educational background. It is also important to note that most K-drama male characters exhibiting soft masculinities are heterosexual, asserting heterosexuality as mainstream in Korean pop culture. While there have been indications of queer desires in characters with soft masculinity traits in popular dramas such as Secret Garden (2011), Reply 1997 (2012), Reply 1994 (2013), and Prison Playbook (2017), these characters tend to serve a side story to the central heterosexual romance. 
Finally, soft masculinities, as the plural form indicates, contain variations. For example, although the male leads Jang Geu Rae in Incomplete Life (2014) and Seo Joon Hee in Something in the Rain (2018) both demonstrate a few typical traits of soft masculinities such as having "pretty" faces and being sensitive, as ordinary white-collar office workers, they lack the power and privilege of hegemonic masculinity. It is also not uncommon for icons of soft masculinities to play traditionally masculine roles such as bodyguards or military officers such as Ji Chang Wook and Song Joong Ki in K2 (2016) and Descendants of the Sun (2016), respectively. Ji and Song's roles in these dramas hybridise aspects of Korean militarised masculinity through their display of a muscular body and military skills and the image of a romantic and sensitive gentleman. Soft masculinities, as this thesis shall show, may be understood differently by different people. While acknowledging variations, my thesis focuses on the commercialised, romanticised portrayals of "dream men" rather than ordinary men because the former ones are more popular among transnational audiences (dos Santos, 2020) and more frequently emerged in informants' narratives.

\section{Transnational Reception of Korean Soft Masculinities and Contribution to Research}

Many Hallyu audience studies focus on the themes of gendered identification, desire, and negotiation of gender ideals and note a distinction and/or overlap between imagination/fantasy and "reality" (as lived experience). While some authors such as Hayashi (2005) and Oh (2011) suggest that romantic Korean dramas help fulfil emotional needs audiences already have (but may have lost or forgotten), others, including Schulze (2016) and Min Joo Lee (2020), suggest that the dramas trigger desires which audiences have harboured before and motivate them to discover new gender relations they cannot find within their own culture. In the latter, the boundaries between fiction and reality, i.e. imagined and lived experience, can be blurred. Common patterns of viewing experience found by existing research include escapism and absorption, ambivalence, and disidentification.

Research into transcultural consumption of Korean dramas in contexts outside Vietnam has foregrounded the cathartic and escapist function of Korean dramas through their portrayal of ideal love that overcomes obstacles and perfect male leads. This escapist experience has been found in women and, to a lesser extent, men of various generations, socio-economic backgrounds, and regional contexts. Much research on the Japanese reception of Hallyu focuses on the phenomenal success of the hit drama Winter 
Sonata (2002) in Japan (Hayashi, 2005; Soobum Lee \& Hyejung Ju, 2010; Ingyu Oh, 2011; Sun Jung, 2011) and underscores Japanese women's longings for pure love and nostalgic reminiscences of their youthful pasts. Such longings manifest themselves in the women's repetitive watching of Winter Sonata and their desire for the male protagonist's gentle charisma and unconditional romantic devotion. Ingyu Oh (2011) argues that married Japanese women's melancholic identification with K-drama romance enables them to engage with their unfulfilled desire for either a lost or imagined lover.

Escapism has been highlighted as a familiar pattern of identification among female audiences, even though the level of engagement may vary, with some audiences enjoying temporary relief while others develop "parasocial relationships," i.e. imagined relationships with entertainers or TV characters (Horton \& Wohl, 1956). Lin and Tong (2008) and Chan and Wang (2011) document Asian women's indulgence in K-drama romantic "fantasyland" as a means of temporary stress relief. Ko et al. (2014) focus on the class dimension of the viewing experience and find that working-class Peruvian female viewers immerse themselves in such stories to temporarily forget about everyday struggles and dream about a perfect man who can pull them to the top of the social ladder. Putri and Yatim (2019) find that single Indonesian female fans consume dramas as sites of emotional support to escape negative feelings and seek out romantic emotions inaccessible in real life. Hassim et al. (2019), like Putri and Yatim, report international fans' feeling of becoming overly attached to characters and being "transported" to a romantic fantasy world.

Escapism is not unique to female audiences. Lin and Tong's (2007) research finds that Hong Kong men enjoy romantic and idealistic love stories as a way to fill a gap between their romantic desires and their own marital life. These male viewers, subject to the cultural pressure for men to repress emotions, find in Korean dramas a cathartic outlet that permits them to identify with vulnerable male characters who sometimes cry. This cathartic function is also observed by Lin and Kwan (2005), who note that Hong Kong female professionals feel touched by scenes of both women and men sobbing. They suggest that male characters' display of feelings resonates with women's fantasy about men's hidden emotional side.

Escapism aside, the key behind soft masculinities' appeal seems to lie in the combination of "feminine" and "masculine" traits in male characters who are privileged, sometimes even authoritarian, but unabashedly romantic and charming. Delving into the 
complexity of audiences' desire for this blend, Jung (2011) discusses actor and singer Rain as a celebrated example of hybrid masculinity. Jung notes how Singaporean fans embrace Rain's performance of cuteness and sexiness in the hit drama Full House and on stage, marked by his display of a muscular body. Female fans also enjoy Rain's performance of childish authoritarianism in Full House, especially when this characteristic is gradually replaced by more caring behaviours as his relationship with the female lead develops. According to Jung, Singaporean middle-class female audiences find this transformation amusing because it both recalls and subverts patriarchal norms.

Some studies show that Korean dramas allow viewers not only to engage with existing feelings but also to form new feelings. Schulze (2016) notes that Korean dramas motivate international female fans to collectively consider possibilities that they have not imagined before consuming K-dramas, such as a relationship with a younger, "cute" and "sexy" man, only to playfully dismiss these possibilities for their "inappropriateness", considering their age or even married status. Schulze's observation of Korean dramas' impact on fostering new desires is extended by Min Joo Lee's 2020 doctoral thesis, which explores how consuming Korean dramas has motivated young Western women to travel to Korea and seek romance with local men. Lee demonstrates that her informants' indulgence in K-drama depictions of romantic and sexually non-aggressive masculinities has shaped expectations of Korean men whom they seek to date.

Not all audiences wish to engage with soft masculinities in real life, however. Murell (2019) finds that young Koreans draw a clear distinction between kkonminam on screen and those who actually emulate them. According to Murell, Korean female interviewees are not interested in dating kkonminam because they appear "weak" and in need of care. Real-life pretty boys are also regarded as immature "bad boys," who contrast with the considerable and sweet kkonminam on television. Within the Hong Kong context, Maliangkay and Song (2015) find that Hallyu fans view male representations in Korean pop culture as fictional and idealised constructions of masculinity and thus receive these in a distant manner. These fans may enjoy watching icons of soft masculinity but do not imagine getting in contact with or copying these men in their daily lives because they perceive these men as "too effeminate" and irrelevant to their daily life (Maliangkay \& Song, 2015, p. 174).

Negotiations of gender ideals have also been found in Hallyu studies in different contexts. Tambunan (2015) shows how young Indonesian female viewers reject aspects of soft masculinities such as over-the-top fashion and effeminate looks, which run counter 
to Indonesian hegemonic masculinities influenced by Islam, yet celebrate male characters' more culturally acceptable behaviours, such as romantic gestures and "manly" manners. Noting similar ambivalent attitudes, Ayuningtyas (2017) finds that Indonesian female fans accept K-pop male idols' makeup and feminine looks as part of their profession but would not tolerate the same in a romantic partner. Meanwhile, Putri and Mintarsih (2020) examine American fans' greater tolerance of soft masculinities exemplified by the K-pop band BTS and find that female fans would consider dating feminised men like BTS members, whereas male fans accept members' soft manners but still prefer traditionally masculine traits.

Other studies find unfavourable reception and disidentification among audiences. Creighton (2009), Ainslie (2017), and Jeehyun Jenny Lee et al. (2020) note how social stigma associated with watching Korean dramas has made international viewers hesitate to share their viewing experiences. David C. Oh (2012) finds that male Korean American high schoolers view Korean actors as less masculine than their American counterparts because they "act cute" like Korean actresses do (the female teenagers in this sample, however, do not report the same view). Viewing Korean mass culture as "girly," "feminine," and "sappy" because of its overemphasis on romance and male display of cuteness, these young men are unwilling to use Korean pop culture as a means to construct an ethnic identity (pp. 269-270).

Research on Vietnamese reception of Korean soft masculinities remains limited, and what exists concentrates on male entertainers' appearance. Thu Ha $\mathrm{Ngo}$ (2015) finds that Vietnamese fans enjoy Rain's performance of hybrid masculinity in the hit drama Full House because they admire how his physical "manliness," marked by Rain's tall and wellbuilt body, is combined with his performance of a "clumsily cute" character (p. 148). Ha Hoang (2020) shows that Vietnamese fans accept G-Dragon (leader of K-pop band Big Bang)'s gender-blurring images because they regard the singer almost as a family member and enjoy his performative versatility, i.e. G-Dragon's combination of androgyny and cuteness with other images of swagger and "cool" masculinity, rather than because of a gendered desire for androgyny. Ngo and Hoang provide helpful case study analyses of Vietnamese reception of soft masculinities but do not delve into the themes of gendered identifications and desires.

As I proceed to the end of the chapter, I want to highlight four observations. First of all, extant research reveals Korean dramas and Hallyu as fertile ground for exploring complex gendered desires, identifications and negotiation. These studies indicate that 
certain audiences consume Korean dramas not merely as "entertainment" but as a means to discover their lost selves and relations they have had with others, imagine alternative gendered subject positions/relations, and interact with alternative masculinities. They suggest that Korean dramas are contributing to the proliferation of romantic imaginations and even alternative realities, and that consuming Korean pop culture can be complex, enriching, and even subversive, as when transnational female fans explore their newfound desires for much younger, feminised men (Schulze, 2016) or seek to date men in a country on the other side of the world instead of more "macho" men at home (Min Joo Lee, 2020).

Second, these studies demonstrate that viewers' experiences can be both personal and collectively shared. This topic becomes even more fascinating when one considers Korean dramas' resonance with audiences around the world, suggesting an influence beyond geographical and cultural proximity. Some patterns of gendered desire, identification, and negotiation in these studies resonate with my own findings of such phenomena as escapism, parasocial interactions, romantic imaginations, female melancholia, and experiences of upward mobility, ambivalence, and disidentification. The difference my study makes is that I focus on case studies and thus delve deep into personal experiences by connecting individuals' consumption with lived experiences. In so doing, I reveal the multi-layered psychological meanings of viewing experiences and locate these experiences within distinctive Vietnamese social contexts.

Third, audience research into men's experience is overshadowed by that concerning women in number and diversity of methods. Such research also tends to focus on heterosexual desires rather than non-heterosexual desires. I argue that further attention to men's reception and queer desires could help enrich this scholarship, and I seek to do so in Chapters 5, 6, and 7. My explorations of male viewers' attention to the narratives of improvement and self-presentation (Chapter 5) and queer pleasures (Chapter 7 ) attempt to offer insights that open avenues for further research into men's reception of K-dramas and soft masculinities.

Last, research within other contexts concerning gendered experience is rich and insightful, but such scholarship on Vietnam remains comparatively limited, a gap all the more striking in this case, as the country has been one of the most receptive for K-dramas and soft masculinities have been emulated there. By exploring the Vietnamese reception of soft masculinities via a method rarely found in Hallyu research as well as audience 
studies, I hope to extend the investigative territory of this important topic and inquire further into the psychosocial meanings of transnational audiences' viewing experience, thus enriching scholarship on Hallyu. 


\section{Chapter 2: A Retreat from Life: In Search of the Extraordinary}

In their study of Hong Kong female professionals' consumption of Korean dramas, Lin and Kwan (2005) note how these women compartmentalise their life into public and private realms. In the former, especially at work, the women try not to show weaknesses in order to project the image of independent, competent professionals. In the latter, they allow themselves to be "traditionally feminine," that is, more emotional and romantic than usual while watching Korean dramas. The dramas offer them a space to engage with their feminine desires, which they do not show to the outside world. Lin and Kwan's (2005) findings echo similar observations made by Hayashi (2005) in her research on Japanese female fans of Winter Sonata (2002). Hayashi notes that Winter Sonata's depiction of emotional excess and its evocation of tears offers female fans a break from pragmaticism and self-discipline so that they can get in touch with their innermost desires. Drawing from Radway's (1984/1991) idea of a woman's "time to herself" in romance reading, Hayashi foregrounds the role of private fictional consumption in giving women a refuge from the "real" world.

The respondent profiled in this chapter, An, found such a retreat in the fictional world of Korean dramas, which she watched in solitude. An was among the women who engaged with the dramas most intensely in my sample (the others are discussed in the next chapter). She held a more vivid, emotionally charged memory of favourite scenes than most participants and displayed a parasocial relationship with favourite dramas through her recitation of those scenes. Via a psychosocial analysis of An's narrative, I argue that An, who stoically faced harsh life circumstances, found comfort for her selfpositioning of "invisibility" through her engagement with melodramatic scenarios in Korean dramas. Her case exemplifies what Whitehouse-Hart (2014, p. 27) terms "a seeking out of emotion" for cathartic ends among media audiences, a psychological phenomenon also noted by such studies into transnational K-drama consumption as those of Hayashi (2005) and Putri and Yatim (2019). This case study of An illustrates how K-dramas function as "compensatory fiction" that accommodates women's unfulfilled psychological needs, much as Radway (1984/1991) notes for literary romance.

This chapter first presents An's long-time desire and struggle for recognition and her self-positioning as an "invisible person." It continues with an account of her active engagement with K-drama characters, particularly extraordinary male protagonists. This engagement, I argue, is intimately connected to her framing of herself as socially 
“invisible." In discussing An's relationships with drama characters, I address two primary themes. The first is An's desire for the extraordinary masculine Others, who embody strength, agency, and power, the qualities that she might desire for herself and her ideal partner. This theme shows An's emotional investment in perfect male characters as an escape from the mundane but oppressive reality of her daily life and her feeling of social invisibility. Secondly, I analyse An's negotiation of gender ideals as she viewed icons of soft masculinities in traditionally masculine roles, juxtaposed with her adherence to Vietnamese ideals of hegemonic masculinity. This theme reveals her positive response to Korean television filmmakers' strategy of constructing feminised masculinity within a patriarchal framework (Khai \& Wahab, 2017). Within such a frame, "pretty boys" are feminised via conspicuous attention to looks and display of vulnerability; their emotional display is, however, confined to the private sphere, and they remain masculine and powerful in public (ibid.). Overall, An's narrative shows fantasy as "the setting of desire" (Laplanche \& Pontalis, 1986, p. 26-27; Butler, 1990b), in which An engaged with not only mediated scenarios but also her imagination of escaping the ordinary. Put another way, Korean dramas create a space in which An has constructed and developed her own connections with characters and melodramatic scenarios.

\section{Lifelong Struggle for Recognition and Retreat to Korean Dramas}

When I met 30-year-old An, she was working for a newspaper known for its coverage of state propaganda, despite her lack of interest in politics. A well-educated woman from a working-class family, An came across as humble and introverted. Her narratives revealed constant feelings of being bored and lost, and it appeared that the more dissatisfaction An felt towards her life, the richer her inner world became. Throughout two interviews, An discussed her dissatisfaction with life: she was not passionate about her job and worked only to support herself. An displayed loneliness, revealing that she had never had a romantic relationship. She longed for love and wished for something beyond her ordinary life, which she sought to partially fulfil through brief travels and media consumption.

The most prominent theme in An's life account is a struggle to gain recognition from others. An joked that she had "the supernatural ability of invisibility," by which she meant that people failed to notice her, despite her continuous attempts to draw attention. An shared: "When doing school performances, I wanted to be at the centre, but I was always the smallest, ugliest person at the margin (chuckles)." She recounted: "If a stranger wants to ask for direction, and my friend and I are together, they'd ask my friend 
instead of me, maybe because I look a bit fierce (dữ dằn) or something. Everyone acts like that." An often made self-deprecating comments with a chuckle, a sign of nonseriousness (Myers \& Lampropoulou, 2016), or with a hint of humour and nonchalance in speech or mannerisms, probably to soften her tone. This habit suggests the way in which An usually coped with her identity insecurity, as An confided: when she did not get the attention she desired, she accepted the situation without complaints.

Ever since she was a child, An has been subject to peer pressure because of her parents, relatives and nosy neighbours' habit of comparing An with peers. In Vietnam, this common practice, which involves telling children about well-behaved and accomplished peers as exemplars of filial piety, is called the con nhà người ta (literally other families' kids) syndrome (see: Soucy, 2000, p. 193). People around An incessantly reminded her of what she lacked, i.e. her perceived unremarkable academic performance and later her failure to get married. This "pressure of the public gaze" polices Vietnamese people's day-to-day behaviours and drives their continuous efforts to improve the reputation of themselves and their families; women tend to be more concerned with this pressure than men (Soucy, 2012, p. 152-154). The pressure has caused An to suffer from feelings of inadequacy and to develop "status anxiety" (Sennett \& Cobb, 1972), as she internalised social expectations. Specifically, An manifested a keen sense of competitiveness: she made efforts in everything she did, not necessarily to be the best, but to remain above average and to be recognised as a good student, daughter and person. Although An said she hated being compared to others, she did so often during interviews: she talked at length about how her academic performance compared to her peers, how she performed at entry recruitment tests with a potential and current employer, how her best friends had married but she had not, and how her younger brother obtained a master's degree before she did. She spoke of her earnest wish during school years: "I really really wanted one thing — that the teachers would make eye contact with me when lecturing," acknowledging her longing for recognition. In An's case, teachers as authority figures became especially important, probably because her family, relatives, and neighbours did not duly acknowledge her efforts. When asked about the highlights of her life, An underscored the moments in which people paid her special attention, such as being recognised by lecturers and fellow students for obtaining the highest mark in an exam or winning a slot for a university exchange course in Eastern Europe. An spoke of the year spent overseas as memorable, for it permitted her to cast aside others' expectations and live her life freely. 
Societal and parental expectations have had tremendous influences on An's life. Explicit in her narrative is the desire to fit in. An's frustration with others' expectations and their pressurising attitude is a typical example of how social norms and ideals can do violence to individuals (Butler, 2004). While An resented such imposition, she acknowledged that the pressure of those expectations constantly pushed her to progress. Butler's theorisation of humans as "bounded beings" applies here: "our very sense of personhood is linked to the desire for recognition, and that desire places us outside ourselves, in a realm of social norms that we do not fully choose, but that provides the horizon and the resource for any sense of choice that we have" (2004, p. 33). The sense of obligation An felt towards others is common in Vietnam, where relations to kin and extended families can foster a desire to cultivate belonging and shape individuals' selfimages, decisions and aspirations, especially among women (Gammeltoft, 2014; 2018; see also Trang T. Nguyen, 2021; Shohet, 2021).

As An grew older, the pressure for her to marry grew, a common situation for Vietnamese women in their late twenties and thirty, as marriage is a "universal expectation" locally and those who do not marry and have children usually suffer from social stigma and isolation (Bélanger, 2004; Soucy, 2012; Earl, 2014; Gammeltoft, 2014; Thanh Thi $\mathrm{Vu}, 2015)$. An wanted to marry but could not find a suitable partner. Having struggled in keeping up with peers all her life, An found herself suffering from a sense of not belonging when her two closest friends each married around the same time several years ago. "If I don't [get married], I would become isolated (lạc lõng) in those conversations [about marital life and children]," An explained her fear of being left behind. This problem became more acute as An could not "fix" it by herself, in contrast to how hard work improved her grades. An's narrative of her struggle for recognition is crucial to understanding her inner world, as she reported finding solace in Korean dramas because of her dissatisfaction with life. She noted her interest in dramas that feature women with the same "supernatural ability of invisibility" as herself and their relationships with men who are "everyone's idols." An revealed her experience of strong identification with these ordinary women and desire for the extraordinary men: "[When watching dramas with such a plot] I always imagined myself as the female lead (chuckles) and wished (chuckles) that someone remarkable [an extraordinary man] would appear in my life too." The way An confided her intense involvement with chuckles made me feel like it was a confession and highlighted her awareness of Korean drama's strategy of targeting ordinary female consumers such as herself. 
An's emotional investment in K-dramas may be correlated with her sense of alienation, as she "lost" her two best friends (her major source of comfort and recognition) to their busy marital life, she did not find passion from work, and she lacked a strong sense of purpose. These biographical details are important in considering An's identification with socially unrecognised female characters and how she projected her hopes on them. Such identification was most apparent in how An watched two dramas with the Cinderella plot of an ordinary woman becoming romantically involved with an outstanding man: Another Miss Oh (2016) and Jealousy Incarnate (2016). This trope, popular among women, provides a romantic fantasy in which an average woman is validated through a special man's attention, offering the identifying female consumers "reassurance for their value" (Radway, 1984/1991, p. 106).

An found herself relating to Oh Hae Young, the protagonist of Another Miss Oh, an ordinary woman who is incessantly compared to a classmate of the same name seen as more beautiful and intelligent. "I've been in the exact situation as she was," An stressed. She stopped watching the drama, however, as the story neared its conclusion because "I found her remaining stuck and I didn't want to continue being stuck" and "she remains useless in people's eyes." An thought of Oh Hae Young as stuck because she does not show evident passion for her career, remains an object of ridicule throughout the drama, and falls in love with a man whom An saw as not morally good enough. The drama may have become uncomfortable for her, despite its eventual happy ending. This example shows how An projected her expectations onto the female lead: she was sensitive to the fact that Oh does not obtain social recognition, even though she is not a failure: Oh holds a middle-class job, and the male lead ultimately chooses her over her similarly named former classmate, who happens to be his ex-girlfriend. The character stagnates according to An's standard of success, which involves gaining social recognition. An's saying "I didn't want to continue being stuck", as if speaking of her own situation (instead of "I didn't want her to remain stuck") suggests that she put herself in the character's position. That An watched Another Oh Hae Young when she suffered an existential crisis because of her boredom with her job and her failure to get married despite pressures, made it more important for her to find inspiration on screen as catharsis. She noted: "I wanted to see how they [struggling female leads] manage to pull themselves out of [unfavourable] situations." This example suggests that An hoped to find role models in Korean dramas and wished to engage with a problem-solving process and achieve a sense of resolution through the dramas. As An sought role models on screen, she found herself preferring Jealousy Incarnate, which recounts a relationship between a 
struggling weather forecaster and a star news anchor with superior background and reputation. Like Another Miss Oh, Jealousy Incarnate shows the protagonist being constantly compared to co-workers deemed more attractive and competent. The difference between the two shows is that the struggling weather forecaster, unlike Oh Hae Young, showed greater devotion towards work and managed to gain recognition for such devotion as the story progresses.

Although on screen and in real life An admired both professionally devoted men and women, it is usually men that offer her visual pleasure: "men are most attractive when they are working, doing something they love." Adhering to a conventional ideal of gender roles, An noted in contrast that she found women beautiful when they took care of their family, even though she implied that she understood that such thoughts were anti-feminist in this day and age. The subsequent section further explores An's celebration of qualities of hegemonic masculinity.

\section{Parasocial Interactions with the Extraordinary Masculine Other}

This section discusses how engaging with the extraordinary masculine Other, i.e. perfect heroes in Korean dramas offered An relief from life. Dramatic situations, which highlight the outstanding character of male leads, starkly contrast with An's mundane life, which she views as nothing special. Extraordinary heroes, who embody idealised traits, also differ from her self-described "invisible" identity.

As shown earlier, the regulation of heteronormative norms and expectations as inevitable conditions of life (Butler, 2004) is evident in An's ideal of masculinity. Her view of the ideal man as a worker, problem-solver, and most especially, women's protector and saviour, was manifest in her fascination with seeing women as the object of male gallantry and protection. Discussing The Heirs (2013), An highlighted how the hero Kim Tan, when suddenly coming upon boulders while driving, tries to protect his passenger by bracing her with his arm as he swerves to avoid the obstacles. When An talked about Yoo Shi Jin, her favourite character in Descendants of the Sun (2016), she quoted Yoo with amusement: "it is my duty as a soldier to protect children, the elderly and pretty women," accentuating her ideal of protective masculinity.

The most detailed description An provided was of a scene from the drama $K 2$ that highlights not only her admiration for the gallantry of the protagonist bodyguard Kim Je $\mathrm{Ha}$ (played by Ji Chang Wook) but also her identification with his female boss, a 
supporting character who is the object of his protection. The woman, Choi Yoo Jin, a forty-something wealthy, beautiful, manipulative wife of a politician, hires Kim, also known by his codename K2. Although K2 falls in love with Choi's stepdaughter, An was cheering for him to become romantic with Choi instead. The following excerpt, in which An reenacted a situation in K2, offers insight into An's fascination with the lead character:

So he entered. There were lines of bodyguards here, he tackled them all. Then he made a fire, because the door was locked, and they wanted to harm her [Choi]. It was impossible to open the door from outside. He had no choice but to make a fire, so the fire alarm automatically rang, and the door opened from inside. The room had an automatic sprinkler system: when the fire alarm went, water rained down. Yeah, the scene was very beautiful. After tackling all the bodyguards outside, he fixed his clothes. Then he carried an umbrella, a black one, and entered. Everyone inside panicked, they had no idea what was going on. Everyone ran away. But...she just sat there. She was betrayed, disappointed. He covered her with the umbrella, and then handed her a handkerchief (Thi: wow - laughs) Yeah. Very thoughtful. Why so ${ }^{13}$ I was so impressed how someone would still use a handkerchief, because in this modern day, almost nobody uses one. (Thi: Is that so? How did that impress you?) I felt like that person must be very meticulous (chin chu) (Thi: yeah?) Yes. Umm... Afterwards, he covered her, gave her the handkerchief and led her out. They got out. All of that...the rain...the grey background and the pair both dressed in black. (Thi: yeah) The scene was so impressive. It looked so terribly sad. Yeah... As he held the umbrella to cover her, he patted her on the shoulder and said [speaking as if she were the character in a deep, calm voice]: "Straighten your shoulders, your enemies are watching you." I've watched that scene over and over, countless times."

This scene, a typical example of the rescue fantasy, shows K2's expertise as a bodyguard. Without being ordered to enter the locked room, he senses that his boss is in trouble and saves her, demonstrating his decisiveness and timely action and intuitive reading of the situation. K2 hands Choi a handkerchief, not merely for her to wipe her wet face but also as a comforting gesture. The handkerchief triggers a sense of nostalgia for values such as chivalry and courtesy. K2's act of patting Choi's shoulders and reminding her to resume her usual posture also shows support and an understanding of her emotions. The character possesses desirable elements of the ideal masculinity dictated

${ }^{13}$ An asked this question rhetorically. 
by the Chinese Confucian wen-wu dyad, of which wen is mental and cultural attainment and $w u$ is the mastery of physical or martial strength (Louie, 2002). He shows his cultured, polite demeanour through gentle, thoughtful gestures; his mental strength (calmness and decisiveness) in dealing with challenging situations; and his martial prowess.

To understand An's identification with the non-romantic relationship between K2 and Choi, it is important to note that Choi Yoo Jin (played by Song Yoon Ah) is no ordinary woman. She is a powerful villain who resorts to any means possible, including murder, to fulfil her thirst for power. However, she is still a character who elicits identification: she became a villain upon having been ill-treated by her rich father and betrayed by her adulterous husband. An pointed out that Choi became villainous because she had no one to rely on. It seems no coincidence that An strongly identified with Choi: a woman who is lonely, unloved (in the romantic sense), and misunderstood by those around her. Despite her sufferings, Choi must put on the front of a strong woman to assert her power. Beneath Choi's tough exterior, she longs for love and understanding. While Choi does not show overt romantic feelings for $\mathrm{K} 2$, she desires friendship with him. Their mutual trust in matters of secrecy indeed suggests the possibility of a meaningful friendship. Being a lonely woman who has not experienced romantic love and who has learned to internalise dissatisfactions, An appeared to identify with Choi's quiet sufferings and stoicism. She seemed to have found something of herself in Choi - her state of helplessness, her loneliness, her longing for love and understanding, and especially, her yearning for a masculine protective figure. The fact that Choi possesses considerable social power, despite her inner despair, gives her a charisma that differentiates her from some other helpless K-drama female characters; Choi's simultaneous power and powerlessness make her intriguing.

Although An did not point it out, upon entering the room where Choi is locked inside with others who threaten her power, K2 says "let's leave" to her. These others are, importantly, members of her own family, including her stepbrother and the mistress of her father, who became her stepmother. Similarly, although An loved her family, she resented their relentless policing and pressure and regarded them as antagonists. K2 leads her out of her state of helpless imprisonment. The "rain," created by the sprinkler, adds release and catharsis to the scene. Not only is Choi now rescued, but she also realises that she has possibly gained a trustworthy new friend who can understand her and that perhaps there is new hope in her life. Choi, however, will not leave her loveless marriage because she cannot give up the power she wants as compensation for her emptiness. 
Later, as K2 and Choi part ways near the end of the drama, he again tells her to "leave," to free herself of her thirst for power in a scene that An also noted as memorable and having watched multiple times. Again, I could not help noticing a similar state of hopelessness for An and the character. Like Choi, An wanted to escape the world she lived in, but could not easily leave that "comfort" zone. Though oppressive, the environment she lived in was what she was familiar with and gave her a sense of belonging. K2's urging Choi to "leave" may have "spoken" to An's inner longing to "leave" and reflected her wish for change. Leaving, for An, was difficult, but she had considered it. An shared that she was saving to move out of her parents' home to live elsewhere and considering further studies abroad.

As the excerpt above suggests, $\mathrm{K} 2$ is a saviour in his relationship with Choi. Not only did he work to support her and protect her, but with his actions, he also taught her about kindness and trust, which she had forgotten. Such a relationship, in which a man changes a woman's life, either by serving as an inspirational figure (as in Jealousy Incarnate) and/or by saving and protecting her (The Heirs, Descendants of the Sun, K2), fascinates An. She wished that she too would become a protagonist and find her hero, a guide to lead her, perhaps, out of her current stagnation.

Chivalrous acts, for An, should be "genuine," and not simply displays of human kindness but specific displays of kindness by men to women - which for An, women are entitled to because they are physically weaker. An's identification with the rescue fantasy seems to reflect her longing for protection and warmth from the masculine Other and, at the same time, a sense of lack of agency or particularly, female hopelessness. One might say that her identification and desire stem from her internalising a patriarchal culture that sees men as leaders/problem-solvers and women as followers. Of course, An could also identify with the rescuer while vicariously enjoying his display of masculine agency, yet little of her narrative suggests this. Her desire for masculine protection and guidance appears far more prominent. The qualities demonstrated in An's favourite K-drama heroes recall female romance readers' ideal of the perfect man in Radway's (1984/1991) study: a physically strong man who is also attentive and caring. In a remark that aligns with psychoanalysis, Radway posits that such an ideal man "evokes the memory of a period in the reader's life when she was the center of a profoundly nurturant individual's attention" (1984/1991, p. 84). Radway's emphasis on the hero's "nurturant" quality is noteworthy, as the ideal man in female imagination may combine both desirable traits of traditional masculinity and femininity. 
The male characters whom An admired, while differing in profession, social position, and purpose, have in common strong motivation, talent, kindness, and protectiveness towards women. These extraordinary men, according to An, contrast with men in ordinary life, who mostly disappointed her because they were not "gallant" enough. ${ }^{14}$ Indeed, in cases where An observed gallant behaviour in men, she questioned their motives. According to An, many Vietnamese men can be gallant when they need to please a woman but are not genuinely kind. An seemed to seek a form of masculinity that goes beyond the performative and is essentially pure: gallantry not for recognition, but for gallantry's sake.

An's level of emotional investment in her favourite dramas and ideal male characters is striking. Among my participants, few showed as strong memory of scenes or intense emotional attachment to them as An did (Minh and Kim in the next chapter are other examples). An's reproduction of the scenes gave them personal and compelling meanings, as I realised when I later watched K2 (I had not watched the drama before I interviewed her) and found that watching the rescued scene did not impress me as much as An's re-creation of it. An's distinctive description of the scene gave it a special meaning, as if I were watching the scene through her emotions or revisiting her emotions through the scene. Her frequent quotation of dialogues in attempts to re-enact scenes, as if she had been playing those favourite lines in her mind, suggests An's strong parasocial interaction with K-drama characters. This parasocial interaction is most apparent in An's discussion of another favourite character of hers, doctor Park Hoon (played by Lee Jong Suk) in Doctor Stranger (2014). An described him as "incredibly handsome" in his white coat, conducting an operation and demonstrating his otherworldly medical expertise. An blurred the boundaries between reality and fantasy at one point when she said she once "saw" actor Lee Jong Suk all around her: "I liked him so much that I saw him all around me. In front of me, left of me, right of me, because I always watch and keep his image in my mind." Her words indicate how fantasy can penetrate reality and become akin to lived experience. An's strong parasocial interactions with Kdrama characters suggest the simultaneous occurrence of the psychic phenomena of "projection" and "introjection" (see: Knight, 1940; Laplanche \& Pontalis, 1973). An projected her despair, hope, and wishes onto characters. Her loneliness caused her to

\footnotetext{
14 The Vietnamese word used is ga lăng, a derivative from the French adjective galant. This adjective is still widely used in contemporary Vietnamese to praise men's polite treatment of women, although the word may now be judged as old-fashioned in English-speaking societies.
} 
identify with characters such as Choi Yoo Jin: she wished for them to be loved, understood, and protected. Watching the sprinkler scene multiple times may have comforted her, as she may have imagined herself rescued and released to freedom. An also appears to have experienced introjection: she took the characters into herself as she internalised dialogues and spoke of characters' emotions as if her own. This concurrence of projection and introjection is common in the experience of identification, as the subject envisions being in someone else's shoes and at the same time makes them part of herself, forging a link between her life and fantasy (Knight, 1940; Frost \& McClean; 2014). Identification, as Knight (1940) points out, is "always based on a subtle interaction of both introjective and projective mechanisms" (p. 335, original emphasis); potent identification is experienced as an individual forms an attachment with a living or imagined figure.

I suggest that An's engagement with extraordinary men reflects her desire to escape the ordinary and perceived social invisibility, to be rescued and relieved from life's dissatisfactions. When An engaged with characters and scenarios on screen, she created a world of her own and integrated the narrative into her inner world. Favourite scenes, which An frequently returned to, especially during "bad times," comforted and animated her. As An often watched Korean dramas at night, after a long day of work, in her room, the dramas served as a private, intimate space for self-indulgence. One may view such viewing habits as a personalised ritual replete with meaning; as Robinson (1984) remarks, "when I fantasize, I am becoming withdrawn, and I enter a self-contained narcissistic universe" (p. 126). An explained why she watched television dramas alone: "I often cry during moving scenes, and I don't want my parents to see my crying," indicating both the need to intimately engage with scenes in private without intrusion and the dramas' function of emotional release. ${ }^{15} \mathrm{Her}$ solitary viewing reveals how she allowed herself to be in touch with a "traditionally feminine" side, as noted in Lin and Kwan's (2005) research on Hong Kong viewers who otherwise project the image of independent, capable women at their workplace. While An did not show a desire to present herself as a particularly strong or independent woman, she indicated her stoicism and self-discipline in how she endured everyday dissatisfactions.

\section{Negotiation of Gender Ideals}

\footnotetext{
${ }^{15}$ An revealed a notable detail that her mother also watched a lot of Korean dramas, but the mother and daughter did not watch them together and seemed to enjoy the dramas in their own ways. Many informants also shared that their mothers watch Korean dramas.
} 
As discussed, An's admiration for K-drama male leads reveals identification with such aspects of hegemonic masculinity as competency, bravery, and protectiveness that fit a "saviour" role. There is, at the same time, evidence that her ideal is not only influenced by traditional influences but also global trends of male beauty. I now discuss how her case exemplifies Butler's (2004) argument that sexuality is never a complete outcome of the regulatory ideal.

The following excerpt, from when I showed An images of actor Lee Jong Suk, and other popular metrosexual Korean actors, reveals the complexity of her gender negotiation as she constructed her ideal of masculinity:

Thi: (following previous questioning) What about these images?

An: ah...I used to really like this smile, this guy has a very beautiful smile, in my opinion (chuckles).

Thi: "used to", no longer?

An: no...not now. [My infatuation with] Lee Jong Suk was around 2013.

Thi: So you like guys for a certain period of time?

An: Yeah, [look at] this, it's always like this, his lips, they always look so sexy, like he always has glossy red lipstick, like a tomato.

Thi: Really, okay.

An: I really like his mouth.

Thi: What about the other photos?

An: This photo, I can't even recognise who it is, those baby cute things...I find idols all the same. I don't like such [idol] looks.

Thi: Okay. (switches to the next slide)

An: Are we moving to the music industry... I don't know these guys.

Thi: No, these are all actors. If you've seen Reply 1994, this guy [Yoo Yeon Seok] stars in it.

An: I haven't seen Reply 1994. But..., you see, these images, all Korean idols are like this. I...I've seen a lot of youths crazy about these, but I don't. Because I don't see the...how to call it, I don't find them really like men.

Thi: Okay (chuckles).

An: They look so frail, so made-up. When men don't pay attention to their beauty, that's when they're very beautiful.

Thi: So if a man is too conscious of his own beauty, he's not beautiful?

An: Right, not if he pays too much attention. 
Thi: Okay, anything else? Is it the colours [the men were dressed in colourful, pattern-laden clothes] that you don't like [or something else]? Can you please describe what exactly you dislike?

An: I dislike...I mean the projected image. All of it, makeup, hair style, etc. I like guys that are thorny, dust-covered, not always neat and well-groomed, with makeup on and all. (Thi: umm) These guys...So well-crafted (chin chu). Not exactly well-crafted but... what to say...the kind of image that they really try to make so perfect, so immaculate. I wouldn't like them as much as the image of someone in a dust-covered military uniform. (Thi: really, I see)

Thi: (takes notes) dust-laden... What else?

An: Umm... This guy has such a pronounced nose. I like pronounced noses.

Thi: So you find them beautiful, you just don't like this kind of projected image, or you don't find them beautiful at all?

An: When examining every feature of their face, looking at their whole face, these people, I find Korean idols all alike. But in a certain character, when they present in their face the character's emotions, maybe l'll come to like [them] even though I don't like looking at them like this [well-groomed, with make-up on].

On the one hand, as shown here and throughout both interviews, An found kkonminam or "idol"-like men conventionally attractive. She acknowledged that she liked Lee Jong Suk's reddish, voluptuous lips and his boyish, cute smile, and pronounced noses. These features, in addition to light skin and double eyelids, are typical features of globalised and regionalised cosmopolitan beauty ideals (Jones, 2008; Fu, 2010; Holliday \& Elfving-Hwang, 2012; Yip et al., 2019) that have penetrated the Vietnamese urban culture (Thu Ha Ngo, 2015). On the other hand, An disliked men in metrosexual commercial photo shoots and found them unmanly. In her emphasis on others' infatuation with these "idol" images, especially the youth's, she distanced herself from a trend she perceived as immature.

An's favourite characters are played by Lee Jong Suk, Ji Chang Wook, and Song Joong Ki, icons of soft masculinity known for youthful "baby" faces. Even though they sometimes appear in "dust-covered" roles (Ji Chang Wook as the bodyguard in K2; Song Jong $\mathrm{Ki}$ as a soldier in Descendants of the Sun), they remain known for white, smooth skin, youthful looks with a hint of fragility and femininity, and endorsements of beauty products. However, An emphasised that she became attracted to these actors, not because of their "idol" looks but their portrayal of "manly" men. Their traditionally 
masculine roles, which show physical and/or intellectual strength and maturity, allowed her to justify infatuation with their beauty and to fully embrace it. Without those "manly" roles, An may have neither been drawn to the actors nor appreciated the value of their well-groomed looks. Lee Jong Suk, for example, is famous for his soft masculinity, yet he often plays a successful, intelligent man protective of his lover. Traditional masculine attributes make it possible for An to embrace K-drama actors with feminised, metrosexual looks like Lee. An showed receptiveness to a production strategy common in Korean dramas, in which beautiful men display both traditionally feminine traits such as attention to looks and "sensitivity" and "masculine" ones like power and privilege (Khai \& Wahab, 2017).

An described her ideal of masculinity in the excerpt above with the words gai góc, bụi bặm and elsewhere, she used the term sương gió, which may be fairly translated as "thorny," "dust-covered" and "foggy-windy," respectively. These evocative terms, associated with elemental forces and nature, vividly trigger images of the desirable rugged man. A "dust-covered, thorny and foggy-windy" man is one who has worked hard, usually at manual tasks (and therefore his clothes are not clean but covered with dust); who has lived through and overcome difficulties in life (fog and wind); and who cannot be easily trifled with (he shows his "thorns" when necessary). He is strong, independent, capable, and thus probably dependable and trustworthy. These terms suggest an element of authenticity: he is just the way he is with no need for special grooming, and he neither pretends to be someone else nor tries to project a deceptive image. The association with labour and experience, as suggested in those words, projects traditional ideals of masculinity, marked by physical strength, autonomy, maturity, and reliability. This association between masculinity and physical labour recalls Walkerdine and Jimenez's 2012 study about working-class masculinity, in which a participant speaks nostalgically about how he came home covered with grime and dust after "doing real physical work" (he was a steelworker). When he was made redundant and switched to a job at a supermarket, however, he lost not only this pleasure but also a sense of identity based on working-class masculinity.

An further emphasised the importance of maturity and experience to masculinity when she discussed her high regard for Korea's compulsory military conscription. An noted that she had become interested in actors such as Song Joong Ki when she read about their completing military service, even though she paid little attention to them before that. Even though Song had appeared in several dramas and shows she had viewed, his 
boyish looks had not attracted her interest until he completed his service and starred in Descendants of the Sun in a "manly" role as a patriotic military officer. The completion of military service, for An, marks maturity because military training, discipline, and experience make it possible for someone to become a "real man." Her perceptions are in congruence with Korean views on the matter (Insook Kwon, 2001; Aramchan Lee, 2017), as Insook Kwon (2001) explains:

Many South Korean people believe that the required couple of years of conscription are a real turning point in the acquisition of a trained muscular body and male maturity. Military service is viewed as a time that can serve to change young conscripted soldiers into responsible men who can support their families and co-operate (obey) in organised civil society. An honorable discharge means the end of adolescent wandering and resisting social order. (p. 35)

For these reasons, media consumers like An attach greater value to Song's militarised body over his pre-conscription body. Song's performance as a soldier in Descendants of the Sun after his discharge may well enhance the sense of authenticity that audiences feel in his portrayal of the role (Yezi Yeo, 2017).

An's view of metrosexual-looking men as unmanly and of dust-covered, thorny men as real men again suggests a normative ideal of masculinity and reflects what Butler (2004) terms "coercive criteria" informed by norms that define what count as "real" men and "real women" (p. 206). An's perceptions of masculinity show how such coercive criteria govern individual judgments. Furthermore, as Butler (1997, 2004) would put it, desiring "the right kind of men," or the "real men" may also suggest that one is a proper, a real, or "normal" woman.

An's distancing from young people's admiration of idols suggests an implicit desire to be seen as a thoughtful, mature woman who appreciates "real men" and is consistent with her overall self-presentation during both interviews as a mature woman who provided logical, rational explanations for her behaviours and others'. While An denied interest in metrosexual looks, her willingness to accept them when accompanied by such traditional masculine attributes as physical strength and decisiveness means that she resisted the superficial (projected beauty that gives a hint of vanity) but was willing to acquiesce if the same men showed "depth." In other words, An attempted to convey that she was neither shallow nor rigid: she would invest in the character for their "inner" quality rather than simply the outer beauty. 
Despite the governance of normative ideals apparent in An's gender views, it is important to remember An's fascination with images of a cosmopolitan beauty ideal. Butler's theorisation concerning the regulation of norms (2004) is instructive here. For Butler, social norms regulate individual feelings and practices through a process of normalisation in which ideals and expectations are constructed. The way such ideals develop and are absorbed, however, is not always known to individuals, as evidenced by how some find themselves unwittingly attracted to certain things and people. While norms regulate our feelings, they do not totally control these feelings. Although our subjection to norms is inevitable, it can be flexible and negotiable, as Butler asserts:

The staging and structuring of affect and desire is clearly one way in which norms work their way into what feels most properly to belong to me. The fact that I am other to myself precisely at the place where I expect to be myself follows from the fact that the sociality of norms exceeds my inception and my demise, sustaining a temporal and spatial field of operation that exceeds my self-understanding. Norms do not exercise a final or fatalistic control, at least, not always. The fact that desire is not fully determined corresponds with the psychoanalytic understanding that sexuality is never fully captured by any regulation. Rather, it is characterized by displacement, it can exceed regulation, take on new forms in response to regulation, even turn around and make it sexy. In this sense, sexuality is never fully reducible to the "effect" of this or that operation of regulatory power. (Butler, 2004. p. 15)

Following Butler, perhaps the very fact that icons of soft masculinity are placed in "manly" roles makes them "sexier." Perhaps the combination of femininity and masculinity fascinated An more than she could adequately elucidate. Desire is fascinating precisely because it does not always stand within regulatory power and can be subversive. One might even interpret An's enjoyment in watching men who combine aesthetic traits of traditionally perceived masculinity and femininity as a form of queer pleasure, which Doty (1993) notes, is prevalent and can be observed in all people regardless of sexual orientation. ${ }^{16}$ This enjoyment may stem from a desire for complexity in characters or for

\footnotetext{
${ }^{16}$ One year after our research encounters, An told me, via a chat message, that her gender views had changed significantly: her following of gay and transsexual celebrities has made her form sympathy with gender-nonconforming people and realised the appeal of certain (but not all) gender-non-conforming images. I refrain from adding this information to the main discussion because it is not part of my officially collected data. However, I find it important to note that An's acknowledgement of her changed views can be further evidence of how gender ideals may change over time and of queer pleasure.
} 
traits that are not easily categorisable into simplistic gender ideals. I discuss this queer pleasure in greater depth in Chapter 7.

\section{Concluding Notes}

This chapter engages with two primary themes found in An's viewing experience. First, her emotional engagement with male protagonists reflects her desire for the extraordinary as well as a wish to escape the ordinary through these characters. Such characters' outstanding qualities may seem traditionally masculine but incorporate traditionally feminine traits such as sensitive manners and a nurturing character. Second, An's negotiated desires for K-drama male leads, which combine aesthetic traits of traditional masculinity and femininity, reveal a complexity that is not reducible to traditional masculine-feminine binary values. These themes of emotional immersion and negotiated desires reveal the interplay of different forces in An's construction of masculinity: hegemonic masculinity, globalised trends of male beauty, and her yearning for protection and warmth.

While I draw an association between An's disappointment with life and identification as invisibility and her parasocial relationship to extraordinary masculine Others on screen, I do not mean to belittle her viewing experience as a reflection of her lack of agency, competence, or power. The tendency to portray women's consumption of soap operas as passive, uncritical, or even unhealthy can be found in some studies, including Putri and Yatim's (2019) otherwise insightful work. I oppose this pathologising tendency and wish to refrain from applying this approach here. First, I find it arbitrary to judge fans' agency and power from their indulgence in pop culture. While I highlight An's feeling of hopelessness, she was not more "hopeless" than the average Vietnamese woman. From an objective observation, An is an independent-thinking professional in a middle-class job, and she has had accomplishments in life that she can be proud of and that, as she noted herself, people did notice. Her social reality was also not so grim, even though her inner reality pointed to a state of helplessness, due to the high value she placed upon social recognition. An judged herself harshly, much as she judged the character Oh Hae Young, who does well but struggles to achieve appreciation. In addition, even though An demonstrated a preoccupation with male characters that at times may border on obsession (as when she "saw" Lee Jong Suk everywhere around her), she noted that her preoccupation had been a brief phase. An's identification with the rescue fantasy can actually be seen as a "guilty pleasure," a private way for her to live 
her traditionally feminine and emotional self as the professionals in Lin and Kwan's 2005 research do.

An's fascination with Korean dramas is part of her rich and colourful inner world, which she kept mostly to herself. Her case study reveals that the individual viewing experience can be intricate and laden with psychosocial meanings and amply demonstrates why a single case like this is worthy of in-depth analysis. Her fan-like investment in the dramas illustrates how fictional worlds bring meaning to media consumers' ordinary lives as well as how consumers add distinct meanings to such fiction through their individual interpretations, as Henry Jenkins notes in Textual Poachers (1992/2013). An's story serves as a stepping-stone for my further explorations of how lived and viewing experiences can be intimately linked and how such links reveal a great deal about both the individual and the society they live in, as the next chapters will continue to illuminate. 


\section{Chapter 3: Caught in the Atmosphere of Love}

One of the "specialities" that Korean dramas produce is the ideal of an all-consuming love that heals and completes souls while challenging social barriers. Through strategic use of nostalgic music and romantic settings, Korean dramas create an atmosphere of love that mesmerises audiences (Ma; 2007a; Cagle, 2014). These dramas add to the global production of romantic scripts that shape audiences' understanding of love and propel our "imaginary longing" for romance (Illouz, 2012).

This chapter deals with how viewers indulge in Korean dramas' constructed atmosphere of love by discussing the narratives provided by three female participants: two single young women, Minh and Kim, and a married woman named Thanh. Following sociologist Eva Illouz's analysis of how media-constructed love fantasies shape romantic imaginations in her books Consuming the Romantic Utopia (1997) and Why love hurts (2012), I explore women's experience of "imagining having emotions" (Feagin, 1988, p. 493) via Korean dramas. For Minh and Kim, who had never experienced a romantic relationship, it was the imagination of being in a loving relationship with an ideal man. Their cases exemplify how romantic pop culture allows audiences to experience "anticipatory emotions" or "emotions about emotions to come" (Illouz, 2012, p. 206), even before a lived experience of romance takes place. For Thanh, it was the imagination of being passionately in love, which Thanh's relationship with her husband, though harmonious, could not offer. Thanh's story is a case of female melancholia similarly observed in Japanese married female viewers, who long for the passionate love they never had or had lost (Hayashi, 2005; Soobum Lee \& Hyejung Ju, 2010; Ingyu Oh, 2011; Jung, 2011). This experience of female melancholia can be drawn from Sigmund Freud's concept of melancholia (1917/1957), defined by a complex, unresolved experience of loss.

Overall, the chapter highlights how female viewers use pop culture, in this case Korean dramas, as "technologies of imagination" (Illouz, 2012, p. 2017) that cultivate the feelings of love inaccessible in real life. By touching on unfulfilled desire, I extend my discussion of Korean dramas' compensatory function in female viewers' life, which is initiated in the preceding chapter about An. The chapter discusses Minh and Kim's stories first, then continues with Thanh's.

\section{Desire for Romantic Moments}


Born in the same year, 25-year-old Minh and Kim grew up in working-class homes. Although I met the two women separately, I found many similarities between their narratives. Minh was a copywriter and Kim an event organiser. Minh's parents never went to university, while Kim's did not finish high school. The ways Minh and Kim grew up were, however, different. Minh enjoyed a mostly idyllic childhood and adolescence, while Kim went through harsh younger years due to her parents' lifestyles that she saw as irresponsible, including most notably her mother's gambling. Despite their working-class background, the two women and their younger siblings became educated and all went to recognised universities. Both expressed pride in overcoming the difficulties associated with their backgrounds to become educated. Being aware of social stratification and the importance of educational advantage, Minh and Kim manifested a strong sense of selfawareness and desire for self-improvement, which they acquired through education, skills courses, and social activities. Eloquent in their speech, the two women had little difficulty articulating their ideas. They were both K-pop fans as teenagers, but this tendency to idolise performers faded as they matured. Such fandom has been part of youth culture in Vietnam in the 2010s (Ha Hoang, 2020). As both women were friendly and open, interviews at times felt like casual "girls' talk" rather than research fieldwork. However, encounters with Minh left me feeling upbeat while talking to Kim at times felt as if we were having a therapy session in which she lamented personal problems.

Minh and Kim said they had never had a romantic relationship. Both women, especially Kim, expressed a longing for one. Minh indicated envy towards a K-drama character who was "lovely-dovey" with her boyfriend. Kim sometimes spoke of "my boyfriend" to refer to a future relationship she hoped to have (e.g., "my boyfriend should be..."). When discussing romance in dramas, Kim often related female characters' situations/behaviours to herself and her own life, indicating a strong identification. In addition to Korean dramas, Kim also watched Chinese TV dramas and read Chinese literary romances (truyện ngôn tình ${ }^{17}$ ). As Kim complained, "I've never been pampered by anyone," she expressed a wish to meet a man who would love her dearly and treat her with gentleness. Inexperienced in romantic love, the two women acknowledged Korean dramas as a cultural source to vicariously experience romance and observe romantic practices. Both enjoyed watching moments of intimacy, which sometimes involve the display of male vulnerability. When introducing It's Okay, That's Love (2014),

\footnotetext{
17 Chinese literary romances are especially popular among young women. Like romantic Korean dramas, truyện ngôn tình portray a passionate relationship between a privileged and romantically devoted man and an ordinary woman. Truyện ngôn tình is generally considered a lowbrow genre. See: Hoàng Phong Tuấn (2016) for a discussion of Vietnamese youth's consumption of truyện ngôn tình.
} 
a favourite drama that she had watched multiple times, Minh cited a scene in which the male lead explains why he fell deeply in love:

Minh: It [the situation] is when he [protagonist Jang Jae-Yeol, played by Jo In Sung] has started dating this woman, and she asks him "why me?", the very classic situation [when a woman asks a man] - "why me?", you know (laughs)... Thi: (laughs) okay.

Minh: Then he said, "You might not like it." He said, "I have a mentally ill mother who opens every door in the house because she can't stand trapped air, even in winter. My brother is in prison, and I'm this and that [he has his own psychological problems], but you still accept and understand me. Do you think I could ever meet someone like you? No." (laughs)

Thi: (laughs) umm.

Minh: I mean, the characters are interesting. They [the filmmakers] make it very interesting. I felt moved. Being a girl I was moved.

Thi: How did it move you?

Minh: I feel that...in real life, boys hardly ever talk about their weaknesses. They rarely say things like "my parents argue all the time", or "my family isn't well off"...। mean people usually try to make a very good performance. At work, I realise that everyone tries to show off their best side. I was so moved when I watched that scene and how he talks about his family. Even though he's a rich writer, with a lot of fans, he has to be very serious, he has to take a deep breath...before he can tell her. I mean, they set it up very carefully, making it convincing.

I later confirmed Minh's accurate memory as I watched the drama after interviewing her: the character indeed takes a deep breath before telling his girlfriend why he loves her. Minh indeed watched the scene closely multiple times. She also pointed out an aspect in this "confession" scene that she found amusing: after answering his own question with a "no" ("do you think I could ever meet someone like you?"), Jang Jae Yeol said: "If you know someone else like that, please let me know so that in case you leave me, I know I still have a chance." By combining a serious response and a joke, Jang manages to show his commitment, assure her of her uniqueness and specialness (no one accepts and understands me better than you) and still, assert his autonomy: he could accept rejection and manage it if she leaves him. Minh's remark on how men are rarely 
permitted to express vulnerable feelings reflects an expectation fostered in many cultures including Vietnam towards men's emotional restraint and stoicism (Nghe et al., 2003; Thanh Thi Vu, 2020). Minh observed that men usually only showed a performative self and that social expectations prevented them from being "true to themselves" and being accepted with weaknesses. Her emphasis on "being a girl I was moved" showed that she viewed men as "others" whose inner world she had yet to access. She implied that this scene allowed her to observe something out of the ordinary, as if she had snuck into a man's private space. Throughout her narratives, Minh represented herself as an "understanding woman" who showed sympathy towards others. She further explained why she appreciated the scene as a critical viewer:

I think those situations are carefully set up to afford men a chance to say things that they can't say in ordinary scenarios. No one without a reason would say that my mother is insane, that my brother is in prison...that he [the brother] is a thug. It's a very private situation, very... It requires real mutual understanding to share. You wouldn't see such a situation in real life. But on screen, the situation is very soft, like water flowing, it makes you realise... "Yes, this drama is really good."

Minh's reference to filming contrivances indicated how she enjoyed the progression of the romance. Minh elucidated: "The dramas present numerous scenarios to explain how one person comes to understand another." When Minh said emotional scenes were deliberately designed to allow men to say things they can't say in ordinary scenarios, she seemed to suggest that fictional characters may speak for ordinary men and, in a way, encourage women to sympathise with men and understand them. This example suggests her appreciation of emotional realism in Korean dramas. For Minh, the confession scene illustrates how true love works: it shows why a promiscuous man ended up becoming serious about a woman. She reasoned that the female protagonist Ji Hae Soo (played by Gong Hyo Jin) loved him for "his true self," including his vulnerability, and not just for his good looks or wealth. Ji's career as a psychiatrist gives her further advantages for understanding a man with a problematic background. Minh's critical comment on the effectiveness of the plot's progress recalls Bui's (2007) remark on how Korean dramas specialise in showing the "inner workings of love from various angles and perspectives" (Exceptional Scriptwriting section, para. 3). Indeed, most Korean dramas portray the nuances of romance from its budding phase to (more often than not) a happy ending. For young people with little romantic experience like Minh, dramas offered glimpses into the intimacy of love. Watching emotional scenes may have enabled her to imagine herself as the "understanding girlfriend" that she wished to become and to prepare herself for such 
a role. The appeal of the "emotional man" is also seen in Kim's description of her favourite scenes. Kim spoke of how scenes of male leads crying at crucial moments stood out in her memory:

Kim: ...A man may appear very strong and manly, but when he returns home... I hope...I want to see a bit of his vulnerability, so that I can stroke [him]. I believe that inside everyone lies something vulnerable. And when we can see their vulnerability, it means we're important to them. I hope I can see that vulnerability, from my future boyfriend.

Thi: Is that so?

Kim: Yes.

Thi: Like in which dramas?

Kim: I love seeing men cry. When I watch dramas...my God, all the scenes where men cry leave a strong impression on me. For example, umm...(thinking) But they have to cry in a manly way.

Thi: They cry, but they need to cry in a manly way?

Kim: Bridal Mask is an example. He [protagonist Lee Kang To, played by Joo Won] cries because he is torn between love, friendship, his family and his country. My favourite scene is after he just killed his best friend's brother. Have you watched this drama?

Thi: No, I haven't.

Kim: It's his best friend, who happens to be Japanese. It hurts him immensely too because he has lost his whole family, and that is his best friend's brother. He was very close to that person [Kim goes on to elucidate how Lee is compelled to kill his best friend's villainous brother].

Kim mentioned another crying scene that moved her in The Heirs (2013):

I wasn't impressed by this drama, but my favourite crying scene is [in The Heirs] when he [the lead] cries when he has to break up, when he learns that his father got rid of his girlfriend, that the father gave her money so that she moved out. He's so sad that he can't protect the girl he loves. That scene. (Thi: Umm. So he cries then) I even cropped a photo of that scene and posted it on Facebook (Thi: The scene where Lee Min Ho [the actor's name] cries?) yes. 
Like Minh, Kim enjoyed scenes of men showing vulnerability to their lover. When shown romantic photos from Korean dramas, Kim singled out one from the romantic drama While you were sleeping (2007):

I also like this one. I like being a shoulder for someone to lean on (Thi: For a man to lean on?) Not a man who is always weak, but when he feels tired, he can lean on my shoulder.

For Kim, the man's pose indicates the woman's importance to him as someone to whom he can show his tiredness. Note, again, that rather than discussing the scene in the third person, Kim inserted herself into it, a common pattern found in her narrative, which differs from Minh whose retellings manifested more distance. Like An in the previous chapter, Kim projected her desires onto characters. It seemed that romantic scenes gave Kim the imagination of being a man's "special person." Illouz (2012) calls this phenomenon "fictional imagination," which she explains as "the imagination deployed when reading or interacting with fictional material, and which in turn generate emotions" (pp. 209-210).

Scenes of a man's admitting his private issues or leaning on a girl's shoulders, which Minh and Kim respectively noted, are intimate moments that men only show to their beloved. The two informants' pleasure in seeing men at vulnerable moments indicates their curiosity about men's inner worlds, a realm they were yet to explore in real life, and their wish for a meaningful romantic attachment. Lin and Kwan (2005), highlighting Hong Kong women's pleasure in scenes of men at vulnerable moments, indicate that the appeal of these scenes stems from men's typical concealment of their emotional side. Kim's display of a scene of Lee Min Ho crying, making him a spectacle of emotionality, is aimed to express feelings of identification and empathy and to seek corresponding reactions of male vulnerability from an imagined "intimate public" (Berlant, 2008), who might offer her a sense of belonging.

It should be noted, however, that Minh and Kim did not particularly like emotional men. Rather, they enjoyed seeing how men who show emotional restraints in public open up to their beloved at vulnerable moments. Before discussing how she liked to see a man cry, Kim stressed that such a man "may be strong and manly outside," which is consistent with a conventional expectation for men to display strength and power in public. She restricted male displays of vulnerability to the domestic realm, where a man returns to his partner (herself, as she imagined it), and emphasised that she was not interested in "a man who is always weak." Kim's construction of boundaries for masculine performances resonates with romantic Korean dramas' common strategy of showing a powerful man 
become "feminine" in the private sphere while remaining "masculine" in public (Khai \& Wahab, 2017). Such feminised representations of masculinity may appeal to audiences but do not necessarily challenge patriarchy.

Kim's note "but the man must cry in a manly way" indicates a particular male ideal: he can shed tears, but he must not do so like a woman. Her remark echoes other participants' reactions towards men's crying scenes in Korean dramas. Some indicated that, while men can cry when they are upset, they should appear to fight back the tears rather than crying without restraint, and they should only do so in truly agonising situations such as the death of a family member. Like Kim, some participants set boundaries for "doing masculinity" as evidenced in frequently used words like "reasonable" (vừa phải), "okay," "acceptable" (được), "unacceptable" (không được), "excessive" (quá), "too much" (quá múc), which indicates negotiations of gender ideals informed by cultural sources. For example, when remarking on an actor's metrosexual photo shoot, Minh said: "This is reasonable, not too sentimental or too gay." This demarcation of gender boundaries, subject to the regulatory ideal of heterosexuality (Butler, 2004), renders non-conforming behaviours unacceptable and sustains norms regarding what a man should be like. I further discuss this emphasis on limits to gender performativity in Chapters 6 and 7.

As noted earlier, male leads in Korean dramas are frequently privileged men who enjoy high social positions and wealth. Echoing An (Chapter 2)'s fascination, Minh explained the appeal of extraordinary men:

Minh: ...Men in dramas are usually very successful. Korean dramas always feature powerful people, like CEOs. We hardly ever see someone ordinary, you know. There're also those writers, those very handsome lady-killers. And the actors...We almost never see someone who is just an ordinary officer worker. I think there are some, but they don't appeal to the mass. The ones who appeal are a lieutenant who'd willingly sacrifice himself for his country, a young emperor, a CEO... or a writer, or a policeman. Let me think of more to fill in the list. A lawyer, an heir. I mean... there're no ordinary people...An excellent lecturer, too. Yeah, only that type of man, an ideal. I like it very much.

Thi: You mean you like their professional brilliance?

Minh: I mean I like the vibe that those characters bring.

The fact that K-drama male leads are usually privileged, powerful men makes their vulnerable moments more intriguing. What appeals to Minh and Kim is not the image of 
a man breaking down, but rather the image of a strong man breaking down, because the strong man possesses remarkable charisma (the extraordinary vibe) that distinguishes him from the masses. According to "modern" rules of love, an ideal man may not be emotional, but he should be emotionally available, an indicator of his emotional competence (Riessman, 1990; Illouz, 1997). The ability to express oneself, even if it involves the revelation of weakness, is now deemed important to the success of modern romance, following the ideal of companionate partnership (Riessman, 1990). Emotional labour is no longer exclusively a women's duty. Contemporary Vietnamese women have indeed increasingly expressed their desire for a companionate relationship in which men are willing to communicate and share emotions (Earl, 2014; Zharkevich et al., 2016; Thanh Thi Vu, 2020). In many cases, the courage to reveal one's weakness can be seen as an inner strength, as in when writer Jang in It's Okay, That's Love bares his family problems, combining seriousness and nonseriousness. Modleski (1982) illuminates the female pleasure of seeing a strong man become vulnerable to his "special person": "He must need her in spite of all his strength, rather than because of his weakness" (p. 46). The moment when a prince lets down his armour and shows his wounds to his lover melts hearts.

The representation of men as powerful but tortured souls is common in Korean dramas. K-drama males frequently suffer from traumatic abuse or loss of a family member. This trope is employed to put the female and male protagonists together after misunderstandings, as the female lead is led to see moments of the man's vulnerability and begins to identify with him and eventually fall in love. As Kirkham (1995) argues, a perfect man must at some point suffer a wound to become accessible to women's imagination. There is also a female pleasure of reading men. Modleski (1982) notes how in both Harlequin and Gothic romances, the heroine is preoccupied with analysing the hero's puzzling behaviour. Readers are then invited to participate in an enjoyable investigation into "the secret underlying the masculine enigma" (Modleski, 1982, p. 34). Korean dramas sometimes use this trope to entice audiences: first, they show men as cold-hearted and haughty or a seeming playboy, only to later reveal that he is, in fact, gentle and kind. For Minh and Kim, reading men is pleasurable because, as they both shared, they had yet to become particularly close to men. Although Minh and Kim took pleasure in seeing men become emotional in intimate moments, they primarily saw the ideal man as physically and mentally strong. Kim showed how she imagined being protected by a man:

Kim: (Pointing at a photo) This, I like this. I like being hugged from behind. 
Thi: How so? You've watched this drama?

Kim: I haven't watched this drama. But I like a tall man, someone taller than me hugging me from behind, it makes me feel sheltered (được che chở). You know, I always have a feeling...always...I have a bit of a faint heart ${ }^{18}$, so I always feel like someone is standing behind me. So... if a man hugs me like that, I feel much safer. When I sleep, you know... (Thi: Yeah?) I usually lean my back right against the wall so there'll be nothing else between me and the wall, and I turn to the empty space in front of me, so I can confirm that nothing's there. Do you understand? It's like that.

This excerpt shows Kim's longing for an affectionate gesture: a "back hug" imbued with masculine tenderness. Her longing indicates a fantasy of security brought by love. Although Kim had not watched the drama from which the scene was extracted, she was familiar with the image because it is ubiquitous in K-dramas. Alongside her desire, Kim manifested an anxiety that may have been formed by life experience: her mother's gambling had caused her family to flee loan sharks when Kim was in high school. By virtue of her familial background, Kim has suffered from isolation and mistreatment by her classmates. Ensuring that there is no immediate danger helps Kim feel in control. Similarly, Hà (married woman, featured in Chapter 6), who also had a problematic childhood emphasised her preference to lie next to the wall because of anxiety. Hà said, "I feel like being sheltered by a man," and "people like me who prefer lying next to the wall to feel safe would really enjoy being hugged from behind by a boyfriend, it's like having someone to lean on and feeling safe."

Many participants in my study highlighted women's desire to be sheltered (được che chơ). The verb che chơ (shelter) was frequently cited to describe a desirable masculine function that also has a traditionally feminine undertone. When asked about her ideal man, Minh said: "I still like the type who performs precisely masculine roles: attending [to a woman] and sheltering [her]." Minh's adherence to hegemonic ideals of masculinity is best captured by the following remark:

Patriarchy, in a way...has a good aspect. People see patriarchy as something imposing. But in a relationship, the man should be the one taking the risk, and when it comes to familial finances, they should be the one shouldering [heavy responsibilities]. When they do that, they must develop decision-making skills, and

\footnotetext{
${ }^{18}$ She meant that she was vulnerable and easily startled here.
} 
there must be those who follow them. I think it's intrinsic masculinity. They're allowed to do things that let them feel like a man. (Thi: umm) And these include things like offering [women] protection.

Here, Minh highlighted how she thought patriarchy might benefit both men and women: by allowing men to "feel like a man" and women to be protected and cared for. As Thanh, whose narrative I discuss in the next section, said: "it is a women's instinct to desire to be sheltered." These women manifested a conventional view that sees expected gender roles as natural and inherent to a person's sex. This conflation of a gender ideal with gender essence, common in many cultures, has perpetuated deep-rooted binary gender systems (Butler, 1990/2006).

Like its English equivalent "shelter", the verb che chơ evokes a homely, cosy feeling and suggests instinctive nurturant attributes, as in how a baby is sheltered in the mother's arms. Che chở connotes not only pragmatic but also affective functions, unlike bảo vệ (to protect), which simply implies the act of fulfilling a duty. What one is sheltered from is not necessarily life-threatening danger; it can be mundane discomforts of everyday life, such as rain, heat, or sun. This seeming mundanity evokes a feeling of security needed for the precarity of life, where risks are omnipresent. Because life is inherently unpredictable and unstable, the desire for a sheltering Other becomes poignant: when one cannot be confident of one's own capacity to confront risks, one desires an Other who is "larger" and more reliable than oneself. This desire indicates a state of hopelessness inherent to being.

In consistency with a desire for this sheltering quality in men, some women highlighted maturity and physical strength as important. When discussing their wish to be sheltered, An in Chapter 2, Kim and Thanh in this chapter, and Hà in Chapter 6 explained that they, or women in general, were physically weak and thus needed a masculine shoulder to lean on. This feeling echoes Vietnamese conventional gender ideals, which see men as the protector and women the protected (Nguyen Thi Thu Ha, 2012). Traditional Vietnamese culture, embedded in folk songs and poems, views women as having less agency than men and treats fate as determining women's life (Schafer, 2010; Soucy, 2012; Linh Khanh Nguyen, 2016a; Dung Hoang \& Tran Phan, 2019). By contrast, men are regarded as having the confidence and ability to change and conquer fate (Soucy, 2012; Dung Hoang \& Tran Phan, 2019). It is also common for Vietnamese women to see themselves as physically weak due to female physiology and reproductive role (Gammeltoft, 1999; 2001). 
Despite Minh and Kim's profound interest in the dramas, they also demonstrated that they engaged with these dramas critically. As I have shown, Minh mostly narrated scenes in the third person and showed her awareness of the dramas' strategy of creating extraordinary male characters to appeal to ordinary masses. Kim displayed stronger identifications but at one point indicated frustration with trendy dramas' Cinderella plots because of their emotionally exploitative character. Kim explained that she used to like such plots as a teenager because it gave her (false) hope but changed her attitude:

She [the female protagonist in a drama] has to be that beautiful, she has to be that tall, and she has to have good luck too. I personally never enjoyed any good luck all my life. Seriously. I never saw myself lucky. Even when I try to be positive and force myself to think I'm lucky, I still suffer from bad luck. So I won't ever get lucky like her [the titular character in What's Wrong with Secretary Kim (2018), who captures the heart of her wealthy boss], that l'll get to become a secretary to some CEO. I found it too unrealistic, so I stopped watching.

Kim's assertion that "she has to be that beautiful" (to date an ideal man) echoes common Vietnamese views that see the pairing of privileged men and beautiful women as compatible. This ideal of compatibility is expressed in a common idiom - trai tài, gái sắc (talented men go with beautiful women), later updated into a modern version that says chân dài, đại gia (long-legged ladies go with rich men). Compatibility here is not about the compatibility of class, but the matching of male economic and social capital with female beauty, i.e. bodily capital. Elucidating her frustration with the Cinderella plot, Kim said it used to draw her attention and nurture her hope for a relationship with a perfect man, which she no longer viewed as a healthy experience. Kim's frustration is reminiscent of the expressions of irritation found in young Chinese female consumers of Korean dramas in Wilson's 2011 research, who felt that romantic dramas exploited their emotions, including their boredom with existing life, their need for romantic indulgence and escapism, and their desire for non-existing perfect men.

Despite efforts to keep distance from Korean television romanticism, Minh and Kim's narratives manifested their hopes for real romance. For these young women, love lies in the future. Having yet to experience love, they learn it through observing others' relationships and consuming mediated romances. Constructed fantasies like Korean dramas offer a cultural frame through which the informants develop "anticipatory emotions" and romantic ideals (Illouz, 2006, p. 206), which may include expectations about how couples should act during courtship and what makes a relationship work. The 
two informants' narratives echo Putri and Yatim's observation of how Indonesian single female fans view romantic Korean dramas as "learning material for what they had never had in their own romantic lives" (2019, p. 193). Engagement with Korean dramas helped Minh and Kim construct their idea of a perfect romantic partner who combines qualities of hegemonic masculinity with socially valued "feminine" traits such as being protective in a nurturing way (sheltering) and being romantic and emotionally expressive.

\section{Emotional emptiness and the Charging of "Love Energy"}

Unlike Minh and Kim who displayed hope for their love life in future, Thanh, a married woman, acknowledged love in its most ideal form as something she could never have. Having settled into a pragmatic, "good enough" marriage, she no longer actively sought passionate love but experienced it through Korean dramas.

Thanh, 31 years old, worked in public relations. An educated woman of workingclass background, Thanh had a three-year-old son and manifested a more progressive outlook on gender relations than many Vietnamese women of her generation. A previous relationship and her current marriage show an unconventional element: in the former, she paid for most dates; and she now earned more than her husband. She emphasised that she and her husband shared domestic chores, as she felt men and women should always do in a modern relationship. When asked about the most influential male person in her life, Thanh did not mention her father or husband but instead spoke of how her son's birth had caused her to change her worldviews and lifestyle.

Thanh has a harmonious marriage. Her husband, who works in banking, respects her and is attentive to her. She described her husband as a "mild" (hiền) and "good" (tốt) person. However, she repeatedly referred to him by the word nhat (tasteless, insipid, or flat, which is usually used to describe food of mediocre quality or films/books that do not excite strong emotions. Her use of the same word to describe her marriage indicates a lack of emotional satisfaction. Because of what Thanh perceived as her husband's uninteresting personality and limited knowledge of the world, she did not admire him and spoke slightly critically, saying that he only knew things within his work expertise and did not try to broaden his knowledge. This led to a gap in their worldviews, as Thanh met people she saw as knowledgeable and talented through work. Thanh and her husband seemed both emotionally and intellectually incompatible. Towards her husband, Thanh showed an ambiguous attitude; she explained: "with my husband, sometimes I cannot determine whether it is love or not." Asked what led to her marriage, Thanh said matter- 
of-factly: "it may be love or it may not, but it ended up with a result." For Thanh, marrying her husband was the result of a natural process, as they had dated for several years, and she had had no other suitors. Emotional lack thus led to Thanh's consumption of Korean dramas. She said: "I think my [emotional] life is insipid, but life on screen is salty (mặn), therefore...except for some dramas with tasteless love stories, [I find that] they [Korean dramas] are all interesting." Thanh's view of love is consistent with a universal ideal of love as "extraspecial" (Illouz, 1997, p. 118). Her metaphorical use of "salt" recalls Illouz's highlight of the importance of "that little extra" needed to make a relationship romantic and fulfilling - "a small but crucial difference commonly conveyed in such metaphors as a 'spice,' a 'flavour,' a 'zest'” (Illouz, 1997, p. 118). In colloquial Vietnamese, mặn is used to describe something eventful, deep, or complex, and in some cases even erotic.

Thanh revealed the affective significance of Korean dramas to her life thus:

Thanh: ...Sometimes I told my husband that I was so emotionally flat (quá nhạt), my husband was so flat (quá nhạt) that... for me not to divorce him, I have to watch Korean dramas, so my senses of love (cảm xúc yêu thương) are awakened. My [female] friends feel that way too, [we] often say that sometimes we watch Korean dramas we'd feel that love is so beautiful. It turns out that boys can show certain lovely attributes, not insipid, tedious like our husband. And then l'd feel...oh, life is still beautiful, and I feel that...I want...I may be able to love my husband more.

Thi: In what way?

Thanh: Like when you were watching, you felt like a source of energy was pumped into you.

Thi: (chuckles) Is that so?

Thanh: Yes, like being charged with some energy of love and feeling...although my husband... he does not measure up [to the ideal] but... We'd feel... the boys would be... There are still lovely people who'd make us feel things. Not just tedious like we often think.

Thi: Lovely in what ways?

Thanh: Like Song Joong Ki [the actor]. He's so lovely, isn't he? Umm... his gestures are very affectionate. His gaze... the way he looked at her [Song Hye Kyo, the female lead in Descendants of the Sun]...Oh...so loving. Loving. So affectionate. I never felt my husband looked at me like that. 
Thi: No?

Thanh: No.

Thanh's description of watching Korean dramas as providing her with energy recalls Radway's (1984/1991) note on how literary romances gave female readers hope and motivations to deal with their domestic duties, i.e. taking care of husbands and kids. The Vietnamese verb bom (pump) suggests both the force and volume of the energy recharging process and evokes a state of emotional emptiness that regularly begs refilling. The fantasy world of Korean dramas thus helps sustain Thanh's emotional life. Love in Korean dramas is a spice that adds flavour to her "flat" life, and K-drama male characters remind Thanh of a loveliness somewhere outside her life. Even if this loveliness is elsewhere, knowledge of its existence gives her hope. Stressing the male lead's "loving gaze" as an appeal offered by her favourite drama, Descendants of the Sun, which she watched twice, Thanh elaborated:

Song Hye Kyo, I don't think she is very affectionate (tình cảm), either on screen or in real life, not so affectionate. But Song Joong $\mathrm{Ki}$ is very affectionate, his gaze [upon her] is always affectionate. People often say that he must have fallen for her before the filming. That's why they got married [in real life] so quickly. It [his feelings for her] must be real.

Here Thanh further indicated her immersion in romantic intimacy on screen thanks to its quality of emotional realism. She connected the two actors' onscreen chemistry to their real-life romance. ${ }^{19}$ As Thanh again stressed her fascination with the affectionate gaze, which accentuates the desirability of the one being gazed at, she seemed to experience envy and said, "I never felt my husband looked at me like that." The affectionate gaze suggests not only the desirability of the one being gazed at but also evokes the special feeling of being in love and being the centre of someone's attention. Thanh's attentiveness to the male lead's affectionate gaze indicates her immersion in the love story, which allowed her to "imagine emotions" (Feagin, 1988).

The appeal of Descendants of the Sun, for Thanh, cannot be separated from the appeal of its male lead. Explaining this appeal, Thanh cited Song's smile, his affectionate

\footnotetext{
19 The actors' divorce in mid-2019 led to a period of collective mourning online among Vietnamese K-drama viewers, especially women. Some fans voiced how they "lost faith in love" because of the divorce, revealing how they had projected their own expectation of "true love" onto the couple. My interviews with Thanh took place a few months before the announcement of the divorce.
} 
and flirtatious gaze, his manners and speech alongside his expertise as special forces soldier Yoo Shi Jin in Descendants of the Sun. This dialogue from the first episode of the drama illustrates how Yoo holds a light but amusing conversation with the female protagonist, Doctor Kang Mo Yeon, over the phone:

Yoo: I really want to see you tomorrow.

Kang: (smiles, looks pleased) Are you always that straightforward?

Yoo: I mean, I need to meet you for medical treatment tomorrow.

Kang: (appears embarrassed, tries to keep calm) Right. That was what I meant.

Yoo: That wasn't really what I meant.

This playful banter illustrates how Yoo expresses his eagerness to see the doctor playfully. Yoo is forthright but knows how to show his desire in a light tone. The early episodes of Descendants of the Sun, with such scenes of flirtations, show love buddings between the soldier and the doctor. What Thanh finds amusing in the couple's relationship is their emotional compatibility: they can "read" each other and hold interesting conversations. Moreover, their relationship is full of surprises and excitement, as Yoo keeps appearing and disappearing in Kang's life because of the volatile nature of his job. Aspects of novelty and amusement in this fantasy are absent in Thanh's marital life, which has become routine. Thanh shared her emotional void with married friends because "our husbands could never measure up." Korean dramas can thus be integrated into women's intimate talk, which also involves husbands, children, and family matters. The dramas gave Thanh hope and reminded her that "life is still beautiful," or "there are still lovely people." Radway (1984/1991) elucidates the "hope" that romantic media offer married women like Thanh:

"[Literary] Romances are valuable to them in proportion to their lack of resemblance to the real world. They choose their romances carefully in an attempt to assure themselves of a reading experience that will make them feel happy and hold out the promise of utopian bliss, a state they willingly acknowledge to be rare in the real world but one, nevertheless, that they do not want to relinquish as a conceptual possibility." (p. 100)

Similarly, Korean dramas promise Thanh the "conceptual possibility" of passionate love. When asked to elaborate on the process of having "love energy" pumped, Thanh used an analogy: 
Let's say, you don't know how to appreciate art. But someone introduces you to a work of art, you go to see it and you realised "yes, this is it," and suddenly you feel that some knowledge, the ability to appreciate art is pumped into you. Then suddenly you realise that life around you does offer some artistic things.

Thanh compared ideal love to art, something she could only observe from a distance, suggesting unfamiliarity. Ideal love, like art, is beyond Thanh and her mundane world. The discovery of art/ideal love, however, offers her enlightenment, evidenced in her repeated use of words like "suddenly" (bỗng nhiên) and "realise" (nhận ra). For Thanh, ideal love seems to be for admiration and inspiration only, rather than something she can reach, touch, and feel for herself, an abstraction she had never really experienced firsthand. At the same time, however, the vicarious experience of ideal love on screen, like the discovery of art, may offer her tools to better appreciate the beauty of her mundane life.

\section{The Loss of the Ideal}

Thanh's experience of emotional emptiness is hardly unique but is echoing the similar experience of many married women. Minh, who observes married women around her, spoke insightfully of some women's need for romance:

I think a woman, however grown-up she is, whatever position she has reached... Inside her remains a little girl, a young girl. She still wishes to be paid attention to, to be loved. And all that diminished compared to the past when they [a couple] dated or lived together without kids, without worries. I saw how my mother was drawn to Korean dramas too; she liked Full House, because it is ideal. I feel like people get disappointed with their marriage, and then there are stresses and strains... I think watching Korean dramas gives people an ideal space that brings back past emotions. They may shout out loud, they may feel their heart throb for someone [a K-drama character]. Many older sisters ${ }^{20}$ (các chị) in their late 20 s still watch those dramas, which I don't think l'll still watch when I reach their age. These sisters can enjoy... for example, sharing information. You must be very interested to share information and gossip about a drama. I feel that they're under pressure,

${ }^{20}$ Vietnamese people tend to address one another by kin terms (Szymańska-Matusiewicz, 2012; Sidnell \& Shohet, 2013). 
and they lose those emotions. And films, dramas, entertainment arts help fill this emotional gap.

Minh described watching dramas as a way in which mature women of different generations dealt with the loss of romantic emotions and viewed this loss sympathetically. Her note of women sharing information and chatting about dramas again reminds us of an "intimate public" based on a sense of affective commonality (Berlant, 2008), in which women collectively "mourn" their loss of young passionate love. Minh's emphasis on how married women and her mother "still" watched "those dramas" (she referred to idol dramas for young people here) further highlighted her notion that inside every woman remains a little girl, a fragile, innocent creature who enjoys the "privilege" of powerlessness and immaturity, and thus deserves love and protection. The term "little girl" also evokes the sense of youth and beauty that mature women mourn as forever lost. Minh repeatedly linked marriage with "stresses and strains," which prevent the continuity of romance as "the way it was before." Popular romantic stories help bring back emotions from the pre-marital life that married women once enjoyed, when they were pampered and loved, unlike their current situations, tasked with attending to others as wives and mothers. Viewing Korean dramas, for some, can be a physical experience, i.e. making the heart throb, signalling excitement and infatuation. This affective experience reminds them of young love at its prime, which is no longer there.

Thanh also suffered from the loss of romantic emotions facing many married women. Her loss, however, is a loss of an ideal, rather than a "real" passionate love, which, as Thanh confided, she had never experienced. Not only did she describe her marriage as "flat," she also spoke of her past relationship with her ex-boyfriend with indifference. She rationalised that her attitude might partly reflect her own personality and how she had never been a passionate person. She even questioned if she was capable of passionate love and concluded that she was not. Yet Thanh is very much aware of such love, the kind that "some people die and revive for" and she expresses her yearning for the fantasy of such love through watching Korean dramas.

There is an apparent gap between Thanh's romantic experience and the love portrayed in popular culture. Thanh explained that (ideal) love should be tempestuous, underpinned by intense longing when apart or self-sacrifice for the benefit of the other. She also described it as something "people die and revive for" (a universal idea of love as constitutive of suffering). These all sound familiar, for they recall the typical love relationship portrayed in popular culture. This is an example of how, as Illouz argues, 
"collective fantasies burden the romantic experience" (2012, p. 199), because the lived experience and the real partner cannot "measure up to" the ideals. Thanh's consciousness of the universal love fantasy seemed to have played a role in alienating her in relationships: she became a critic of her own love life, judging it from a distance. Her awareness of more passionate romantic relationships around her, such as her friends', made her lack of emotional fulfilment even more acute.

As Thanh never experienced passionate love, it is not quite correct to say she lost it. Rather, she lost the ideal of passionate love. Because she never really lost passionate love as an experience, she cannot fully identify or comprehend the loss; even if Thanh is aware of the loss, she cannot know what she really lost. Following Freud (1917/1957), one might say that Thanh suffers from melancholia, an unconscious or ambiguous experience of sadness incurred by a loss that cannot be mourned. Freud's description of melancholia is instructive here:

In one class of cases it is evident that melancholia too may be the reaction to the loss of a loved object; where this is not the exciting cause one can perceive that there is a loss of a more ideal kind. The object has not perhaps actually died, but has become lost as an object of love [...]. In yet other cases one feels justified in concluding that a loss of the kind has been experienced, but one cannot see clearly what has been lost [...] (1917/1957, p. 155)

Losing a love-object can mean a double loss of both the love-object and the self that might be attached to the love-object, i.e. the kind of life and subjectivity one might have with the love-object. The love-object, however, can never be fully lost in the sense that it is totally forgotten or overcome, but it may be permanently preserved in the individual's mind, precisely because it is not really mourned. Thanh's longing for the ideal of love was melancholically preserved in her subjectivity and thus kept haunting her. Following Freud, Butler (1997) calls this process of preservation "melancholic internalisation," or "melancholic incorporation." As conscious as she was of passionate love, Thanh also showed ambivalence towards the ideal, a symptom Freud ascribed to melancholia. She said that even though she enjoyed ardent love on screen and compared it with her passionless marriage, she would likely "hate" for someone to love her excessively and shower her with attention, saying that she would not be able to reciprocate such overwhelming love: 
When I watch Korean dramas, I really like [scenes of passionate love]. But when I think about the same thing happening to me, l'd feel that it is kinda crazy, l'd be shocked to meet someone so into me.

Thanh expressed, in an animated tone, her discomfort about such an imagined situation with emotionally charged words like "crazy" (điên), "shocked" (sốc) and (elsewhere) "scared" (sợ). Summing up, she said, as if to convince herself and me: "I said my life was insipid, but I think it suits me. I just want...I think I suit this kind of life. I don't express my feelings intensely, and I don't want others to be so intense [about me]."

In the end, Thanh's attitude towards ideal love remained ambivalent. As she shared her thoughts, she sometimes contradicted herself and was unable to fully describe her feelings. One possible explanation among many, however, is that Thanh needed to rationalise her emotional life to reconcile it with her mundane marital life. She may have felt that she "should" be content with her marriage as her husband was a good partner in customary spousal roles; "a kind person" with whom she bore a child that she dearly loved. Convincing herself that "this is good enough" might permit Thanh to sustain a normal life and reasoning that she was not capable of impassioned love might help her cope with the unmourned loss of ideal love. Connecting Thanh's case with Minh's remark on women's collective mourning for lost love, one might argue that romances in various form have helped sustain a melancholic feminine culture that produces both gratifications and discontents (Radway, 1984/1991) and allows women who are not fully satisfied with their love life to acknowledge the loss of passionate love. ${ }^{21}$

Vietnamese women's melancholic identification with Korean dramas like Thanh's has a lot in common with the experience of melancholia observed in Japanese viewers of the drama Winter Sonata (Hayashi, 2005, Soobum Lee \& Hyejung Ju, 2010, Ingyu Oh, 2011; Jung, 2011). Ingyu Oh (2011) argues that married Japanese women's melancholic identification with K-drama romance allows them to get in touch with their unfulfilled romantic desire for either a lost or imagined lover. Hayashi (2005) draws attention to how female fans of Winter Sonata simultaneously maintain their "pragmatic" marriage, which did not offer them emotional fulfilment, and actively indulge in "the fantasy of a heartthrobbing romance" (p. 44). Consuming romantic dramas, as Hayashi suggests, supplements these women's lives without actually threatening their "boring" marriage. There are, however, differences in how Japanese and Vietnamese audiences consume

\footnotetext{
${ }^{21}$ I expand my discussion of Vietnamese women's melancholic engagement with romantic Korean TV dramas as a collectively shared experience with a greater theoretical focus on the psychoanalytic concept of melancholia in Gammon (in press).
} 
Korean dramas. To embrace Korean pop culture, Japanese consumers often have to contend with a Japanese collective aversion towards Korea, which sees Korea as an inferior country (Mōri, 2008; Oh, 2011), a complex feeling that Ingyu Oh (2011) terms "postcolonial melancholia." Vietnamese consumers generally do not show animosity towards Korea but view the country as a development model to learn from (Suh et al., 2006; Shim, 2006), despite backlash about a Korean cultural invasion and memory of Korea's participation in the Vietnam War as a US ally. In addition, Japanese women have been observed nostalgically seeking in romantic Korean dramas values felt lost in Japan, such as men's courtesy and pure love (Jung, 2011). Such an attitude has not been found in Vietnamese audiences within this study or others. Generally, Japanese audiences tend to show a "retrospective-looking" attitude towards Korean pop culture, whereas Vietnamese audiences display a "forward-looking" attitude (see: Oh, 2011; Andrew Eungi Kim et al., 2013).

\section{Concluding Notes}

In their study of the international reception of Korean dramas, Kim and Omerbašić (2016) note how these dramas offer viewers from various countries a world in which they can imagine alternative lives, identities, and ways of being. They argue that such imaginings help "broaden their [the viewers'] immediate experiences" (Kim \& Omerbašić, 2016, p. 2). This may feel true for many viewers, such as the young and inexperienced who have yet to explore ardent love or a man's inner thoughts, like Minh and Kim. I would argue, however, following Illouz (2012), that the glamourous, affect-laden world of Korean dramas can also contribute to the narrowing of experiences (or perceptions of experiences) in reinforcing and perpetuating a universal heteronormative ideal of love and gender: that love should be extraordinary, overwhelming and everlasting and that men are meant to protect women. Within such a heteronormative framework, however, the dramas propose a variety of possibilities in romantic relations for audiences to reflect upon. Whether the dramas gave the participants hope for the future or made their longing for "true love" more acute, watching clearly meant more than fleeting entertainment and gave them rich emotions they could not experience or had yet to experience in real life.

This chapter and the previous one both explore how female viewers engage with the imaginary masculine Other in multiple situations, such as the display of masculine power, practices of courtship, and intimate moments of love. Both chapters show an active "seeking out of emotion" (Whitehouse-Hart, 2014, p. 27) as compensation for lack 
of emotional fulfilment. It is important to note that despite the informants' emotional involvement with Korean dramas, their desire for Korean men on screen has not corresponded to a desire for Korean men in real life. Neither An nor the three informants in this chapter expressed a desire to seek romance with ordinary Korean men, nor did they idealise these men. Their engagement with soft masculinities in Korean dramas seemed to remain strictly in the realm of fantasy; they were well aware that male protagonists are constructed "dream men" who do not exist. Although Thanh reported emotional privation in her marriage with her husband, only An expressed disappointment in Vietnamese men more generally. Longings for romantic passion, which remain unfulfilled, were salient in their narratives but were not blamed on local men or men in general. Kim and Minh expressed hope that they would have a relationship with Vietnamese men in the future, and An did not seem to seek a relationship with foreign men. 


\section{Chapter 4: The Absence of the Ideal}

Korean Wave texts' "structure of appeal," as Sooyeon Lee (2012) terms it, rests in their construction of fantasies involving ideal love and ideal characters that exemplify "perfect" masculinity and femininity. Lee argues that such fantasies reflect Korean society's wishful imaginations precisely because of their lack of verisimilitude. Specifically, romantic utopias constructed by Korean dramas involve overwhelming, unforgettable romantic moments independent of the mundanity of everyday life (Illouz, 1997). These fantasies reinforce the ideology of hegemonic heterosexual romance as well as "proper" manhood and womanhood. Fang-Chih Irene Yang (2008a) and Lie (2016) point out that transnational audiences of K-dramas, especially women, are interpellated as "dreamers" who seek engagements with a better alternative world. Such a romantic wonderland is opened up by the presence of a perfect man, who embodies all the stereotypically desirable traits women wish for (Lie, 2016), inviting escapism.

Deliberate constructions of idealised romance and idealised masculinities, as Fang-Chih Irene Yang (2008a) shows, invite as much resistance as receptiveness. In Taiwan, the deliberate heightening of emotions and highly romanticised aspects of Korean dramas have been met with both celebration and rejection (Yang, 2008a). According to Magnus Wilson (2011), Chinese consumers dismiss the quality of Korean drama due to its melodramatic excesses and escapist elements, and even those who enjoy the genre acknowledge their pleasure with self-mockery or a sense of guilt for engaging with a perceived time-wasting genre. Maliangkay and Song (2015) argue that Hong Kong male and female fans view male representations in Korean pop culture as idealised and thus treat them with a sense of distance. These fans may enjoy these representations but do not imagine meeting similar male figures or emulating them in their daily lives.

This chapter discusses the combination of both receptiveness and resistance toward Korean soft masculinities by exploring three female informants' life accounts and viewing experiences. These informants displayed a resistant reading toward romanticised constructions of masculinity and gender ideals by questioning their plausibility, even though they largely enjoyed K-dramas. Through their unwillingness to suspend disbelief and denial of a desire for K-drama "dream men," they presented their viewing experience as different from how they perceived the majority of female viewers receive the dramas. The young women of this chapter, Hạnh, Trang, and Nga, all in their 20s, differ from the women in preceding chapters in terms of viewing experience. They manifested much less 
emotional investment than those in Chapters 2 and 3, even though two of them (Hanh and $\mathrm{Nga}$ ) watch Korean dramas quite often. While those in previous chapters sought vicarious romantic experiences through K-dramas, Hanh, Trang, and Nga consumed dramas primarily to release stress. They did not seek to indulge in fantasies with dream men but rather to enjoy stories. Even when they did enjoy idealised men on screen and manifested signs of gendered identification and desire, these signs were not particularly strong or enduring. To wit, my informants presented themselves as down-to-earth women who did not daydream about a whirlwind romance or alternative worlds. Their narratives serve as counterexamples to a tendency in audience research to limit women's consumption of television romance to an escapist function, which feminist scholars such as Spence (2005) warn against. The informants' stories show how they did not seek to quench desires for extraordinary romantic alternatives in Korean dramas, but rather, to entertain themselves and, as in the cases of Hanh and $\mathrm{Nga}$, to re-engage with the real world through fictional consumption.

I chose Hạnh, Trang, and Nga as participants because of their familiarity with soft masculinities, as demonstrated by the Korean dramas they mentioned in their application forms. Despite their eligibility, the three women's lack of emotional involvement with Kdramas caused me difficulty during interviews. Unlike those in preceding chapters, who talked without much questioning as if they had been waiting for a chance to tell their story, I used prompts more often with the women in this chapter and even at times asked leading questions, which the FANI method warns against. Although our interviews were cordial, my informants largely showed a lack of emotional investment in the dramas, which was linked to resistance to both K-drama's idealised and commercialised representations of masculinities, which they found non-existent in real life, and its "romantic utopia" (Illouz, 1997) and "dominant happiness script" (Ruti, 2018). This romantic trope, reinforced by Kdramas as part of global romantic pop culture, perpetuates the idea that true love must be extraordinary and give life an all-encompassing meaning. In this chapter, I first introduce the participants' background, then discuss their worldviews and lack of romantic expectations. I then delve into how the participants dismissed Korean dramas as detached from reality and drew a distinction between the dramas and real life. I then discuss signs of identification and desire in the women's viewing experience despite their rejection of K-dramas' effects on themselves.

\section{Pragmatic Worldviews, Lack of Romantic Expectations, and the Absence of Ideals}


When we met, Hanh was a 26-year-old university student who also identified herself as a social activist. Having left her home city in north-central Vietnam eight years ago, Hạnh moved to Hanoi to study at a university but dropped out in her second year upon realising that her major was not right for her. Hạnh has since worked in hospitality, which includes work such as waiting tables. A year before our interview, Hạnh resumed her study in another major at a larger university which she deemed more suitable. Having come out as bisexual to friends in high school, Hạnh became involved in the LGBT rights movement. She has dated both cis and transsexual men and used to co-habit with a transsexual partner. Her worldviews reflect a refusal to be bound by heteronormative ideals and stereotypes, corresponding to her identity as bisexual. Unlike many Vietnamese women's expectations of men to perform the breadwinning role, Hạnh held the egalitarian view that men do not have to provide for women and practised this ideal on dates. In her most recent relationship with her transsexual partner, she insisted on paying rent after moving in with their family, whom she lived with until the two broke up.

Trang, 24 years old, was a fitness trainer. Like Hạnh, Trang moved out of her hometown in north-western Vietnam to live in Hanoi and further her studies after high school. Trang had a university degree but, unlike her parents who worked for the government, she did not desire an office job and preferred the physicality of her current profession: "As a fitness trainer, I want to inspire others. I want people to live comfortably true to themselves and understand themselves." Trang said she did not think too much about relationships or marriage because her current goal was self-development. She wanted to broaden her knowledge by taking courses to become better at her job. When asked about traditional Vietnamese ideals of womanhood, Trang spoke of her mother and said that although she respected ideals of women as devoted wives and mothers, she chose to "live firstly for myself." This desire to deviate from traditional femininity, marked by women's complete dedication to family and children, even at the expense of their own interests, and to prioritise individualist aspirations has become increasingly common among younger urban Vietnamese women who are exposed to more liberal ideals (Nguyen Bich Thuan \& Thomas, 2004). Trang watched K-dramas less often than Hạnh and Nga, and much of her discussion focused on Reply 1988 and Reply 1994, which she had most recently watched. Trang recalled how she became absorbed in dramas during her student years, binge-watching at night and sleeping the next day. However, work had put an end to this habit.

Nga, 27 years old, had recently been married and was about to move back to her and her husband's hometown in northern Vietnam. She graduated from a college in Hanoi 
and had previously worked in a clerical position but had quit in anticipation of the move. Nga showed greater conformity to social expectations than Hanh and Trang in having married despite not being totally ready for marital life, but she manifested strong opposition to patriarchal values in interviews. Nga expressed regrets that she would now have to commit to marital responsibilities, including becoming a mother, which is perceived as essential to Vietnamese womanhood. Advising me not to return to Vietnam after graduation, Nga said she would have married a Westerner to escape Vietnamese patriarchy if she had been better at English. She saw gender inequality in Vietnam as resulting not only from men but the patriarchal structure of the traditional family. She wished for a balance of gender roles in domestic space: "Men must share domestic chores with women, without question. If men could bear children, l'd want them to do so too." Nga noted that she had asked her husband to cook and wash the dishes when they were dating to train him to become a good partner.

Being an avid K-pop fan, Nga sometimes watched Korean dramas to follow Korean idols that she supported. Her parasocial relationships with Korean entertainers were strong: Nga watched dramas starring her favourite entertainers but boycotted those featuring entertainers she disliked because of their affiliation with companies rivalling those she supported. Nga watched popular K-dramas "because everyone talks about them." For Nga, consuming Korean dramas and other Asian television products serves an "integrative function," which fosters bonds with family and friends and contact with others in general (Katz \& Gurevitch, 1973). Nga enjoyed the social experience of chatting about plots of popular dramas. She even read online recaps of trendy Korean dramas that she refused to watch, just to know "what was going on."

Hạnh, Trang and Nga share pragmatic worldviews and a lack of expectations towards romance and an absence of an ideal for romantic partners. When asked, "How important is love to you?", Hạnh stressed, "It should be first about myself, the feelings I have inside," rather than how much someone loves her and seeks to please her. Hanh showed no clear preference for a particular kind of relationship and saw herself as a rational person in relation to love. Similarly, when I asked Trang if she ever wanted a passionate love like in dramas, she responded:

No (chuckles). No need. There's no need for anyone to live and die for anyone. Everyone has their own responsibility. We shouldn't make anyone suffer or let anyone take responsibility for us. You take responsibility for whatever you do. 
When I asked further if she expected anyone to take responsibility for her, implying a committed relationship, she reiterated: "You need to take responsibility for yourself, unless you're a kid. And you need to teach a kid to take responsibility for herself too." She underscored the importance of autonomy in individuals, regardless of gender. Trang, then single, did not emphasise any specific hopes about future relationships. She said, "I just want to be with someone who makes me feel comfortable (thoải mái), which means I don't have to think too much. I don't need especially passionate love, just one that makes me comfortable." Her repetition of the word "comfortable" accentuates a wish to be her true self in a relationship. Trang said she used to daydream about passionate love with an attractive person as portrayed in romantic dramas when she was younger but no longer gave it much thought. She elucidated: "I've become more realistic and no longer daydream the way I used to; and I've met people who liked me and whom I liked. There's no need to dream anymore since l've had experience." Having had romantic experiences that enriched her life seemed to have made Trang more emotionally independent and confident.

Nga had had no romantic experience before she first met her husband three years earlier. Nga said that she was so involved with computer games that she had not thought about romance. She acknowledged that it was unusual for a young woman to be indifferent to men and that her mother even used to question whether Nga was a lesbian.

Corresponding to their pragmatic worldviews and the lack of romantic expectations, Hạnh and Trang manifested resistance toward ideals of masculinity. Hạnh stressed: "I don't have any ideals in mind, I don't like constructing any kind of ideal." This resistance correlates with her position as a bisexual woman and LGBT activist, which casts her outside a strictly heteronormative ideology.

When asked about her ideals of masculinity, Trang was perplexed. She seemed to have not thought much about this matter and joked about it. She revealed that the men whom she had fallen for were very different from one another and that she could not explain why she liked them. Later, in response to my prompts, Trang mentioned good looks, kindness, and determination as attributes she would appreciate in men but stressed that she did not judge them by fixed criteria. Trang remained flexible in her opinion of masculinity throughout two interviews, in keeping with her self-presentation as open-minded. For example, Trang said it was important for men to take good care of their looks because it would give them an advantage in meeting people, but if a man was not attentive to this aspect, she said it was okay too: "It depends on the [working] 
environment. If someone works in an environment that does not entail meeting a lot of people or that does not require much attention to looks, like designing, sitting at one place, not meeting people much, then it's up to them." Likewise, Trang stated that a man should preferably be gallant to women, but if not, it is not a problem. "I don't expect others to be one particular way, I just accept them as they are," Trang said, emphasising her nonjudgmental attitude. Trang said she was not particularly interested in images of meticulously groomed men because excessive investment in looks did not attract her. However, she retained a neutral attitude, saying "It's just not my type," as she preferred men who adopt a casual style and appear comfortable with themselves. In response to an image of a crying man on screen, Trang said, "It's just the natural expression of emotions. Boys and girls are the same, they all have emotions, crying doesn't matter."

Hạnh and Trang's resistance to ideals seems related to a resistance to stereotypes. Wetherell and Edley (1999) note this resistance to stereotypes in their study, in which some male informants emphasised "the ordinariness of self; the self as normal, moderate or average" and [that they are] "without pretensions, as normal or ordinary kinds of men" (p. 343). Ideals, as Wetherell and Edley indicate, represent hyper-performances, suggesting inauthenticity and perhaps unrealistic expectations. In opposing archetypes, their male informants presented themselves as casual, ordinary men at ease with themselves. Echoing this study, my participants' resistance to ideals reflects their view of ideals as potentially superficial and restrictive and suggests their desire for authenticity and identification with a down-to-earth self-image. Hanh and Trang represent a new generation of women who refuse to be bound by hegemonic ideals of gender. While they did give examples of favourite K-drama heroes, these men do not share common traits except physical attractiveness and thus do not represent any particular ideal of masculinity. My informants' emphasis on autonomy fits a feminist ethos, which runs counter to an internalised sense of weakness found in my other female participants and Vietnamese women in general.

Nga gave the clearest response about her ideal of masculinity: the kind of man her father was, hard-working and respectful of his wife. Her husband, from her description, seemed to live up to this ideal, even though Nga complained about him being a pushover. She had not, however, actively looked for a boyfriend according to a fixed set of criteria.

Unlike other informants, who held vivid expectations towards love and men and highlighted a desire to be loved, treasured, and protected, Hạnh, Trang, and Nga 
professed a lack of romantic expectations. Single women like An (Chapter 2), Minh and Kim (Chapter 3) talked about ideal men they had yet to meet, while Thanh (Chapter 2) compared her husband with ideal men on screen and found him much less loveable. In contrast, neither Hạnh, Trang, nor Nga emphasised expectations towards men, even though they cited preferences in response to my prompts, and Nga never compared her husband to K-drama male leads. Furthermore, except for Thanh, all informants thus far were single and with limited romantic experience. Accordingly, their longing for such an experience might have caused them to become more involved in the dramas for vicarious romantic pleasures. In contrast, the three informants in this chapter had had meaningful romantic relationships. Hạnh and Trang, though not currently in relationships, seemed well aware of what one entails and separated fantasy and reality distinctly. In other words, phase of life may play a role in viewing experience, just as Trang acknowledged that she stopped daydreaming once she experienced romance herself.

\section{Resistance to Constructed Fantasies}

To understand the lack of emotional attachment that the three participants showed towards Korean male leads, it helps to articulate the ways in which they resisted idealised constructions of romance and masculinity. During interviews, they demonstrated a tendency not to take depictions of love and masculinity in Korean dramas seriously, manifested in their frequent use of humour (i.e. jokes and chuckles) while discussing the topic. Their tone was light and nonchalant.

For Hạnh, verisimilitude makes a story or a character relatable. She decided against watching the popular drama Descendants of the Sun because she was not drawn to the story and because "Song Joong $\mathrm{Ki}$ is too beautiful" for his role: "He is a special forces soldier, but his face always looks so smooth and nice." The problem for her was not Song's beauty, as Hạnh enjoyed watching other kkonminam in other dramas, but rather the incongruity of his looks and his role. Nga also noted this incongruence, commenting that youthful, innocent-looking actors in the roles of powerful men like conglomerate CEOs were not believable.

Hạnh remarked in response to images of Winter Sonata that the hit drama was "too romantic," "from their [the male and female leads]'s facial expressions to how they express their love." According to her, the male and female leads always seem as if they are "up in the clouds, as if they had no material pressure." Glamour, the very factor that draws viewers to Winter Sonata and Korean dramas, characterised by the display of 
beautiful bodies, glamorous clothes, and fancy cosmopolitan sites as dating spaces (Ma, 2007b; Creighton, 2009), did not particularly appeal to Hanh. Winter Sonata's idealised portrayal of romantic relationships between upper-middle-class men and women and its aesthetic quality did not impress her. Hạnh also disliked the hyper-performative aspects of soft masculinities:

I don't like dramas like [What's Wrong with] Secretary Kim where the rich guy reserves a whole amusement park to entertain [the object of his desire]. It's so bizarre, I don't like show-off behaviour like that. I just like it when they show affection in a simple way, like cooking for someone when they get sick. I don't like making a big deal out of it.

Hạnh's appreciation of such mundane efforts of care with pragmatic value further reflects her preference for "authentic," ordinary love (which can be seen as an ideal itself, albeit running counter to ideals enforced by romantic pop culture). Likewise, Hạnh disapproved of the deliberate display of men's naked torso in dramas, an "excuse" for the men to show their bodies, because "they look as if they were going to hit me!". She evocatively compared bodily display to assault, signalling a feeling of being threatened. One might suggest that the display of a naked torso is such a straightforward exhibition of virility or phallic power that it renders the man a potential assailant. Her reaction reveals how hyper-performative masculinities can be repulsive. Hanh added, however, that she could accept bodily display if the character took off his shirt to do something, with a concrete purpose rather than to show off.

Without showing strong disapproval, Trang also underscored the unrealistic aspect of Korean dramas, pointing out that K-drama male leads, such as Choi Taek in Reply 1988 and Chil Bong in Reply 1994 are often naïve (ngây thơ) and carefree (vô lo). Both characters enjoy financial security thanks to their outstanding expertise in unconventional professions (Taek is a professional Go player in his teens, while Chil Bong plays basketball) and are portrayed as without worries. Trang remarked: "Naivety may be good in some respects, but I wouldn't like it in a serious relationship." She added, however, that it was understandable for male leads in Korean dramas to remain carefree, considering that they are usually well-to-do.

Similarly, Nga dismissed realism in Korean dramas. When asked if she relates any drama to her life, she responded: "Korean dramas have nothing that I can relate to, all are full of colours [implying the dramas' rosy representations of life]. Nga stressed, "I watch Korean dramas just for the sake of watching. There's no connection to life." For 
$\mathrm{Nga}$, watching romance and ideal men on screen is mostly for entertainment because she viewed them as unrealistic, especially considering many Korean entertainers' sexual scandals. Idealised representations on Korean television, for $\mathrm{Nga}$, were not reliable reflections of everyday masculinities. In addition, Nga expressed distaste for the theme of first love, which often sees male and female leads continue their relationship from childhood until adulthood. Nga viewed this theme as very unlikely because she had never witnessed any real relationships like that. Nga also dismissed Cinderella plots as unrealistic. Like Hạnh, she referred to K-drama male leads such as those in Lovers in Paris and Boys over Flowers as "everyone's dream," because "women all wish to have a handsome, wealthy and kind lover," except herself, a pragmatist:

I'm not a female lead. The female lead always has some outstanding attribute. She's either beautiful or very kind-hearted or exceptionally talented at something. I'm not a female lead in a drama, how could I possibly meet a male lead like that? We meet people within our own league.

Nga's emphasis on the ideal of compatibility in romantic relationships recalls Kim's similar emphasis in the previous chapter. There is, however, a noteworthy aspect to Nga's response to my inquiry about relating to characters. While adamantly denying identification, Nga revealed a mildly self-protective attitude toward it, as if it could be harmful to "dream" out of your own league. Her emphasis on "knowing my place" shows pragmatic self-positioning. According to Butler (2015), identification and disidentification are not necessarily mutually exclusive phenomena (see: Theoretical Underpinnings in Introduction). In considering a relatable character's position in a theatrical performance, spectators are aware of the impossibility of too close an identification ("I am not that character") but still go through "the lure of identification" (Butler, 2015, p. 27). For one to "reach" the state of mostly complete identification, one needs to "overcome" the apparent difference that stands between one and the other object. Nga refused to succumb to "the lure of identification" and therefore arrived at "determined" disidentification.

In response to Korean dramas' (as part of the global pop culture) interpellation of the mass audience as dreamers (Yang, 2008a), my three informants showed a clear resistance to the constructions of made-in-Korea dreams, even as active consumers. While enjoying the dramas, they were aware that these constructions are deceptive. Trang resisted the "true love" script by dismissing the "need" to have someone "to live and die for," while Hạnh and Nga resisted "the men of fantasy" by refusing to let idealised 
representations interfere with their lived experiences. They kept a distance from fantasy by holding to the "ground" of reality.

Audiences' tendency to maintain a critical distance between themselves and what they view is not uncommon in television consumption. Drawing from interviews with middle-class viewers, Seiter (1990) suggests: "people often compare their own television viewing to that of the imagined mass audience, one that is more interested, more duped, more entertained, more gullible than they are" (p. 63). Seiter's (1990) and Skeggs et al.'s (2008) studies find that middle-class viewers tend to deny their emotional investment in television as a way of presenting the self as critical consumers. While I would argue that my participants denied emotional attachments partly due to their self-understanding as down-to-earth, such attachment did not seem connected to their class background. Considering their provincial background, professional status, and urban lifestyle, none of the three informants fit neatly the idea of middle class or working class, nor did they express or imply a wish to identify with either category. The women were educated but did not present themselves as sophisticated. They did not offer critical interpretations of the dramas as Văn (Chapter 7) or saw the dramas as "below" their maturity and intellectuality like Tài (Chapter 6 ). They simply pointed out the unrealistic aspects of Kdramas.

The dismissal of Korean drama as unrealistic is not uncommon among transnational viewers of the genre. Fang-Chih Irene Yang (2008a) notes how Taiwanese consumers use words such as "surreal," "rainbow soda," "fake," "ridiculous," and "unbelievable" to describe them (p. 293). Yang also reveals how Taiwanese public discourses both acknowledge a desire for Korean drama as a full-packaged romantic realm and criticise the genre as a harmful distortion of reality. Wilson (2011) finds that young, well-educated Chinese viewers describe K-drama as a mediocre form of entertainment that they watch out of boredom, and some even view their consumption as a waste of time. Chan and Wang (2011) note that even though Singaporean women enjoy watching the sensitive and romantic men of K-dramas, they view them as massmanufactured fantasy products.

Comparing Hạnh, Trang, and Nga's viewing experiences with those of other informants, one can identify contrasting reactions towards idealised, aestheticised representations of romance and masculinity. Whereas these idealised representations render it difficult for the informants in this chapter to relate to K-drama fantasies, they motivated An, Minh, and Kim in previous chapters to aspire to something beyond their 
current life. As I have shown, the latter group were occasionally critical and did mention the lack of realism in Korean dramas in their narratives. The difference between the two groups lies in the degree of willing suspension of disbelief. Those in the preceding chapters immersed themselves in romantic fantasies because of the pleasure they received from them, not because of their realism. As Fang-Chih Irene Yang (2012) points out, Taiwanese fans watch idealised TV romances because these constructed dreamlike worlds offer temporary relief from everyday struggles. The informants in this chapter sought such relief as well and enjoyed the fantasy but kept a greater distance from it, "exiting" the fantasy when they finished watching and not letting it linger within their minds or hearts.

Hạnh, Trang, and Nga's lack of emotional attachment, however, does not mean that they did not enjoy certain male characters. The three informants all acknowledged that romantically devoted men in Korean dramas moved them, revealing ephemeral moments of succumbing to "the lure of identification" (Butler, 2015, p 27). Nevertheless, they mostly described romantic situations in the third person and did not place themselves within them as Kim did in Chapter 3. For Hạnh, Trang, and Nga, the characters' appeal comes from the intrigue of a constructed narrative rather than their embodiment of preexisting ideals.

\section{Enjoyment and Patterns of Identifications and Desires}

This section explores noticeable signs of identification and desire in the informants' viewing experience, which are limited compared to those found in earlier chapters. These include Trang's physical reactions to romantic moments in a drama, Hanh's momentary identification with the "realistic" narrative of a Cinderella-themed drama, and Nga's emotional investment in tear-jerking stories.

\section{Physical Reactions}

In my first interview with Trang, I found it difficult to elicit insightful answers from her patchy memory for details from the Korean dramas she watched. Therefore, I re-watched a few romantic scenes from Reply 1994 and Reply 1988 with her in the second interview, which produced stronger reactions. As I showed her romantic scenes, she started to recall past emotions. She remembered replaying numerous times the Reply 1994 scene in which the character Chil Bong confessed his feelings to $\mathrm{Na}$ Jeong, recalling that she could feel her heartbeat as she watched. Trang also shared how she cried as she 
watched a scene in which $\mathrm{Na}$ Jeong rejects Chil Bong's feelings once and for all with a hug and warm-hearted words for him. Trang said she could relate to both passionate unrequited love and inability to reciprocate. Physical reactions such as the strong heartbeat and tears which Trang experienced upon her first viewing suggest her immersion in fantasy. Drawing on Jean-Paul Sartre's theorisation of the "imaginary feelings" (1940/2004), Tim Dant's (2012) discussion of such a dream-state is instructive:

Watching television has much in common with the dream-state or hallucination in that viewers have to 'suspend reality,' the consciously experienced paramount reality of the everyday world, to give themselves up to the story and the lives of the people represented, whether fictional or actual. Even the bodily responses accompanying these states Sartre describes - flickering eyes, twitching hands, raised heartbeats, arousal - are reminiscent of those that come with watching scenes. (p. 188)

Trang's response to romantic scenes highlights the impact of fictional consumption on audiences' feelings, demonstrated in bodily reactions. Because of its "naked display of emotion," Linda Williams (1991) describes melodrama as a "body genre" alongside horror and pornography. Williams notes that these genres have the power to make the spectator's body become "beside itself with sexual pleasure, fear and terror, or overpowering sadness" (p. 4). Trang also manifested a fascination with the "affectionate gaze" in the drama Reply 1988, which she watched twice:

Trang: I remember a montage in which everyone [a group of youngsters living in the same neighbourhood] play together and then fall asleep together, probably in Taek's room. Afterwards, Taek wakes up and gazes at Deok Sun. It's my impression of Taek.

Thi: Is it at the end of the drama?

Trang: No, it's where they're playing together, all in one room, and then fall asleep together. And then Taek opens his eyes and looks at Deok Sun.

Thi: What do you find impressive about that scene?

Trang: The passion.

Thi: What do you feel about such passion?

Trang: It's relatable. 
Thi: Is that so? Who did you relate to?

Trang: Taek (chuckles).

Thi: How so?

Trang: Because...if you like someone, you want to look at them all the time.

While the informants in previous chapters also mentioned "the lover's affectionate gaze" in their narratives, the difference between their reception and Trang's is that they manifested a desire to receive the loving gaze while Trang identified with the one who gazes. Through the reversal of the gaze, Trang did not demonstrate a wish to be desired, but rather to desire and her identification with the feeling of being in love and the pleasure from admiring a loved one, that is, the pleasure of forgetting, of losing oneself in the moment and indulging in a pleasant sight. Trang's identification thus shows an agentive self-positioning.

My interviews with Trang reveal that she did enjoy the dramas and identify with the characters while watching, but the feelings did not linger long. She "moved on," unlike An, Minh, or Kim who could recall details vividly and showed that the dramas had had lasting emotional effects. Trang enjoyed the story but did not connect it closely with her own situation or internalise the characters' emotions. She prioritised her real life, which she was satisfied with, over fantasies.

\section{Realism and Identification}

Hanh did not recognise herself in most dramas but identified with the female lead Gil Ra Im in Secret Garden (2010). The character, played by Ha Ji Won, is aggressively courted by Kim Joo Won, a much wealthier man, played by Hyun Bin. Aware of their class difference, Gil initially resists Kim's pursuit but eventually succumbs. According to Radway (1984/1991), this Cinderella plot gives women the fantasy of being desired by a "dream man" and fosters a sense of importance, uniqueness, and desirability despite having a disadvantaged background. I have observed this reading in both viewers online and this project's participants. Many female viewers in Vietnamese online fan forums have expressed a longing to have a perfect man who desires, protects, and financially supports them like the female lead. Hạnh, however, identifies with Gil Ra Im not because of a possibility for upward mobility but because of the class struggle she endured. Recounting a former relationship with a younger man, Hạnh said she felt pressured because of his much richer family: 
It [the situation] sometimes made me feel like a female lead in a drama. There're barriers which [different] economic conditions create. [We] couldn't share [similar views]. Traveling together, for example. I don't want to depend on someone financially... because I feel, if we break up, I'll owe them. I also told him [her exboyfriend] forthright that I didn't want him to pay for me.

Hanh came to identify with the female lead in Secret Garden because she disliked being in a relationship in which a man is much better off than her. Gil suffers from her boyfriend's mother's disapproval and social scrutiny because she is poor. Her ideal of independence made Hạnh see the dating situation as challenging rather than embracing the opportunity for socio-economic mobility. While Hanh acknowledged that romantically devoted and privileged Korean male leads may be the ideal that most women wish for, she denied ever wishing for a similar lover. At one point, when discussing romantic devotion, Hanh notably placed herself in the man's position instead:

Hạnh: People would be like, "Oh, I wish I had a boyfriend like that."

Thi: What about you?

Hạnh: I never wished for anyone who loves me like that, because I don't believe they exist.

Thi: But did you enjoy it [devoted love on screen]?

Hạnh: Yes, I did, obviously I enjoy watching people dying and coming back to life for love. Like in Sorry I love you, how the male lead is devoted to the female lead until the end. But if it were me, I wouldn't sacrifice myself that much, I don't have it in me to sacrifice like in the drama.

Notably, when Hạnh said she did not "believe" in the existence of unconditionally devoted masculinities, she implied that they are unrealistic and should not be taken seriously. She drew a distinction between herself, a realistic viewer, and those who readily embrace this commercialised construction of masculinity and who buy the "dominant happiness script" (Ruti, 2018). In placing herself in the sacrificing position rather than benefiting from such sacrifice, she also reminds us that fantasies of transcendental love, like those in Korean dramas, require devotion and sacrifice from both sides, which many female viewers ignore because of their greater attention to male characters' behaviours. Again, Hạnh showed her egalitarian ideal of love in which both parties contribute to a lasting relationship. 
Trang's reversal of the gaze and Hạnh's placing herself in the male lead's position contradict the lack of active female self-positioning in the informants of previous chapters, who characterise women as passive recipients of love. These examples instead suggest that they identified with an active, giving role, not only in fantasy but also in real-life relationships.

\section{Boredom and the Search for Heightened Sensations}

During our interview, Nga mentioned many Korean dramas that she had watched but dismissed several as "unimpressive," "nothing special," "average," "without climax." However, she kept watching to keep up with friends, follow a trend, or simply kill time. As a result, it was difficult to sense that they had inspired rich emotions in her. However, Nga reported that tragic endings, despite usually leaving her frustrated, tend to linger in her mind, unlike "happily ever after" endings, which she found "unrealistic" (ảo).

Indeed, Nga shared that she felt frustrated and cried throughout the night as she watched the tragic ending of Uncontrollably Fond (2016), not because she found the love story special, but because the male lead dies in his lover's arms. She seemed to have indulged in the pleasure of sadness, indicating how vicarious suffering can bring enjoyment. To seek out such pleasure, Nga also consumed other genres of romances such as Chinese dramas and Chinese literary romances (truyện ngôn tình ${ }^{22}$ ), which often have similarly tragic endings for protagonists in such conflicts as being caught between their feuding families. She also enjoyed watching dramas in which relationships struggle because of extramarital affairs, acts of betrayal, or unresolvable misunderstandings. In other words, Nga manifested a desire to explore alternative worlds of sufferings in the phantasmatic realm. Despite such enjoyment, she also described these stories as exaggerated and impossible. Nga's intense identification during and immediately after viewing Uncontrollably Fond's ending and her simultaneous rejection of its quality (she said its content was "nothing special") proves further that narratives of the viewing experience should not be taken at face value. As Nga insisted on romantic Korean dramas' average quality and lack of realism, avowing intense investment in a drama would be incongruent to her self-image as a critical and realistic viewer.

Thompson (1995) discusses how contemporary media offers a way to access impossible scenarios, including the kinds of sufferings unlikely to happen: "Few people in the West today are likely to encounter someone suffering from extreme dehydration or

\footnotetext{
${ }^{22} \mathrm{Kim}$ in Chapter 3 also reads this genre, which is popular among young women.
} 
starvation, someone shot by sniper fire or maimed by mortar shells; but most will have witnessed suffering of this kind on their television screens" (pp. 208-209). Nga spent considerable time on "average" dramas and even sought to immerse herself in tragic stories which she criticised as exaggerated representations of reality because of boredom. Svendsen's (1999/2005) philosophical reflections link boredom, or emptiness, with "the lack of meaning" (p. 25) in human life. ${ }^{23}$ Nga's interest in sensational experience, driven by boredom, is demonstrated in her active participation in online gossip and following scandals. She spoke of others' shocking scandals at length and with greater amusement than how she discussed her own relationship. Nga also revealed her occasional attempts to pick fights with her husband to make their relationship less "flat." Nga became disappointed when he did not respond aggressively as she hoped; "lovers have to fight once in a while, otherwise their relationship stays boring."

Despite seeking out emotions evoked by tragedy, Nga obviously did not wish to experience tragedy herself but rather seemed curious about what it feels like to be in a terrifying situation, such as being cheated on by a partner or losing a loved one. This interest perhaps stems from a feeling of precaution and the need to build resilience by preparing mentally for unfavourable events (Goldstein, 2009), as some believe that the knowledge one acquires from such fictional engagement may come in handy if one needs to cope with similar events (Mar \& Oatley, 2008). Goldstein (2009), who investigates young adults' experience of sadness induced by fictional engagement, finds that although viewers of sad films can feel sadness as intense as that experienced when recalling a discomforting event, the former is "unadulterated sadness," and not mixed with anxiety, unlike the latter. The fact that viewers are free from anxiety and can let go of the fictionally induced experience, in contrast to the experience of discomfort in real life, makes it possible for them to engage intensely with the induced sadness and allow for fiction's cathartic function to work to the full (Goldstein, 2009). As Mar and Oatley (2008) note, fictional involvement encourages audiences to "experiment in a controlled and safe manner with intentions, emotions, and emotion-evoking situations that would be impossible and often highly undesirable in the real world" (p. 183). Nga's attraction to tragic dramas and scandals may also come from her keen awareness of the insecurity of life in Vietnam, which she underscored by mentioning local news stories about sexual

\footnotetext{
23 This reminds me of the Lacanian lack, the "void of being" that comes with an unsettling sense of incompleteness and that, according to French psychoanalyst Jacques Lacan, drives humans towards a constant search for the illusory state of plenitude (Lacan, 1966: Ruti, 2008 \& 2018). This desire for the (delusional) completeness that drives some people to forms of entertainment can be observed in An's case as well (Chapter 2). I regret not to engage with this promising area for theorisation here because as it might go beyond the scope of my research. However, I find it important to make this note of connection here for further reflections.
} 
scandals, marital breakups, accidents, and crimes. Consuming fictional tragedies might help Nga deal with her fear of uncertainty and losing control. According to WhitehouseHart (2014), audiences' return to trauma on screen reflects "the wish to find a way out of the problem and to promote change, however minute" (p. 37). Yi (2018) contends that viewers may still find Korean dramas with plots about disastrous events, however exaggerated, realistic because of the precarity of their own lives, laden with risks such as losing a job or their social position.

Hạnh, Trang and Nga showed that their experience of identification did not come from wishful thinking, i.e. their wish for certain events to happen, but rather their association with experiences in real life. For Hạnh, being less economically secure than an ex-boyfriend made her identify with a female character. For Trang, having been in love brought her closer to affectionate male characters. And Nga found sensational and tragic scenarios in dramas intriguing probably because familiarising herself with these situations helps her deal with the fear of uncertainly and losing control associated with life, which she perceived as unpredictable and precarious.

\section{Concluding Notes}

The informants' narratives show how they enjoyed Korean dramas in their own way, not necessarily in the ways television producers and local discourse seem to expect them to, such as imagining upward mobility through romantic fantasy or imagining romance with a perfect man. Their investment was in the narrative rather than in characters. Even if they identified with characters and experienced heightened emotions such as sadness, they "moved on" from such emotions and reflected critically upon what they watched after immersing themselves within it. This process further shows how informants consume dramas for their personal purposes in a manner reminiscent of that described by the "uses and gratifications" approach to media consumption (Katz \& Gurevitch, 1973). By watching romantic Korean dramas critically, Hạnh, Trang, and Nga presented themselves as agentic consumers who refused to accept ideologies imposed upon them. Through such a refusal, they distinguished themselves from the imagined "uncritical masses" who are presumed to be more receptive towards K-dramas' commercialised, idealised construction of romance and masculinities. Their refusal to invest was not related to class status but rather identification with a down-to-earth self-image.

The viewing experiences of Hạnh, Trang and Nga are reminiscent of the ambivalence towards K-drama consumption found in such studies as those of Fang-Chih 
Irene Yang (2008a), Chan and Wang (2011), and especially Wilson (2011). The women's narratives reveal a hidden sense of defensiveness similarly found in Wilson (2011), which explains the need to resist popular genres of melodrama because of their distortion of reality and emotionally exploitative nature. To enjoy the genre without being "exploited" or falling into the lure of wishful thinking, my informants drew a clear distinction between the romantic fantasies portrayed in these dramas and their own lives.

The chapter also documents that gender-egalitarian values and past experiences can play a role in the reception of K-drama romance and soft masculinities. As my informants accentuated the importance of being independent in life as well as in romantic relationships, they resisted identifying with female leads portrayed as passive recipients of love from privileged men. This chapter, therefore, counters stereotypical depictions in television studies of female viewers as passive consumers of soap operas and victims of patriarchy (cf. Spence, 2005). 


\section{Chapter 5: Your Bodies Are Our Future ${ }^{24}$}

Humans have long made use of artificial means to enhance their minds and bodies. Michel Foucault calls these means "technologies of the self" and defines them as those which:

permits individuals to effect by their own means or with the help of others a certain number of operations on their own bodies and souls and thoughts, conduct and way of being, so as to transform themselves in order to attain a certain state of happiness, purity, wisdom, perfection, or immortality (Foucault, 1988, p. 25).

Such technologies of the self may include sexual chastity or indulgence, abstinence or dietary regimes, physical and intellectual engagement, religious activities, or keeping diaries (Foucault, 1988; Hernández-Ramírez, 2017). Individuals adopt these techniques, which require continuous practice in both thought and action, to know themselves and take care of themselves (Milanzi, 2001). Such mechanisms, for Foucault, are exercised out of one's "ethical duties to the self" (Gauntlett, 2002, p. 129). Self-care practices, however, are not independent of external forces; rather, they are enforced through governing techniques that convince individuals of the need to behave themselves (Foucault \& Blasius, 1993, pp. 203-204). In this era of globalisation, by allowing a proliferation of messages about technologies of the self, contemporary neoliberal states shift social responsibilities to the hands of individuals (Rose, 1996).

In this chapter, I depart from Butler to discuss Foucauldian technologies of the self and explore how some of my working-class informants selectively adopted K-drama narratives in their constructions of self. Through consumption of these dramas, they reflect on life and ways to improve their bodies and minds. This idea of television texts as a self-making technology has been explored by studies such as Abu-Lughod (2000), Matza (2009), and Nguyen-Thu (2019), among others. While Abu-Lughod explores how Egyptian television melodramas allow viewers to emotionally engage with their modernised self, Matza (2009) examines the ways in which a popular self-help-like radio talk show encourages Russian audiences to embrace self-governing ideals and practices. Most relevantly, Nguyen-Thu (2019), who focuses on Vietnamese consumption of Latino

\footnotetext{
${ }^{24}$ This title is inspired by the chapter Bae Yong-Joon, Soft Masculinity, and Japanese Fans: Our Past Is in Your Present Body in Sun Jung's (2001) book Korean Masculinities and Transcultural Consumption. In contrast to my focus on Vietnamese forward-learning attitude in receiving Korean dramas, however, Jung's chapter addresses "retrospective learning" mode among Japanese fans of Hallyu, which is reflected in how they seek to satisfy postcolonial nostalgic desires through consuming soft masculinities.
} 
and East Asian soap operas in the 1990s following Đổi Móri, argues that these foreign soap operas became a technology of the self as local audiences integrated their narratives into personal lives and embedded them in self-making processes. The role of trendy East Asian dramas such as Japanese and Korean dramas as a tool for reflexivity for young audiences living in modernising Asian cultures due to their portrayals of young urbanites' struggles has been foregrounded in such studies as $\mathrm{Hu}$ (2008) and Chan and Wang (2011). In this globalised era, neoliberal societies have witnessed a proliferation of technologies of the self in the media due to increasing emphasis on the idea of individuals as masters of their own lives and futures (Ouellette \& Hay, 2008). This chapter seeks to enrich this body of research with a focus on contemporary Vietnam and male consumers.

To develop my argument, I draw on Vietnamese working-class urban migrants' reception of representations of privileged masculinities and romantic narratives in Korean dramas. The informants' reception is conceptualised within an overall forward-learning attitude (Oh, 2011; Andrew Eungi Kim et al., 2013), characterised by a desire to explore the culture of a more developed country. This attitude is manifested in the ways they drew "lessons" from two prominent themes in Korean dramas: the individual process of overcoming obstacles, asserting autonomy and pursuing dreams, and the presentation of urban middle- and upper-class men's lifestyles. These themes, which highlight aspirations for upward mobility and modernity, are often encapsulated in male characters, who serve as "a symbol that denotes the capacity for consumption in Korea" (Lim, 2008, p. 133) and "a perfect embodiment of both a modern and cosmopolitan figure" (Han, 2019, p. 43). Through their assertive behaviours, conspicuous display of wealth and power, and the ability to transform the lives of those from a lower class, male protagonists in such hit dramas as Boys over Flowers (2009) and The Heirs (2013) represent the dreams of mass audiences. They possess the minds and bodies that fit an ideal of modernity and a future the informants desire. Via a psychosocial exploration of the viewers' forward learning attitudes, I explore how the male informants constructed a "modern" self that fits their metropolitan, highly mobile lifestyles through the argument that class awareness plays a significant role in their responsiveness to Korean dramas' common theme of class struggle and conquering fate.

I first outline the participants' identification with a self-image of a modern man and their egalitarian gender ideals through a summary of their biographies, which helps elucidate patterns of identification and desire in their viewing experiences. These include their flexible views regarding, if not outright embrace of, soft masculinities. I then delve into a common theme in their narratives of attention to class struggles and identity issues 
in Korean dramas and the lessons they drew from these dramas. This study distinguishes itself from previous research concerning the class dimension of K-drama audience reception through its specific focus on upwardly mobile men of a working-class background. The participants discussed in this chapter, two of whom I interviewed twice and one once, share a working-class background and experience of mobility as they migrated from much less developed areas to Hanoi to pursue higher education and a better life. They all presented themselves as heterosexual, although I never explicitly asked about sexual orientation. While studies such as Baldacchino (2008), Yang (2008b), and Ko et al. (2014) have focused on female reception of Korean dramas through a classoriented lens due to a presumed prevailing female identification with Cinderella-like heroines, similar research concerned with male consumers remains limited. This chapter shifts the focus to such under-researched subjects within the context of Vietnam.

\section{Flexible Life and Progressive Gender Ideals}

At the time of the interviews, Toàn was a 23-year-old university student majoring in philosophy. Having grown up in a province adjacent to Hanoi, he spoke with a local dialect, which indicates his rural background. According to Toàn, his parents, who both farmed and had other physical labour jobs, had little education and their outlook in life, like their fellow villagers, was narrow. Fed up with his hometown's emphasis on traditional ideals of marriage and collectivist attachment to kin, Toàn questioned the relevance of such deeply rooted values. He aspired to achieve a reputation as an academic and to travel the world. For Toàn, "a true man" should be one with "an ego" (phải có cái tôi): he is educated, not easily manipulated, and lives the way he wants without regrets. Cái tôi (ego, or the "l"), as Toàn describes it, needs to be understood in the Western individualist sense of self as opposed to the traditional Vietnamese understanding of the self in close relations to kin and society (Marr, 2000; Doan, 2021). ${ }^{25}$ The "I" here is the neoliberal subject that takes responsibility for itself and denies the influences of others in its thoughts and actions. The description of someone as "having an ego" in contemporary Vietnamese discourse does not imply that the person is egocentric (thinking of oneself as more important than others) but rather emphasises independence.

\footnotetext{
${ }^{25}$ According to Marr (2000), prominent Vietnamese intellectuals during French colonialism such as Hoài Thanh and Nguyễn Văn Huyên contend that the individual (cá nhân), or the "l" as a subject independent of society did not exist in Vietnam before Westernisation. See Doan (2021) for a historical discussion of the development of the expressions of self in Vietnamese literature.
} 
Toàn underscored mental strength as a modern man's indispensable quality and prioritised the inner world over outer appearance. Toàn said he just wanted "a normal, non-troublesome life that is not too busy" and that he did not dream of extravagant wealth because "you'd always worry about losing money." His opinions showed a deviation from Vietnamese hegemonic masculinity, which is concerned with achieving stability and becoming a breadwinner (Nguyen \& Simkin, 2017; Institute for Social Development Studies, 2020). The fact that Toàn majored in philosophy can be seen as also deviating from those of similar backgrounds, who tend to pursue "practical" majors such as business and technology.

Ninh, a 26-year-old, had grown up in a quiet northern province and moved to the capital city six years previously. Both his parents and his older sister were factory workers. Like Toàn, Ninh drew a sharp distinction between his earlier and current life, mentioning "personal advancements," "networking," and "knowledge" as advantages that Hanoi offered. Ninh showed up for interviews well-dressed and spoke with confidence. Having majored in foreign language studies in a university that also hosted international students, worked in various jobs, and dated women, Ninh appeared to have adapted well to metropolitan life. Like Toàn, Ninh manifested deviations from hegemonic masculinity as he was not concerned with achieving stability and maturity. Instead of pursuing a permanent career, Ninh juggled part-time jobs as a tour guide and insurance salesman, an arrangement that affords him extra time to "keep contact with my family, relax, have fun, and learn additional skills." Toàn and Ninh's relaxed choices are at odds with an urban "achievement-conscious society" where individuals' "worked-at projects" towards success are constantly under scrutiny (Bayly, 2014, p. 505) and a globalised performance-oriented culture (Ruti, 2018). It is not uncommon, however, for young men like them to prioritise personal freedom and enjoyment when they are not in any serious relationship. Despite such deviations, Toàn and Ninh were each accumulating social and cultural capital (Bourdieu, 1984) that would facilitate mobility to a middle-class life. Toàn expanded his social network by attending academic seminars and becoming acquainted with scholars, while Ninh enjoyed studying foreign languages and befriending foreigners.

Vinh, a 37-year-old unmarried man, grew up in a disadvantaged mountainous area in northern Vietnam. He is a member of an ethnic minority group, which distinguishes himself slightly from "Kinh" people, the dominant ethnic group in Vietnam). Ethnic minority groups, including Vinh's, make up about 15 per cent of Vietnam's population but represent 73 per cent of its poor population (World Bank, 2018, p. 23). These groups 
usually live in remote and mountainous areas. Among my informants, only Vinh and Trang (Chapter 4 ) are members of ethnic minority groups.

Vinh belongs to an earlier generation who grew up witnessing the country's transformations following Đổi Móri. A graduate in business economics from a prestigious university, he worked as an assistant to an entrepreneur. Vinh admitted to lacking "the vocabulary to describe fully" his viewing experience and sometimes struggled to get his messages across. He described himself as not handsome and not successful, and as having had a poor but happy childhood. He did not go into detail about how difficult his earlier years were because "it is inappropriate for a man like me to complain a lot about my problems." Vinh was far more concerned than the two younger informants with establishing a good career but did not seem to have had the success he wished for. He briefly mentioned the pressure to support his parents financially as they age, which he viewed as important in fulfilling the role of a good son.

The three participants' life narratives show them as migrants who teeter between working-class and middle-class identities: the former had perhaps become irrelevant to them to some degree, while they were striving toward the latter through education and acquired social and cultural capital. Their disadvantaged backgrounds seem to have motivated Toàn, Ninh, and Vinh to identify with modernised values, as they were also in the process of constructing a "modern self" that fits metropolitan life. Their views are partly manifested in more egalitarian gender perspectives. Toàn and Ninh set "modern" criteria for prospective girlfriends, which contrast with common expectations encouraging women to be submissive and capable in the domestic arena (Pettus, 2003; Ngo Thi Ngan Binh, 2004; Manh Cuong La, 2012). Toàn hoped for a girlfriend who would be good-looking, educated, and independent. He was critical of university classmates who "set a goal of marrying a husband who they can [financially] depend on completely". Ninh wanted a girlfriend who would "like to enjoy life like me," be pretty, well-informed (hiểu biết), astute (sắc sảo), and, he emphasised, "not easily bullied."

As a model, Ninh cited his favourite character, Lee Bong Yi, in the drama Smile, Dong Hae (2010-2011), a working-class woman who defends herself and others from bullies. "I really admire how she handled conflicts calmly with sharp words that no one can deflect," Ninh elaborated. He said that he would appreciate a woman who knows to show her claws when attacked - a survival skill for contemporary society; he was not impressed with women who quietly suffer. He also said that he sought a companion whom 
he can enjoy life with and who is his equal, highlighting a woman's cultural competence in the public realm.

Vinh's ideal partner would be "a modern woman" who works while being "loving and caring" to his parents - to wit, someone who balances modern and traditional values. Vinh stressed, however, that emotional labour should be balanced: as a husband, he would respect his wife's family as well. According to Vinh, the expectation for men to serve as the pillar of the household (tru cột), i.e. play the breadwinner role is now an ideal rather than a truly enforced practice: "Nowadays, both parties need to contribute. It's common to say [that men are pillars of the household], but in this day and age, it doesn't matter if a man can be the pillar." The gender views that the three informative expressed are progressive even by Hanoian standards, and their sensitivity to class struggle, as the next section presents, offers insights into the role their consumption of Korean dramas played in how they juggled modern and traditional selves.

Although the men did not present themselves as K-drama fans, they all acknowledged watching the dramas as a form of "learning." Toàn said viewing popular K-dramas was a way for him to keep up to date with the latest trends and what people were thinking and talking about, while Ninh acknowledged that dramas helped him learn about Korean lifestyles. Vinh, despite not having watched a new K-drama for nearly ten years due to his busy life, participated in my research because K-drama viewing had been part of his cherished adolescent years and gave him valuable "life lessons" that he had carried into adulthood.

\section{Preoccupation with Identity and Class Struggles}

A prominent theme in my interviews with Toàn, Ninh, and Vinh is their concern with identity and class struggles. All three demonstrated a fascination with identity-switching tropes that see the rich lose power or yield it to the poor, or the poor catch up with, or even dominate the rich, themes that foreground the fragility of class status while promoting a neoliberal message that anyone can "make it." In their repetition of this theme, Korean dramas open "a world of fantasy where viewers can imagine the escape from the harsh realities of social class differences in the globalisation process to achieve modernity" (Han, 2019, p. 44). Toàn indicated a disidentification with perfect male leads in Korean dramas, who have everything from looks to inherited wealth and power: 
Some people may identify with them, but I don't. I don't have such good luck. I wasn't born into that kind of environment. There's nothing [about them] to like. I can't hope for it [what they have]. They're just strangers.

He identified more with the character Lee Dong Chul in East of Eden (2008-2009) because Lee had grown up in poverty but managed to overcome great challenges and take control of his life instead of depending on others' help. For Toàn, the success of a man from a difficult background is far more impressive than those who "already have facilitating conditions [to succeed]." Yet, there were moments in The Heirs (2013) where Toàn identified with the male lead, an heir to a conglomerate, for his emotional problems. Struggling to articulate his point, Toàn showed me, via a streaming site, a scene in which Kim Tan (the male lead) reveals himself as the son of his father's clandestine concubine rather than his legal wife and introduces his birth mother to both his upper-class fiancée and her mother. This scene illustrates Kim's determination to live with his true identity and his love for the birth mother. Toàn praised Kim's "bravery" in revealing his identity, which "makes it more difficult for him to inherit." Due to Kim's revelation, his engagement to his fiancée is called off, allowing him to pursue the daughter of his family's domestic helper. Despite Kim's privilege, he still suffers from class struggle, as he has to live under a disguised identity and his father strongly opposes his relationship with a woman of lower status. As Toàn noted, he usually adopted a distanced attitude in watching rich kids' lives on screen, signalling his "outsider" position in relation to the characters. Nevertheless, Kim's issues in coming to terms with his identity and fighting to protect his love despite his father's objection brought the character affectively closer to Toàn:

Looking from a different angle, you'd see him just as a youngster. A young man who...(pauses reflexively)...dares to do things... I mean, a young man like us, who is very determined, who boldly pursues love, who... I mean, you no longer see him for his status but instead see him as just another human being, a young person living by his own desires, and so he seems more relatable.

Kim's confrontation with his "inferior" identity as a concubine's son rather than an heir to a conglomerate's fortune moved Toàn. The scene can be read as an inspiration to live "true to oneself." Identification is made possible via recognisable struggles - the difficulty of accepting one's stigmatised background, defying parental expectations, and pursuing love, and these struggles, confronting a modern self within a changing society haunted 
by traditional values, endow the character with a crucial authenticity that Toàn identified with.

Ninh also expressed fascination with the theme of identity, status and class struggle. He mentioned scenarios related to this topic numerous times while discussing dramas he had watched. For example, Ninh was impressed with the makeover scenes in Boys over Flowers (2009), in which a wealthy man buys his working-class girlfriend fancy clothes, brings her to a beauty salon, and has her "transformed into a totally different person." The woman, who is regarded as ordinary, suddenly becomes a beautiful object of envy and now enjoys glamour and recognition. Ninh brought up this situation a few times, indexing how intrigued he was by such metamorphosis. The remarkable transformation highlights cosmetic treatments and material consumption as technologies of the self. Ninh seemed to admire both the man's power to transform and its outcome: the woman, who now unexpectedly exudes beauty and charm. This magical change of identity embodies a neoliberal logic that instils belief in possibilities for the ordinary to become extraordinary through the application of appropriate technologies. Ninh's fascination with this transformation recalls mass audience interest in makeover reality shows, which nurture the neoliberal idea of selfhood as an ongoing project. Another identity-related scenario Ninh brought up was from Clean with Passion for Now (2018), which portrays how a company CEO and a psychiatrist, i.e. men of high social positions, each fall in love with a cleaner. Ninh explained why the drama moved him:

Even after her true identity is revealed, the guy who likes her still initiates talk with her so the two can find out more about each other. Despite being aware of her low status, he still accepts her for her good character and honesty.

This Cinderella theme prioritises virtue over status and wealth and feeds a wish for equality and fairness. The union between rich and poor through romance reflects a "soft," escapist solution to ongoing class conflicts that cannot be easily resolved (Yang, 2012). In a similar vein, Vinh highlighted this promotion of social equality through love and friendship in Korean dramas:

In the present society, pragmatically speaking, rich people just hang out with rich people. But in dramas, despite being very rich, they somehow like to hang out with the poor. They share things, sympathise with one another, and build up mutual understanding to become good friends. This taught me that whatever life is like, you have to live with a sincere heart. 
(...) The same with love. Some rich women date [poorer] men whom her family oppose, but they still overcome obstacles, they still love each other genuinely and end up together.

At one point, Vinh made a seeming Freudian slip that implied how he may have imagined himself in the position of disadvantaged characters:

Some dramas show a friendship between someone who is very privileged, lives in the city, has wealthy and influential parents, and another who comes to study in Hanoi from a very disadvantaged family.

The conflation of "Hanoi" with "Seoul" (where most K-dramas take place), a mistake that Vinh did not recognise as he spoke, suggests that he identified with characters' disadvantages, especially migration and lack of resources. His interest in class-crossing friendships may come from a wish to be judged for character rather than economic capital and to be treated as equal to those of higher socioeconomic status. Vinh also highlighted the Cinderella plot of Shining Inheritance (2009), in which a wealthy CEO transfers her wealth to an industrious, kind-hearted young woman she befriends rather than her lazy grandson, who is supposedly the rightful inheritor. The grandson, predictably, in another story about the triumph of virtue over privilege, falls in love with the young woman and learns lessons in morals from her.

Vinh stressed that Korean dramas motivated him to reflect on his weaknesses and work to become a better person. He likened this effect to "meeting a beautiful woman but not gathering the courage to approach her" and being aware of his socio-economic deficits. He said that the portrayal of hard-earned success in K-dramas encouraged him to improve himself, highlighting the dramas' motivational function. "In this life, you always need to make efforts, and everything comes with a price," Vinh reasoned.

Toàn, Ninh, and Vinh each forgot the bulk of the content of the Korean dramas they had watched, but recalled situations of status transformations and class struggles. Their sensitivity to this theme may arise from their awareness of disadvantages vis-à-vis more privileged people and their struggle to adapt to competitive urban life. Their "hidden injuries of class" (Sennett \& Cobb, 1972) seem to have revealed themselves in their accounts of viewing, even though they did not elaborate on economic hardships or any overt discrimination they had gone through. Indeed, migrants in northern Vietnam often 
suffer from institutionalised and social discrimination (Nghiem Lien Huong, 2006; Sawamoto, 2014). Unlike Hanoi's official residents, whose rights and benefits are secured by their status in the household registration (hộ khẩu) system ${ }^{26}$ and who tend to enjoy immediate familial support, migrants occupy a more vulnerable position as người ngoại tinh (literally, people from outside the city) (Nguyen Tuan Anh et al., 2012; Karis, 2013a \& 2013b; Sawamoto, 2014; Minh T. N. Nguyen, 2019). Without an emotional and social base in the city, immigrants hold a tenuous position as "unofficial Hanoians" (Karis, 2013b). A prolonged cultural distinction sees established Hanoians as superior to migrants in knowledge and manners (Nghiem Lien Huong, 2006; Sawamoto, 2014; Minh T. N. Nguyen, 2019). As prospective partners in the dating market, male migrants may also suffer a disadvantage compared to established Hanoians with more stable living conditions and favourable social networks. Consequently, knowledge of the informants' attention to class struggle is instrumental to understanding their viewing experiences as engagement with technologies of the self imbued in Korean dramas.

\section{Pursuing Dreams as Self-actualisation and a Focus on the Inner Self}

When asked about his general impression of Korean dramas, Toàn highlighted the recurring theme of "living with a dream." For Toàn, "Korean dramas evoke things that the world should lean towards":

Normally you'd think the gap is impossible to bridge, but they [Korean dramas] encourage it [that the gap can be bridged]. And [the dramas show] dreams that are considered impossible. Vietnamese, especially old people, often think that way. But Korean dramas tend to show how people live their dreams. I feel we should live like that. In fact, young people now think like that. They can't live the previous way anymore. They have to live out their dreams. The older generations were oppressed by so many things, they didn't have the concept of dream in mind.

For Toàn, "the gap" is anything that stands between a person's present reality and his dream, whether the dream is wealth, a desired occupation, lifestyle, or romantic love. This theme of filling gaps is frequent in Korean dramas. Toàn drew upon a common generational conflict in Vietnamese society, which sees elders as gatekeepers of

\footnotetext{
${ }^{26}$ Hộ khẩu, similar to China's hukou, is a means of governance meant for population statistic collection, economic planning, and the allocation of social services. Hộ khẩu ties a person to a specific place and the kind of social benefits they are entitled to due to their belonging to such place. Karis (2013a) and Sawamoto (2014) offer thorough explanations of this governing system and its impact on domestic migrants in their respective dissertations. In 2020, however, the government announced that it would get rid of the hộ khẩu in the future to relieve bureaucratic work.
} 
traditions and norms and youth as a new force resisting such traditions and open to modern values and lifestyles (Marr \& Rosen, 1998; Nguyen \& Thomas, 2004). Since the country began its integration into the global economy in 1986, there has been a gradual switch from a "culture of discipline" to a "culture of pleasure" that promotes consumption and new ways of living (Dormeier Freire, 2009).

Toàn reasoned, "dreaming always poses risks, so it's not encouraged." For him, the stability that older generations insist on maintaining has become less relevant: "[Dreaming is] necessary for integration in the new age, because we're living in a hightech era, and change is inevitable and unstoppable." Again, he distanced himself from traditional pressures to adhere to others' ideals rather than living for oneself and pledged engagement with a modern self. His mention of "dreaming" recalls Yang's (2008a) observation about how K-dramas assert young audiences' "right to dream" (p. 290). In Toàn's case, dramas embody his dream of breaking social constraints, overcoming obstacles linked to his background, and asserting his ego and needs, and offer a world in which self-actualisation reigns.

Korean dramas' theme of pursuing dreams is sometimes conveyed through an unlikely love story. An unlikely love can be between the very rich and very poor or between those who are supposed to remain rivals for life; such love usually transgresses traditional values such as filial piety by defying parental opposition. As often seen in Korean dramas, parental approval is typically a prerequisite to marriage in Vietnam, though parental influence has waned in recent decades (Bélanger \& Khuat, 2001; Nguyen \& Belk, 2012, p. 113; Thanh Thi Vu, 2015). This theme of "rebellious" romantic individualism, according to Baldacchino (2014), "represents a deregulation of desire that threatens the social and moral order" (p. 15). This theme intrigued Toàn because it "connects class groups that seem impossible to ever converge." The following excerpt explains further his preoccupation with the motif:

Thi: You said watching love stories made you reflect on reality, how so?

Toàn: Like how can two people from two vastly different class groups be together. One is too rich while the other is too poor... I feel it's just impossible, how can they end up married? It's implausible. Yet a drama makes it possible. And that makes people want to watch the drama.

One unlikely love story Toàn mentioned occurs in My Princess (2011), which revolves around a relationship between a conglomerate heir and a princess in the drama's fantasy 
version of Korea in which monarchy continues to the present. The heir initially attempts to send her overseas as her presence threatens his inheritance. However, he eventually falls in love with her and yields his own wealth to help restore the monarchy.

It [the man's sacrifice for the princess] may be unlikely, but at least I found the actors' performance convincing, so I found it quite real. I know it's unlikely to happen in real life, but I still believe people could have genuine feelings. Maybe it's possible in real life too. There's no harm in believing. One must live with hope instead of being pessimistic.

Toàn's questioning of unconditional love and the fact that he also found the depiction of such love "quite real" at the moment of watching indicates the simultaneous presence of identification and disidentification, which, for Butler (2015), are not mutually exclusive. Butler (2015) explains this experience as "a form of dissociation that allows me to believe and not believe at the same time" because "I [the spectator] become double to myself as a process of simultaneous identification and disidentification (p. 27). The intrigue of the situation lies in how the impossible is rendered possible on screen. Toàn did not believe in its plausibility in real life, but the performance of impossibility entices him. Emotional realism (Ang, 1985) possibly gives him hope that even if the reunion of people who are supposedly not "meant to be" is not present in his immediate life, it is present somewhere in life.

For Toàn, love is about not just emotional fulfilment but also individual choice. He found the defiance of conventions and external forces that comes with young people's pursuit of love especially admirable because he grew up in an oppressive environment that accentuates societal approval. According to Toàn, romantic relationships and marriages in his social circles are not driven by profound love like in dramas, but rather by pragmatic calculations, such as whether each partner can fulfil expected roles and meet parental approval. Cultural proximity may help foster identifications in this context, as both Koreans and Vietnamese experience tensions that result from the clash of deeply rooted Confucian values, including filial piety and collectivism, with modern ideologies; Kdramas provide "a public imaginary space" for those tensions (Lin, 2002, para. 1). Passionate love in Korean dramas, therefore, impressed Toàn:

Thi: So you're drawn to extraordinary love like that [in Winter Sonata]?

Toàn: Yes. Because humans need something that's not ordinary. And love is the easiest way to transcend the ordinary. 
Thi: Are you talking about Winter Sonata, or other dramas?

Toàn: I mean the kind of love that transcends ordinary life. It creates a centre for people's inner world.

Thi: Creating a centre for people's inner world...

Toàn: Normally, we lead very distracted lives, either because of financial worries, or aging, or illnesses. There's nothing that makes people strive towards the core of life.

Thi: Keep going.

Toàn: I mean, life must be like that to become memorable. If you're always worried, either about money, or career and position, or children, what kind of meaning does life offer?

Toàn is concerned with a philosophical question - the meaning of life. For him, everyday worries distract people from finding their raison d'être and engaging with their inner selves. Witnessing those around him, including his parents, fellow villagers, and friends, in a constant state of worry and seeking societal approval seemed to have made Toàn weary of monotony and led him to consider deviating from expectations. His distaste for norms and stereotypes signals his wish for a break from social pressures, which he would increasingly be required to endure, considering his imminent need to enter the workforce and build a career following graduation. His idea of love as creating a centre for the inner world echoes Baldacchino's (2014) remark on how Korean dramas reinforce a "modern" ideology of romantic love that prioritises a previously unacceptable affective individualism. This idea of love as self-enriching is similar to Hardt and Negri's (2009) philosophical take on love:

Love is productive in a philosophical sense too-productive of being. When we engage in the production of subjectivity that is love, we are not merely creating new objects or even new subjects in the world. Instead, we are producing a new world, a new social life. (pp. 180-181)

Underlying the theme of true love is a sense of authenticity: following your heart and your inner calling, which again meshes with Toàn's idea of an autonomous self. It is this sense of authenticity that made Toàn identify with Kim Tan in The Heirs. As Toàn's discussion of the drama shows, while Toàn felt distance from Kim's wealthy background, he came to identify with the character for his bold engagement with his "true" identity as a concubine's son and daring to address status gaps, even at the cost of defying traditions, 
i.e. parental and social expectations. Toàn identified with Kim's performance of authenticity and autonomy.

Tài's appreciation of autonomy likewise explains why he enjoyed male characters that show solution-oriented, independent thinking. His favourite K-drama male characters are Lee Dong Chul in East of Eden and Yoo Shi Jin in Descendants of the Sun; the former is a tough but kind-hearted gangster, while the latter a talented special forces captain. Toàn praised their good looks, resourcefulness, intelligence, and manliness. These characters are outstanding problem-solvers who combine the wen (cultural attainment) and $w u$ (mastery of physical strength) ideals of Chinese Confucian masculinity (Louie, 2002). Notably, Toàn was not particularly interested in how these characters treat women on screen, but rather, how they present themselves as self-determined individuals who conquer obstacles. This particular aspect distinguishes the ideal man in Toàn's vision from traditional ideals, which emphasise men's capacity but which also dictate this quality as necessary for men to support their family and help those inferior to them. For Toàn, a man should be strong first and foremost for himself, that is, living with an ego, a motto he set for himself.

\section{Attention to Privileged Men's Habitus}

Whereas Toàn focused on themes of asserting autonomy and pursuing dreams, Ninh and Vinh paid attention to male characters' lifestyle and mannerisms, reminiscent of Bourdieu's "habitus," marked by a particular disposition shared by people of a certain class (1984). Toàn focused on practices of improving mental strength and enriching the inner world, while Ninh and Vinh were drawn to aesthetic and bodily presentation of the self. In everyday urban life, both of these mechanisms are enacted out of one's ethical duties to the self, as Foucault contends (Foucault, 1988; Gauntlett, 2002).

When shown metrosexual images of Korean actors, Ninh extolled their wellgroomed looks and confident pose, combined with an aloof gaze that demands attention and admiration. Citing the common proverb tốt gỗ hơn tốt nước sơn (literally, quality wood is better than nice outer paint), Ninh stressed: "today both wood and paint should be good." In reaction to photos of actors displaying six-pack abs, a prevalent trope in Korean dramas, Ninh said the image inspired him to get in shape and thus engaged positively with the Korean Wave's usual strategy of using celebrities' "sublime" bodies to prompt "sensory overload of amazement" as part of a neoliberal scheme to foster a social discourse that sees the body as a form of human capital requiring continuous care and 
enhancement (Shin, 2016, pp. 618-619). Ninh responded positively to a neoliberal invitation to adopt technologies of the self. For him, taking care of one's looks equates to being "polite." He elaborated:

I think it [self-care] is good. They say "teeth and hair come first to create an impression" (cái răng cái tóc là góc con người), you dress well for other people, not to look at yourself. Koreans always make sure to look good when they go out. This is their strength vis-à-vis Vietnamese men: they actively take care of themselves before being urged to, unlike Vietnamese men who don't pay attention to looks and lack a sense of self-care. Vietnamese youth nowadays do care more about looks, but self-care has been on the Koreans' agenda for ages.

Here, as elsewhere in his narrative, Ninh framed self-care, i.e. work on the body that involves the use of cosmetics and makeups, fitness training, and bodily adornment, as a way of showing respect to others, i.e. a public service. For Ninh, paying attention to one's looks is a "civilised" way of being. His view of the body as functioning for others to look at recalls Bourdieu (1984) on middle-class concern with the body as "body-for-others" ( $p$. 213). This idea also echoes Butler (2004): "The body has its invariably public dimension; constituted as a social phenomenon in the public sphere, my body is and is not mine" ( $p$. 21). This view sees the body, "an object of will and discipline" (Shin, 2016, p. 621) as constituting a social identity that one cannot escape. Ninh's understanding of self-care coincides with Korea's conventional perception of beauty practices as not only a personal matter but also part of social etiquette (Elfving-Hwang, 2013) that accentuates a duty to "please the eye." Ninh saw Korean male entertainers as models for Vietnamese men, who lag in the art of self-presentation. He acknowledged how he himself had learned from Korean men by using skin-care products to take care of his looks as well.

Ninh was also impressed by "how they [Korean actors on screen] washed their face and sprayed cologne all over in the morning" because these self-care practices show how the men are "well prepared/meticulous" (chin chu). Such scenes, common in Kdramas, show a man straight from a shower, looking fresh and immaculate and displaying a well-built, slim body as he faces the mirror and displays sensuous appeal as he prepares for a new day. At times characters are shown choosing business attire and a tie. These practices not only show body-care consumption as carrying an "air of fantasy" and demonstrating "a desire not just to smell good but to carry an aura of modernity and status and a whiff of prosperity" (Nguyen Bich Thuan \& Thomas, 2004, p. 143), but also 
signal readiness to enter the public arena as a willing object of the social gaze and a productive member of the workforce. This pleasurably portrayed aesthetic labour evokes identifications and imaginations among audiences.

According to Elfving-Hwang (2020), idealised representations of male professionals in Korean media "train" men to "assume a fashion-conscious male consumer gaze" (p. 135). Ninh's attention to male characters' morning routine suggests a fascinating array of gazing acts in his viewing experience: he gazes at both another man on screen and that other man's reflection in the mirror, as the character also gazes at himself in the mirror. This multi-perspective homoerotic gaze is a moment of narcissism that highlights male beauty and virility. The presentation of self-care engaged Ninh as a willing "learner" in Korea's neoliberal regime of self-care. The bodily performance of metrosexual masculinity also exhibits dynamism and professionalism and offers audiences visual pleasure from desiring either the man's perfect body or his consumption practices, which make such immaculate looks possible. The well-calculated exhibition of a man's self-care, from the way he applies cologne to how he leisurely slides into a new suit and straightens a matching tie, almost suggests a sequence from a grooming lesson for men. The morning routine enhances a sense of worth: that the man is important, and the people he will meet that day are important too. This deliberate exhibition demonstrates a man's embodied financial, social, and cultural capital and his upper-class status. Modernity is embedded in this capital, and metropolitan sophistication is shown in male characters' looks, manners, and speech. For many audiences, these men readily become spectacles of desire.

Vinh was also impressed by metrosexual actors, whom he found "beautiful from head to toe." In response to photo shoots of popular Korean actors, made-up and wearing pattern-laden, colourful clothes, he said:

These days, it's good to dress like that. These days, men should wear something slightly feminine too. It's not that we should be too effeminate to look trendy or something, but we should mix and match. For example, when I go out to have coffee with a friend, I can try pants or a T-shirt with a cute, funny picture or logo. You should wear what makes you feel good and comfortable.

Vinh repeatedly mentioned "these days" (thời buổi này) to signal his modern view, implying the importance of living according to current norms, which involves being up-todate with youth culture and following fashion trends. He endorses mix and matching 
apparel items as part of metropolitan habitus, which reflects "the consequent freedom of selection among possible variants" and "the need to self-define one's own individual style" (Amatulli et al., 2015, p. 345, original emphasis). Additionally, Vinh's advocacy for "wearing what makes you feel good," which may involve wearing "something slightly feminine," encourages freedom of expression.

Apart from the performance of metrosexuality, which offers aesthetic pleasures, Korean dramas also direct attention to aesthetic values in presenting characters' lifestyles. Ninh highlighted K-dramas' tendency to aestheticise "the man in the kitchen" image:

Ninh: I feel that the image of a man getting to the kitchen, especially to take care of a sick girlfriend, breaks the stereotype that says men should be tough. They can be soft in the kitchen.

Thi: What kind of stereotype?

Ninh: I don't think that way, but Vietnamese society upholds that stereotype. It's probably because of the way they filmed it. Whenever a man cooks, he looks so handsome (đẹp) and charming (duyên dáng), domestically able (đảm đang) and skilled (thành thạo), I mean skilled at cooking. When they cook, they are so meticulous. It's beautiful, more beautiful than when a male character in a Vietnamese drama goes to the kitchen.

Thi: What about women who cook?

Ninh: It's not special to me, not noticeable. Vietnamese dramas hardly ever show men in the kitchen, and even if they do, they can't show men's considerateness (chăm chút) or meticulousness (tinh tế).

While most participants in my sample approved of images of men cooking, Ninh was especially enthusiastic. He remarked that he enjoyed cooking himself, seeing this act as a warm display of affection. For him, "breaking stereotypes" makes the performance intriguing, compared to the common image of a cooking woman, which he did not find "special." As with the morning routine, there is deliberation behind this romanticised display of male cooking. Not only do such scenes show the man as a caring partner, but they also demonstrate his embodied cultural capital, manifest in what Bourdieu (1984) terms "(the) bourgeois ways of treating food, of serving, presenting and offering it" ( $p$. 421). The calculated combination of a man's good looks and his refined manners in the kitchen, again, makes him a charming and sophisticated spectacle, indicating that there 
is more to him than meets the eyes. By highlighting how men in K-dramas look "more beautiful" than their counterparts in Vietnamese dramas, Ninh again demonstrated a forward-learning attitude that upholds Korean pop culture as superior in aesthetic quality. Aesthetic elements in Korean dramas also fascinated Vinh, who saw them as part of dramas' romanticism:

They [the male characters] are very meticulous. For example, a man brings a very beautiful bouquet of flowers when he visits his sick girlfriend. I was so impressed, couldn't help noticing. The girlfriend is sitting in the hospital hall when the young man enters and gives her the bouquet, without a word. I mean, they don't need to say much but still show romance and passion. It's not only the actors who are beautiful, every detail is beautiful as well, from the bouquet to the way the flowers are tied together. I was, like, "wow, so beautiful."

Here, the performative act of preparing and offering flowers also points to a character's social and cultural competence: he has an eye for beauty and manifests his affection in a simple but romantic way.

Notably, Ninh and Vinh both used the term văn minh (civility) repeatedly to describe the ways in which characters socialise and behave, i.e. manifestations of their class habitus. Văn minh, derived from the Chinese wenming, can be translated as either civilisation, civility, or (being) civilised, depending on context (Harms, 2016). Scholars of contemporary China have discussed how the Chinese government has made use of this concept to promote a sense of self-discipline so that people police their behaviours and demonstrate themselves as responsible citizens (Zhang, 2010; Harms, 2016); this form of governance can also be seen in Vietnam (Harms, 2016; Nguyen-Thu, 2016). Within everyday Vietnamese discourse, concern with văn minh has been observed in workingclass people and the better-off alike, reflecting a local desire for a more developed and cultured society and the government's promotion of civility as a citizen's responsibility (Pettus, 2003; Linh Khanh Nguyen, 2016a; Harms, 2009, 2014, 2016; Minh T. N. Nguyen, 2019). Harms (2014) underscores that this idea of civility, upheld by urban Vietnamese, "encourages individuals to discipline their actions, comport their bodies, and live their lives in ways that do not unduly impinge on collective interests" (p. 228). Although Vinh simply stated, "everything is beautiful in K-dramas," Ninh was specific in acknowledging how he studied Korean aesthetics, which pay attention to "simple but beautiful items." The characters' taste manifests in how they decorate their homes, and again, how they 
dress. Ninh cited a remark a character makes when shopping: "This ruffle dress was trendy in 2017 but is out of date in 2019." He also observed how characters' houses are "minimalist, not too packed with stuff, but still give the impression of decorum and comfort." A minimalist style suggests refined rather than ostentatious consumption.

Forward-learning viewers like Ninh and Vinh are attentive to "a soft menu of consumption involving experiences, feelings, and interactive intimacy" that Korean dramas offer (Creighton, 2009, p. 23). Immersing themselves in simulated Korean worlds that combine Western and Korean consumption choices, K-drama audience members like Ninh and Vinh gravitate towards new lifestyle options, including romanticised leisure and recreation activities (Creighton, 2009). Their aspiration for a modern self is also reflected in how they pay attention, albeit perhaps unconsciously, to the cultural and social capital embodied in Korean icons of masculinity.

Toàn, on the other hand, did not particularly enjoy Korean entertainers' metrosexual images, but he did not disapprove of these images. Although he said "they all look the same," he accepted such images as necessarily performative. For Toàn, entertainers need to attract attention as part of their job, and "no one would pay attention to something simple." When I asked his opinion if he sees someone dressed similarly in real life, Toàn emphasised that "it's probably just for work," adding that doing so would help one "create an impression" and "gain the spotlight." Thus, even though Toàn was not interested in meticulous, metrosexual grooming, he held flexible, non-judgemental views. Notably, a sense of alienation laid in his response that "these clothes would not suit me anyway" to explain why he was not interested in metrosexual images. Toàn thus meant that metrosexual grooming would only augment the appeal of a model, not an ordinary man whose appearance does not stand out. This alienation was also present in Vinh's response when he said that he "envied" these entertainers for their fair, bright skin and slim, fit, tall bodies. Toàn and Vinh's reactions reflect their experience of their own body as inferior. This sense of inferiority in Vietnamese people is well-documented in Thomas's (1998) research concerning Vietnamese migrants' feeling of inadequacy in relation to Western white bodies due to being "smaller" and "less noticeable" in public ( $p$. 80). At the same time, Toàn and Vinh's experience indicates their sense of belonging to a class lower than Korean entertainers, whose conspicuous bodies, or "bodies in possession of money" (Carolan, 2005, p. 92) fit perfectly into expensive clothes. This experience also reflects a sense of socio-economic inferiority that emphasises bodily 
shortcomings and lack of status. Ninh, by contrast, styled himself in a metropolitan fashion and spoke of how he wanted to learn from the images.

Ninh and Vinh also admired K-drama male protagonists for their character, which enables them to serve as moral models of a modernised culture-albeit one inflected with Confucian values: strong and resourceful but also caring and kind. Asked if he finds Korean characters "manly," Vinh again emphasised a "modern" context: "These days, I think we shouldn't care too much whether someone looks manly or not, " but rather that people should "pay attention to their (men's) behaviour and acts in everyday life." Vinh cited the character Han Tae Suk in Autumn in my Heart, who helps people around him quietly and unconditionally. Vinh related this situation to how he and his friends helped each other through tough times. Vinh did not emphasise gender-specific attributes for a masculine ideal, but rather kindness and generosity in making a man "a good person" (người tốt). Throughout our interview, Vinh did not refer to particular models of masculinity but simply stressed the idea of a "good man/person." For him, traditional ideals of masculinity have become archaic, and universally appreciated human goodness matters more. His attitude suggested a break from the constraints of ideals, atypical of men of his generation.

Ninh believed that the ideal man should be "strong when needed but also gentle when circumstances require," like the title character in Smile, Dong Hae. Ninh was impressed with how Dong Hae handles both his own love triangle, i.e. how he sorts out his feelings without offending either woman, and the triangle his mother is embroiled in, gradually opening his heart to the mother's new lover while coming to terms with his biological father, who he thought had abandoned his mother. In particular, he shows love and gentle devotion towards his mentally ill mother, demonstrating filial piety. Overall, Dong Hae shows his skill in maintaining harmonious relationships with the people around him.

Relating K-drama male characters' behaviours to real life, Ninh commented that gender relations in Vietnam nowadays are much better than before, but the way men treat women should still be improved. "Men should behave more gently, they should not talk loudly or yell at others to intimidate them." He argued, "Everyone likes being treated with gentleness, why can't Vietnamese men do so as well?" According to him, trying to understand others (rather than commanding obedience) would also help men handle problems and thus benefit themselves. Again, Ninh exhibited a modern self that leans 
toward soft and "civilised" ways of resolving conflicts. Ninh's views point to an ideal of "flexible masculinity" that enables men to "move freely back and forth between a traditional male identity and an alternative identity" as a way to adapt to contemporary economic and cultural conditions (Garousi et al., 2016). He inclined towards modern discourse but did not abandon tradition. His own urban migration and his jobs in the hospitality and service industries may explain this high regard for versatility.

\section{Concluding Notes}

The three informants of this chapter acknowledged their consumption of Korean dramas as a learning process: dramas taught Toàn to "dream," made Ninh aware of ways to better his looks and self-presentation, and motivated Vinh to continuously improve himself. I would argue that dramas, as a technology of the self, have helped nurture the informants' "capacity to aspire," defined by knowledge of various means to achieve individual aspirations and a tendency to explore these means to fulfil wishes (Appadurai, 2004). As Appadurai aptly points out, this capacity is not evenly distributed in any culture due to individuals' uneven possessions of resources. It is therefore not an exaggeration to suggest that Korean dramas have contributed to the informants' construction of an aspiring self instrumental to their pursuits of upward mobility. Nurturing hopes and dreams is especially important for migrants because it allows them to cope with the challenges of their mobile lives and gives them motivations to strive, as Nghiem Lien Huong (2006) notes about Hanoi-based migrants' pursuit of better lives.

Toàn, Ninh, and Vinh all highly valued "modern" characteristics embodied by male characters, even if they appreciated slightly different traits. Toàn emphasised autonomy, self-determination, and intelligence, whereas Vinh believed a man should be kind, generous and civilised, and Ninh focused on how a man should be civilised and versatile in handling social relationships. Both Ninh and Vinh paid attention to the ideal men's middle-and-upper-class habitus, which displays privilege and cultural capital. They all saw male protagonists as role models and actively engaged with the narratives of improvement and modernity that characterise popular Korean dramas. It is important to note, however, that the informants did not necessarily recognise themselves in privileged male characters they enjoyed watching. A sense of distance lay in such enjoyment: they were keenly aware that these male characters enjoy much greater comfort and advantage than they did. 
The three informants also shared a lack of emphasis on the ideal of "the patriarch" who decides matters for others and leads a family, and possessed generally flexible and egalitarian gender views. Correspondingly, they accepted, if not embraced, representations of soft masculinities. The traditional binary of masculinity and femininity did not seem to have a tight grip on them, especially Ninh and Vinh. Their living circumstances, which involved moving from a birthplace where collectivist values are upheld, to the capital, which encourages greater individualism, as well as status mobility may have driven them to form "modern" views that suit their current life. The need for adaptation facing domestic migrants, or as Nhu Ngoc K. Pham et al. (2018) put it, "an assimilation quest into the city lifestyle" (p. 119) may have promoted their tolerance towards differences and fostered an openness to change, even if they did not abandon traditional values. The informants' receptiveness to K-drama construction of masculinities reflects a "forward learning" attitude, characterised by their view of Korea as an examplar of development and of characters as inspirational models. Through their observation of privileged and attractive male characters, these working-class men saw in Korea and its urban lifestyles a desirable future.

The fact that male and female migrants who came from less economically developed regions (Chapter 4 and here) showed more progressive gender views, including resistance to patriarchy and advocacy for women's independence than those who grew up in big cities (Chapter 2, 3 and 6) is striking. The flexibility that migration entails may possibly explain their open-mindedness, a factor more salient for my male informants here than the female informants in the previous chapter. Indeed, the more egalitarian views observed among migrants in this study point to a possibly remarkable social change that deserves further study. Focusing on the experience of "becoming urban" (e.g., Nguyen Tuan Anh et al., 2012) from a gender lens may provide fruitful insights into the impacts of migration on personhood. 


\section{Chapter 6: Resistance to Gender Threats}

Experience can play a vital role in the way consumers receive media products. In their research into anti-Hallyu audiences in Thailand, Malaysia and the Philippines, Ainslie et al. (2017) report that some Hallyu fans lose interest in Korean pop culture as they mature and come to see the dream world constructed in Korean mass culture as catering to a naïve youth. In this chapter, I explore such a change of attitude occasioned by changed experience via an exploration of three informants' life narratives that potently highlight the ideological clash between soft masculinities portrayed in Korean dramas and the patriarchy-inflected views of gender that pervade Vietnamese society.

Tài, Hà and Vy, each of whom I met twice, shared a great deal in terms of lived and viewing experience. First, as educated, middle-class adults in their early 30 s, they bore considerable familial obligations, which made them identify with heteronormative ideals of gender. Second, all three had been fans of the romantic drama Winter Sonata (2002), an epitome of Hallyu in Asia (Hayashi, 2005; Creighton 2009; Jung, 2011; Lie, 2016), and its male protagonist Bae Yong Joon, one of the most successful icons of Korean soft masculinity. Over time, however, their fandom subsided until they stopped consuming K-dramas or began consuming them differently. Although the three informants acknowledged that Winter Sonata was endearingly linked to their younger selves, its sentimental content had lost relevance to their present ideal of romance and desirable masculinity. Third, they all resisted romanticised, aestheticised and feminised construction of masculinities, and their resistance was anchored in their clear distinction between fantasy and reality. Last, each also acknowledged that their changed attitudes towards Korean dramas arose from their experience of growing up and becoming more disillusioned with life. Through a psychosocial analysis of their narratives, I argue that their resistance towards soft masculinities reflects an unconscious defence against a "gender threat," by which I mean any gender construction that threatens to disrupt dyadic gender ideals and falls outside people's demarcated boundaries of intelligible gender performances. I base my argument here on Judith Butler's theorisation of gender regulation in Bodies That Matter (1993/2011): "if to assume a sex is in some sense an 'identification,' then it seems that identification is a site at which prohibition and deflection are insistently negotiated. To identify with a sex is to stand in some relation to an imaginary threat" (p. 64).

These informants' reactions towards soft masculinities reflect this defence, at times demonstrated in the form of "gender anxiety," especially in the case of Tài, a male 
informant (Hà and Vy are both female). Normative views clearly influenced their construction and re-construction of gender ideals, exemplifying Butler's argument for the coercive force of such norms $(1997 ; 2004)$. This chapter explores how these informants resist soft masculinities, which seem to belong to "a domain of abject beings," or "unliveable" and "uninhabitable" zones of social life" (Butler, 1993/2011, p. xiii) incompatible with their gender projects. I begin by discussing each informant's life narrative, viewing experience, and gender ideals, then proceed to an analysis of the common patterns in these ideals.

\section{Tài: "I don't want to be near [metrosexual men]"}

At the time of our interviews, Tài was a single 32-year-old language teacher and translator who is fluent in English and Korean. He was recruited through a mutual friend's introduction. While Tài had now achieved middle-class status, he grew up in a workingclass home. Tài was living with his family in a neighbourhood surrounded by relatives. He had two married older sisters who had moved away to live with their in-laws.

As a teenager, Tài enjoyed Korean dramas, including Winter Sonata, and idolised Bae Yong Joon, whom he saw as an icon of male beauty. This interest in Korean pop culture influenced his decision to study the Korean language. He used to visit the Korean cultural centre to watch movies and learn about Korea. However, Tài was the most reluctant among my participants in recounting his previous engagement with K-dramas. He said he had not watched an entire drama for many years and had recently only watched trailers from extracts of a few hit dramas out of curiosity.

Tài largely subscribed to hegemonic ideals of masculinity, which emphasise maturity, autonomy, and competence. Asked what makes a man handsome, Tài said that a man must be tall and have a face that exudes "depth." He elucidated: "Having depth means they do not look like a teenager, but their face reveals their maturity." Tài valued talent and morality, especially honesty, and also underscored the importance of selfdetermination, sharing that he "really hated" weak-minded (nhu nhượ) men who are unable to make decisions for their own lives: "I'm independent, I always want to lead my own life, but I don't like to impose [my ideals] on others." Tài planned to marry and have children. In his ideal family, the husband is the breadwinner, although the wife should work and contribute financially; she should be chiefly responsible for housework, but the husband must also help. He elaborated: "l'd look down on a man who doesn't earn a 
stable income, can't support his wife and children and can't make decisions... l'd find them untalented, useless, and indecisive."

Tài manifested signs of unease in discussing soft masculinities. In response to shots of carefully groomed male entertainers, Tài said the images were too "performative/decorative (màu mè ${ }^{27}$ )" and stressed that maintaining such looks would be "time-consuming." He added that these images are "too glossy" and "too feminine." Citing the K-pop band Big Bang as an example of excessive grooming, Tài dismissed their androgynous, colourful style as "eccentric" (dị) and "crazy" (điên). To highlight the abnormality of such images, Tài referred to Korean men whom he has worked with and observed when travelling in Korea: "Only entertainers look like this, ordinary Koreans are not so highly groomed; Koreans do not always like [to project] colourful [self] images; they are very business-minded." While Tài said taking care of one's appearance might be necessary in certain contexts, he placed limits on male grooming:

Okay, you can dye your hair, you can use hair wax or something, but don't be too colourful. If I meet a man who has cologne all over or looks too glossy, l'd cringe and not want to be near them

Such a reaction reflects what Butler (1997, p. 136) calls a "gender anxiety" that creates a need for individuals to defend themselves against abject bodies (in this case, effeminate men). By keeping a distance, Tài marked these imagined flamboyant men as belonging to the uninhabitable realm of the abject. Despite such distaste, however, Tài said he would not necessarily judge an androgynous-looking man solely from his appearance. "If I talk to them and feel that we can get along, we can still be friends." This caveat reflects a tendency among urban youth towards flexible, non-judgmental attitudes. Tài may raise his guard when feeling a "gender threat," but conversations may assure him that the person is in fact "safe." For Tài, representations of romantic soft masculinities only suit teenagers like his nephews, and he saw himself as having outgrown those images. Tài stressed his preference for industrious masculinity that is not hyper-performative:

Before, I thought someone with fair and white skin was beautiful, but now I find it feeble looking; a healthy person should be active and on the move; tender looks do not fit modern environment.

\footnotetext{
27 The word màu mè, used by both Tài and Hà, can be translated literally to English as "colourful." Within this context, it means behaving (especially dressing) in a conspicuous way to impress.
} 
In emphasising that maintaining well-crafted images like some Korean entertainers would be "too time-consuming", he stressed the "aesthetic labour" (Elfving-Hwang, 2020) they must practice. However, because aesthetic labour is part of entertainers' work, he recognised that such practices are acceptable for them: "I think it [metrosexual looks] only fits the entertainment world. In real life, only artists dress like that." For Tài, an "ordinary" person looking so invested is unacceptable because excessively invested looks would not fit ordinary life.

Tài approved of two themes in the photo sets I showed: men cooking and men showing their torso. He said he had "a positive feeling" about cooking men because they depict a mundane activity that he and many men nowadays engage in, indicating an egalitarian view of gender roles that did not equate cooking with femininity. Tài said he felt "envious" towards images of muscular and fit men, seeing them as embodying an unattainable perfection.

Tài framed his past engagement with Korean dramas as part of a trend that pervaded Vietnamese youth culture during the 2000s. He stressed that he only enjoyed the dramas passively: "As a teenager, you don't analyse what you watch." He described watching the dramas as a social experience and thus both normalised the practice and mitigated his agency in such practice. Tài generally discussed Korean dramas in a distanced manner, speaking about aspects of the production process and others' reception rather than his own. Describing romanticism in Korean dramas as packaged, Tài stressed the dramas' appeal to others rather than himself:

Romanticism in Korean dramas is the kind that brings tears to the audience. It taps into... what to say, audiences' sympathy, their empathy, sometimes it combines with the beauty of the scenes and with the soundtrack to bring their emotions to a peak (...). Those elements lift people's spirits up, make them feel good, and draw them to the drama.

Tài's analysis of Korean dramas echoes middle-class participants in studies by Seiter (1990) and Skeggs et al. (2008) concerning the reception of soap operas and reality TV, respectively. Their participants preserved critical distance by presenting their consumption of mass-produced media forms as a process of learning skills (Seiter, 1990: 64). Tài's discussion of Korean dramas resonates with Seiter's argument: "people often compare their own television viewing to that of the imagined mass audience, one that is more interested, more duped, more entertained, more gullible than they are" (1990: 60). 
Indeed, Tài attributed his change of attitude to his rising lifestyle as a member of the Vietnamese middle-class:

They [Korean actors] wear new outfits in every scene, those outfits are not only new but also very beautiful. Then [when I was young] I hadn't travelled overseas, so I thought, "Oh, their streets are so beautiful, everything is alluring, and every dish is delicious." But later, I travelled and ate and wore those things. If you've had them all and you find them ordinary, you would no longer find them alluring.

His comment resonates with the link found by Ainslie et al. (2017) between changed attitude towards Hallyu in Southeast Asian audiences and recent socio-economic developments. They observe that Southeast Asian audiences' growing access to myriad forms of global media has made some consumers lose interest in Korean pop culture.

At times Tài revealed past feelings towards Korean dramas only to immediately disavow them: "I think the male lead [in Winter Sonata] is very quick to cry, sometimes I found it moving, even wanted to cry along, but now I think back and ask myself how it could be possible." He explained this changed attitude to his study of marketing, which exposes media manipulation. "They build up climaxes and compel you to wait [for the next episode], and there's a lot of product placement and cosmetics display in Korean dramas," Tài argued. "Now I know they are all performances; things aren't really as beautiful as I used to think." It is, however, not only the commercialisation of Korean dramas that made Tài change his attitude. In our second interview, he revealed deeper reasons, which pertain to his disillusionment with romance and fundamental life change after his father's death: 28

Thi: You said earlier that you think people shouldn't depend on others, that no one should depend on anyone at all. That makes me think of Korean dramas, because in there they [the characters] live entirely for their lover, even die for their lover. How do you feel about that?

Tài: I used to find it so wonderful, but now I just find it ridiculous. I find it unrealistic. First, I think only your parents are irreplaceable. Or siblings who share your blood.

\footnotetext{
28 Tài's narrative demonstrates a tendency to avoid discussing emotional events in specific details and to switch to rational thoughts immediately after revealing emotions. I note such emotional evasion as a sign of his unwillingness to engage with his past, which involves distressing events. I regret to refrain from deeper analysis of his emotional evasion here to focus on the content of his narrative. I offer a more thorough discussion of his emotional avoidance in Gammon (2021).
} 
Everything else is replaceable. You can love someone and then love someone else. Circumstances change, emotions change.

At university I used to like someone, very much, was even crazy about them. Kind of. Several years later, I calmed down and I changed. I think oh, what a fool, how could you like [her] so much. Because I'm the realistic type. I used to face incidents in life, changes in life, so now I find those things...those things are nothing...And Koreans, they're very pragmatic. If a relationship doesn't benefit them, they'll break up, and it's very normal. I think it [complete romantic devotion] only exists in dramas.

Thi: You mentioned incidents that made you change. Can you share a little about that?

Tài: First, when I broke up with [my] ex-girlfriend, for example. ${ }^{29}$ Second ....after a family member passed away for example. Then I was depressed, stressed, not good, for example...or because I quit my job. When I quit my job, I realised that having a stable job, stability can be very important. Women are pragmatic now. They may date but they don't want to marry someone aimless, without stability. For example, two people might date, but when they graduate from university, the woman might marry someone else who is better off. I saw a friend in such a situation. I can't say she is a bad woman.

Tài's views reflect a social reality: recent research shows that many Vietnamese women prioritise men's ability to make money over other qualities in judging them as a partner (Yeoh et al., 2014; Thi Quynh Trang, Nguyen, 2015; Linh Khanh Nguyen, 2016a; Warren, 2017, p. 44). Tài was not overtly critical of female pragmatism but rather adapted himself to fit it. He no longer wanted to be the sort of financially unstable and aimless man whom a woman might date but not marry. He reflected on his past self with reproach ("what a fool") and saw his previous emotional investment in love as a sign of weakness. Tài's approach to deceptive aspects of Korean dramas may stem from feeling betrayed by a fantasy that promised him eternal and passionate love. This experience of disillusionment recalls Kim's frustration with Korean dramas' Cinderella plots, which she used to enjoy as a teenager (Chapter 3). Life as Tài has experienced it apparently does not promise him the "one true love" in which a woman will never leave him like in a Korean drama.

\footnotetext{
${ }^{29}$ It is unclear whether Tài referred to one specific ex-girlfriend or more than one. Nouns in Vietnamese do not indicate number.
} 
Awakened to the deceptive nature of mass-produced romance, Tài ridiculed himself for being led astray by profit-driven Korean filmmakers.

Tài's attitude towards romance also changed after the death of his father, which he only revealed in the second interview (in the first, he spoke of "my parents" as a unit as if his father were still alive). Questioned about his switch to disinterest in sentimental Korean dramas, Tài revealed how his life had changed:

Actually... Five years ago, my father passed away. It was a... let's say, a major incident that stops me from seeing life with rose-coloured glasses. I feel... Those entertaining things...they are just... doing their job. Their job is to amuse people, to entertain. Entertainment resembles the tourism industry in some respect. But...the people producing such work, they really work very hard, it's not fun for them. As I have understood that, I think the entertainment is no longer purely fun.

In addition to disenchantment with romance, the death of his father had a fundamental impact upon him. The loss of close ties can seriously disrupt an individual's sense of self, because "when we lose some of these ties by which we are constituted, we do not know who we are or what to do" (Butler, 2006, p. 22). Such disruption in one's sense of self may cause a subject to yearn for a coherent identity that fits changed circumstances, an identity that warrants more secure self-perception.

With his father gone, Tài became the head of the household. He revealed how he had a duty as the only son to take care of his family, a common expectation in Vietnam due to a societal emphasis on filial obligation and men's role as the pillar of the household (See: Rydstrøm \& Drummond, 2004; Phạm \& Eipper, 2009; Shohet, 2013). Tài stressed that although he was the youngest child, with two sisters he is the eldest son, a position deemed significant due to traditional Vietnamese emphasis on patrilineage (Rydstrøm, 2002; Horton \& Rydstrøm, 2011). His sense of duty became much more important with his father gone and his sisters married off. He also may have felt this pressure more acutely by living in close proximity with his relatives and, therefore, under their constant gaze. In fact, Tài performed the image of a responsible family man during the interviews. Although I commented it was a bit dark, he did not turn on the light to avoid disturbing his grandmother who slept nearby; in the middle of a conversation, he moved us to another room to avoid making noise and bothering a young cousin's homework; and at times he went to another room to check the cousin's progress. Familial obligations may give Tài a sense of purpose yet also put pressure on him. Therefore, indulging in the past or its 
diversions, to Tài, may harm his sense of current self, which he tried to assert, and may be why Tài drew an emphatic line between his old self and present self.

Tài's attempts to show his keen awareness of K-dramas' strategies for appealing to viewers reveal himself as a "defended" psychosocial subject (Hollway \& Jefferson, 2000), who is "invested in particular positions in discourses to protect vulnerable aspects of self" (p. 27). Here, Tài manifested his investment in the position of a knowing viewer who cannot be deceived. Tài's attitude is strikingly reminiscent of Jim, a participant in Cohen's (2012) psychosocial audience research, who presented himself as someone immune to cinematic tricks (p. 180-189). Perhaps not coincidentally, Cohen also found a link between Jim's desire to appear as a strong, independent man and his father's early death, which, according to Jim, caused him to mature faster and think of himself as "the man of the family" who must take care of his depressive mother.

\section{Hà: “l'm only into manly men”}

Hà, 34 years old, grew up in a middle-class family. Her father was a doctor and her mother an accountant. She had a master's degree in business administration and had worked for the government for nearly ten years. She was married and had three children, two boys and one younger girl, who all live with her husband's family, including her motherin-law and brother-in-law. Hà spoke with a no-nonsense, straightforward attitude. Much of her talk centred around family relationships, and sometimes she spoke as if giving me lessons about marriage, drawing from her experience.

Hà had a difficult upbringing. Her father beat her regularly and favoured her two brothers. She said frankly, "My father doesn't love me at all because I'm a girl, he only likes sons." Her mother was not as abusive but complicit in the father's ill-treatment. As a result, Hà kept a distance from her parents and saw her husband's family as a better home. When she started her first job, she was subject to constant verbal sexual harassment at work, which caused her to quit. Although a victim of misogyny, Hà holds gender views that can be regarded as sexist. She sees men and women as inherently different, from their brain structure and thinking logic to the ways they cook and hang laundry. According to Hà, except in a few extraordinary cases, women tend to be emotional, cannot think logically like men, and therefore cannot lead as well. She added that female leaders would have to sacrifice personal happiness: "Female leaders usually don't have a good marriage, it's difficult to keep [a marriage], because men tend to dislike 
doing women's tasks, they're not even capable of doing them." She cited her own husband and her friends as examples of how men cannot do housework as well as women. Such views reflect how many Vietnamese have internalised role assignments that subjugate women within the domestic sphere and pressure women to put their family first at the expense of self-interests and career advancements (Truong, 2008; Nguyen Thi Thu Ha, 2012; Manh Cuong La, 2012; Jardine, 2019; Hong Tien Vu et al., 2019). While Hà's views lie at odds with those of most participants, who see men and women as equally able in most aspects, they reflect existing gender ideologies upheld by many Vietnamese (Soucy, 2012; Bergstedt, 2016; Ngoc Lan Thi Dang, 2017). Hà's insistence on women's intellectual inferiority to men does not stem from animosity towards women but a belief in gender difference. According to her, women, as the weaker sex, should be loved, respected, and protected by men. She hoped that her daughter would be "cared for and cherished" more than she had been and would enjoy the "intellectual and cultural freedom" that she had not had due to parental oppression.

Hà's husband was the primary breadwinner, while Hà spent more time attending to their children. Her husband held an executive position in a large corporation, and she spoke of his professional success with a hint of pride. Trusting his "better" ability to make judgments, Hà let him make the final decisions on such "big issues" as major purchases and investments. She was, however, unhappy with their unequal share of housework. According to Hà, her husband worked hard, but he rested when he came home. Hà, on the other hand, still had to do "tons of work" after returning home from her own job, including cooking, cleaning, and childcare. Her complaint echoes studies that foreground the unequal share of housework between men and women in Vietnam (Kelly, 2004; Ngo, 2004; Khuat et al., 2014; Higgins, 2015).

Unlike Tài and Vy, Hà still watched Korean dramas. She stressed that she did not watch them for the romance but to learn about Korean culture or appreciate aspects such as music and fashion. Her attitude thus echoes Seiter's (1990) observation of middleclass audiences' tendency to frame their viewing experience as a learning process. Like Tài, Hà attributed her past keen consumption of romantic dramas to social trends, stressing that it was a passive practice: "I had no analytical skills and knowledge of Korea, I just absorbed what was passed to me."

As a teenager, Hà idolised Bae Yong Joon, seeing him as the epitome of male beauty. She hung posters of Bae in her room and regularly bought photos of his images then. Hà said that she still felt a surge of emotions when shown pictures of Bae alongside 
his female co-star in Winter Sonata. Images from Winter Sonata reminded Hà of her first romantic feelings (rung động đầu tiên) in high school. Recalling the scene where Bae's character first took the hand of the heroine, Hà mentioned how she had wishfully imagined herself in the same scenario. She elucidated that the drama's depiction of first love suited her at the time. She stressed, twice, that "I was really craving a relationship like that [in Winter Sonata]" and attributed such yearning for love to her parents' lack of attention.

Like Tài, Hà contrasted her previous fan practices with her current attitude towards Korean dramas and soft masculinities. She described K-drama romanticism as "overdone," "exaggerated," and "childish." After discussing her pleasure in Winter Sonata as a teenager, she added that now she found the drama "too sentimental" (quá sến). She linked her earlier fascination with immaturity and a lack of romantic experience: "Now I don't like this kind of romanticism, it's unrealistic. It's for teenagers." Hà said she appreciated soft masculinities until her personality established itself in the later years of university. Hà's criteria for ideal masculinity then shifted to pragmatic traits.

According to Hà, her father's abusive behaviour resulted in her forming a "deep fear" of men, which only gradually dissolved after harmonious relationships with exboyfriends and later her husband. Hà said she would not feel "safe" dating someone too handsome, sharing that her husband looks "fine," but her ex-boyfriends were "not only old but also ugly." She accentuated that she did not like men with feminine facial features and preferred men who look "thorny" (gai góc ${ }^{30}$ ) and "rugged" (gân guốc). Hà's description of rough masculinity contrasts with Korean soft masculinity, which $\vee y$, the next participant, described through antonyms like "smooth" (nhã̃n thín) and "glossy" (bóng lộn). These two opposed sets of terms connote not only appearance but also differing degrees of life experience in men.

In discussing Korean dramas, Hà constantly related their depiction of masculinities to real-life situations, her gender views, and her relationships with Vietnamese men and regularly dismissed undesirable traits. Hà emphasised that she preferred much older men who are knowledgeable, calm, and protective. It is not a stretch to think that she sought a patriarchal figure to serve as the loving father she never had. Emphasising that her two much older ex-boyfriends, both PhD holders, as her "type," Hà acknowledged their support during her relationships with them. She described how they would calm her and

${ }^{30}$ I explain An's use of this word in Chapter 2. 
help her find solutions for problems. She described the traits in men she found desirable and undesirable:

It would not [impress me] when men keep behaving impulsively, like acting romantic this and that, but [what impresses me is] that they help me, not to show off, not to please me, not to score points, but out of a protective masculine nature.

Hà added that she did not need someone to offer her sweet words when she fell into trouble, but one who helped her solve problems. If a man could not provide practical help, Hà would prefer supportive silence regarding a quiet but supportive attitude as more meaningful than sweet words. This view reflects a Confucian-rooted cultural emphasis on modesty in speech, which dictates that inner attitudes and actions are more important than words (Thi Hong Nhung Pham, 2018). What Hà would approve of, I would argue, is a proper display of empathy, a skill that must be learned. Hà's appreciation of composure and maturity in men also evokes a Confucian ideal of self-cultivation characterised by a focus on inner strength and emotional restraint (Seung-Hwan Lee, 2004). She, therefore, valued men's "inner virtue" over "outer performances," which, for her, are not reliable indicators of kindness.

Hà's resistance to hyper-performative masculinities is worth noting as she drew a distinction between perceived performance and authenticity. ${ }^{31}$ Hà opposed compulsive romantic practices that she saw as insincere. Such hyper-performed acts are widely shown by K-drama male leads who would throw a party for a woman or shower her with fancy gifts. Hà's resistance is reflected in her viewing experience. For example, she preferred the stoic Sergeant Major Seo Dae Young in Descendants of the Sun to the playful, light-hearted protagonist, Captain Joo Shi Jin. ${ }^{32}$ Seo is outwardly cold, seemingly emotionless, and had broken up with his girlfriend because of her father's opposition, but steadfastly loves her and cares for her quietly. Captain Joo, on the other hand, is much more expressive and looks more feminine. Hà dismissed Joo's "flirtatious gaze" (mắt mũi đong đưa) and viewed his manliness as "too performative" (màu mè). ${ }^{33}$ Hà also approved of the character $\mathrm{K} 2$, a bodyguard, in the drama $\mathrm{K} 2$, appreciating his "manliness" as shown in his protectiveness towards his girlfriend. However, Hà stressed that she liked K2's

\footnotetext{
31 This resistance is also shown by An (Chapter 2), who stressed that she wanted men to be kind and protective out of a "genuine nature" rather than an inauthentic desire to impress. Hanh in Chapter 3 also demonstrated aversion to hyper-performed romantic practices such as reserving a whole amusement park to entertain a lover in What's Wrong with Secretary Kim.

32 Note how her preference is opposite to Văn (Chapter 7) who prefers Joo over Seo because of Seo's rigid masculinity.

${ }^{33}$ Amusingly, Thanh (Chapter 3) stressed Captain Joo's gaze as part of his charm. She described his gaze as "affectionate" and "loving", showing the intensity of his feelings for the female lead.
} 
character, not his appearance, because Ji Chang Wook, the actor, looks too youthful and perhaps, too beautiful. "His face does not convey ruggedness and experience," she elaborated. Nevertheless, she likes Ji's muscular body as it shows good health and masculine strength.

When I reminded Hà of her teenage desire for passionate love, she explained that her view of an ideal lover had changed: “I don't need someone to be crazy about me, being crazy in love can blind a man and make him weak. I don't need that, I need a strong man who can protect and shelter me." ${ }^{34}$ This view again illustrates her high regard for men's rationality and protectiveness, traits that she perceived as masculine, over emotionality, which she saw as a feminine characteristic. Her vision echoes Tài's emphasis on the traditionally masculine role of breadwinning over the perceived "feminine" trait of being romantic. Hà also added, "Maybe my heart has hardened (cảm xúc bị chai sạn) over time," implying that experience had caused her to become less romantic and emotional.

Hà's favourite Korean drama is My Mister (2018), which features a forty-something engineer, whom she described as her ideal man. ${ }^{35}$ Park Dong Hoon, the protagonist of My Mister, does not project soft masculinity, even though the actor Lee Sun Kyun may have shown some typical traits in his earlier roles, e.g., in Coffee Prince (2007). Though a good-looking middle-class man, Park is often shown in simple outfits, making him look like an ordinary, exhausted white-collar employee. He goes through a mid-life crisis as his wife cheats on him with his younger boss, and he faces difficulties at work because his boss conspires to have him fired. As a department head, Park is protective of his junior co-workers and goes out of his way to support one half his age, an impoverished, struggling woman named Lee Ji An (played by IU). In contrast to "too-good-to-be-true" younger male leads of hit dramas, Park serves as a hero of ordinary life. According to Hà, Park meets all her criteria for ideal masculinity: maturity, problem-solving skills, calmness, stoicism, and thoughtful leadership. The relationship between Park and Lee, albeit platonic, echoes the kind of paternal relationship Hà used to have with her much older ex-boyfriends, in which they protected her from the harshness of life. The fact that Park does not try to have an affair with Lee proves further to Hà that he does not "perform" and

\footnotetext{
${ }^{34}$ Note female participants' frequent use of the word "shelter" (che chơ) and my analysis of the term in Chapter 3. ${ }^{35}$ My Mister fits a new genre of contemporary Korean dramas that has become popular in the late 2010s and portrays the brutality of the corporate world and the state of precarity faced by corporate white-collar employees (Elfving-Hwang, 2017). According to Elfving-Hwang (2017), portrayals of struggling white-collar male workers in dramas like Incomplete Life reflect an attempt to portray "authentic masculinities."
} 
only helps her out of a masculine instinct to be kind and protective to disadvantaged people, indicating what Hà celebrated as a sense of authenticity.

As Hà manifested an overdetermined desire for manly men, she kept dismissing attraction to feminised masculinity. She disliked the photo of a man leaning his head on a woman's shoulder in a bus from While You Were Sleeping that I showed her: "men should act as the pillars, I like leaning on a man, if I had to do things myself, I would get so tired; men are born hunters, so they are stronger." She also expressed aversion to the metrosexual images of Korean actors that I showed, describing these images as "too well-groomed," "too feminine", even though she acknowledged the men's beautiful faces. In response to four photos of men in the kitchen, Hà approved of one in which she found that the man looks manly while rejecting the "more feminine" others and stated that she liked to see a man "looking rugged and strong while doing a feminine task." She implied that men in the kitchen, a traditionally feminine space, must look manly to disavow association with femininity.

\section{Vy: "There is no such thing as an ideal man"}

$\mathrm{Vy}, 30$ years old at the time of our interview, was occasionally freelancing as an interior design consultant in addition to her role as a housewife with three daughters. She had grown up in Saigon but joined her husband in Hanoi after they married. Like other participants, Vy had become interested in Korean culture as a teenager and had even studied the language in Seoul for a few years. Vy's husband, like Hà's, demonstrated certain typical traits of Vietnamese hegemonic masculinity: a breadwinner in a technical job who financially supported not only his wife and children but also his parents; he was nearly ten years older than her.

Vy's relationship with her parents during her younger years suffered because of their imposition of strict discipline. Feeling suffocated as the first daughter in an exemplary family, Vy spoke of a period of rebellion when she practised self-harm and caused trouble at high school. "My mother suffered because she tried hard to mould me into someone like her but didn't succeed." While Vy resisted her mother's discipline, she seemed to have internalised it into adulthood, which manifested itself in the ways she judged other's behaviour by their self-discipline and -organisation. She repeatedly used words like "tidy, neat" (sạch sẽ, gọn gàng) and "dirty, terrible, messy" (bẩn, kinh khủng, bầy hầy) to describe a man's way of living or his looks. She also seemed to apply her mother's 
discipline to her daughters (whom, she noted, should be taught differently from sons) as she taught them proper ways to stand, sit and eat.

Vy was the first person to apply to participate in my project. Her determination and commitment to engage was demonstrated in travelling to my home despite its relative distance and bringing her baby, whom she nursed in the first interview. Unlike Tài and Hà, Vy's connection with Winter Sonata is deep and lingering. She watched Winter Sonata multiple times and made repeat visits to Nami Island, where the drama was filmed. Nevertheless, such impact has little to do with her engagement with soft masculinities or even the romantic love story. She seemed more interested in re-engaging with her past than discussing the content of Winter Sonata.

Winter Sonata's affective impact on Vy went beyond its melancholic love story primarily by virtue of the filming location's connection to her time as a student in Korea and her marriage. Vy had visited Nami Island with her husband when they were dating in Korea. She re-visited the island with her infant first child when she and her husband separated for months due to her refusal to move in with her parents-in-law. ${ }^{36} \mathrm{Vy}$ shed a tear when shown pictures of the Winter Sonata couple because she was reminded of both the fictional couple's separation due to an accident that caused the male lead's perceived death as well as her own. While the photos I displayed also showed the couple's happy time together on Nami Island, Vy dwelled on their separation: "It's running through my head that, 'oh, he's about to die,' this is the part when he is about to die, and such a beautiful period is going to end." She stressed that "my own feelings are embedded in the scene" and that she could not, therefore, give an "objective" opinion on the images. To sum up, Vy's relationship with her husband went through a similar pattern to the Winter Sonata couple: they met and fell in love, only to go through a separation, largely due to problems with parents, before reuniting.

Despite such a strong emotional resonance between her life and the drama location, Vy showed a disidentification from Korean romanticism and soft masculinities, if not the disapproval Tài and Hà displayed. Like the other two, however, Vy's eventual disidentification is linked to her experience of growing up and disenchantment in life. When asked about ideal men, Vy refuted the idea forthright: "there is no such person." She reacted as if I were asking whether she believed in Santa Claus. The very idea of ideals seemed to trigger defensiveness in her, resulting in a resolute rejection. Even

\footnotetext{
${ }^{36}$ It is a general expectation in Vietnam that the bride moves in with the in-laws (although there have been increasingly alternative cases in urban Vietnam); a bride's refusal to do so can be seen as a form of rebellion and may cause familial conflicts (see: Gammeltoft, 1999; Hy V. Luong, 2003; Bergstedt, 2016).
} 
though $\mathrm{Vy}$ mentioned desirable traits in men such as responsibility, consideration, knowledge, and talent, she repeatedly stressed that no man is perfect. Her narratives in our interviews highlight a few critical incidents that influence her views of masculinity: her stay in Korea changed her opinions about Korean culture and Korean men; marital conflict between $\mathrm{Vy}$ and her husband due to different lifestyles and worldviews had resulted in a period of separation; Vy's view of her father, whom she admired when young, had also changed over time. While $V y$ did not explicitly cite these biographical details as the reasons for her changed attitudes, the flow of her narratives, facilitated by a free associative approach, suggests such a link. For example, when asked about ideal masculinity, Vy dismissed it, citing examples of men's faults, including those in Korean men she had observed during her studies, her husband, and her father.

During her time in Korea, Vy had interacted with Korean men more closely. Drawing a distinction between Vietnamese male students and Korean counterparts, Vy stressed a much higher degree of performativity (mức độ đối phó) in the latter. The verb Vy used, đối phó, traditionally means to deal with or handle something, but it has gained a more contemporary connotation of performing in a given situation or in front of certain people (such as those with authority) and thus implies that behaviour does not reflect "real" character. She underscored the social pressure on Korean male students to maintain a good public image, despite their "true" nature of being messy and impolite:

When going out, they "shine," men use skincare products, dress up, and [pay attention to] all details. Generally, they pay great attention to details so that they look good in front of people, but behind all that... terrible. They smoke, drink, and spit a lot (chuckles).

Her observations disappointed the young $V y$, who came to Korea imagining that "perhaps, l'll find someone like in dramas." Vy said that Korean men's conspicuous performativity caused her to put her guard up. She came to see their refined outer appearance and polite manners as a front that conceals negative qualities. For her, this made Vietnamese men more "genuine and approachable" despite their shortcomings. To make matters worse, Vy discerned how Koreans look down on Vietnamese women because rural Vietnamese women were marketed and sold as brides to Korean men. $V y$ was often asked in Korea if she was a marriage migrant. Reflecting on her time there, she remarked, "Fortunately, I didn't marry a Korean man."

As noted, Vy also became very disillusioned with her father, a government cadre of high status. When young, she saw her father as an ideal husband who fulfilled not only 
the breadwinning role but also loved and respected his wife. However, later she observed that he improperly used his reputation to borrow money to help a relative without consulting her mother, which occasioned a large debt to her family. He also flirted with women in a social group he had joined, unknown to her mother. While Vy stressed that she still respected her father, her idealisation of him ceased. "Everyone has an ugly side," she concluded.

Like Tài, Vy distinguished between Korean fantasy and real life: "Life in Korea is very materialistic, it's almost the opposite of life on screen. The romanticism is superficial, beautifying the drama. It makes the drama beautiful. They [Korean people] accept such beauty beside the ugly as entertainment, they don't live with such beauty, which does not exist in real life." Acknowledging that the love story in Winter Sonata once absorbed her, Vy said, "I've passed it, it's passed."

For Vy, men's romantic practices in dramas are "overdone" (lố). ${ }^{37}$ She stressed that no man in real life acted like the male characters, who would leave work to chase after a woman or leave parents behind to take her away to "escape." Vy said she preferred her husband's small gestures, such as having her watch repaired, doing housework, and playing with the kids. Vy appreciated her husband's sense of responsibility during their separation, demonstrated in his steady transference of money to support their child, despite their lack of contact. Vy indicated that she desired responsibility and care in a partner rather than "excessive" romantic acts.

Vy did not show overt disapproval of soft masculinities like Tài and Hà, but rather a disidentification that accompanies an acknowledgement that they are "too beautiful": "Those images [display] typical Korean beauty. But what's that beauty for? For performance, but what else?". Vy repeatedly asserted that Korean actors' beauty may suit others but emphasised her desire for practical traits. Vy described Korean metrosexual men as "very smooth" (nhãn thín) and glossy (bóng lộn), hinting at not only their smooth skin and clean-shaven face and body but also their well-groomed images. She compared this type of masculinity to the "dust-covered" (bụi bặm), "rugged" (gai góc) looks projected by heroes in Western pop culture. Again, note Vy's use of the word "smooth" to describe soft masculinity and Hà's use of "rugged." "Smooth" evokes the images of youth and innocence, while "rugged" conjures up experience and struggles.

37 Lố can also be translated as "ridiculous." 
Vy said she idolised Bae and saw him as "manly" when she was a teenager but now found him ẻo lả (effeminate). ${ }^{38}$ She recalled that as she had then yet to meet many men, Bae's image suited her ideal of masculinity:

For me now, masculinity is not about being glossy (bóng bẩy), finely smooth (mịn màng) like actors these days. They are terribly polished, terribly smooth (chuckles). They are too neatly combed (chải chuốt quá), too beautiful. They pay so much attention to their image. Masculinity for me now is demonstrated in behaviour, in the ways one treats others. For example, a manly man can't flinch from a barking dog or ignore a child who trips.

Here Vy brought up socially defined traits of masculinity as desirable: strength and protectiveness to weaker subjects. Yet, even someone who embodies those good traits cannot be perfect because $\mathrm{Vy}$ argued that such a person never existed.

\section{The rule of Normalcy and Gender Boundaries}

As my participants' narratives show, significant events led to substantial changes in their views of life and gender. For Tài, those events include becoming an adult with greater familial responsibility following the loss of his father and relationship breakup(s). For Hà, experiences of growing up, getting married and mothering, made her more pragmatic. For $V y$, her stay in Korea where she observed the culture from a closer distance, incidents of marital conflict, and the discovery that her idolised father was less than perfect, all had an impact upon her. As the participants either acknowledged or hinted, those experiences caused them to change and distance themselves from soft masculinities. Tài stopped watching Korean dramas altogether and criticised aspects of Korean soft masculinity; Hà watched dramas but ridiculed images of soft masculinity; and $V y$ came to view ideal masculinity as fiction.

Material and mundane demands of life play a significant role in the participants' perception and presentation of themselves. Their busy life prevented them from enjoying romanticism, while exposure to reality caused them to identify less with romanticised, aestheticized constructions of masculinity in pop culture. Life has made them more aware of the demands of relationships and thus further identify with pragmatic traits of masculinity. Their rejection of soft masculinities is consistent with self-presentation as responsible, busy adults not manipulated by mediated fantasies.

\footnotetext{
38 Ẻo lả suggests weakness and delicacy.
} 
My informants associated soft masculinities with not only femininity but also immaturity and a lack of pragmatic thinking and behaviour. Soft masculinities did not correspond with their self-presentation as heterosexual adults. Their adult roles as "only son," "wife and mother of three" seem to have led them to form determined identification with hegemonic ideals of gender. They preferred action-oriented and solution-based traits to hyper-performed ones and behaviour to looks; none cited looks or style first in their view of ideal masculinity. All underscored the importance of men's sense of responsibility and deemed hegemonic ideals because of social and personal expectations for a man to play the traditional roles of breadwinner, problem-solver, and protector. In Butlerian terms (2004, p. 206), adhering to "coercive criteria" of gender norms reassures them of their position as "real man," or "true woman" (who desires the "right" kind of men) and offers a coherent sense of self fitting their gender role. Alternative constructions, therefore, become "threats" that may disrupt traditional dyadic gender ideals. Echoing Butler's notion of gender anxiety, Yumiko lida helps illuminate this defensive attitude:

Perhaps, those who strongly react against unconventional gender practices have their own good reason to be fearful of the dissidents, for their gender identities are immediately dependent upon the undisrupted operation of phallocentric discourse. This dependency, moreover, could be more than just psychological, but may also involve total personal well-being, for the gender identification via the symbolic penetrates the formation of sexuality and thus personhood (lida, 2005, p. 69).

This statement again reminds of Butler's (2004) theorisation of gendered norms, normativity, and normalisation, which construct what can be accepted and what not. The norms govern ideas of gendered possibilities, the who and what of gender behaviours, namely whom to date, whom to marry, whom to identify with, whom to desire, which behaviours can be enacted, and which cannot.

During their teenage years, as the participants acknowledged themselves, they did not have much romantic experience. Therefore, their views of "normal," "proper" gender behaviours were not firmly established. Furthermore, idolising soft masculinities, a new set of images that had not really existed before in local media, was trendy among youth during the participants' adolescence, which normalises desires for such images. As my informants matured, however, soft masculinities became less acceptable among adults due to their perceived opposition to pragmatic, normative traits. This tendency may have been aggravated by growing resistance to Korean pop culture within Vietnamese society and weariness with Korean formulaic mass culture. The participants began to 
discern the distance between mediated constructions of Korean soft masculinities and masculinities in real life.

A prominent feature of all three participants' descriptions of soft masculinities is their use of such words as "excessive[ly]" (quá múrc), "overdone" (quá), "terribly/very" (rất) to describe non-normative performances of soft masculinities in terms of grooming and romantic practices. At times uttered in an emphatic voice, those words revealed the speakers' unease with feminised representations of masculinity that transgress the rule of normalcy. Their emphasis on such violations indicates that conspicuously feminised performances exceeded the terrain they had demarcated for their own social life. At times they manifested a defensive attitude towards such images: Tài stressed that he did not want to be near metrosexual men, Hà said she would feel unsafe with a man who is "too beautiful" and well-groomed, and Vy stressed that such men were "not for me."

What none acknowledged is that "proper" enactment of hegemonic, "normal" masculinity, which they approve of, must also be learned. If, like Butler, we understand gender as performative, then mundane acts, which are internalised and routinely practised, become accepted as reflecting the "truth," or "core" of one's gender. This belief in the "essence" of gender is demonstrated in several examples, such as Hà and Vy's emphasis on "real" men's protective nature. Such beliefs contradict the fact that some traits perceived as inherently masculine require training to become part of a man's habitus (Bourdieu, 1984). "Masculine" characteristics such as protectiveness, when performed frequently enough at some point, unconsciously become "authentic" and trusted as genuine indicators of masculinity. This process of gender performativity reflects Ahmed's remark that "the work of repetition involves the concealment of labour under the sign of nature" (2014, p. 145). Hyper-performances, however, are not accepted because they are too conspicuous. Instead, such performances are marked as "abnormal" and give rise to doubt of authenticity. For example, as some people observe that Vietnamese men are not as passionate in love as K-drama male leads, they may dismiss a man who would sacrifice everything for a woman like in a drama as "unrealistic" or even "ridiculous." The repetitive assertions of Tài and Vy that "even Koreans in real life don't dress that way" and "no man in real life acts like [K-drama] male characters" show how their views were heavily affected by social norms. The prerequisite for acceptability towards a particular behaviour is that many people have done so.

The rule of normalcy also governs terrain where hyper-performed acts are accepted. For example, as Tài said, entertainers "can" be "eccentric" because they work 
in an industry where looking eccentric is not unusual. When placed in an ordinary context, such hyper-performances are marked as abnormal and thus unacceptable. To be appropriately masculine is to fit within the zone of gender intelligibility. Spilling over the edge of intelligibility risks negative judgments. Each person demarcated individual boundaries for performances of masculinity: men can pay attention to looks, but not too much; men can be sweet in love, but not so much that his acts are suspected as "performances." My participants' narratives show how the assumption of a coherent identity position comes at a cost: it requires continuous practices of "producing, excluding, and repudiating a domain of abjected specters that threaten the arbitrarily closed domain of subject positions" (Butler, 1997, p. 149).

\section{Concluding Notes}

The participants discussed in this chapter along with Hanh, Trang, and Nga from Chapter 4 shared resistance towards romanticised constructions of masculinities. All compared Korean men on screen with men in real life, concluding that the former group is only a commercialised phantasmatic construction. The younger female participants in the earlier chapter, however, saw men in Korean dramas as "dream men" and expressed enjoyment in watching them, whereas Tài, Hà, and Vy demonstrated disidentification or a sense of distaste. Lived experiences play a role, as the older participants in this chapter seem to have had more diverse experience, including painful life-changing events, than the previous informants and bear greater familial responsibilities. ${ }^{39}$ The informants' domestic obligations seem to bring them closer to hegemonic ideals of masculinity, which emphasise characteristics such as maturity, breadwinning and problem-solving capacity, responsibility, leadership, and protectiveness - all pragmatic traits that ensure a man can fulfil his socially expected role as head of household and achieve social respect.

By focusing on older participants in this chapter, however, I do not mean to imply that maturity and experience necessarily result in diminished engagement with Korean soft masculinities. As other chapters have shown, some older viewers show considerable interest in romantic Korean dramas and soft masculinities in distinctive ways. Middleclass married women like Thanh and Hà, who share certain living conditions, may hold very different perceptions of soft masculinities, as Chapter 3 and this chapter illustrate. It is important to restate that the key to immersion in romantic pop culture forms like K-

\footnotetext{
${ }^{39} \mathrm{I}$ do not rule out the possibility that the participants in Chapter 4 might have chosen not to reveal distressing events to me. However, with the existing data, this is a comparison I venture to make.
} 
drama is a willing suspension of disbelief, that is, a readiness to indulge, even to forget one's own life at moments of viewing.

This chapter helps partly explain the backlash against soft masculinities in Korean pop culture highlighted in studies such as Ik Ki Kim et al. (2014), Chen (2016), H. Lee (2017), and Ainslie et al. (2017). I have focused on discussing viewers' aversion to Korean feminised masculinities as personally constructed rather than as part of a countering social attitude as in Chen (2016) and Kim et al. (2014). The informants in this chapter have changed their attitude towards soft masculinities due to changes in personal lives rather than larger social influence of such factors as nationalist sentiments, as those studies suggest. Their shift demonstrates how phase of life plays a substantial role in the reception of gender ideals: experience makes people change, and adapting to new life circumstances often requires adjusting views on oneself and the world.

My study of the non-fans (or almost anti-fan like Tài) in this thesis responds to the call for more studies regarding non-fans, who receive much less attention in audience research due to the inconveniences associated with recruiting non-fans and eliciting data from them (Gray, 2003). Wilson (2011), who studies Chinese non-fans' lukewarm reception of Korean dramas, emphasises that research on non-fans and anti-fans is worthwhile when discourses concerned with a genre have extended beyond its content, as in the case of Hallyu products. In Vietnam, much like China, many people do not watch Korean dramas, but become familiar with the romanticism portrayed within them, through knowledge of friends of family members who watch these dramas. Discourses about whether watching Korean dramas is worthwhile or a waste of time, why this genre appeals especially to women, and whether Korean romanticism reflects reality at all have entered social discourses. Studying both fan-like and non-fan experiences helps offer an overall picture of how Korean romanticism and soft masculinities are perceived in Vietnam. 


\section{Chapter 7: Queering Korean Pop Culture}

In his book Making Things Perfectly Queer (1993), Alexander Doty defines "queerness" as "a quality related to any expression that can be marked as contra-, non-, or antistraight" (p. xv). He argues that queer readings and pleasures are pervasive in mass culture because gender representations always carry the potential to trigger "complex, often uncategorizable, erotic responses from spectators who claim all sorts of real-life sexual identities" (xvi). This potential of popular representations to tap into queer desires may be enhanced in an era in which the commercial advantages of appealing to diverse audiences are increasingly recognised (DeAngelis, 2017). As a result, we have come to witness "a significant investment in exploiting ambiguities and continuities between 'cute' and 'sexy,' and between 'soft' and 'hard' bodies" worldwide (ibid., p. 196).

In this chapter, I explore Vietnamese reception of the queer spaces in contemporary Korean pop culture, which increasingly offers alternative gender images, and thereby contributes to an inter-Asia queer scene (Chuyun Oh \& David C. Oh 2017). A growing body of research has addressed queer desires and identifications of K-pop (e.g., Sinnott 2012; C. Oh 2015; 2017; C. Oh \& D. C. Oh 2017; Laforgia \& Howard 2017; Shin 2018, Oleszczuk \& Waszkiewicz 2020), Korean cinema (Jooran Lee 2000; Cagle 2007; Kim \& Singer 2011; Soh \& Ngo 2014; Kwon 2016; Ungsan Kim 2017; Ungsan Kim, 2008) and to a lesser extent, Korean television (Lavin 2015; Chuk Tik Sze, 2016, Glynn \& Jeongmee Kim 2017; Lessard 2019). Notable studies include Chuyun Oh's examinations of how international female fans fantasise about alternative relationships with men, such as one in which women dominate, through their viewing of K-pop male dancers' gender-fluid practices (Oh, 2015; 2017), or Sinnott's 2012 article about Thai women's appropriation of Korean boy bands' androgyny. Despite this growing scholarship, studies of male audiences remain overshadowed by those focusing on female experience, not least because women are more active consumers of Korean pop culture and queer fan fiction (Kwon 2016; 2019). Notably, little research has addressed the consumption of K-pop and K-dramas among non-heterosexual men, whose desire for alternative gender practices and ideals may motivate them to seek alternative representations of masculinity in global media. How do such men respond to images of soft masculinities in Korean popular culture?

To address this question, I consider two queer Vietnamese men's reception of Korean soft masculinities with a focus on where such representations in Korean television dramas intersect K-pop. Without claiming representativeness considering its very small 
sample, the chapter adds to this under-researched topic. I follow the narratives of two queer men, Văn and Huy, whom I met three times and twice, respectively. My encounters were fortuitous as I recruited participants without a specific requirement regarding gender identity. These two informants came of age during a dynamic period of changing gender politics in Vietnam, during which the local LGBT movement has become increasingly vibrant. As a result, the government decriminalised same-sex marriage in 2013 , legalised sex-alteration operations the following year, and has also shown nascent attempts to better protect LGBT rights (see: Huong Thu Nguyen 2016; Mai 2017; Horton and Rydstrom 2019; Horton 2019; Human Rights Watch 2020).

Neither Văn nor Huy consumed the dramas frequently or manifested strong signs of immersion, marking themselves as non-fans like those in the previous chapter. This chapter does not mean to exaggerate the effects of Korean dramas upon them but rather reveals the various interpretations their viewing evoked. Văn watched to relax during free time and to connect with parents and friends. He presented himself as a critical commentator rather than a keen fan. Huy was even less engaged: he only watched dramas shown on local television, unlike most participants who watched those circulated online, following trends and friends' recommendations. Most dramas did not have a lingering effect on Huy, and he could only articulate thoughts following prompts.

In what follows, I consider their accounts of life as queer men in Vietnam before turning to their viewing experience, as such narratives are instrumental to understanding their reception. Both men acknowledged that being non-heterosexual played a role in their perceptions of gender issues and ideals and presented queer pleasures in observing attractive male characters. Moreover, the imposition of social norms exerted contradictory effects on them: Văn wished to break free from heteronormativity, while Huy chose to partly conform, and tempered his identifications with images of soft masculinity.

\section{Life as Non-heterosexual Men}

Văn, 24 years old at the time of our interviews, worked for a non-profit organisation. Văn demonstrated typical traits of the upwardly mobile middle-class: born into an urban family, he was well-educated, well-read, mild-mannered; his plans to study abroad and possibly pursue an academic career played a role in his participation in my project. During interviews, Văn carefully chose words and sometimes used academic terms in English to present ideas. 
Văn went to an elite high school and a recognisable university. His father, who had worked for the air force until retirement, and his older brother, a married pilot, both represent middle-class hegemonic masculinity. Originally from southern Saigon, Văn moved to Hanoi with his family when he was twelve. By the time of the interviews, Văn was living alone in one of his family's houses, which is quite uncommon for young unmarried Vietnamese who generally live with parents. During visits home, Văn occasionally watched K-dramas with his parents. Văn had come out as gay to them in his second year of university, which can be seen as early timing, as Vietnamese young people, especially those who identify as gay, are usually reluctant to tell parents about their sexual life (Trinh et al., 2009; Trần Thanh Hồng Lan, 2016; Dinh \& van Teijlingen, 2019). Although Văn's family did not react aggressively to this revelation, and his father and brother showed general signs of acceptance, his mother continued to hope that Văn would marry a woman someday. Like many Vietnamese gay men, Văn risks being unfilial in living true to his sexual desires (Horton, 2019).

Văn acknowledged that his work in development, his increasing awareness of LGBT activity, and feminism had all changed him. He had wished for the belonging that comes through conforming to traditional gender norms when he was younger but now felt that there was "no need to fit into any particular category." Although Văn previously identified as gay and disavowed sexual feelings for women, ${ }^{40}$ he found himself feeling an attraction to a female friend, which did not develop into a relationship. Knowing that his boyfriend had dated women before him made Văn further question the fixity of sexual orientation. He concluded: "I become increasingly convinced that gender (giới tính) no longer matters." Defining himself as "queer" (he used the English word), Văn asserted, "I want to break free from the mould." Văn used the term "queer," which lacks a close equivalent in Vietnamese, often; its flexibility and foreignness seemed to help him describe non-normative gender identities and practices without limiting their meaning to homosexual connotations. Among my participants, only Văn used this borrowing.

Văn appeared comfortable enough with his sexuality to reveal his orientation to family, friends, and co-workers. He did not flinch at my questions about his relationships and reported his own ways of causing "gender trouble." For example, Văn wore a skirt

\footnotetext{
${ }^{40}$ Văn told me that this attitude previously foreclosed all romantic possibilities he might have with women. This phenomenon is explained by Butler (1997) as the outcome of a desire for a coherent homosexual identity. This desire entails the subject's repeated attempts to dismiss a relationship with heterosexuality and his "overdetermined identification" with homosexuality (p. 149).
} 
during a workshop just to know "what it feels like" and concluded that it felt "normal." He carefully prepared his cross-dressing, however, only changing into the skirt in a restroom upon arriving at the workshop. On the one hand, his skirt-wearing was an experiment in challenging socially imposed ideals of how male bodies should perform. One might say that Văn used his body as a "theatrical device" (C. Oh \& David C. Oh, 2017, p. 13) for mundane activism. On the other hand, his subversive act was practised amidst the relative safety of educated familiars who would not show overt judgmental attitudes. Văn was aware of the risk he might run if he did so outside this safe zone. This awareness of unsafe zones was also evidenced in Văn and his boyfriend's agreement to limit any public display of affection to gatherings with friends, although it was more his boyfriend's concern than his.

Huy, whom I met through another participant's introduction, was 31 at the time of our interviews and working as a tour operator. He showed up well dressed for our two meetings, and his smart fashion style, complete with stud earrings and trendy motorbike, indicated a careful investment in looks. Describing himself as an introvert, Huy was shy and mild-mannered. He shared that he had recently become very busy with work but exercised at a gym regularly to keep fit. Despite a university degree, he did not show intellectual interests, and unlike the articulate Văn, he struggled a great deal during interviews. More than once, Huy said that my questions about his affective reception of Korean dramas were "difficult," indicating that he probably never dwelled on the topic. We experienced long, awkward silences at times, despite his visible efforts to accommodate my research agenda, including watching the drama I hear your voice (2013) to better respond to my questions in the second interview.

Huy was more reticent than Văn about his relationships. Instead of mentioning "my boyfriend," "ex-boyfriend" like Văn, Huy used the ambiguous, gender-neutral term người ta ("that person," "someone," "the other person") to refer to either a boyfriend or a date. He was, however, comfortable enough to tell me that he was "not straight" the first time we met. Coming from a dysfunctional home, Huy described his father and married younger brother as "irresponsible" men who neglect their families. He did not confide much in his parents and had never come out to them. Having struggled to come to terms with his sexuality, Huy reported feeling an "inferiority complex." He had long questioned his sexual orientation ("why am I like this?") before finally coming to accept it. Huy reported his experience of joining an online community for gay people late in high school: 
"I thought I was alone, but then I found out that there were plenty of others [like me]." Such a discovery seemed to give him a sense of comfort and solidarity.

Huy said, "I live a normal life like others, only my preference for dating is different." Huy's frequent use of the term "normal" (bình thường) signals a desire to fit into heteronormative society. It is not uncommon for the adjective "normal" to recur in nonheterosexual people's narratives in both Vietnamese discourse and other contexts (Renold, 2004; Trần Thanh Hồng Lan, 2016; Baudinette, 2017). Trần Thanh Hồng Lan (2016) reveals that some Vietnamese gay men seek to maintain a "healthy" lifestyle to prove themselves "normal" and be socially accepted. Such a desire may come from a traditional stigma against homosexuality as a disease, which was perpetuated until the recent LGBT movement (Richard Quang-Anh Tran, 2014; Horton, 2014; Trần Thanh Hồng Lan, 2016). In contrast to the more experimental Văn, Huy subscribed to more dichotomous notions of gender. He expressed preferences for boundaries to gender performances and, to some degree, has lived by regulatory ideals of heterosexuality (Butler, 2004). While maintaining a non-judgmental attitude towards friends' overt performances of gayness, Huy set a boundary for himself:

I want to make sure not to make a fool of myself (giũr sao cho không bị quá lố). I look like a boy, so I need to dress appropriately. I can dress up, but not to the point of wearing women's clothes. And I wouldn't gesticulate flamboyantly on the streets (ra đường hoa chân múa tay ẻo lả).

Huy revealed his wish for coherent, consistent gender identity, to fit stereotypes of how a male looks and acts, but to engage in same-sex relationships, which remain in the private sphere. He displayed a desire to be recognised for similarity to heterosexual men, not difference. Huy's rule of not showing effeminate mannerisms may derive partly from his awareness of public aversion towards non-normative gender practices. Societal expectations demand that local gay people "keep a low profile" and confine same-sex intimacy to the private arena rather than the public sphere (Thi Huyen Linh Nguyen, 2019, p. 548). Looking and acting conspicuously gay in Vietnam may result in homophobic harassment (Horton, 2014).

Huy wished for "more accurate" representations of gay people on local television and cinema because "gay characters tend to appear effeminate (ẻo la ${ }^{41}$ ) and wear women's clothes, so people think all gay guys are like that." Vietnamese media often

\footnotetext{
${ }^{41}$ Note also Vy's similar use of ẻo lả in Chapter 6 (page 147).
} 
portray male homosexuals as excessively effeminate and use them for comic relief (Thi Huyen Linh Nguyen, 2019), which may come from a historical conflation of homosexuality with overemphasised femininity (Richard Quang-Anh Tran, 2014), and reflect a social wish for gender coherence: if a male-born person desires a man, the person is no different from a woman. Such reductive logic, as Butler (1993) would argue, aims to maintain the "illusions of continuity between sex, gender and desire" (p. 317). Attitudes toward gender aside, drawing attention to one's sexuality also conflicts with a Vietnamese cultural reluctance to express the individual self in public (Nualart, 2016, p. 4; Charton \& Boudreau 2017). In other words, those who are gay are portrayed as eccentric others, which emphasises a distance between them and the heterosexual majority. To advance the Butlerian line, Huy foreclosed acting camp in a wish to be recognised as "normal." At the same time, Huy's objection to such stereotypical representations can be seen as a resistance to being reduced to a simplified gender identity and to the restrictive view that sees homosexuals as inauthentic imitations of heterosexuals (Doty, 1993; Butler, 1993). Huy's decision to pass as straight in public, however, does not dictate his private life. While keeping up his appearance of "a boy," Huy prefers to assume a more feminine role in a romantic relationship. He likes his lover to look "manly" and be "gallant" (a popular ideal for masculinity, as shown in previous chapters):

With friends, I'm flexible. If I can, I'll treat [them]. But on a date, I want the other person to be a little gallant. I'm not short on money, but I want to feel that they are trying to please (chiều) me and dominate me (trên cơ mình) a bit.

Huy's ideal of male gallantry suggests that he prefers adhering to Vietnamese heteronormative dating practices, with one party (his partner) playing a breadwinning and pursuing role while the other (Huy) is pursued. A romantic partner who is trên co', as Huy indicates, should be able to display his greater economic power and use it to please Huy; he should be willing to pay, the same way Vietnamese men often pay on dates to exhibit their potential ability to financially support women. This preference applies to dates only, as Huy stressed that he did not want to financially depend on anyone. Huy's adherence to heteronormative gender norms is not uncommon among local queer people (Yên Mai, 2017). 
Văn and Huy both share the unpleasant memory of being teased by schoolmates for not being "strong" and "manly" enough. Văn noted being called "womanly" (đàn bà ${ }^{42}$ ) and pê đêt (a derogatory term for homosexual males) by peers at secondary schools. This experience of harassment due to a failure to perform heteronormativity is common among Vietnamese homosexual adolescents (Human Rights Watch 2020). Both Văn and Huy ignored the harassment and avoided lashing out in response. They seem reconciled to the fact that people need time to accept homosexuality. They come out to those they are comfortable with and are more cautious with others. Their cases show how gay people carve out possible spaces to manage on "the sexual margins," as Butler (1990/2006) terms it (p. xxviii). Both Văn and Huy's life stories show personally and socially applied constraints. Văn wished to break free from heteronormative norms but was aware of the limits to what he could do and therefore restrained his gendered experiments and romantic practices, while Huy made sure not to appear conspicuously effeminate and draw social disapproval, seemingly due to his consciousness of social prohibitions and his desire to fit in. The following section will unfold the men's queer pleasures in watching soft masculinities and their construction and negotiation of gender ideals.

\section{Reception of Soft Masculinities and Gender Ideals}

For Văn and Huy, the representation of masculinities in Korean pop culture offered queer pleasures. Both acknowledged that they probably gazed at male stars more often than their straight peers who also watch Korean dramas. Văn elaborated, "They [his male friends] wouldn't say that the captain [in Descendants of the Sun] is handsome," but would praise the female characters' beauty instead.

As Wetherell and Edley (1999) put it, "recognised social ideals (such as macho man) can act both as a source for invested identity and as an 'Other' to position oneself against" (p. 351). Văn distanced himself from the macho man and often used the generic term "traditional masculinity" to describe male behaviours in patriarchal cultures that allow men to display their spatial and symbolic domination, such as smoking, swearing, acting violent, and passing objectifying judgments on women's bodies. Corresponding to his wish to "break free," Văn celebrated non-conforming gendered performances. Drawing a distinction between Western and Korean representations of masculinities, he pointed out

\footnotetext{
42 The meaning of đàn bà in this context is different from the use of đàn bà in Huy's later discussion of male pettiness. The meaning of đàn bà here seems to denote feminine mannerisms only.

43 Pê đê generally connotes negative judgment, but recently has been used by members of the LGBT community themselves to de-stigmatise and normalise the term.
} 
that male characters in Western TV shows and films tend to look tough and strong, be protective of others, wear suits, swear profusely and demonstrate violent behaviours. He found such representations "boring" and "predictable." For Văn, Korean pop culture, on the other hand, has diversified ideals of masculinity by showing variations, such as men with smooth, pale skin and make-up, men who are thin and tall rather than muscular, or who charm people with displays of cuteness. Văn pointed out, with a hint of amusement, that one would never find in a Western show a man making a heart (thả tim) with his hands, wearing a face-cleansing mask to maintain his skin quality, or kissing a piece of fruit, as in Korean pop culture. These new representations of masculinity, for Văn, helped broaden public imagination of what a man could be like.

When asked about his ideal of masculinity, Văn cited Captain Yoo Shi Jin Descendants of the Sun, who is also the favourite character of An (Chapter 2), Thanh (Chapter 3), and Toàn (Chapter 5). According to Văn, Yoo is "cool, which means he is cold, decisive, knows what he wants, but looks a bit queer"; "not so muscular, not so crude"; "a bit scholarly-looking (thur $\sinh ^{44}$ ) but still shows decisiveness and physical strength." Văn also noted how Yoo is expressive and affectionate in love but controls his emotions at work, in the sense that he remains calm when incidents occur and focuses on solving problems. Stressing that he admired Yoo's decisiveness, Văn said the attribute is not exclusively a male trait. "My boss, a woman, is decisive and I like that too," he added. According to Văn, in displaying traits stereotypically associated with femininity and masculinity, Yoo exhibits a multi-faceted character worth watching. In contrast, Văn disliked Sergeant Major Seo, Yoo's co-worker, who shows "traditional" masculinity: darker skin, a rugged face, and maintaining a stiff upper lip. Seo's rigidity made him difficult to relate to for Văn; he stressed that he preferred multi-faceted characters, who enable him to observe development over time and human complexity (note Hà's opposite reaction in Chapter 6, who preferred Seo to Yoo). This preference indicates that Văn did not approach characters as ideals so much as stories that invite explorations.

Văn expressed amusement in response to photos of actor/singer Rain and found it "interesting" that Rain exhibited versatile masculinity by blending style codes, at times showing a muscular body and chest and gazing away coolly while keeping his hair long and feathered, and at others making cute hand gestures, wearing a green baggy V-neck jumper with a violet collar or a violet silk scarf. Văn said he liked "hybrid" and "queer" looks. Văn also enjoyed other Korean entertainers with non-conforming gender practices,

\footnotetext{
${ }^{44}$ See Literature Review and Contexts for an explanation of the construction of the scholarly masculinity present in some Asian cultures, including China, Korea and Vietnam.
} 
such as G-Dragon, a member of the boyband Big Bang, known for wearing metallic, bright-coloured outfits and accessories that resist more typical male styles. G-Dragon also draws attention to gender playfulness, including cross-dressing practices. Văn said he would like to try glittery outfits like G-Dragon's, stressing his own experimental attitude that seemed to respond to invitations made by androgynous entertainers like G-Dragon to consider bodies as sites of potentiality. When shown an image of a man crying (from Reply 1988), Văn celebrated the image and similar scenes in K-dramas:

He does not hide his tears or cover his face, he just cries. I like natural emotional expressions. There's nothing to hide...I think...I prefer this to [someone] casting their tears away and saying that men don't cry. I like these sincere expressions of emotions, not hiding anything. But I don't know why... somehow in Korean dramas, people look beautiful even when they're crying, men or women. I mean... I quite like that kind of freedom.

Văn saw the image as a symbol of freedom, in which a man permits himself to express his emotions, signalling resistance to the cultural repression of male vulnerabilities. More broadly, scenes of men expressing feelings and crying in Korean dramas offer male viewers struggling under patriarchal norms an outlet for emotional release (Lin \& Tong, 2007). As this example and the earlier ones illustrate, Văn's identification with soft masculinities is connected to his experience of having to restrain traits treated as "unmanly" by society.

Such identification, however, did not come with suspended disbelief for Văn, who regarded this image as a commercialised, packaged product of Korean pop culture and discerned the aestheticising tendency of Korean dramas to show characters as beautiful no matter what. Indeed, recent dramas have tended to treat male faces in tears as spectacles that are attractive and evoke sympathy. This aestheticisation of the crying face suits a Vietnamese cultural "vindication of beauty," which may tolerate aesthetically pleasing non-conforming gender representations that could be otherwise frowned upon (Nualart, 2016, p. 8). The cult of beauty may grant attractive non-conformers more acceptance while rejecting those deemed less visually pleasing. Văn also noted the dramas' strategy of glamourising men who are cooking by displaying them neatly dressed in the kitchen and, as Văn noted, "skilful like a chef." He viewed such filming tactics as creating "the myth of the dream man" (huyền thoại soái ca), noting that he borrowed French philosopher Roland Barthes's idea. The ultimate effect renders these men attractive and "cool" when working in the kitchen, a traditionally feminine space. In 
drawing attention to the deliberate construction of the dream man as a myth, Văn presented himself as an audience member with critical acumen who enjoyed the myth but also approached it with a sense of alienation.

Just as Văn celebrated alternative representations of men as feminine and vulnerable, he also enjoyed portrayals of women as strong, independent, decisive, and professionally capable because he thought they reversed gender stereotypes. He expressed a particular appreciation for stuntwoman Gil Ra Im in Secret Garden and surgeon Kang Mo Eun in Descendants of the Sun, both of whom are devoted to their professions, and commented that his own inability to take pride in a marginalised sexual identity made him relate to Gil for the discrimination she suffered as a poor orphan.

Like Văn, Huy acknowledged that Korean pop culture represents unique forms of masculinities that distinguish themselves from Western archetypes. Huy spoke of "sweet" (ngọt ngào) and "baby-faced" handsomeness, which runs counter to the Western "man's man," but did not express a preference, saying that each has its own appeal. Nevertheless, Huy said he could relate better to Korean male representations because of the racial proximity. For Asian consumers like Huy, just like Japanese fans in Lie's 2016 discussion, Korean male stars may "occupy the right distance" because they are tall and attractive foreigners but remain approachable since they do not look too different (p. 129).

Huy's description of Korean soft masculinities as "sweet" (ngọt ngào) connotes not only an aesthetic quality but a man who is warm and eager to please others, in opposition to "tough" masculine archetypes. Huy's embrace of "sweet masculinity" is revealed in his enjoyment of situations in which a man expresses affection to his lover, which Huy said he sometimes wishfully imagined being part of. For example, Huy liked a scene from I Hear Your Voice (2013) in which a man hugged a woman from behind. The man, much taller than the woman, exudes protective warmth, gentleness, and devotion. Upon noticing Huy's ambiguous expressions concerning romantic practices, I ventured to ask: "Would you like to be the one being hugged or the hugger?". ${ }^{45}$ With some hesitation, Huy answered in a lower tone, "hugged," and added, "but it depends [when it comes to other romantic scenes]." Huy's enjoyment of the scene, marked by his wishful imagination of

\footnotetext{
45 This moment made me ponder a methodological question: should I always stick to the FANI method (which is against closed questions) or should I allow occasional flexibility? While my question may have limited Huy's answer and appeared rather forceful, the result did help consolidate my sense of the queer pleasure he took from Korean dramas. Without such specific question, Huy would probably always remain ambiguous.
} 
being hugged by an attractive man, suggests queer pleasure, which he possibly hesitated to reveal due to unease about discussing his sexuality in detail. Such pleasure may have been disguised by general expressions such as "exciting," "enjoyable," or "fun" that Huy used to describe his reception of romantic scene and soft masculinities without articulating further how much enjoyable a scene was for him.

Huy's desire to fit in and the influence of norms seemed to make it difficult for him to identify with all aspects of soft masculinities. For him, some representations were attractive and admirable, while others went too far due to what he saw as effeminate stylings. Huy approved of Rain's photos where he shows his muscular chest and looks indifferent and gazes away but dismissed others in which the singer wears a V-neck sweater and a violet silk scarf. Huy found the former pair of photos sexy and the latter "too womanlike." However, Huy enjoyed the image of Rain giving a sweet smile and creating a heart shape with his hands curled over his head, calling it "lovely" (đáng yêu). It appears that Huy does not associate such performance of cuteness with effeminacy. His positive reaction here resonates with studies by Sherman and Haidt (2011), Nittono (2016), and DeAngelis (2017), which underscore how cuteness exudes warmth and elicits social engagement as well as a positive attitude towards those who display it. His reaction is also congruent with the Korean view of men's aegyo as a way to show affections and please others (Han, 2016).

Huy enjoyed representations of soft masculinities as long as they did not show what he regarded as effeminacy. He liked actor Kim Bum's appearance and described Kim as "scholarly looking" (thư sinh) and "mild-mannered" (trông hiền), suggesting an appreciation of non-aggressive, approachable looks in men. While Huy said Lee Jong Suk's "childish" face and mannerisms did not impress him, he regarded Lee "cute" (dễ thương) and "lovely" (đáng yêu) in some photo shoots. For Huy, Lee, an icon of soft masculinity, like Kim, seems to embody an alternative type of attractiveness, even though Lee was not a "man's man." Nevertheless, for his ideal of masculinity, Huy, more conventionally, preferred maturity. Huy said he especially liked Song Seung Heon as a gangster in East of Eden (2008-2009), where Song looks "cool" (ngầu) and seductive. He also praised actor Lee Dong Wook for his mature, gentlemanly looks. Both middleaged actors are regarded as symbols of masculine wealth and success. This praise seems to correspond with Huy's preference for a man who could play a dominant role as a potential lover. 
Huy manifested ambivalence towards Korean men's attention to looks. On the one hand, he approved of some male entertainers' careful grooming and extolled images of men displaying a well-built naked torso as "gorgeous," without elaborating. Evoking the demands of modern life, Huy underscored the need to look good for others, echoing Ninh's view of self-care as public service in Chapter 5. He stressed that within the gay community, looks are of utmost importance: "It's said that what's inside is most important, but these days, if you're not good-looking, you can't make an impression and make people want to explore what's inside." Supporting this view, Huy said he often dressed up "a little" to look chic and applied basic skincare products. On the other hand, Huy stressed that "some attention is good, but I don't like going overboard," objecting to Korean men's excessive use of make-up. Unlike Văn, Huy did not like the crying man image, finding it "too sentimental." Like Minh and Kim in Chapter 2, Huy said he would feel moved if a male character cried for a "valid" reason, such as when a loved one dies, but he did not like it when they cried a lot for love: "it would be weird for a man to cry a lot in love," while women can do so because "girls are already emotionally weak (yếu đuối)." Huy also shared the following view, which marks masculinity as different from femininity:

I don't think manliness necessarily lies in appearance. Appearance is just one dimension. Manliness is about a man's way of thinking and acting. Many men are straight but very womanly (đàn bà). They are petty (nhỏ nhặt), trivial (chi li), not generous (phóng khoáng). Men need to be a bit generous, should not be nitpicky (so đo), and must act decisively (quyết đoán). Looks are only part of it. When we see someone, we may say, "Oh, he looks so manly," but their behaviour isn't in sync with their looks.

While Huy challenged conventional judgments of gender by looks, he drew on a traditional Vietnamese logic that sees men and women as inherently different. The term phóng khoáng combines the meanings of "generous", "open-minded" and "liberal," and Huy used it to indicate both a willingness to spend money (probably in a social gathering or in a relationship), a receptiveness to others' ideas, and the tendency to not hold grudges. Social expectations maintain that because men neither pay attention to details and resent others nor lament their disadvantages in "small matters," they are more generous than women. In Vietnamese culture, small-minded women are generally tolerated because the tendency to nitpick and gossip are conventionally seen as in women's nature. This essentialist gender differentiation is reinforced and practised in both everyday rhetoric and ways of living (Leshkowich, 2014; Linh Khanh Nguyen, 2016b; Minh, T. N. Nguyen, 2019). Again, by setting gender boundaries, Huy shows how "the 
norm governs intelligibility, allows for certain kinds of practices and action to become recognizable as such, imposing a grid of legibility on the social and defining the parameters of what will and will not appear within the domain of the social" (Butler, 2004, p. 42).

\section{On Romance}

Like most participants, Văn and Huy appreciated the intricacies of romance depicted in Korean dramas. Văn said, "life is not as romantic as in Korean dramas, so we watch to experience romanticism," adding that viewing gave him various emotions: "Even if [a drama] is sad, it's the kind of sadness I can endure." His statement evokes Geraghty's (1991) comments regarding the affective impact of soap operas: "Soaps offer a continually shifting kaleidoscope of emotional relationships which allow the audience to test out how particular emotional variations can and should be handled" (p. 41). Huy likewise enjoyed meticulous depictions of romantic progress, such as how some K-drama couples move from mutual dislike to love. Huy shared that the portrayal of budding romance and its progress intrigued him. For Văn and Huy, following a fictional romance thus felt like a vicarious experience of love, in which moments of both euphoria and conflict (at times depicted comically) could be pleasurable. Watching a love story from the beginning until its usual happy end offered them a warm feeling of fulfilment.

Văn and Huy acknowledged that Korean dramas inspired audiences to practise caring gestures with lovers. Văn noted that the dramas' portrayal of obstacles, including even life-threatening situations, reminds viewers of the precarity of life and the need to value their relationships. Likewise, Huy noted that by showing the way couples treat each other, Korean dramas gave instructions on how to become a better romantic partner. Huy cited a situation in I Hear Your Voice, in which the female protagonist turns away from a necklace in a store because it is expensive. The male lead, however, returns to buy it for her, knowing that she likes the item. Huy said, "I like being surprised," implying that he wished to be treated the same way. The character's behaviour fits Huy's view of an ideal lover as someone who performs gallantry as a provider. Huy noted that he liked to surprise a romantic partner as well. According to Huy, Korean and other romantic Asian dramas provide viewers with scripts to emulate and, therefore, may help enrich their own relationships.

Thi: Do you have any specific imagination [of a romantic scene], like a specific drama or a specific act? 
Huy: Scenes of a sneak kiss, for example. I find those lovely. Or a surprise, like taking someone to a place decorated with flowers, or holding a surprise party for the other person. I remember the scene of [a couple] cycling side by side between a line of trees [referring to a scene in Winter Sonata shown to him earlier]. I find that scene very beautiful too.

Thi: Have you ever tried [any of those things]?

Huy: Yes, I have. For example... Not so long ago. To mark [our] one-month anniversary, I casually asked that person out somewhere. Upon arrival, as a surprise. I offered a gift and explained what the day meant.

Here, Huy mentioned romantic practices that entail preparation, emphasising the importance of "surprise." Huy said, however, that not all Korean romantic scripts can be emulated because they involve a public display of physical affection. He added that it would be "embarrassing if people look," implying consciousness of public scrutiny of gay romantic practices. His reticence again reflects his self-policing that confines same-sex romantic displays to private space.

Văn and Huy also pointed to unrealistic portrayal of romance in dramas. Văn said with a chuckle, "Korean dramas always end when couples get back together. We never know what happens afterwards", highlighting his awareness of the dramas' failure to portray the stresses and strains of everyday life and their effects on romantic relationships. Huy said he did not view the happily-ever-after trope as realistic, stressing that "it is all part of a script." Indeed, Korean dramas often make use of the "dominant happiness script" (Ruti, 2018) that perpetuates a heterosexual romantic utopia.

Lived experience seems to play a role in the ways Văn and Huy responded to this dominant happiness script. Văn's parents got along well, and his older brother appeared to have a successful marriage. Although he had had relationships that did not end happily, Văn occasionally mentioned a future with a permanent partner, perhaps his current boyfriend, but said he did not expect his relationship to be as romantic and "eternal" as in dramas. Nevertheless, he was not pessimistic about his romantic future. Huy showed himself as less optimistic and attributed his caution to unhappy marriages around him:

I don't really long for marriage. I've seen lots... my parents, my younger brother. I feel that marriage really ties people together, you have to take a lot of responsibility. If you can't fulfil those [responsibilities], you shouldn't [get married]. 
Everyone wants to be happy but it's not necessarily happiness if you force yourself to live with someone.

While acknowledging K-drama romance as an ideal to look up to, Huy pointed out how experience made him realise that life operated differently. He noted that, in contrast to how K-dramas make conflict comedic and amusing and can turn it into romance, differences in real relationships were not easy to overcome. Huy said that without obvious obstacles, relationships (including his own) can still end because of differences in personality and lifestyles. According to Huy, true happiness in married couples is rare. When he spoke of people ending up permanently happy, he mentioned real-life couples that he knew of rather than K-dramas, further underscoring his view that only reality counts. At the same time, by pointing out that marriage is not a must, Huy manifested his resistance to a dominant happiness script and a refusal to live the false hope of a hegemonic heterosexual ideology (Ruti, 2018).

Huy also cited both his own dysfunctional family and the norm of non-commitment in the gay community as reasons for his pessimism:

In my community, people meet, decide that they like someone at first sight and it [a relationship] begins. There's no finding out about each other. They care a lot about looks. They decide immediately.

Huy compared contemporary homosexual relationships to "instant noodles," emphasising their transience, and he noted that it was difficult for gay men, including himself, to remain faithful to a single lover. The reasons he cited include an obsession with looks, an inability to resist temptation, and a lack of legal and social mechanisms to keep same-sex couples together. He pointed out a dilemma of modern life: the abundance of choice clashes with a yearning for meaningful love and commitment (Illouz, 2012). However, one needs not view the tendency towards non-commitment negatively. If non-commitment can be seen as a form of freedom, then this freedom is inaccessible to most heterosexuals. As Ahmed (2014) notes, queer people are "free from the scripts of (hetero)normative existence" (p. 164). Huy's matter-of-fact attitude means he does not form expectations but accepts reality as it is.

\section{Concluding Notes}

Văn and Huy's reception of soft masculinities and romantic Korean dramas reveal different outcomes of the imposition of hegemonic gender norms. For Văn, cultural 
insistence on gender differentiation caused a feeling of alienation and boredom with patriarchal masculinity, motivating him to identify with feminised masculinities. The same social mechanism, on the other hand, made it difficult for Huy to identify with androgynous representations. Nevertheless, watching romantic Korean dramas enabled both to enjoy elements of queer pleasures, including gazing at well-groomed, handsome men, enjoying alternative performances of masculinity, and engaging with romantic situations.

Although the two informants largely enjoyed romantic portrayals in Korean drama, they showed awareness of the genre's construction of a utopia in which love gives life an all-encompassing meaning. Văn underscored how the dramas keep creating "myths" through perfect male protagonists and happily-ever-after endings, while Huy resisted the heteronormative trope in his refusal to see marriage as a necessity. Korean romantic narratives were viewed as ideal but remained a domain of entertainment, with which they could engage while also maintaining distance. Like previous chapters, this chapter foregrounds the influence of local norms on K-drama consumers and how their engagements with fantasy relate to their own sense of reality.

With only two non-fan participants in my sample, it is difficult to make broader inferences about whether Korean drama as a genre particularly resonates with Vietnamese queer men's gendered desires. This chapter, however, contributes to the under-researched scholarship regarding queer media reception in Vietnam, despite the growing consumption, especially by youth, of local and international media products catering to queer pleasures (Lan Duong, 2017; Nguyễn Thị Kiều Anh \& Nguyễn Thị Thanh, 2018; Thi Huyen Linh Nguyen, 2019; Trịnh \& Nguyễn, 2020). The articles by Trịnh and Nguyễn (2020) and Nguyễn Thị Kiều Anh \& Nguyễn Thị Thanh (2018), for example, provide introductions to the presence of Japanese and Chinese boys love and queer fiction in Vietnam, but do not discuss audience consumption in detail. Studying queer consumption of foreign pop culture in particular would reveal the intricacies of queer consumers' emotional worlds, especially where local media foster stereotypical views of queer people and reinforce biases rather than portraying them as complex gendered beings (Bui Thi Thanh Hoa, 2018; Thi Huyen Linh Nguyen, 2019). In light of the existing interplay of various, even contradictory, discourses that inform the lives of members of the LGBT community, this line of research promises fascinating findings. 


\section{Conclusion}

As the thesis nears its end, let me remind readers of the key themes that my research questions sought to address. First, the thesis has explored how the gendered desires of Vietnamese viewers in their 20 s and 30 s interact with their experience of viewing soft masculinities in Korean television dramas. Second, it has scrutinised how these viewers identify or disidentify with soft masculinities and has elucidated the psychosocial meanings of their (dis-)identifications. Third, the thesis has investigated the ways in which these desires and (dis-)identifications are linked to gender negotiations. To conclude the thesis, I first present my reflections on methodological contributions and limitations, and then summarise my primary findings and discuss how these findings address the research questions.

\section{Reflections on Methodologies}

With its focus on significant biographical details, my study has delved deep into the individual experience of viewing. To gain psychosocial insights, the study has pursued an interdisciplinary approach that combines the theories and analytical tools characterising sociology, psychology, psychoanalysis, cultural studies, queer theory, and poststructuralist philosophy. In joining the nascent application of a psychosocial approach in audience research shown in Cohen (2012), Whitehouse-Hart (2014) and Johanssen (2018a; 2018b), I hope that the thesis helps pave the way for further audience research using this innovative method. By depending less heavily on psychoanalysis than the mentioned psychosocial audience studies, I also hope that the thesis proves more approachable to academics in other disciplines and the wider public.

My thesis also contributes to a broader body of empirical research using narrative interviews with a focus on life stories as its primary method. A strength of such a project, as Chawla (2006) points out in her review of research into life experiences, is its focus on "life-span perspective" (p. 361), or attendance to the impact of past experiences on informants' feelings and behaviours. While a method involving multiple interviews within a short period of time is not the best way to capture the diachronic changes over an individual's life span that longitudinal research would reveal, its retrospective approach helps unfold formative events in people's life (in this case, influences on informants' gender views). My study has shown how attending to informants' current phase of life in relation to their past experiences is instrumental to understanding their worldviews, because the lifestyles they can afford, the obligations they bear, and the positions they 
hold play considerable roles in the construction of their visions. The significance of informants' phase of life is shown prominently in Chapter 6, where the informants showed a remarkable shift in attitudes towards romantic Korean dramas and soft masculinities as they matured and took greater familial duties, especially in comparison with younger informants who were enjoying a more carefree life. The role of changing phase of life in individuals' reconstruction of gender ideals and practices has been observed in studies such as Minh. T. N. Nguyen (2018a), which show how turning points such as getting married can change men's self-image and worldviews. As Cook aptly puts it:

(T)he performativity of masculinities is not uniform or un-contradictory across different spheres of life. Instead, at different stages of life and in different spheres of life at the same time, the different demands of masculinities are performed and performative, often in contradictory ways that change over time. (2007, para 25)

There are, however, challenges to the practice of Free Association Narrative Interview method. As I have specified in Introduction, FANI aims to invite informants to tell a story and, ideally, structure the interview themselves with little intervention from the interviewer. Narrative interviews that took place within this project and elsewhere (e.g., Byrne, 2003), nevertheless, show that not all informants are inclined to tell a story with minimal prompts. Except for female informants in Chapters 2 and 3, most of the other informants featured in my later chapters struggled to tell a story smoothly. Some had difficulty discussing events in their lives, or the K-dramas they had watched and even enjoyed. Not everyone came to an interview with a story waiting to be told. Some informants' narratives were constructed with continuous prompts from me. If "free talk" is understood as a smooth narrative produced without much prompting, some informants' narratives would not count. This challenge seemed to make interviews appear less satisfactory than expected during research encounters. I find it important to highlight this challenge and thus suggest other academics who consider the same method prepare for it. In my case, to cope with this difficulty, I resorted to visual aids, which had indeed helped facilitate the flow of narratives. Displaying photos and showing extracts from K-dramas had enabled struggling informants to engage better with the topic of soft masculinities, which they probably had not really pondered upon prior to the research encounter. These additional methods had allowed me to elicit important data that might have been otherwise missed.

The study's reliance on narrative, which is the strength of the method, also comes with a limitation. Using a style that unfolds stories in its focus on individual experiences 
has made it at times difficult to discuss many participants' experiences together for compare and contrast purposes, as doing so may disrupt the overall narrative flow. I could not, for example, bring all participants' responses together to discuss how they reacted to metrosexual images or the images of men cooking because all the space available has been reserved for discussing individual experiences. This limitation may be a common problem facing most narrative studies, not just FANI research, as narratives tend to be multi-layered and the prioritisation of individual case studies cannot always be reconciled with other possible models of analysis.

As an innovative in-depth model of investigating individuals' inner worlds, including their unconscious drives, FANI might face charges of over-interpretation. For some scholars, psychosocial research might give the impression of understanding about the informants more than they know themselves and cast their experiences as more complex than they actually were (Frosh \& Baraitser, 2008). In response to the latter charge, I side with Whitehouse-Hart (2014, p. 183) in arguing that viewing experiences are intricate and thus deserve in-depth, multi-layered interpretation for its potential of producing various insights. To take viewing experiences lightly, I contend, would be wasting insightful data about audiences. In response to the former charge, I agree on the risks of "wild" interpretation and misinterpretation, hence the need for caution in handling data. Throughout the thesis, I presented how the informants made sense of their own experiences by citing their statements and my interpretations of such narratives, which can be traced to evidence within their narratives. In addition, I occasionally showed how informants' narratives were produced in response to my questions, thereby revealing the linguistic and conversational context of narratives. My frequent use of direct quotes from informants and presentation of the contexts in which these texts were presented has helped offset the risk of overinterpretation and offered possibilities for alternative interpretations, should any scholar wish to pursue this endeavour. I acknowledge the fact that there is no single way of interpreting a story and agree with Bhattacharya's (2016) call for "embracing multiplicity" in narrative research. I hope to have been able to shed light on informants' compelling stories and add insight to the existing wealth of audience research and Hallyu reception studies.

\section{Summary of Findings}

My study has demonstrated that audiences' viewing experiences are intimately connected to biographical factors and living circumstances. This finding corroborates Whitehouse-Hart's (2014) idea that "viewing is psychosocial", which underscores 
audiences' use of media texts for both psychological and social needs. In particular, the study has explored the personal, mostly affective meanings of viewers' narratives, driven by relevant lived experiences and attendant feelings. At the same time, it has shown how narratives that come to the fore as a result of social discourses like traditional gender norms and feminist ideas reveal desires for belonging to a community or projecting a particular identity (Archard, 2020).

FANI helped me explore aspects of viewers' inner worlds in ways that were illuminating and enriching, which might not have emerged with an interview method that does not attend to biographical details and encourage free talk. Soliciting broad narratives through open-ended questioning allowed me to construct a vivid picture of informants' lives. This portrait includes salient details on familial background and lived experiences. Although at times the information initially seemed unrelated to the research questions, often it was later found instrumental to understanding how informants' visions and viewing experiences were shaped. Explicit and implicit reasons behind informants' consumption were made visible through applying FANI's interpretative method of forging links between the narrators' biographical details and viewing experience. Furthermore, the method's distinctive strategy of attending to both the content and performance of narratives has helped me understand why informants relayed their stories as they did. The ways they presented themselves as mature adults (Chapter 2 and 6), a family man (Chapter 6), progressive men (Chapter 5 and 7 ), and independent, pragmatic women (Chapter 4) mattered a great deal. Attending to both biographical details and self-presentation has allowed me to examine how gender views were shaped by conscious and unconscious motivations, formed through continuous engagements with social discourses and dominant ideologies. Referring back to my argument about the interactions between gender performances and gender performativity (p. 25), it follows that the informants' reactions to soft masculinities - a set of performances of masculinity on screen, are forms of gender performativity informed by various contributing social discourses.

My thesis also highlights the diversity of viewing experiences by expanding on existing audience research, which at times essentialises audiences or identifies general trends rather than examining individual perspectives. Viewing involves an intricate process that has multiple meanings dependent on individual needs and desires and thus results in varied patterns of gendered identification, desire, and negotiation. As my empirical chapters have shown, these patterns can include such themes as escapism, 
parasocial interactions, romantic imaginations, melancholia, desire for upward mobility, queer pleasures, ambivalence, and disidentification.

For example, An's (Chapter 2) emotional involvement with Korean dramas and male characters can be traced to her loneliness, alienation, self-positioning as invisible and a desire for recognition, while a lack of emotional fulfilment seems to have motivated Minh, Kim and Thanh (Chapter 3) to engage with K-drama love stories. Thanh's enjoyment of dramas appears directly related to her dissatisfaction with a passionless marriage and a desire for an ardent love she had never had, which suggests an experience of melancholia. For Toàn, Ninh and Vinh, the male informants in Chapter 5, engagements with autonomous, often privileged male characters seemed linked to desire for upward mobility, modernity and a concern with practices to enhance minds and bodies. Tài, Hà and Vy in Chapter 6 moved from an embrace of soft masculinities to a rejection of these constructions. Their disidentifications correlate closely with their changing social positions as mature adults and parents. The non-fans in Chapters 4 and 7 manifested little emotional investment in soft masculinities but took pleasure in viewing these images due to how they facilitated stress relief and queer pleasures. My study has shown that attending to both fan-like and non-fan involvements in audience research helps capture the varieties of media engagement in fruitful ways. If, following Gray (2003), such an awareness helps us consider how particular media texts "fit into society" (p. 77), then my study reveals both acceptance and rejection of aspects of soft masculinities.

The research attests to the polysemy of soft masculinities. Gender ideologies often influence how audiences receive soft masculinities, but not always predictably. One might be tempted to draw a correlation between progressive gender views and acceptance of soft masculinities, but the situation often revealed itself as more complicated. Indeed, Tài and Hà, who upheld traditional heteronormative ideas, disapproved of soft masculinities because of their perceived association with effeminacy and non-pragmatism. However, An, Minh and Kim, who adhered to aspects of patriarchal ideals, embraced soft masculinities because these representations blend highly valued qualities such as power and leadership with "feminised" traits such as emotional expressiveness and gentleness, which facilitate a companionate relationship. Hạnh, Trang and Nga in Chapter 4, who held more egalitarian views and indeed enjoyed soft masculinities, refused to take these images seriously. As I have emphasised throughout my thesis, informants presented their gender views and perceptions of soft masculinities according to a personalised logic, rendering easy assumptions about the association between gender ideologies and views of soft masculinities problematic. Complex reactions to soft masculinities correspond to 
the polysemy of soft masculinities, which can simultaneously comply with and subvert patriarchal gender norms.

As I conclude, I want to re-emphasise the extent to which the interplay of multiple formative influences shapes gender views. In showing how participants internalised traditional norms and negotiated or even resisted them, my study contributes to a "rethinking of the violence of the gender ideal" (Butler 1992, p. 85). As most chapters demonstrate, adherence to gender norms demarcates boundaries for performances of masculinity, by which non-normative performances are often judged as inauthentic and undesirable. At the same time, my analysis illustrates how television drama can function as a site of play (Briggs, 2010) that complicates conventional understandings of gender. Although heteronormative norms remain at work, competing forces such as feminist ideas and neoliberal values also showed their influences among my informants, leading to such sentiments as a celebration of compassion and gentleness in men, an acceptance of male grooming, expectations of more equal gender relations, and an embrace of queer desires. Gender norms were upheld, but also constantly rearticulated and modified to accommodate complex gendered desires and identifications.

More specifically, traditional gender ideologies manifested a powerful influence. These include Confucian-inflected ideals that dictate a binary understanding of masculinity and femininity and a hierarchy in favour of men in social relationships as well as the wen/wu construction of masculinity inherited from China, which emphasises physical and mental self-cultivation (Louie \& Edwards, 1994; Louie, 2002). While I note "competing forces" in opposition to these traditional norms, I have throughout underscored the influence of multiple global discourses upon my informants' gender views. These include media-propagated images of male beauty (Chapter 2 ), international romantic popular culture with its prevailing ideologies of monogamous heterosexual love (Chapter 3 and 7), feminist ideas (Chapter 4 and 7), depictions of Western machismo (Chapter 7) and neoliberal sensibilities (Chapter 5), among others.

The celebration of male strength, talent, privilege, power, dominance, determination, and protectiveness towards women among many informants suggests an embrace of hegemonic masculinity and adherence to social norms. Along with this embrace, the study finds frequent appreciation of men's emotional work, when they are understanding, supportive, expressive, and compassionate in romantic and social relationships. My observation of my informants' high regard for men's emotional labour is 
consonant with recent studies such as Earl (2014), Zharkevich et al. (2016), and Thanh Thi Vu (2020), which highlight Vietnamese women's desire for a companionate relationship in which both partners communicate and share emotions. In order to be valued, however, it is regularly felt that such emotional work should be performed in the "right" manner according to each person's logic, as appreciation of compassion and romantic gestures alone do not necessarily accompany an acceptance of men's display of vulnerability. Some informants readily accepted men's expressions of vulnerability, while others frowned upon it. The value that some informants placed on traits in men that cut against traditionally expected qualities, such as strength and leadership, indicates a personalised re-modification of normative ideals rather than a challenge to those ideals. Their appreciation of qualities seen as difficult to find in men, however, does not necessarily indicate high expectations of men around them but rather their construction of an "ideal man" in response to my questions.

Perhaps surprisingly, the male informants who participated in this study seem to hold relatively more egalitarian views of gender relations than their female counterparts. This finding supports my observation that hegemonic masculinity has been perpetuated by not only men, but also women who see benefits in the view of men as those who lead, protect, and provide. It is, of course, not impossible that male informants may have felt pressure to display more egalitarian gender attitudes in response to me, a female, middleclass $\mathrm{PhD}$ student, and the women may have been more willing to reveal non-egalitarian gender views. Given the interviewer's significant role in the meaning-making process (Walkerdine et al. 2001; Butler, 2005; Ewing 2006; Johanssen, 2016), my involvement cannot be ignored. At the same time, even if these men felt compelled to portray themselves as more egalitarian-inclined, that would in itself suggest awareness of equality discourses and openness to change in gender relations.

I have also found that informants' gender outlooks incline toward flexibility. Despite some informants' traditional views, which point to continuity in social norms, most manifested non-judgmental attitudes: they might state that they "disliked" or were "not interested" in an image or concept but generally framed their opinion as part of personal preferences. Most of their narratives fit into the "liberal discourse of tolerance" (Byrne, 2003 , p. 41) that characterises present-day urban life in Vietnam. This tendency may be explained by the fact that all informants are millennials who grew up during an age of globalisation. Living through this era, younger Vietnamese have observed the intermingling of varied viewpoints and representations of gender in the media and/or real 
life and might find flexibility more appropriate than rigidity. Similarly, as all informants have been involved with tertiary education and lived in urban areas, they may have become more familiar with expectations to tolerate differences. This observation is congruent with findings from previous studies, such as Phuong An Nguyen (2007), Martin (2010), and Earl (2014), which report greater flexibility in gender views and practices in younger urban Vietnamese.

As a concluding set of observations about my findings, I want to highlight the influence of Korean popular culture in Vietnam, with a focus on romantic Korean dramas and soft masculinities. My study has demonstrated how Korean dramas have become a reference point through which audiences reflect on their own romantic life and/or develop an idea of a desirable relationship. While the dramas' repeated articulations of a heteronormative ideology do not necessarily mean audiences will adhere to such ideology, they do serve as a resource that audiences draw upon in thinking about romance. Even those in Chapter 4 who resist romanticised constructions of romance and masculinity still view the relationships and ideal masculinities portrayed in Korean dramas as widely desired.

Within Korean dramas' heteronormative frameworks, images of soft masculinities diversify Vietnamese viewers' imaginations by highlighting alternative gender relations in which men are more emotionally involved and more willing to show vulnerabilities. Soft masculinities help normalise images of domestically able men (e.g., men who cook and serve other caring roles) and familiarise audiences with images of "cute", "pretty", and well-groomed men. Both Korean dramas and K-pop accommodate queer desires and foster intricate responses that may be uncategorisable from a gendered lens. The positive response of some informants to feminised traits in soft masculinity icons suggests greater openness to alternative constructions of masculinity and gender relations in parts of contemporary Vietnamese society.

The import of Korean dramas, along with other foreign cultural products, has contributed to modern romanticism in Vietnam since Đổi Móit. This contribution should not be downplayed in a country emphasising collectivist values, where individualism and individualist romance have not always been promoted, if not discouraged (Salemink \& Nguyễn, 2019). The informants demonstrated that engaging with Korean dramas allowed them to indulge in various imaginations, from conjuring means to maximise the self to constructing an ideal romantic partner, entertaining desires to love and be loved, and considering new ways to express romantic emotions. One might note how Thanh in 
Chapter 3 likened watching romantic Korean dramas to an enlightening experience such as the discovery of art! Informants' engagements with what they watched showed nuanced interactions between the individual need to reflect on the self and various invitations to explore private emotions found in global pop culture. Ultimately, therefore, Korean dramas serve as a "technology of imagination" (Illouz, 2012, p. 2017) or, to recall Foucault, a technology of the modern self, permitting audiences to contemplate their own lives and gender relations in many possible ways. 


\section{Bibliography}

Aarseth, H. (2020). Against the grain? The craving for domestic femininity in a genderegalitarian welfare state. European Journal of Women's Studies, 1-15.

https://doi.org/10.1177/1350506820970241

Abelmann, N. (2003). The Melodrama of Mobility: Women, Talk, and Class in Contemporary South Korea. University of Hawai'i Press.

Abu-Lughod, L. (2000). Modern Subjects: Egyptian Melodrama and Postcolonial Difference. In T. Mitchell (Ed.), Questions of Modernity (pp. 87-114). University of Minnesota Press.

Ahmed, S. (2014). The Cultural Politics of Emotion (2nd ed.). Edinburgh University Press. Ahn, Ji-Hyun \& Yoon, E Kyung (2020). Between Love and Hate: The New Korean Wave, Japanese Female Fans, and Anti-Korean Sentiment in Japan. Journal of Contemporary Eastern Asia, 19(2), 179-196. https://doi.org/10.17477/jcea.2020.19.2.179

Ainslie, M. J. (2017). Korean Soft Masculinity vs. Malay Hegemony: Malaysian Masculinity and Hallyu Fandom. Korea Observer, 48(3), 607-638.

http://scholar.dkyobobook.co.kr/searchDetail.laf?barcode $=4010026001550$

Ainslie, M. J., Lipura, S. D. \& Lim, J. B. Y. (2017). Understanding the Hallyu Backlash in Southeast Asia: a Case Study of Consumers in Thailand, Malaysia and Philippines.

Kritika Kultura, 28-091.

https://journals.ateneo.edu/ojs/index.php/kk/article/view/KK2017.02805/2412

Amatulli, C., Guido, G., Mileti, A., Tomacelli, C., Prete, M. I. \& Longo, A. E. (2016). "Mixand-Match" Fashion Trend and Luxury Brand Recognition: An Empirical Test Using Eye-tracking. Fashion Theory, 20(3), 341-362.

https://doi.org/10.1080/1362704X.2015.1082294

Ang, I. (1985). Watching Dallas: Soap opera and the melodramatic imagination (D. Couling, Trans.). Methuen \& Co (Original work published 1982).

Ang, I. (1990). Culture and Communication: Towards an Ethnographic Critique of Media Consumption in the Transnational Media System. European Journal of Communication, 5(2), 239-260. https://doi.org/10.1177/0267323190005002006 
Ang, I. (1996). Feminist desires and female pleasure: on Janice Radway's Reading the Romance. In I. Ang, Living Room Wars: Rethinking media audiences for a postmodern world (pp. 98-108). Routledge.

Appadurai, A. (2004). The Capacity to Aspire: Culture and the Terms of Recognition. In V. Rao \& M. Walton (Eds.), Culture and public action (pp. 59-84). Stanford University Press.

Archard, P. J. (2020). Psychoanalytically Informed Research interviewing: Notes on the Free Association Narrative Interview Method. Nurse Researcher, 28(2), 42-49.

https://doi.org/10.7748/nr.2020.e1718

Arend, P. (2016). Consumption as common sense: Heteronormative hegemony and white wedding desire. Journal of Consumer Culture, 16(1), 144-163.

https://doi.org/10.1177/1469540514521076

Artz, L. (2015). Telenovelas: Television Stories for Our Global Times, Perspectives on Global Development and Technology, 14(1-2), 193-226.

https://doi.org/10.1163/15691497-12341341

Avieli, N. (2019). Forbidden from the Heart: Flexible Food Taboos, Ambiguous Culinary Transgressions, and Cultural Intimacy in Hoi An, Vietnam. In J. Ehlert \& N. K. Faltmann (Eds.), Food Anxiety in Globalising Vietnam (pp. 77-103). Palgrave Macmillan.

Baldacchino, J. (2014). In Sickness and in Love? Autumn in My Heart and the Embodiment of Morality in Korean Television Drama. Korea Journal, 54(4), 5-28.

Baldacchino, J.-P. (2008). Eros and Modernity: Convulsions of the Heart in Modern Korea. Asian Studies Review, 32(1), 99-122.

https://doi.org/10.1080/10357820701871922

Baudinette, T. (2017). Constructing identities on a Japanese gay dating site: Hunkiness, cuteness and the desire for heteronormative masculinity. Journal of Language and Sexuality, 6(2), 232-261. https://doi.org/10.1075/jls.6.2.02bau

Bayly, S. (2014). How to forge a creative student-citizen: Achieving the positive in today's vietnam. Modern Asian Studies, 48(3), 493-523.

http://www.jstor.org/stable/24494657 
Bảo Ngọc (2021, April 9). Đàn ông nam tính trên phim Việt: Yếu hay thiếu? [Manly men in Vietnamese cinema: weak or lacking?]. Zing news.

https://zingnews.vn/dan-ong-nam-tinh-tren-phim-viet-yeu-hay-thieu-post1202304.html

Bélanger, D., \& Khuat Thu Hong (2001). Parents' involvement in children's marriage: Intergenerational relations in the choice of a spouse in Hanoi, Vietnam. In J. Kleinen (Ed.), Vietnamese Society in Transition: The Daily Politics of Reform and Change (pp. 250-263). Het Spinhuis.

Bélanger, D., \& Khuất Thu Hồng (2002). Too Late to Marry: Failure, Fate or Fortune? Female Singlehood in Rural North Vietnam. In J. Werner \& D. Bélanger (Eds.), Gender, Household, State: Đổi Mới in Vietnam (pp. 89-110). Cornell University.

Bélanger, D. (2004). Single and Childless Women of Vietnam: Contesting and Negotiating Female Identity? In L. Drummond, \& H. Rydstrøm (Eds.), Gender Practices in Contemporary Vietnam (pp. 96-116). Singapore University Press.

Berg, S.-H. (2018). Local Buzz, Global Pipelines and Hallyu: The Case of the Film and TV Industry in South Korea. Journal of Entrepreneurship and Innovation in Emerging Economies, 4(1), 33-52. https://doi.org/10.1177/2393957517749072

Bergstedt, C. (2016). Cultivating Gender: Meanings of Place and Work in Rural Vietnam. NIAS Press.

Berlant, L. (2008). The Female Complaint: The Unfinished Business of Sentimentality in American Culture. Duke University Press.

Bhattacharya, A. (2016). The many ways of knowing: Embracing multiplicity in narrative research. Qualitative Social Work, 15(5-6), 705-714.

https://doi.org/10.1177/1473325016652683

Bland, B. (2011, September 5). Vietnam sees more women filing for divorce. Financial Times. https://www.ft.com/content/60466878-d39a-11e0-bc6b-00144feab49a

Bourdieu, P. (1984). Distinction: A Social Critique of the Judgment of Taste (R. Nice, Trans.). Harvard University Press. (Original work published 1979)

Boydell, L. (2009). Analysing discourse psycho-socially. In S. Clarke, \& P. Hoggett (Eds.), Researching Beneath the Surface: Psycho-Social Research Methods in Practice (pp. 241-266). Routledge.

Briggs, M. (2010). Television, Audiences and Everyday Life. Open University Press. 
Bui Manh Hung (2007). Vietnam: Where Korean TV Dramas Flourish. Koreana, Winter Issue, 21(4). In Growing Popularity of Korean Dramas among Viewers Worldwide (various authors). https://www.koreana.or.kr/

Bui Thi Thanh Hoa (2018). The Representations of Transgender Persons in Vietnamese Online Media [Master's dissertation, Flinders University]. https://theses.flinders.edu.au/view/0baf424b-cd4f-49e2-9626-78d6fc0fe5b7/1

Bui, Hai Thiem (2015). In Search of a Post-Socialist Mode of Governmentality. Asian Journal of Social Science, 43, 80-102. https://doi.org/10.1163/15685314-04301005

Butler, J. (1992). The Body You Want: Liz Kotz Interviews Judith Butler, interview by Liz Kotz for Artforum, November 1992, 82-90.

Butler, J. (1988). Performative Acts and Gender Constitution: An Essay in Phenomenology and Feminist Theory. Theatre Journal, 40(4), 519-531. https://doi.org/10.2307/3207893

Butler, J. (1990a/2006). Gender trouble: feminism and the subversion of identity. Routledge. (Original work published 1990)

Butler, J. (1990b). The Force of Fantasy: Feminism, Mapplethorpe, and Discursive Excess, differences: A Journal of Feminist Cultural Studies, 2(2),105-124.

Butler, J. (1993/2011). Bodies that Matter: on the discursive limits of "sex". Routledge. (Original work published 1993)

Butler, J. (1995). For a Careful Reading. In S. Benhabib, J. Butler, D. Cornell, \& N. Fraser (Eds.), Feminist Contentions: A Philosophical Exchange. Routledge.

Butler, J. (1997a). Excitable speech: a politics of the performative. Routledge.

Butler, J. (1997b). The psychic life of power: theories in subjection. Stanford University Press.

Butler, J. (2000). Restaging the Universal: Hegemony and the Limits of Formalism. In J. Butler, E. Laclau \& S. Žižek (Eds.), Contingency, Hegemony, Universality: Contemporary Dialogues on the Left. Verso.

Butler, J. (2004). Undoing gender. Routledge. 
Butler, J. (2005). Giving an account of oneself. Fordham University Press.

Butler, J. (2006). Precarious life: The powers of mourning and violence. Verso.

Butler, J. [Big Think]. (2011, June 2011). Judith Butler: Your Behavior Creates Your Gender [Video]. YouTube. https://www.youtube.com/watch?v=Bo7o2LYATDc

Butler, J. (2015). Theatrical Machines. differences: A Journal of Feminist Cultural Studies, 26(3), 23-42. https://doi.org/10.1215/10407391-3340336

Byrne, B. (2003). Reciting the Self: Narrative Representations of the Self in Qualitative Interviews. Feminist Theory, 4(1), 29-49. https://doi.org/10.1177/1464700103004001002

Cagle, R. L. (2007). Taking the Plunge: Representing Queer Desire in Contemporary South Korean Cinema. In F. Gateward (Ed.), Seoul Searching: Culture and Identity in Contemporary Korean Cinema (pp. 283-298). State University of New York.

Cagle, R. L. (2014). 'Don't Forget': The Musical Dimensions of South Korean Television Drama. In Jeongmee Kim (Ed.), Reading Asian Television Drama: Crossing Borders and Breaking Boundaries (pp. 193-214). Bloomsbury Academic.

Carolan, M. S. (2005). The Conspicuous Body: Capitalism, Consumerism, Class and Consumption. Worldviews, 9(1), 82-111. https://doi.org/10.1163/1568535053628436

Carruthers, A. (2001). National Identity, Diasporic Anxiety and Music Video Culture in Vietnam, In Yao Souchou (Ed.), House of glass: culture, modernity, and the state in Southeast Asia (pp. 119-149). White Lotus Press.

Chan, B., \& Wang, X. (2011). Of prince charming and male chauvinist pigs: Singaporean female viewers and the dream-world of Korean television dramas. International Journal of Cultural Studies, 14(3), 291-305. https://doi.org/10.1177/1367877910391868

Charton, L. \& Boudreau, J. (2017). 'We or them,' 'you and I,' and 'l': spaces of intimacy and (not so) public displays of affection in Hanoi. Gender, Place \& Culture, 24(9), 13031322.

Chawla, L. (2006). Research methods to investigate significant life experiences: review and recommendations. Environmental Education Research, 12(3-4), 359-374. https://doi.org/10.1080/13504620600942840 
Chen, L. (2016). The emergence of the anti-Hallyu movement in China. Media, Culture \& Society, 39(3), 374-390. https://doi.org/10.1177/0163443716646176

Choi, J. (2012). Multivocal Post-Diasporic Selves: Entangled in Korean Dramas. Journal of Language, Identity \& Education, 11(2), 109-123.

https://doi.org/10.1080/15348458.2012.667305

Chowdhury, I., Johnson, H., Mannava, A. \& Perova, E. (2018). Gender Gap in Earnings in Vietnam: Why Do Vietnamese Women Work in Lower Paid Occupations? World Bank. https://openknowledge.worldbank.org/handle/10986/31485

Chua, B. H. (2012). The Structure of Identification and Distancing in Watching East Asian Television Drama. In B. H. Chua, Structure, Audience and Soft Power in East Asian Pop Culture (pp. 89-102). Hong Kong University Press.

Chua, B. H., \& Iwabuchi, K. (Eds.) (2008). East Asian Pop Culture: Analysing the Korean Wave. Hong Kong University Press.

Chuk, Tik Sze (2016). Queer Representations in Korean Media - Heteronormativity, Homonormativity, and Queer Transgression [Master's dissertation, University of Hong Kong]. http://hdl.handle.net/10722/241413

Chung Peichi (2013). Co-Creating Korean Wave in Southeast Asia: Digital Convergence and Asia's Media Regionalization. Journal of Creative Communications, 8(2-3), 193-208. https://doi.org/10.1177/0973258613512912

Clarke, S. (2002). Learning from experience: psycho-social research methods in the social sciences. Qualitative Research, 2(2), 173-194.

https://doi.org/10.1177/146879410200200203

Clarke, S. (2008). Psycho-Social Research: Relating Self, Identity, and Otherness. In S. Clarke, H. Hahn \& P. Hoggett (Eds.), Object Relations and Social Relations (pp. 113135). Karnac Books.

Cohen, M. (2000). So cool it's Korean. Far Eastern Economic Review, 163(36), 84-85.

Cohen, R. (2012). Cinematic Constructions of the Female Serial Killer: A Psychosocial Audience Study [Doctoral dissertation, Cardiff University]. http://orca.cf.ac.uk/id/eprint/46698 
Collins, R. (2015). Vietnamese Literature After War and Renovation: The Extraordinary Everyday. Journal of Vietnamese Studies, 10(4), 82-124.

https://www.jstor.org/stable/26377892

Cong Huyen Ton Nu Nha Trang (1987). The Role of French Romanticism in the New Poetry Movement in Vietnam. In Truong Buu Lam (Ed.), Borrowing and Adaptations in Vietnamese Culture, Southeast Asia Paper No. 25, Center for Southeast Asian Studies (pp. 52-62). University of Hawaii at Manoa.

Connell, R. W. (1995). Masculinities. Polity Press.

Connell, R. W. (1998). Masculinities and Globalization. Men and Masculinities, 1(1), 323. https://doi.org/10.1177/1097184X98001001001

Cook, E. E. (2017). Aspirational Labour, Performativity and Masculinities in the Making. Intersections: Gender and Sexuality in Asia and the Pacific, 41.

http://intersections.anu.edu.au/issue41/cook.html\#t53

Creighton, M. (2009). Japanese surfing the Korean wave: Drama tourism, nationalism, and gender via ethnic eroticisms. Southeast Review of Asian Studies, 31, 10-38.

Đặng Thiếu Ngân (2020, April 2). Thiếu Ngân: 'Cuộc sống khắc nghiệt, người Hàn cần sự đẹp đẽ trên phim để cân bằng [Thiếu Ngân: 'Koreans consume television romance as compensation for harsh reality] (Hiền Hà, Interviewer). Zing News.

https://zingnews.vn/cuoc-song-khac-nghiet-nguoi-han-can-su-dep-de-tren-phim-de-canbang-post1064052.html

Dang Ngoc Hoang Truc, Chankrajang, T. \& Nguyen Thi Hai Yen (2017). Patterns and Trends of Single Motherhood in Vietnam in 1999 and 2009. Journal of Demography, 33(1), 26-51.

Dang, Ngoc Lan Thi (2017). Insights into Vietnamese Culture of Gender and Factors Hindering Academic Women's Advancement to Leadership Positions. In M. H.

Kohlman, \& D. B. Krieg (Eds.), Discourses on Gender and Sexual Inequality: The Legacy of Sandra L. Bem, Advances in Gender Research (Vol. 2, pp. 19-47). Emerald Publishing Limited.

Dant, T. (2012). Television and the moral imaginary: Society through the small screen. Palgrave Macmillan. 
Dao, Bich Ha (2015). Impacts of rural-urban migration on family relationships and gender relations in mother-migrant and father-left-behind families in Vietnam [Doctoral dissertation, The Australian National University]. http://hdl.handle.net/1885/141396 Dator, J., \& Seo, Y. (2004). Korea as the Wave of a Future: The Emerging Dream Society of Icons and Aesthetic Experience. Journal of Futures Studies, 9(1), 31-44.

DeAngelis, M. (2017). Soft and Hard: Accessible Masculinity, Celebrity, and PostMillennial Cuteness. In Dale, J. P., Goggin, J., Leyda, J., Mclntyre, A. P. \& Negra, D. (Eds.), The Aesthetics and Affects of Cuteness (pp. 194-215). Routledge.

Diderot, D. (1965). On Dramatic Poetry. In Clark, B. H. (Ed.), European Theories of the Drama, Crown Press.

Dimock, M. (2019, January 17). Defining generations: Where Millennials end and Generation Z begins. Pew Research Center. https://www.pewresearch.org/facttank/2019/01/17/where-millennials-end-and-generation-z-begins/

Dinh, Thanh-Hang \& van Teijlingen, E.R. (2019). Factors influencing engagement in premarital sex among Vietnamese young adults: a qualitative study. International Journal of Adolescent Medicine and Health, 20180201, 1-9.

Dixon, C. (2004). State, party, and political change in Vietnam. In McCargo, D. (Ed.), Rethinking Vietnam (pp. 15-26). RoutledgeCurzon.

Doan Cam Thi (2021). Expressions of the Self in Vietnam: Usage of 'l' throughout Literature in nôm and in quốc ngữ. Sojourn: Journal of Social Issues in Southeast Asia, 36(1), 40-67. https://www.jstor.org/stable/26996173

Dormeier Freire, A. (2009). Motorbikes against Ho Chi Minh? Or the icons of a social Transformation in Vietnam. The Copenhagen Journal of Asian Studies, 27(1), 6787. https://doi.org/10.22439/cjas.v27i1.1693

dos Santos, M.R. (2020). A study on the reception of Korean dramas by a Brazilian audience: Gender representation in Age of Youth (청춘 시대) and Hospital Ship (병원선). Latin American and Caribbean Studies, 39(1), 161-187.

Doty, A. (1993). Making Things Perfectly Queer: Interpreting Mass Culture. University of Minnesota Press. 
Drummond, L. (2004). The Modern “Vietnamese Woman”: Socialization and Women's Magazines. In L. Drummond, L. \& H. Rydstrøm, (Eds.), Gender Practices in Contemporary Vietnam (pp. 158-178). Singapore University Press.

Duong, Lan (2017). Through a Trans-Vietnamese Feminist Lens: The Cinemas of Vietnam and the Diaspora. In C. C. Choy \& J. T. Wu (Eds.), Gendering the TransPacific World (Vol. 1, pp. 407-421). Brill. https://doi.org/10.1163/9789004336100_022 Duong Nguyen Hoai Phuong (2016). Korean Wave as Cultural Imperialism: A study of Kpop Reception in Vietnam. [Master's dissertation, Leiden University]. https://hdl.handle.net/1887/37300

Earl, C. (2014). Vietnam's New Middle Classes: Gender, Career, City. NIAS Press.

Earl, C. (2015). Life as lived and life as talked about: Family, love and marriage in twenty-first-century Vietnam. In M. McLelland \& V. Mackie (Eds.), Routledge Handbook of Sexuality Studies in East Asia (pp. 101-111). Routledge.

Elfving-Hwang, J. (2011). Not So Soft After All: Kkonminam Masculinities in Contemporary South Korean Popular Culture. KSAA (Korean Studies Association of Australasia) 7th Biennial Conference. Sydney. Conference paper.

Elfving-Hwang, J. (2017). Aestheticizing Authenticity: Corporate Masculinities in Contemporary South Korean Television Dramas. Asia Pacific Perspectives, 15(1), 5572.

Elfving-Hwang, J. (2020). Competency as an Embodied Social Practice: Clothing, Presentation of Self and Corporate Masculinity in South Korea. In J. Hoegaerds, \& K. Aarvik (Eds.), Making It Like Man: Men, Masculinities and the Modern Career (pp. 133152). Walter de Gruyter.

Elfving-Hwang, J. (2013). Cosmetic surgery and embodying the moral self in South Korean popular makeover culture. The Asia-Pacific Journal: Japan Focus, 11(24), [2]. http://japanfocus.org/-Joanna-Elfving_Hwang/3956

Epstein, S., \& Joo. M. R. (2012). Multiple Exposures: Korean Bodies and the Transnational Imagination. The Asia-Pacific Journal, 10(33). https://apjjf.org/2012/10/33/Stephen-Epstein/3807/article.html 
Espiritu, B. F. (2011). Transnational audience reception as a theatre of struggle: young Filipino women's reception of Korean television dramas. Asian Journal of Communication, 21(4), 355-372. https://doi.org/10.1080/01292986.2011.580852

Ewing, K. P. (2006). Revealing and concealing: Interpersonal dynamics and the negotiation of identity in the interview. Ethos, 34(1), 89-122.

https://doi.org/10.1525/eth.2006.34.1.089

Feagin, S. L. (1988). Imagining emotions and appreciating fiction. Canadian Journal of Philosophy, 18(3), 485-500. https://doi.org/10.1080/00455091.1988.10717187

Ferri, A. J. (2007). Willing Suspension of Disbelief: Poetic Faith in Film. Lexington Books.

Forbes, D., Hull, T. H., Marr, D. G., \& Brogan, B. (1991). (Eds.), Doi Moi: Vietnam's Renovation Policy and Performance. Political and Social Change (Monograph No 14). Australian National University.

Forrester, J. (1998). Instant Noodles Propaganda: Vietnam Television in the Late 1990s. In D. Marr (Ed.), Mass Media in Vietnam. Political and Social Change (Monograph 25, pp 78-90). The Australian National University.

Foucault, M. (1988). Technologies of the Self. In L. H. Martin, H. Gutman, \& P. H. Hutton (Eds.), Technologies of the self: A seminar with Michel Foucault (pp. 16-49). University of Massachusetts Press.

Foucault, M., \& Blasius, M. (1993). About the Beginning of the Hermeneutics of the Self: Two Lectures at Dartmouth. Political Theory, 21(2), 198-227.

https://doi.org/10.1177/0090591793021002004

Freud, S. (1957). Mourning and Melancholia. In The Standard Edition of the Complete Psychological Works of Sigmund Freud (SE), (Vol 14, J. Strachey Trans., pp. 239-257). Hogarth Press. (Original work published 1917).

Frosh, S., \& Baraitser, L. (2008). Psychoanalysis and Psychosocial Studies. Psychoanalysis, Culture \& Society, 13, 346-365. https://doi.org/10.1057/pcs.2008.8 
Frosh, S., Phoenix, A. \& Pattman, R. (2003). Taking a stand: using psychoanalysis to explore the positioning of subjects in discourse. British Journal of Social Psychology, 42, 39-52. https://doi.org/10.1348/014466603763276117

Frost, L., \& McClean, S. (2014). Thinking about the Lifecourse: A Psychosocial Introduction. Palgrave Macmillan.

Fu, K. (2010). Of Plastic Beauties and Flower Boys: Representations of Cosmetic Surgery in South Korean Films. In L. K. Khiun (Ed.), Liberalizing, Feminizing and Popularizing Health Communications in Asia (pp. 167-182). Ashgate Publishing.

Gadd, D., \& Jefferson, T. (2007). Psychosocial criminology: An introduction. SAGE. Gammeltoft, T. (1999). Women's Bodies, Women's Worries: Health and Family Planning in a Vietnamese Rural Community. Curzon Press.

Gammeltoft, T. (2001). 'Faithful, heroic, resourceful: Changing images of women in Vietnam. In J. Kleinen (Ed.), Vietnamese Society in Transition: The Daily Politics of Reform and Change (pp 265-280). Het Spinhuis.

Gammeltoft, T. (2014). Haunting Images: A Cultural Account of Selective Reproduction in Vietnam. University of California Press.

Gammon, Thi Luong (2021). Making sense of discomfort: the performance of masculinity and (counter-)transference, Journal of Psychosocial Studies, 14(2), 89-103. https://doi.org/10.1332/147867321X16218461456999

Gammon, Thi Luong (in press). "I'd Have Divorced My Husband If Not For Korean Dramas" - Vietnamese Women's Consumption of Television Romance and Melancholia. Studies in Gender and Sexuality.

Gamson, J. (2006). Popular culture constructs sexuality. In S. Seidman, N. Fischer, \& C. Meeks (Eds.), Handbook of the New Sexuality Studies (pp. 337-341). Routledge. Garousi, S., Khajeh Dolatabad, R., \& Garrusi, B. (2017). Concerns about body change behaviors, and construction of flexible masculinity among Iranian students. Quality \& Quantity, 51(6), 2831-2846. https://doi.org/10.1007/s11135-016-0448-5

Gauntlett, D. (2002). Media, gender, and identity: An introduction. Routledge. 
Gawlewicz, A. (2016). Language and translation strategies in researching migrant experience of difference from the position of migrant researcher. Qualitative Research, 16(1), 27-42. https://doi.org/10.1177/1468794114557992

Geraghty, C. (1991) Women and Soap Opera: A Study of Prime Time Soaps. Polity Press.

Giang, Le Minh (2012). Governing Masculinity: How Structures Shape the Lives and Health of Dislocated Men in Post-Doi Moi Vietnam [Doctoral dissertation, Columbia University]. Columbia: Academic Commons. https://doi.org/10.7916/D8K93FNF Glynn, B., \& Kim, Jeongmee (2017). Life is Beautiful: Gay Representation, Moral Panics, and South Korean Television drama Beyond Hallyu. Quarterly Review of Film and Video, 34(4), 333-347. https://doi.org/10.1080/10509208.2016.1241615

Goldstein, T. R. (2009). The Pleasure of Unadulterated Sadness: Experiencing Sorrow in Fiction, Nonfiction, and "In Person". Psychology of Aesthetics, Creativity, and the Arts, 3(4), 232-237. https://doi.org/10.1037/a0015343

Gordon, S. F. (2017). Narratives of resistance and resilience: Exploring stories of violence against women. Agenda, 31(2), 34-43.

https://doi.org/10.1080/10130950.2017.1366181

Gray, J. (2003). New Audiences, New Textualities: Anti-Fans and Non-Fans. International Journal of Cultural Studies, 6(1), 64-81. https://doi.org/10.1177/1367877903006001004

Grosse, I. (2015). Gender Values in Vietnam—Between Confucianism, Communism, and Modernization. Asian Journal of Peacebuilding, 3(2), 253-272.

https://hdl.handle.net/10371/94819

Ha Phuong (2017, July 16). Vietnam climbs to seventh worldwide for number of Facebook users: report. VnExpress. https://e.vnexpress.net/news/business/dataspeaks/vietnam-climbs-to-seventh-worldwide-for-number-of-facebook-users-report3614034.html

Han, Ae Jin (2016). The aesthetics of cuteness in Korean pop music [Doctoral dissertation, University of Sussex]. http://sro.sussex.ac.uk/id/eprint/61472 
Han, Benjamin M. (2019). Fantasies of Modernity: Korean TV Dramas in Latin America. Journal of Popular Film and Television, 47(1), 39-47.

https://doi.org/10.1080/01956051.2019.1562823

Han, Woori, Lee, Claire Shinhea, \& Park, Ji Hoon (2017). Gendering the authenticity of the military experience: male audience responses to the Korean reality show Real Men. Media, Culture \& Society, 39(1), 62-76.

https://doi.org/10.1177/0163443716673895

Hardt, M., \& Negri, A. (2009). Commonwealth. The Belknap Press of Harvard University Press.

Harms, E. (2009). Vietnam's Civilizing Process and the Retreat from the Street: A Turtle's Eye View from Ho Chi Minh City. City \& Society, 21(2), 182-206.

https://doi.org/10.1111/j.1548-744X.2009.01021.x

Harms, E. (2014). Civility's Footprint: Ethnographic Conversations about Urban Civility and Sustainability in Ho Chi Minh City. Sojourn: Journal of Social Issues in Southeast Asia, 29(2), 223. https://doi.org/10.1355/sj29-2a

Harms, E. (2016). Luxury and Rubble: Civility and Dispossession in the New Saigon. University of California Press. https://doi.org/10.1525/luminos.20

Harrington, C., \& Bielby, D. (1995). Soap Fans: Pursuing Pleasure and Making Meaning in Everyday Life. Temple University Press.

Harris, P. (2020). 'Just give up the ball': In search of a third space in relationships between male youth workers and young men involved in violence. Criminology \& Criminal Justice, 1-16. https://doi.org/10.1177/1748895820933929

Hassim, N., Jayasainan, S. Y. \& Khalid, N. L. (2019). Exploring viewer experiences with sageuk K-dramas from a parasocial relations perspective. Search: Journal of Media and Communication Research, 11(1), 77-94.

Hayashi, K. (2005). Assessing the Popularity of "Winter Sonata": How do Women's Emotions Affect the Public Sphere in Japan? Korean Association for Broadcasting and Telecommunication, 2, 40-58.

Hayton, B. (2010). Vietnam: Rising dragon. Yale University Press. 
Healy, D. (2013). New Voices: Socio-Cultural Trajectories of Vietnamese Literature in The 21st Century. Asian and African Studies, 22(1), 1-30.

Heng, R. H. (2001). Media Negotiating the State: In the Name of the Law in Anticipation. Sojourn: Journal of Social Issues in Southeast Asia, 16(2), 213-237. http://www.jstor.org/stable/41057063

Hernández-Ramírez, R. (2017). Technology and self-modification: Understanding technologies of the self after Foucault. Journal of Science and Technology of the Arts, 9(3), 45-57. https://doi.org/10.7559/citarj.v9i3.423

Hickman, C. (2019). Children and Climate Change: Exploring Children's Feelings About Climate Change Using Free Association Narrative Interview Methodology. In Hoggett, P. (Ed.), Climate Psychology: On Indifference to Disaster (pp. 41-59). Palgrave Macmillan.

Higgins, R. (2015). Is It My Job to Make Him Care? Middle-Class Women and Gender Inequality in Ho Chi Minh City. Anthropology of Work Review, 36(2), 74-86.

Higgins, R. G. (2008). Negotiating the Middle: Interactions of Class, Gender and Consumerism Among the Middle Class in Ho Chi Minh City, Vietnam [Doctoral dissertation submitted to the University of Arizona].

https://repository.arizona.edu/handle/10150/196062

Hinerman, S. (1992). 'I'll Be Here With You': Fans, Fantasy and the Figure of Elvis. In Lewis L. A. (Ed.), The Adoring Audience: Fan Culture and Popular Media. Routledge. Hoàng Phong Tuấn (2016). Sự đọc bình dân tiểu thuyết ngôn tình [The mass reading of literary romance]. In Nguyễn Đức Lộc (Ed.) Đời sống xã hôi Việt Nam đương đại (Volume 2): Những người thiểu số ở đô thị: Lựa chọn, trở thành, khác biệt [Vietnamese contemporary social life: Minority groups in cities: choices, becoming, differences], pp 329-368. Nhà Xuất Bản Tri Thức [Knowledge Publishing House].

Hoang, Ba Thinh (2013). Vietnamese Women Marrying Korean Men and Societal Impacts (Case studies in Dai Hop commune, Kien Thuy district - Hai Phong city). Academic Journal of Interdisciplinary Studies, 2(8), 782-789.

Hoang, Dung \& Phan, Tran (2019). Gender in Vietnamese. In N. Duffield, T. Phan, \& T. Trinh (Eds.), (2019). Interdisciplinary Perspectives on Vietnamese Linguistics (Vol. 211, pp. 253-274). John Benjamins Publishing Company. 
Hoang, Ha (2020). K-pop Male Androgyny, Mediated Intimacy, and Vietnamese Fandom. In J. V. A. Cabañes, \& C. S. Uy-Tioco (Eds), Mobile Media and Social Intimacies in Asia: Reconfiguring Local Ties and Enacting Global Relationships (pp. 187-203). Springer Nature B. V.

Hoang, Kimberly Kay (2010). Economies of Emotion, Familiarity, Fantasy, and Desire: Emotional Labor in Ho Chi Minh City's Sex Industry. Sexualities, 13(2), 255-272. https://doi.org/10.1177/1363460709359224

Hoang, Kimberly Kay (2011). “She's Not a Low-Class Dirty Girl!”: Sex Work in Ho Chi Minh City, Vietnam. Journal of Contemporary Ethnography, 40(4), 367396.https://doi.org/10.1177/0891241611403481

Hoang, Lan Anh (2011). Gender Identity and Agency in Migration Decision-Making: Evidence from Vietnam. Journal of Ethnic and Migration Studies, 37(9), 14411457. https://doi.org/10.1080/1369183X.2011.623618

Hoang, Lan Anh, \& Yeoh, B. S. A. (2011). Breadwinning Wives and "Left-Behind" Husbands: Men and Masculinities in the Vietnamese Transnational Family. Gender \& Society, 25(6), 717-739. https://doi.org/10.1177/0891243211430636

Holland, N. N. (1975). Dynamics of literary response. Norton and Co. (Original work published 1968).

Holliday, R., \& Elfving-Hwang, J. (2012). Gender, Globalization and Aesthetic Surgery in South Korea. Body \& Society, 18(2), 58-81.

https://doi.org/10.1177/1357034X12440828

Hollway, W., \& Jefferson, T. (1997). Eliciting Narrative Through the In-Depth Interview. Qualitative Inquiry, 3(1), 53-70. https://doi.org/10.1177/107780049700300103 Hollway, W., \& Jefferson, T. (2000). Doing qualitative research differently: Free association, narrative and the interview method. SAGE.

Horat, E. (2018). Rearranging Care, Reconfiguring Gender: Family and Household Business in Post-Đổi Mới Vietnam. The Asia Pacific Journal of Anthropology, 19(1), 5571. https://doi.org/10.1080/14442213.2017.1394909

Horton, P., \& Rydstrom, H. (2019). Reshaping boundaries: Family politics and GLBTQ resistance in urban Vietnam, Journal of GLBT Family Studies, 15(3), 290-305. https://doi.org/10.1080/1550428X.2018.1518739 
Horton, P. (2014). 'I thought I was the only one': the misrecognition of LGBT youth in contemporary Vietnam. Culture, Health \& Sexuality, 16(8), 960-973.

https://doi.org/10.1080/13691058.2014.924556

Horton, P. (2019). Recognising shadows: masculinism, resistance, and recognition in Vietnam, NORMA: International Journal for Masculinity Studies, 14(1), 66-80.

https://doi.org/10.1080/18902138.2019.1565166

Horton, P., \& Rydstrom, H. (2011). Heterosexual Masculinity in Contemporary Vietnam: Privileges, Pleasures, and Protests. Men and Masculinities, 14(5), 542-564.

https://doi.org/10.1177/1097184X11409362

Hu, K. (2008). Discovering Japanese TV Drama through Online Chinese Fans: Narrative Reflexivity, Implicit Therapy and the Question of the Social Imaginary. In Youna Kim (Ed.), Media Consumption and Everyday Life in Asia (pp. 114-126). Routledge.

Human Rights Watch (2020). "My Teacher Said I Had a Disease" Barriers to the Right to Education for LGBT Youth in Vietnam. https://www.hrw.org/report/2020/02/13/myteacher-said-i-had-disease/barriers-right-education-lgbt-youth-vietnam

lida, Y. (2005). Beyond the 'feminization of masculinity': transforming patriarchy with the 'feminine' in contemporary Japanese youth culture. Inter-Asia Cultural Studies, 6(1), 56-74. https://doi.org/10.1080/1462394042000326905

Illouz, E. (1997). Consuming the Romantic Utopia: Love and the Cultural Contradictions of Capitalism. University of California Press.

Illouz, E. (2012). Why Love Hurts: A Sociological Explanation. Polity Press.

Institute for Social Development Studies (2020). Men and masculinities in a globalising Viet Nam. http://isds.org.vn/en/an-pham/men-and-masculinities-in-a-globalising-vietnam/

International Organisation for Migration (2017). Vietnam Migration Profile 2016.

https://publications.iom.int/books/viet-nam-migration-profile-2016

Ives, M. (September 2018). Gay Courtship in Vietnam's 'The Bachelor' Turned Heads Abroad. Back Home? Meh. The New York Times. 
https://www.nytimes.com/2018/09/25/world/asia/vietnam-bachelor-gay-lesbiancontestants.html

Jackson, B. (2017). Confucianism and Korean Dramas: How Cultural and Social Proximity, Hybridization of Modernity and Tradition, and Dissimilar Confucian

Trajectories Affect Importation Rates of Korean Broadcasting Programs between Japan and China. Auctus: Virginia Commonwealth University's Journal of Undergraduate Research and Creativity, May 2017.

James-Hawkins, L., Salazar, K., Hennink, M. M., Vu, Song Ha., \& Yount, K. M. (2019). Norms of Masculinity and the Cultural Narrative of Intimate Partner Violence Among Men in Vietnam. Journal of Interpersonal Violence, 34(21-22), 4421-4442.

https://doi.org/10.1177/0886260516674941

Jamie, N. (1987). Relata, Relationships, and Context: A Perspective on Borrowed Elements in Vietnamese Culture. In Truong Buu Lam (Ed.), Borrowing and Adaptations in Vietnamese Culture, Southeast Asia Paper No. 25, Center for Southeast Asian Studies (pp. 124-140). University of Hawaii at Manoa.

Jang Haeyoung, Nguyen Ngoc Tram Oanh, \& Kwon Seung-Ho (2021). Women's empowerment and transnational consumption of Hallyu in Vietnam. Asian Journal of Women's Studies, 27(2), 184-207. https://doi.org/10.1080/12259276.2021.1924482

Jardine, M. A. (2019). Policing in a changing Vietnam [Doctoral dissertation, University of New South Wales]. http://handle.unsw.edu.au/1959.4/61491

Jenkins, H. (2013). Textual Poachers: Television Fans and Participatory

Culture. Routledge. (Original work published 1992)

Jenson, J. (1992). Fandom as Pathology: The Consequences of Characterization. In L. Lewis (Ed.), The Adoring Audience: Fan Culture and Popular Media. Routledge.

Jimenez, L., \& Walkerdine, V. (2011). A psychosocial approach to shame, embarrassment and melancholia amongst unemployed young men and their fathers. Gender and Education, 23(2), 185-199.

https://doi.org/10.1080/09540253.2010.490202

Johanssen, J. (2016). Did we fail? (Counter-)transference in a qualitative media research interview. Interactions: Studies in Communication \& Culture, 7(1), 99-111. https://doi.org/10.1386/iscc.7.1.99_1 
Johanssen, J. (2018a). The neoliberal subject, reality TV and free association: A Freudian audience study of Embarrassing Bodies. Participations: Journal of Audience and Reception Studies, 15(2), 37-57.

Johanssen, J. (2018b). Psychoanalysis and Digital Culture: Audiences, Social Media, and Big Data. Routledge.

Jones, M. (2008). Skintight: An Anatomy of Cosmetic Surgery. Berg.

Ju, Hyejung (2017). National television moves to the region and beyond: South Korean TV drama production with a new cultural act. The Journal of International Communication, 23(1), 94-114. https://doi.org/10.1080/13216597.2017.1291443 Jung, Sun (2011). Korean Masculinities and Transcultural Consumption: Yonsama, Rain, Oldboy, K-pop Idols. Hong Kong University Press.

Karis, T. (2013a). Ties that Mobilize: Migration, Native Place, and the Politics of Belonging in Urban Vietnam [Doctoral dissertation, University of California, San Diego]. https://escholarship.org/uc/item/6w87n2m6

Karis, T. (2013b). Unofficial Hanoians: Migration, Native Place and Urban Citizenship in Vietnam. Asia Pacific Journal of Anthropology, 14(3), 256-273.

https://doi.org/10.1080/14442213.2013.794156

Katz, E., Haas, H., \& Gurevitch, M. (1973). On the Use of the Mass Media for Important Things. American Sociological Review, 38(2), 164-181.

Keller, V. (2019). Music Keeps Us Together: Pop Songs in Korean Television Dramas. International Journal of TV Serial Narratives, V(2), 95-107.

Kelly, P. (2004). What is known about gender, the construct of sexuality and dictates of behaviour in Vietnam as a Confucian and socialist society and their impact on the risk of HIVIAIDS epidemic. In E. Micollier (Ed.), Sexual Cultures in East Asia: The Social Construction of Sexuality and Sexual Risk in a Time of AIDS (pp. 98-126). RoutledgeCurzon.

Khai, S. W. \& Wahab, J. A. (2017). Prettiness as a Shield: The Romantic Perpetuation of Patriarchy through the Representation of Pretty Boy in Popular Korean Dramas in Malaysia. Media Watch, 8(3), 298-310. 
Khuat Thu Hong, Bui Thu Huong \& Le Bach Duong (2014). "To be good at public and domestic work, I need three heads and six hands": the dilemma of Vietnamese "modern" women. In E. Ochiai, \& K. Aoyama (Eds.), Asian Women and Intimate Work (pp. 167-188). Brill.

Kim, Andrew Eungi, Mayasari, Fitria. \& Oh, Ingyu. (2013). When Tourist Audiences Encounter Each Other: Diverging Learning Behaviors of K-pop Fans from Japan and Indonesia. Korea Journal, 53(4), 59-82.

Kim, Do Kyun \& Kim, Min-Sun (2011). Hallyu: Influence of Korean Popular Culture in Asian and Beyond. Seoul National University Press.

Kim, Hae Joo (2015). Hearing the Korean Global: Hallyu in the Music of K-dramas [Doctoral dissertation, Wesleyan University]. https://doi.org/10.14418/wes01.3.42 Kim, Hyun Mee (2005). Korean TV Dramas in Taiwan: With an Emphasis on the Localization Process. Korea Journal, 45(5), 183--205.

Kim, Ik Ki, Song, Jung Eun, \& Jang, Wonho (2014). Anti-Hallyu in East Asia: The Cases of China, Japan, Vietnam and Indonesia. Korean Journal of Sociology, 48(3), 1-24. https://www.kci.go.kr/kciportal/ci/sereArticleSearch/ciSereArtiView.kci?sereArticleSearc hBean.artild=ART001893869

Kim, Jeongmee (2012). My Lovely Sam-soon: Absent Sex and the Unbearable Lightness of Sweet Korean Romance. In B. Glynn, J. Aston \& B. Johnson (Eds.), Television, Sex and Society: Analyzing Contempory Representations (pp. 111-124). Continuum.

Kim, Joong Keun (2010). The Korean Wave: Korea's Soft Power in Southeast Asia. In D. I. Steinberg (Ed.), Korea's Changing Roles in Southeast Asia: Expanding Influence and Relations (pp. 283-302). Institute of Southeast Asian Studies.

Kim, Kyung Hyun (2004). The Remasculinization of Korean Cinema. Duke University Press.

Kim, Pil Ho \& Singer, C. C. (2011) Three periods of korean queer cinema: Invisible, camouflage, and blockbuster. Acta Koreana, 14(1), 117-136.

https://doi.org/10.18399/ACTA.2011.14.1.005

Kim Su Jeong \& Kim Eun June (2016). 동남아시아 반한류에 나타난 문화적 갈등과 특성:인도네시아와 베트남을 중심으로 [Cultural Conflicts and Characteristics of Anti- 
Korean Wave in Southeast Asia]. 동남아시아연구 [Southeast Asian Studies], 26(3), 150. https://10.0.84.148/kaseas.26.3.201608.1

Kim, Ungsan (2017). "Queer Korean Cinema, National Others, and Making of Queer Space in Stateless Things (2011)." Journal of Japanese and Korean Cinema, 9(1), 6179. https://doi.org/10.1080/17564905.2017.1296803

Kim, Ungsan (2018). The Critical Social Turn of Queer Korean Cinema. Korea Journal, 58(2), 88-112.

Kim, Youna (Ed.). (2013). The Korean wave: Korean media go global. Routledge.

Kim, Grace MyHyun, \& Omerbašić, D. (2016). Multimodal literacies: Imagining lives through Korean dramas. Journal of Adolescent \& Adult Literacy, 60(5), 557566. https://doi.org/10.1002/jaal.609

Kirkham, P. (1995). Loving Men: Frank Borzage, Charles Farrell and the Reconstruction of Masculinity in the 1920s Hollywood Cinema. In P. Kirkham \& J. Thumin (Eds.), Me, Jane: Masculinity, Movies and Women (pp. 94-112). Wishart \& Lawrence.

Knight, R. P. (1940). Introjection, projection and identification. The Psychoanalytic Quarterly, 9(3), 334-341. https://doi.org/10.1080/21674086.1940.11925429

Ko, Nusta Carranza, Kim Jeong-Nam, No, Song I., \& Simões, R. G. (2014). The Korean Wave Hallyu in Looking at Escapism in Peruvian Society. Perspectives on Global Development and Technology, 13(3), 332-346. https://doi.org/10.1163/1569149712341305

Kraevskaia, N. (2009). Collectivism and Individualism in Society and Art after Doi Moi. In S. Lee \& N. H. Nguyen (Eds.), Essays on Modern and Contemporary Vietnamese Art (pp. 103-110). Singapore Art Museum.

Kwiatkowski, L. (2019). A “Wife's Duty” and Social Suffering: Sexual Assault in Marital Relationships in Vietnam. Journal of Aggression, Maltreatment \& Trauma, 28(1), 68-84. https://doi.org/10.1080/10926771.2018.1494237

Kwon, Insook (2001). A Feminist Exploration of Military Conscription: The Gendering of the Connections Between Nationalism, Militarism and Citizenship in South Korea.

International Feminist Journal of Politics, 3(1), 26-54.

https://doi.org/10.1080/713767489 
Kwon, Jungmin (2016). Co-mmodifying the gay body: Globalization, the film industry and female prosumers in the contemporary Korean mediascape. International Journal of Communication, 10, 1563-1580. https://ijoc.org/index.php/ijoc/article/view/3190/1609 Kwon, Jungmin (2019). Straight Korean Female Fans and Their Gay Fantasies. University of lowa Press.

La, Manh Cuong (2012). Social Change and Sexual Expression among Young Married Men in Vietnam. [Doctoral dissertation, La Trobe University]. http://hdl.handle.net/1959.9/496018

Lacan, J. (2006). Écris: The First Complete Edition in English (B. Fink trans.). W. W. Norton \& Co. (Original work published 1966).

Laforgia, P., \& Howard, K. (2017). Amber Liu, K-Pop Tomboy: Reshaping Femininity in Mainstream K-Pop. Kritika Kultura, 29, 214-231.

http://dx.doi.org/10.13185/KK2017.02910

Laplanche, J., \& Pontalis, J. (1973). The Language of Psycho-Analysis (NicholsonSmith, Trans.). W. W. Norton \& Company (Original work published 1967).

Laplanche, J., \& Pontalis, J. (1985). Fantasme Originaire. Hachette.

Lavin, M. (2015). Tomboy in Love: Korean and U.S. Views of Heterosexual Eroticism in the K-Drama First Shop of Coffee Prince. Situations: Cultural Studies in the Asian Context, 8(1), 45-69.

Lâm Long (2021, April 4). Chất đàn ông biến mất trên màn ảnh Việt 20 năm [True men disappears from Vietnamese cinema over 20 years]. VnExpress.

https://vnexpress.net/chat-dan-ong-bien-mat-tren-man-anh-viet-20-nam-4257605.html

Le, Huong (2008). Economic Reforms, Cultural Policy: Opportunities and Challenges to the Arts and Culture in Vietnam in the Age of Globalization. The Journal of Arts Management, Law, and Society, 38(1), 5-18. https://doi.org/10.3200/JAML.38.1.5-18

Lê, Minh Tiến (2020). Sự biến đổi xã hội từ góc nhìn Xã hội học Vi mô qua hai hiện tượng: Bà Mẹ đơn thân và Hôn nhân đồng tính [Social change from a microsociological lens observed in two phenomena: single moms and same-sex weddings]. Tạp chí Khoa học Xã hội Đại học Mở Thành phố Hồ Chí Minh [Ho Chi Minh City Open University's Journal of Social Sciences], 15(5), 49-55. 
Lee, Aramchan (2017). Masculine representation in South Korean cinema. Cine Forum, 26, 201-238. https://doi.org/10.19119/cf.2017.04.26.201

Lee, Hyangjin (2017). The Korean Wave and Anti-Korean Wave Sentiment in Japan:

The Rise of a New Soft Power for a Cultural Minority. In T. Yoon, Tae-Jin, \& D. Y. Jin (Eds), The Korean Wave: Evolution, Fandom, and Transnationality (pp. 185-208). Lexington Books.

Lee, Hyunji (2018). A 'real' fantasy: hybridity, Korean drama, and pop cosmopolitans. Media, Culture \& Society, 40(3), 365-380. https://doi.org/10.1177/0163443717718926

Lee, Jeehyun Jenny, Lee, Rachel Kar Yee, \& Park, Ji Hoon (2020). Unpacking K-pop in America: The Subversive Potential of Male K-pop Idols' Soft Masculinity. International Journal of Communication, 14, 5900-5919.

Lee, Jiyeun \& Park, Sung-Yeon (2015). Women's employment and professional empowerment in South Korean dramas: a 10-year analysis, Asian Journal of Communication, 25(4), 393-407. https://doi.org/10.1080/01292986.2014.968594

Lee, Jooran (2000). Remembered Branches: Towards a Future of Korean Homosexual Film. Journal of Homosexuality, 39 (3-4), 273-281.

https://doi.org/10.1300/J082v39n03_12

Lee, Min Joo (2020). Transnational Intimacies: Korean Television Dramas, Romance, Erotics, and Race [Doctoral dissertation, University of California, Los Angeles]. https://escholarship.org/uc/item/8df6c3pm

Lee, Seung-Hwan (2004). The Social Meaning of Body in Confucian Tradition Between Moral and Political Power. Korean Journal, 44(2), 5-29.

Lee, Soobum \& Ju, Hyejung (2010). Korean Television Dramas in Japan: Imagining "East Asianness" and Consuming "Nostalgia." Asian Women, 26(2), 77-103.

Lee, Sooyeon (2012). The Structure of the Appeal of Korean Wave Texts. Korea Observer, 43(3), 447-469.

Lenzi, I. (2015). Looking Out: How Queer Translates in Southeast Asian Contemporary Art. Intersections: Gender and Sexuality in Asia and the Pacific, 38. http://intersections.anu.edu.au/issue38/lenzi.html 
Leshkowich, A. (2014). Essential Trade: Vietnamese Women in a Changing Marketplace. University of Hawai'i Press.

Lessard, J. (2019). Transnational Slash: Korean Drama Formats, Boys' Love Fanfic, and the Place of Queerness in East Asian Media Flows. In P. Demory (Ed.), Queer/adaptation: A collection of critical essays (pp. 155-174). Springer International Publishing.

Lie, J. (2016). Obasan and Kanryū: Modalities of Convergence of Middle-Aged Japanese Women Around South Korean Popular Culture and Gender Divergence in Japan. Galbraith, P. W. \& Karlin, J. G. (Eds.) Media Convergence in Japan (pp. 124141). Kinema Club.

Lim, In-Sook. (2008). The Trend of Creating Atypical Male Images in Heterosexist Korean Society. Korea Journal, 48(4), 115-146.

Lin, A., \& Kwan, B. S. C. (2005). The Dilemmas of Modern Working Women in Hong Kong: Women's Use of Korean TV Dramas. Asian Communication Review, 9, 23-42. https://hub.hku.hk/bitstream/10722/146529/2/Content.pdf?accept=1

Lin, A. M. Y., \& Tong, A. (2007). Crossing Boundaries: Male Consumption of Korean TV Dramas and Negotiation of Gender Relations in Modern Day Hong Kong. Journal of Gender Studies, 16(3), 217-232. https://doi.org/10.1080/09589230701562905

Lin, Angel M. Y. (2002). Modernity and the Self. M/C: A Journal of Media and Culture, 5(5). https://journal.media-culture.org.au/index.php/mcjournal/article/view/1983

Lin, Wan-shuan (2019). Reconsidering Love in Japanese and Korean Trendy Dramas. Tamkang Review, 50(1), 113-119.

Locke, C., Nguyen, T. T. T. \& Nguyen, T. N. H (2014). Mobile householding and marital dissolution in Vietnam: An inevitable consequence? Geoforum, 51, 273-283. https://doi.org/10.1016/j.geoforum.2013.03.002 Louie, K., \& Edwards, L. (1994). Chinese Masculinity: Theorizing Wen and Wu. East Asian History, 8, 135-148.

Louie, K. (2002). Theorising Chinese Masculinity: Society and Gender in China. Cambridge University Press. 
Louie, K. (2012). Popular Culture and Masculinity Ideals in East Asia, with Special Reference to China. The Journal of Asian Studies, 71(4), 929-943.

https://doi.org/10.1017/S0021911812001234

Lukac-Greenwood, J., \& Rijn, B. (2021). Female therapists' experiences of working with male clients who are sexually attracted to them-An exploratory study using a free association narrative interview method. Counselling and Psychotherapy Research. https://doi.org/10.1002/capr.12392

Luong, Hy V. (Ed.). (2003). Postwar Vietnam: Dynamics of a transforming society. Institute of Southeast Asian Studies, Rowman \& Littlefield Publishers.

Luong, Van Nhan \& Evans, J. (2021). Fans translation in the Vietnamese context: a preliminary study. Asia Pacific Translation and Intercultural Studies, 8(2), 163-177. https://doi.org/10.1080/23306343.2021.1931782

Luong, Thi (2016). The Impact of Korean Dramas on the Consumption of Korean Consumer Products in Vietnam and Audiences' Perceptions of South Korea [Unpublished Master's thesis, University of Westminster].

Ma, S. (2007a). The O of Han Ju: Those Full, (Over)Painted Lips that Dare to Confess. Television \& New Media, 8(2), 107-123. https://doi.org/10.1177/1527476406299155

Ma, S. (2007b). Tradition and/of Bastards in the Korean Wave. In East-West Montage: Reflections on Asian Bodies in Diaspora (pp. 128-140). University of Hawai'i Press.

Maheshwari, G., \& Nayak, R. (2020). Women leadership in Vietnamese higher education institutions: An exploratory study on barriers and enablers for career enhancement. Educational Management Administration \& Leadership.

https://doi.org/10.1177/1741143220945700

Mai Thi Thuy Dung (2015). Promoting Gender Equality in Education in Vietnamese High Schools [Doctoral dissertation, Liverpool John Moores University]. https://researchonline.ljmu.ac.uk/id/eprint/4485/

Mai, Yên (2017). Constructing Queerness in Vietnam: Essentialism, Homonormativity, and Social Hierarchy, Sosiologia, 54(4), 393-409.

Maliangkay, R. \& Song, G. (2015). A sound wave of effeminacy: K-pop and the male beauty ideal in China. In J. Choi \& R. Maliangkay (Eds.), K-pop - the International Rise of the Korean Music Industry (pp. 164-177). Routledge. 
Maliangkay, R. (2010). The Effeminacy of Male Beauty in Korea. The Newsletter (International Institute for Asian Studies), 55. https://www.iias.asia/thenewsletter/article/effeminacy-male-beauty-korea

Maliangkay, R. (2013). Catering to the Female Gaze: The Semiotics of Masculinity in Korean Advertising. Situations: Cultural Studies in the Asian Context, 7(1), 43-61. http://hdl.handle.net/1885/37309

Manietta, J. (2015). Transnational Masculinities: The Distributive Performativity of Gender in Korean Boy Bands [Masters' dissertation, University of Colorado]. https://scholar.colorado.edu/concern/graduate_thesis_or_dissertations/wp988k10f Mar, R. A., \& Oatley, K. (2008). The function of fiction is the abstraction and simulation of social experience. Perspectives on Psychological Science, 3(3), 173-192. https://doi.org/10.1111/j.1745-6924.2008.00073.x

Maresca, T. (2013, May 1). Vietnam: Flawed on Human Rights, but a Leader in Gay Rights. The Atlantic. https://www.theatlantic.com/international/archive/2013/04/vietnamflawed-on-human-rights-but-a-leader-in-gay-rights/275413/

Marr, D., \& Rosen, S. (1998). Chinese and Vietnamese Youth in the 1990s. The China Journal, 40, 145-172.

Marr, D. (2000). Concepts of 'Individual' and 'Self' in Twentieth-Century Vietnam. Modern Asian Studies, 34(4), 769-796. https://doi.org/10.1017/S0026749X00003851

Martin, P. (2018). 'Korean suits are only the latest Vietnamese uniform': Looking past myths of change and continuity in Vietnamese men and masculinities during Đổi Mới. In C. Earl (Ed.), Mythbusting Vietnam: Facts, Fictions, Fantasies (pp. 66-91). Nordic Institute of Asian Studies Press.

Martin, P. (2013). Renovating Masculinity: Urban Men's Experiences and Emergent Masculinity Models in Đổi Mới Vietnam [Doctoral dissertation, The University of Melbourne]. http://hdl.handle.net/11343/38508

Matza, T. (2009). Moscow's Echo: Technologies of the Self, Publics, and Politics on the Russian Talk Show. Cultural Anthropology, 24(3), 489522. https://doi.org/10.1111/j.1548-1360.2009.01038.x 
Mi Ly (2021, April 2). Đàn ông Việt quá... yếu, quá tệ trong phim Việt [Vietnamese men are too... weak, too repulsive in Vietnamese cinema]. tuổi trẻ online.

https://tuoitre.vn/dan-ong-viet-qua-yeu-qua-te-trong-phim-viet-20210402090728844.htm

Milanzi, M. C. (2001). Technologies of the Self: A Seminar with Michel Foucault. Systems Research and Behavioral Science, 18(1), 94. https://doi.org/10.1002/sres.398

Min, Wonjung, Jin, Dal Young, \& Han, Benjamin (2019). Transcultural fandom of the Korean Wave in Latin America: through the lens of cultural intimacy and affinity space. Media, Culture \& Society, 41(5), 604-619. https://doi.org/10.1177/0163443718799403 Minh Hạo (2018). Sao nam giống hệt con gái: chiêu trò để nổi tiếng ở K-pop. Zing News. https://zingnews.vn/sao-nam-giong-het-con-gai-chieu-tro-de-noi-tieng-o-kpoppost817620.html

Mishler, E. G. (1986). Research Interviewing: Context and Narrative. Harvard University Press.

Modleski, T. (1982). Loving with a Vengeance: Mass-Produced Fantasies for Women. Methuen.

Moon, Seungsook (2005). Trouble with Conscription, Entertaining Soldiers: Popular Culture and the Politics of Militarized Masculinity in South Korea. Men and Masculinities, 8(1), 64-92.

Morgan Brett, B. (2010). The Negotiation of Midlife: Exploring the Subjective Experience of Ageing [Doctoral dissertation, The University of Essex].

http://repository.essex.ac.uk/2394/

Mōri, Y. (2008). Winter Sonata and Cultural Practices of Active Fans in Japan: Considering Middle-Aged Women as Cultural Agents. In C. Huat \& K. Iwabuchi (Eds.), East Asian Pop Culture: Analysing the Korean Wave (pp. 127-142). Hong Kong University Press.

Mulya, T. W. (2020, January 20). Queer pop culture. Inside Indonesia. https://www.insideindonesia.org/queer-pop-culture

Myers, G., \& Lampropoulou, S. (2016). Laughter, non-seriousness and transitions in social research interview transcripts. Qualitative Research, 16(1), 78-94.

https://doi.org/10.1177/1468794114561346

Neale, S. (1986). Melodrama and Tears, Screen, 27(6), 6-23. 
Nghe, L. T., Mahalik, J. R. \& Lowe, S. M. (2003). Influences on Vietnamese Men: Examining Traditional Gender Roles, the Refugee Experience, Acculturation, and Racism in the United States. Journal of Multicultural Counseling and Development, 31(4), 245-261.

Nghiem Lien Huong (2006). Work Culture, Gender and Class in Vietnam:

Ethnographies of Three Garment Workshops in Hanoi [Doctoral dissertation, University of Amsterdam]. https://hdl.handle.net/11245/1.307169

Ngo Thi Ngan Binh (2004). The Confucian Four Feminine Virtues (tu duc): The Old Versus the New - Ke thua Versus Phat huy. In L. Drummond, \& H. Rydstrøm (Eds.), Gender Practices in Contemporary Vietnam (pp. 47-73). Singapore University Press.

Ngo, Anh D., Ross, M. W \& Ratliff, E. A. (2008). Internet influences on sexual practices among young people in Hanoi, Vietnam. Culture, Health \& Sexuality, 10(S1), S201S213. https://doi.org/10.1080/13691050701749873

Ngo, Thu Ha (2015). Korean Masculinity in TV Dramas and Local Fantasies: A Case Study of Full House and its Vietnamese Remake Ngôi Nhà Hạnh Phúc. In M. J. Ainslie, \& J. B. Y. Lim (Eds.), The Korean Wave in Southeast Asia: Consumption and Cultural Production (pp. 133-154). Strategic Information and Research Development Centre.

Ngọc Diệp, Hoàng Lê, \& Hà Trang (2019, December 13). Đàn ông Việt trên phim xấu xí, vì đâu nên nỗi? [Ugly Vietnamese men on screen: why?]. tuổi trẻ online.

https://tuoitre.vn/dan-ong-viet-tren-phim-xau-xi-vi-dau-nen-noi20191209150838541.htm

Nguyen Bich Thuan \& Thomas, M. (2004). Young Women and Emergent Postsocialist Sensibilities in Contemporary Vietnam. Asian Studies Review, 28(2), 133-149. https://doi.org/10.1080/1035782042000226684

Nguyễn Thị Kiều Anh \& Nguyễn Thị Thanh (2018, October 12). Tiểu thuyết đam mỹ ở Việt Nam: Cần cái nhìn đối thoại [Danmei in Vietnam: Further dialogue is needed]. Website Khoa Ngũ̃ Văn Trường Đại Học Sư Phạm Hà Nội 2 [Hanoi National University of Education's Faculty of Linguistics and Literature's website].

http://ms.hpu2.edu.vn/vi/khoa-ngu-van/nghien-cuu-khoa-hoc/tieu-thuyet-dam-my-o-vietnam-can-cai-nhin-doi-thoai-139.html

Nguyễn Thị Ngân (2019). Đề tài trong tiểu thuyết các nhà văn nữ Việt Nam đương đại từ góc nhìn giới [Themes in novels of contemporary Vietnamese female writers from 
gender perspective]. Tạp chí Khoa học - Đại học Huế: Khoa học Xã hội Nhân văn [Journal of Huế University: Social Sciences and Humanities], 128(6A), 17-28.

Nguyen Thi Thu Ha (2011). Gender ideologies in the Vietnamese printed media. In D. Majstorović \& I. Lassen (Eds.), Living with Patriarchy: Discursive Constructions of Gendered Subjects across Cultures (pp. 195-216). John Benjamins.

Nguyen Thi Thu Ha (2012). Gender Ideologies in Vietnamese Print Media [Doctoral dissertation, National University of Singapore]. http://scholarbank.nus.edu.sg/handle/10635/36341

Nguyen Thi Thuy Hanh (2009). Reproductive Paradoxes in Vietnam: Masculinity, Contraception, and Abortion in Vietnam. In M. Inhorn, T. Tjørnhøj-Thomsen, H. Goldberg, \& M. La Cour Mosegaard (Eds.), Reconceiving the Second Sex: Men, Masculinity, and Reproduction (pp. 160-178). Berghahn Books.

Nguyen Tuan Anh, Rigg, J, Luong Thi Thu Huong \& Dinh Thi Dieu (2012). Becoming and being urban in Hanoi: Rural-urban migration and relations in Vietnam. The Journal of Peasant Studies, 39(5), 1103-1131. https://doi.org/10.1080/03066150.2011.652618

Nguyen, Arthur \& Özçaglar-Toulouse, N. (2021). Nation branding as a market-shaping strategy: A study on South Korean products in Vietnam, Journal of Business Research, 122(C), 131-144. https://doi.org/10.1016/j.jbusres.2020.08.029

Nguyen, H., Shiu, C. \& Hardesty, M. (2016). Extramarital Sex Among Vietnamese Married Men: Results of a Survey in Urban and Rural Areas of Northern and Southern Vietnam, The Journal of Sex Research, 53(9), 1065-1081.

Nguyen, Hien Thi \& Hoang, Lan Anh (2019). Gender Ideology on Marriage in Contemporary Vietnam. Resiprokal: Jurnal Riset Sosiologi Progresif Aktual, 1(1), 7493.

Nguyen, Hoang Ngoc (1991). Economic Renovation in Southern Vietnam: ChallengesResponses-Prospects. In D. Forbes, T. H. Hull, D. G. Marr, \& B. Brogan (Eds.), Doi Moi: Vietnam's Renovation Policy and Performance (pp. 34-45). Political and Social Change Monogram No 14, Australian National University.

Nguyen, Huong (2015a). The Conceptualization and Representations of Adolescence in Vietnamese Media during the "Reform Era" of Vietnam (1986-1995). Journal of Family History, 40(2), 172-194. https://doi.org/10.1177/0363199015573401 
Nguyen, Huong (2015b). Globalization, Consumerism, and the Emergence of Teens in Contemporary Vietnam. Journal of Social History, 49(1), 4-19.

https://doi.org/10.1093/jsh/shv009

Nguyen, Huong Thu (2016). Navigating identity, ethnicity and politics: a case study of gender variance in the Central Highlands of Vietnam, NORMA: International Journal for Masculinity Studies, 11(4), 255-269. https://doi.org/10.1080/18902138.2016.1259845

Nguyễn, Hữu Minh \& Nguyễn, Thị Thanh Tâm (2014). Phụ nữ nông thôn đi lao động ở nước ngoài: phân tích từ góc độ giới [Rural women's labour migration overseas: an analysis from a gender lens], Tạp chí khoa học xã hội Việt Nam [Vietnamese journal of social sciences], 5(78), 59-71.

Nguyen, Khanh Linh \& Harris, J. D. (2009). Extramarital Relationships, Masculinity, and Gender Relations in Vietnam. Southeast Review of Asian Studies, 31, 127-142.

Nguyen, Linh Khanh (2016a). Women as Fish: Physical Movement and Social Mobility in Contemporary Vietnam [Doctoral dissertation, Syracuse University]. ProQuest Dissertations and Theses Global.

Nguyen, Linh Khanh (2016b). Women as Fish: Rural Migration and Displacement in Vietnam. In P. Taylor (Ed.), Connected and Disconnected in Viet Nam: Remaking Social Relations in a Post-socialist Nation (pp. 109-140). ANU Press.

Nguyen, Nhat Nguyen, Özçaglar-Toulouse, N., \& Kjeldgaard, D. (2018). Toward an understanding of young consumers' daily consumption practices in post-Doi Moi Vietnam. Journal of Business Research, 86, 490-500.

https://doi.org/10.1016/j.jbusres.2017.10.002

Nguyen, Phuong An (2003). Between 'Still Society' and 'Moving Society': Life Choices and Value Orientations of Hanoi University Graduates in Post-Reform Vietnam [Doctoral dissertation, University of Hull].

Nguyen, Phuong An (2004). Pursuing success in present-day Vietnam: Young graduates in Hanoi. In D. McCargo (Ed.), Rethinking Vietnam (pp. 165-176). Taylor and Francis.

Nguyen, Phuong An (2005). Courtship and marriage among university graduates in Hanoi: Changing values in a time of economic liberalization. South East Asia Research, 13(3), pp. 385-415. 
Nguyen, Phuong An (2007). 'Relationships Based on Love and Relationships Based on Needs': Emerging Trends in Youth Sex Culture in Contemporary Urban Vietnam. Modern Asian Studies, 41(2), 287-313. http://www.jstor.org/stable/4132353

Nguyen, T. N. Minh (2015). Vietnam's Socialist Servants: Domesticity, class, gender, and identity. Routledge.

Nguyen, T. N. Minh (2018a). Money, Risk Taking, and Playing: Shifting Masculinity in a Waste-Trading Community in the Red River Delta. In K. Endres, \& A. Leshkowich (Eds.), Traders in Motion: Identities and Contestations in the Vietnamese Marketplace (pp. 105-116). Cornell University Press.

Nguyen, T. N. Minh (2018b). Vietnam's 'socialization' policy and the moral subject in a privatizing economy. Economy and Society, 47(4), 627-647.

https://doi.org/10.1080/03085147.2018.1544397

Nguyen, T. N. Minh (2019). Waste and Wealth: An Ethnography of Labor, Value, and Morality in a Vietnamese Recycling Economy. Oxford University Press.

Nguyen, Thi Huyen Linh (2019). Reading the Youtube sitcom My best gay friends: what it means to be gay in Vietnam. Continuum, 33(5), 540-553.

Nguyen, Thi Quynh Trang, \& Simkin, K. (2017). Gender discrimination in Vietnam: the role of personal face. Journal of Gender Studies, 26(6), 609-617.

https://doi.org/10.1080/09589236.2015.1095083

Nguyen, Thi Quynh Trang (2015). Gender discrimination in the way the Vietnamese talk about face thể diện: Results from interviews with Vietnamese teachers. Qualitative Research Journal, 15(2), 147-154. https://doi.org/10.1108/QRJ-12-2014-0066

Nguyen, Thi Thuy Minh, \& Le Ho, Gia Anh (2013). Requests and politeness in Vietnamese as a native language. Pragmatics, 23(4), 685-714.

https://doi.org/10.1075/prag.23.4.05ngu

Nguyen, Thi Tuyet Mai, Smith, K. \& Cao, Johnson R. (2009). Measurement of Modern and Traditional Self-Concepts in Asian Transitional Economies. Journal of Asia-Pacific Business, 10, 201-220.

Nguyen, Thuc-Doan T., \& Belk, R. (2012). Vietnamese Weddings: From Marx to Market. Journal of Macromarketing, 32(1), 109-120.

https://doi.org/10.1177/0276146711427302 
Nguyen, Trang T. (2021). "I am not a good enough caregiver, and it is my fault": The complex self-concept of Vietnamese female caregivers in dementia care. Dementia, 122. https://doi.org/10.1177/1471301221994359

Nguyen-Thu, Giang (2016). Personal Wealth, National Pride: Vietnamese Television and Commercial Nationalism. In Z. Volcic \& M. Andrejevic (Eds.), Commercial Nationalism: Selling the Nation and Nationalizing the Sell (pp. 86-105). Palgrave Macmillan.

Nguyen-Thu, Giang (2019). Television in post-reform Vietnam: Nation, media, market. Routledge.

Nguyễn-Võ Thu-Hương (2008). The Ironies of Freedom: Sex, Culture, and the Neoliberal Governance in Vietnam. University of Washington Press.

Nilan, P. (1999). Young People and Globalizing Trends in Vietnam. Journal of Youth Studies, 2(3), 353-370.

Nittono, H. (2016). The two-layer model of 'kawaii': A behavioural science framework for understanding kawaii and cuteness. East Asian Journal of Popular Culture, 2(1), 79-95. https://doi.org/10.1386/eapc.2.1.79_1

Nualart, C. (2016). Queer art in Vietnam: from closet to pride in two decades. Palgrave Communications, 1-10. https://doi.org/10.1057/palcomms.2016.9

Nualart, C. (2018). Contemporary Feminist Art in Vietnam: The visual emergence of agency. Irish Journal of Asian Studies, 4, 22-38.

O’Harrow, S., (1995). Vietnamese Women and Confucianism: Creating Spaces from Patriarchy. In W. J. Karim (Ed.), "Male" and "Female" in Developing Southeast Asia (pp. 161-180). Berg Publishers.

O’Shaughnessy, M. (1994). Promoting “emotion": Feelings, film studies and teaching or understanding films; understanding ourselves. Metro, 97, 44-48.

https://search.informit.org/doi/10.3316/informit.148675033684054 (Original work published March 1994)

Oh Chuyun \& Oh, David C. (2017). Unmasking Queerness: Blurring and Solidifying Queer Lines through K-Pop Cross-Dressing. The Journal of Popular Culture, 50(1), 929. https://doi.org/10.1111/jpcu.12506 
Oh Chuyun (2017). "Cinderella” in Reverse: Eroticizing Bodily Labor of Sympathetic Men in K-Pop Dance Practice Video. In X. Lin, C. Haywood, M. Mac an Ghaill (Eds.), East Asian Men: Masculinity, Sexuality and Desire (pp. 123-141). Palgrave MacMillan. Oh Ingyu (2011). Torn Between Two Lovers: Retrospective Learning and Melancholia among Japanese Women. Korea Observer, 42, 223-254.

Oh Youjeong (2014). Korean Television Dramas and the Political Economy of City Promotion. International Journal of Urban and Regional Research, 38(6), 2141-2155.

Oh, Chuyun (2015). Queering spectatorship in K-pop: The androgynous male dancing body and western female fandom. The Journal of Fandom Studies, 3(1), 59-78. https://doi.org/10.1386/jfs.3.1.59_1

Oleszczuk, A. \& Waszkiewicz, A. (2020). Queerness of Hallyu 2.0: Negotiating Nonnormative Identities in K-pop Music Videos. Res Rhetoria, 7(2), 118-131.

Ouellette, L., \& Hay, J. (2008). Better Living Through Reality TV: Television and PostWelfare Citizenship. Blackwell.

Park, Mi-Sook (2017). A Study on Transnational Cultural Flows in Asia through the Case of Hallyu in Vietnam. In Yoon, Tae-Jin \& Jin Dal Yong (Eds), The Korean Wave: Evolution, Fandom, and Transnationality (pp. 245-263). Lexington Books.

Pashigian, M. (2002). Conceiving the Happy Family: Infertility and Marital Politics in Northern Vietnam. In M. Inhorn \& F. Van Balen (Eds.), Infertility around the Globe: New Thinking on Childlessness, Gender, and Reproductive Technologies (pp. 134-151). University of California Press.

Pelzer, C. (1993). Socio-Cultural Dimension of Renovation in Vietnam: Doi Moi as Dialogue and Transformation in Gender Relations. In W. S. Turley, \& M. Selden (Eds.), Reinventing Vietnamese Socialism: Doi Moi in Comparative Perspectives (pp. 309326). Westview Press.

Pettus, A. (2003). Between Sacrifice and Desire: National Identity and the Governing of Femininity in Vietnam. Routledge.

Pham, Hai Chung (2015). Brand Consumption in Contemporary Vietnam [Doctoral dissertation, Bournemouth University]. http://eprints.bournemouth.ac.uk/24523/ 
Phạm Quỳnh Phương, \& Eipper, C. (2009). Mothering and Fathering the Vietnamese: Religion, Gender and National Identity, Journal of Vietnamese Studies, 4(1), 49-83. https://doi.org/10.1525/vs.2009.4.1.49

Pham, Nhu Ngoc K., Do, M., Bui, V. H. \& Nguyen, G. T. (2018). Rural-to-urban migration in Vietnam: Conceptualized youth's vulnerabilities in the city. International Journal of Migration, Health and Social Care, 14(1), 117-130. https://doi.org/10.1108/IJMHSC-11-2015-0044

Pham, Thi Hong Nhung (2018). Confucian Values as Challenges for Communication in Intercultural Workplace Contexts: Evidence from the Motivational Concerns in Vietnamese Politeness Behaviour. In A. Curtis \& R. Sussex (Eds.), Intercultural Communication in Asia: Education, Language and Values (pp. 75-93). Springer. Phan, Khanh-Van (2020). Gender Differences in the Labour Market: The Case of Vietnam [Doctoral dissertation, University of Bath]. https://researchportal.bath.ac.uk/en/studentTheses/gender-differences-in-the-labourmarket-the-case-of-vietnam

Phan Thanh Thanh (2014). Asianization, Imagination, Fan Culture and Cultural Capital of Vietnamese Youth: A Case Study of K-pop Cover Dance Groups in Hanoi Vietnam. 2014 AIKS (Ateneo Initiative for Korean Studies) Korean Studies Conference, "The Hallyu Mosaic in the Philippines: Framing Perceptions and Practice." http://m.ateneo.edu/sites/default/files/attachedfiles/Hallyu\%20Proceedings_Draft1b_2014-Sept-25.pdf\#page=162

Phan Thi Vang Anh, \& Pham Thu Thuy (2003). Let's talk about love: Depictions of love and marriage in contemporary Vietnamese short fiction. In L. Drummond, \& M. Thomas (Eds.), Consuming Urban Culture in Contemporary Vietnam (pp. 202-218). Routledge Curzon.

Phinney, H. M. (2008). Objects of Affection: Vietnamese Discourse on Love and Emancipation. Positions, 16(2), 329-358. https://doi.org/10.1215/10679847-2008-004

Phinney, H. M. (2009). “Eaten One's Fill and All Stirred Up”: Doi Moi and the Reconfiguration of Masculine Sexual Risk and Men's Extramarital Sex in Vietnam. In J. Hirsch, H. Wardlow, D. Smith, H. Phinney, S. Parikh, \& C. Nathanson (Eds.) The Secret: Love, Marriage, and HIV (pp. 108-135). Vanderbilt University Press. 
Putri, A. S. M., \& Mintarsih, A. R. (2020). Bangtan Sonyeondan in America: Soft Masculinity Performance and Audience Response, International Review of Humanities Studies, 5(1), 209-223.

Putri, B. M. S., \& Yatim, D. I. (2019). Parasocial Interaction Among Young Female Devotees of Korean Dramas. ANIMA Indonesian Psychological Journal, 34(4), 188197.

Puzar, A., \& Hong, Y. (2018). Korean Cuties: Understanding Performed Winsomeness (Aegyo) in South Korea. The Asia Pacific Journal of Anthropology, 19(4), 333-349. https://doi.org/10.1080/14442213.2018.1477826

Quach, Trang (2008). Femininity and sexual agency among young unmarried women in Hanoi. Culture, Health \& Sexuality, 10, S151-S161.

https://doi.org/10.1080/13691050701809248

Radway, J. (1991). Reading the Romance: Women, Patriarchy, and Popular Culture. (2nd ed.). The University of North Carolina Press. (Original work published 1984)

Rato, M. (2007). The Decline of Socialist Realism in Post-19875 Vietnamese Literature. MANUSYA: Journal of Humanities, 10(2), 24-40.

Renold, E. (2004). 'Other' boys: Negotiating non-hegemonic masculinities in the primary school. Gender and Education, 16(2), 247-265.

https://doi.org/10.1080/09540250310001690609

Riessman, C. K. (1990). Divorce talk: Women and men make sense of personal relationships. Rutgers University Press.

Riessman, C. K. (1993). Narrative analysis. Sage Publications.

Robinson, S (1984) The Art of the Possible. In The Radical Science Collective (Eds), Free Associations, Pilot Issue (pp. 122-148). Free Association Books.

Rose, N. (1996). Inventing Ourselves: Psychology, Power, and Personhood. Cambridge University Press.

Roseneil, S. (2006). The Ambivalences of Angel's 'Arrangement': A psychosocial Lens on The Contemporary Condition of Personal Life. The Sociological Review, 54(4), 847869. https://doi.org/10.1111/j.1467-954X.2006.00674.x 
Roseneil, S., \& Budgeon, S. (2004). Cultures of Intimacy and Care beyond 'the Family': Personal Life and Social Change in the Early 21st Century. Current Sociology, 52(2), 135-159. https://doi.org/10.1177/0011392104041798

Rosenthal, G. (1993). Reconstruction of Life Stories: Principles of Selection in Generating Stories for Narrative Biographical Interviews. In R. Josselson, \& A. Lieblich (Eds.), The Narrative Study of Lives (Vol 1, pp. 59-91). Sage.

Russell, M. J. (2008) Pop goes Korea: Behind the Revolution in Movies, Music, and Internet Culture. Stone Bridge Press.

Ruti, M. (2008). The Fall of Fantasies: A Lacanian Reading of Lack. Journal of the American Psychoanalytic Association, 56(2), 483-508. https://doi.org/10.1177/0003065108319687

Ruti, M. (2018). Penis Envy and Other Bad Feelings: The Emotional Costs of Everyday Life. Columbia University Press.

Rydstrøm, H. (2004). Female and Male "Characters": Images of Identification and SelfIdentification for Rural Vietnamese Children and Adolescents. In L. Drummond, \& H. Rydstrøm (Eds.), Gender Practices in Contemporary Vietnam (pp. 74-95). Singapore University Press.

Rydstrøm, H., \& Drummond, L. (Eds.) (2004). Gender Practices in Contemporary Vietnam. Singapore: Singapore University Press.

Salemink, O., \& Nguyễn Tuấn Anh (2019). The Pursuit of Happiness in Vietnam. In C. Yuri, J. Tice, \& B. S. Turner (Eds.), Regimes of Happiness: Comparative and Historical Studies (pp. 201-218). Anthem Press.

Sartre, J. (1940/2004). The Imaginary: A Phenomenological Psychology of the Imagination (J. Webber, Trans.). Routledge.

Saville Young, L., \& Frosh, S. (2018). Psychoanalysis in narrative research. In K. Stamenova \& R. D. Hinshelwood (Eds.), Methods of Research into the Unconscious: Applying Psychoanalytic Ideas to Social Science (pp. 199-210). Routledge.

Sawamoto, A. (2014). Vietnam's Rural-to-Urban Migrant Families: Educational and Social Inequalities in a Transitional Society [Doctoral dissertation, Columbia University]. Columbia: Academic Commons. https://doi.org/10.7916/D8XG9P9Z

Schafer, C. J. (2010). Lê Vân and Notions of Vietnamese Womanhood. Journal of Vietnamese Studies, 5(3), 129-191. https://doi.org/10.1525/vs.2010.5.3.129 
Schuler, S. R, et al. (2006). Constructions of Gender in Vietnam: In Pursuit of the 'Three Criteria'. Culture, Health \& Sexuality, 8(5), 383-394.

https://doi.org/10.1080/13691050600858924

Schulze, M. (2016). Inappropriate Desire and Heterosexuality Negotiated: The Case of Women K-Drama Watcher. In A. D. Jackson, \& C. Balmain (Eds.), Korean Screen Cultures: Interrogating Cinema, TV, Music, and Online Games (pp. 293-319). Peter Lang AG.

Schütze, F. (1992). Pressure and Guilt: War Experience of a Young German Soldier and Their Biographical Implications (Part 1). International Sociology, 7(2), 187-208. https://doi.org/10.1177/026858092007002005

Scott, S. and Truong, T. K. C. (2007). Gender research in Vietnam: Traditional approaches and emerging trajectories. Women's Studies International Forum, 30, 243253.

Seiter, E. (1990). Making Distinctions in TV Audience Research: Case Study of a Troubling Interview. Culture Studies, 4(1), 61-85.

Sennett, R., and Cobb, J. (1972). The hidden injuries of class. Knopf.

Sherman, G. D., \& Haidt, J. (2011). Cuteness and Disgust: The Humanizing and Dehumanizing Effects of Emotion. Emotion Review, 3(3), 245-251.

https://doi.org/10.1177/1754073911402396

Shiau, H. (2017). Soft, smooth with chocolate abs: Performance of a Korean masculinity in Taiwanese men's fashion. In K. Iwabuchi, E. Tsai, \& C. Berry (Eds.), Routledge Handbook of East Asian Popular Culture (pp. 212-226). Routledge.

Shim, Doobo (2006). Hybridity and the rise of Korean popular culture in Asia. Media, Culture \& Society, 28(1), 25-44. https://doi.org/10.1177/0163443706059278

Shin, Hisup (2016). The Sublime Body of Hallyu Celebrities: Conflicting Perceptions of Hallyu Celebrities in Korea. The Journal of Literature and Film, 17(3), 611-640.

Shin, Layoung (2018). Queer Eye for K-Pop Fandom: Popular Culture, Cross-gender Performance, and Queer Desire in South Korean Cosplay of K-pop Stars. Korea Journal, 58(4), 87-113 
Shohet, M. (2013). Everyday Sacrifice and Language Socialization in Vietnam: The Power of a Respect Particle. American Anthropologist, 115(2), 203-217.

https://doi.org/10.1111/aman.12004

Shohet, M. (2021). Silence and Sacrifice: Family Stories of Care and the Limits of Love in Vietnam. University of California Press.

Sidnell, J., \& Shohet, M. (2013). The problem of peers in Vietnamese interaction. The Journal of the Royal Anthropological Institute, 19(3), 618-638.

https://doi.org/10.1111/1467-9655.12053

Sinnott, M. (2012b). Korean-pop, tom gay kings, les queens and the capitalist transformation of sex/gender categories in Thailand. Asian Studies Review, 36(4), 453474. https://doi.org/10.1080/10357823.2012.739995

Skeggs, B., Thumim, N., \& Wood, H. (2008). "Oh goodness, I am watching reality TV": How methods make class in audience research. European Journal of Cultural Studies, 11(1), 5-24. https://doi.org/10.1177/1367549407084961

Soh, Weng-Khai and Ngo, Sheau-Shi (2014). I am Pretty and I know It: Redefining Masculinities in The King and the Clown. Media Watch 5(3), 333-344.

Song, Sooho (2020). The Evolution of the Korean Wave: How Is the Third Generation Different from Previous Ones? Korea Observer, 51(1), 125-150.

http://dx.doi.org/10.29152/KOIKS.2020.51.1.125

Sorsoli, L. (2007). Like pieces in a puzzle: Working with layered methods of reading personal narratives. In M. Bamberg, A. De Fina, \& D. Schiffrin (Eds.), Selves and identities in narrative and discourse (Studies in Narrative Vol. 9) (pp. 303-324). John Benjamins Publishing Company.

Soucy, A. (1999). Masculinities and Buddhist Symbolism in Vietnam. In K. Biber, T. Sear \& D. Trudinger (Eds.), Playing the man: New approaches to masculinity (pp. 123134). Pluto Press Australia.

Soucy, A. (2000). The problem with key informants. Anthropological Forum, 10(2), 179199. https://doi.org/10.1080/713650207

Soucy, A. (2001). Romantic love and gender hegemony in Vietnam. In S. Blackburn (Ed.), Love, sex and power: Women in Southeast Asia (pp. 31-42). Monash Asia Institute. 
Soucy, A. (2012). The Buddha Side: Gender, Power, and Buddhist Practice in Vietnam. University of Hawai'i Press.

Spence, L. (2005). Watching Daytime Soap Operas: The Power of Pleasure. Wesleyan University Press.

Straubhaar, J. (2007). World Television: From Global to Local. SAGE

Suh, C. S., Cho, Y. D. and Kwon, S. H (2006). The Korean Wave in Southeast Asia: An Analysis of Cultural Proximity and the Globalisation of the Korean Cultural Products. Academy of Korean Studies.

http://www.ikorea.ac.kr/congress/upload/\%EB\%AC\%B8\%ED\%99\%9431\%EC\%84\%9C\%EC\%A4\%91\%EC\%84\%9D\%EC\%99\%B82\%EB\%AA\%85.pdf Svendsen, L. (2005). A Philosophy of Boredom (Trans Irons, J.). Reaktion Books. (Original work published 1999)

Szymańska-Matusiewicz, G. (2014). The researcher as 'older sister', 'younger sister' and 'niece': playing the roles defined by the Vietnamese pronominal reference system. Qualitative Research, 14(1), 95-111. https://doi.org/10.1177/1468794112465636 Taga, F. (2004). East Asian Masculinities. In M. S. Kimmel, J. Hearn \& R. W. Connell (Eds.), Handbook of Studies on Men and Masculinities (pp. 129-140). Sage.

Taylor, P. (2016) (Ed.). Connected \& Disconnected in Vietnam: Remaking Social Relations in a Post-socialist Nation. ANU Press.

Templer, R. (1998). Shadow and Wind: A View of Modern Vietnam. Little Brown.

Thai, Hung Cam. (2008). For Better or For Worse: Vietnamese International Marriages in the New Global Economy. Rutgers University Press.

Thanh Cao (2018, June 15). Loạt sao nam Hàn Quốc có vẻ đẹp ẻo lả, phi giới tính. VnExpress. https://vnexpress.net/loat-sao-nam-han-quoc-co-ve-dep-eo-la-phi-gioi-tinh3761578.html

The Association for Psychosocial Studies (n.d.). About us. http://www.psychosocialstudies-association.org/about/

Thomas, M. (1998). Estranged Bodies and Vietnamese Identities. The Australian Journal of Anthropology, 9(1), 74-88. https://doi.org/10.1111/taja.1998.9.1.74 
Thomas, M. (2004). East Asian Cultural Traces in Post-Socialist Vietnam. In K. Iwabuchi, S. Muecke, \& M. Thomas (Eds.), Rogue Flows: Trans-Asian Cultural Traffic (pp. 177-195). Hong Kong University Press.

Thompson, J. B. (1995). The Media and Modernity: A Social Theory of the Media. Policy Press.

To, S. (2015). China's Leftover Women: Late marriage among professional women and its consequences. Routledge.

Tran Huu Phuc Tien (2002). Vietnamese Media in Transition: The Boon, Curse, and Controversy of Market Economics. In R. H. Heng (Ed.), Media Fortunes, Changing Times: ASEAN States in Transition (pp 231-248). Institute of Southeast Asian Studies.

Tran Ngoc Angie (2004). What's Women's Work? Male Negotiations and Gender Reproduction in the Vietnamese Garment Industry. In L. Drummond \& H. Rydstrøm (Eds.), Gender Practices in Contemporary Vietnam (pp. 210-235). Singapore University Press.

Trần Thanh Hồng Lan (2016). Đồng tính nam - Lựa chọn và dấn thân (Nghiên cứu trường hợp tại thành phố Hồ Chí Minh [Male homosexuality - Choice and Taking Risks (Research in Ho Chi Minh City)]. In Nguyễn Đức Lộc (Ed.), Đời sống xã hội Việt Nam đương đại: Những người thiểu số ở đô thị: Lựa chọn, trở thành, khác biệt (Tập 2) [Contemporary Vietnamese society: Urban minorities: Choice, Becoming, Difference (Vol. 2)] (pp. 89-152). Nhà xuất bản tri thức [Knowledge Publishing House].

Trần Thị Hường, \& Cao Thị Hải Bắc (2015). Ảnh hưởng của Hàn Lưu tại Việt Nam: Nhìn từ góc độ liên ngành (Phần 1) [The Effects of Hallyu in Vietnam: From an Interdisciplinary Perspective (Part 1)]. Tạp Chí Hàn Quốc [Korean Journal], 3, 1-28. Tran, Allen, L. (2015). Rich Sentiments and the Cultural Politics of Emotion in Postreform Ho Chi Minh City, Vietnam. American Anthropologist, 117(3), 480-492. https://doi.org/10.1111/aman.12291

Tran, Richard Quang-Anh (2014). An Epistemology of Gender: Historical Notes on the Homosexual Body in Contemporary Vietnam, 1986-2005. Journal of Vietnamese Studies, 9(2), 1-45. https://doi.org/10.1525/vs.2014.9.2.1

Tran Thi Minh Thi (2021). Complex transformation of divorce in Vietnam under the forces of modernization and individualism. International Journal of Asian Studies, 1-21. https://doi.org/10.1017/S1479591421000024 
Trịnh Minh Đỗ Uyên, \& Nguyễn Quốc Bình (2020). The Development of Boys Love in Vietnam: From Manga to Dammei Fiction to the Footbal Turf. Mechademina: Second Arc, 13(1), 148-152. https://muse.jhu.edu/article/772395

Trinh, T., Steckler, A., Ngo, A., \& Ratliff, E. (2009). Parent Communication about Sexual Issues with Adolescents in Vietnam: Content, Contexts, and Barriers. Sex Education, 9(4), 371-380. https://doi.org/10.1080/14681810903264819

Truong Huyen Chi (2009). A Home Divided: Work, Body, and Emotions in the Post-Doi Moi Family. In M. Barbieri, \& D. Bélanger (Eds.), Reconfiguring Families in Contemporary Vietnam (pp. 298-328). Stanford University Press.

Turley, W. S, \& Selden, M. (1993). (Eds.). Reinventing Vietnamese Socialism: Doi Moi in Comparative Perspectives. Westview Press.

Ungar, E. S. (1991). Media and Society: Sociocultural Change in Vietnam since 1986. In D. Forbes, T. H. Hull, D. G. Marr \& B. Brogan (Eds.), Doi Moi: Vietnam's Renovation Policy and Performance (Political and Social Change Monogram No 14, pp. 46-53). Australian National University.

Viện Xã hội học, ISEE, Viện Chiến lược và Chính sách y tế (2013). Kết quả trưng cầu ý kiến người dân về hôn nhân cùng giới [Report on survey of citizens' opinions on same-sex marriage]. http://isee.org.vn/wp-content/uploads/2018/11/ket-qua-trung-cau-y-kien-nguoidan-ve-hon-nhan-cung-gioi-2013..pdf

Visser, D. (2002, March 10). What Hip Asians Want: A Little Bit of Seoul. Washington Post. https://www.washingtonpost.com/archive/politics/2002/03/10/what-hip-asians-want-a-littlebit-of-seoul/0b17a0f8-8f70-4c7d-93af-79037eec7c2e/

Vu, Hong Tien (2020). Female leadership in Vietnam: Traditional gender norms, gender quota policy, and the media. In C. Chao \& L. Ha (Eds.), Asian Women Leadership: A Cross-National and Cross-Sector Comparison (pp 109-124). Routledge.

Vu, Hong Tien \& Lee, Tien-Tsung. (2013). Soap Operas as a Matchmaker: A Cultivation Analysis of the Effects of South Korean TV Dramas on Vietnamese Women's Marital Intentions. Journalism \& Mass Communication Quarterly, 90(2), 308-330.

https://doi.org/10.1177/1077699013482912

Vu, Hong Tien, Barnett, B., Duong, Hue Trong, \& Lee, Tien Tsung. (2019). 'Delicate and durable': An analysis of women's leadership and media practices in Vietnam. International Journal of Media \& Cultural Politics, 15(1), 87-108. 
https://doi.org/10.1386/macp.15.1.87_1

Vu, Thanh Thi (2015). Marital Experiences of Young Married Couples in Vietnam [Doctoral dissertation, La Trobe University]. http://hdl.handle.net/1959.9/538254

Vu, Thanh Thi (2020). Love, Affection and Intimacy in Marriage of Young People in Vietnam. Asian Studies Review, 1-17. https://doi.org/10.1080/10357823.2020.1798873

Vu Thi Thao, \& Agergaard, J. (2012). 'Doing Family': Female migrants and family transition in rural Vietnam. Asian Population Studies, 8(1), 103-119.

https://doi.org/10.1080/17441730.2012.646845

Vyrgioti, M. (2019). In the Closets of Fanon and Riviere: Psychoanalysis, Postcolonial Theory and the Psychosocial. In Frosh, S. (Ed.), New Voices in Psychosocial Studies (pp. 23-37). Palgrave Macmillan.

Walkerdine, V., \& Jimenez, L. (2012). Producing Pride in Masculinity: The Hard Steelworker. In V. Walkerdine \& L. Jimenez, Gender, Work and Community After DeIndustrialisation: A Psychosocial Approach to Affect (pp. 92-116). Palgrave Macmillan.

Walkerdine, V., Lucey, H., \& Melody, J. (2001). Growing Up Girl: Psychosocial Explorations of Gender and Class. Palgrave Macmillan.

Warren, J. (2017). Cultures of Development: Vietnam, Brazil and the Unsung Vanguard of Prosperity. Routledge.

Werner, J. (2004) State Subject-making and Womanhoods in the Red River Delta of Vietnam. Asian Studies Review, 28(2), 115-131.

Werner, J. (2009). Gender, Household, and State in Post-Revolutionary Vietnam. Routledge.

Werner, J. S. (2006). Between Memory and Desire: Gender and the remembrance of war in doi moi Vietnam. Gender, Place \& Culture, 13(3), 303-315.

Werner, J., \& Bélanger, D. (Eds.). (2002). Gender, Household, State: Doi Moi in Viet Nam. Cornell University Press.

Wetherell, M., \& Edley, N. (1999). Negotiating Hegemonic Masculinity: Imaginary Positions and Psycho-Discursive Practices. Feminism \& Psychology, 9(3), 335-356. https://doi.org/10.1177/0959353599009003012 
Whitehouse-Hart, J. (2014). Psychosocial Explorations of Film and Television Viewing: Ordinary Audience. Palgrave Macmillan.

Williams, L. (1991). Film Bodies: Gender. Film Quarterly, 44(4), 2-13.

https://doi.org/10.2307/1212758e

Wilson, M. (2011). The Politics of Enjoyment: The Media Viewing Preferences and Practices of Young Higher-Educated Chinese [Doctoral dissertation, University of Westminster]. https://westminsterresearch.westminster.ac.uk/item/900zx/the-politics-ofenjoyment-the-media-viewing-preferences-and-practices-of-young-higher-educatedchinese

Woodward, K. (2015). Psychosocial Studies: An Introduction. Routledge.

World Bank (2018). Climbing the Ladder: Poverty Reduction and Shared Prosperity in Vietnam. World Bank. https://openknowledge.worldbank.org/handle/10986/29684 Yang, Fang-Chih Irene (2008a). The Genrification of "Korean Drama" in Taiwan. China Information, 22(2), 277-304. https://doi.org/10.1177/0920203X08091547

Yang, Fang-Chih Irene (2008b). Engaging with Korean dramas: discourses of gender, media, and class formation in Taiwan. Asian Journal of Communication, 18(1), 64-79. https://doi.org/10.1080/01292980701823773

Yang, Fang-Chih Irene (2012). From Korean Wave to Korean Living: Meteor Garden and the Politics of Love Fantasies in Taiwan. Korea Observer, 43(3), 419-445.

Yang, Hsing-Chen (2014). Flower boys on campus: performing and practicing masculinity. Journal of Gender Studies, 23(4), 391-408.

https://doi.org/10.1080/09589236.2013.795112

Yang, Sunyoung (2019). "Loser" aesthetics: Korean internet freaks and gender politics. Feminist Media Studies, 19(6), 858-872.

https://doi.org/10.1080/14680777.2018.1503191

Yates, C. (2007). Masculine Jealousy and Contemporary Cinema. Palgrave Macmillan. https://doi.org/10.1057/9780230592926 
Yeo, Yezi (2017). The good, the bad, and the forgiven: The media spectacle of South Korean male celebrities' compulsory military service. Media, War \& Conflict, 10(3), 293313. https://doi.org/10.1177/1750635217694122

Yeoh, B. S. A., Chee, H. L. \& Vu, T. K. D. (2014). Global householding and the negotiation of intimate labour in commercially-matched international marriages between Vietnamese women and Singaporean men. Geoforum, 51, 284-293.

Yi, W. J. (2018). Melodramatic Tactics for Survival in the Neoliberal era: Excess and Justice in The Heirs and My Love from the Star. Journal of Korean Studies, 23(1), 153173.

https://doi.org/10.1215/21581665-4339098

Yip, J., Ainsworth, S. \& Hugh, M. T. (2019). Beyond Whiteness: Perspectives on the Rise of the Pan-Asian Beauty Ideal. In G. D. Johnson, K. D. Thomas, A. K. Harrison, \& S. A. Grier (Eds.), Race in the Market Place: Crossing Critical Boundaries (pp. 73-85). Springer Nature Switzerland AG.

Yoon, Tae-Jin \& Jin, Dal Yong. (Eds). (2017). The Korean Wave: Evolution, Fandom, and Transnationality. Lexington Books.

Zhang, L. (2010). In Search of Paradise: Middle-Class Living in a Chinese Metropolis. Cornell University Press.

Zharkevich, I., Roest, J. \& Vu Thi Thanh Huong (2016). Gendered Trajectories Through School, Work, and Marriage in Vietnam (Young Lives working paper 158).

https://www.younglives.org.uk/content/gendered-trajectories-through-school-work-andmarriage-vietnam 


\section{Appendices}

Note: The following appendices are translated from Vietnamese.

\section{Appendix A: Recruitment Ad}

Korean TV Drama viewers wanted!

Picture of a couple in a romantic Korean drama inserted here (photo not available due to copyright matter)

You have watched Korean TV dramas and have something to say about them?

Attend interviews and earn TWO shopping vouchers (each worth VND 100,000)!

Who I am looking for:

- Vietnamese men and women, of any sexual orientation, aged 26-36 years old;

- From anywhere in Vietnam, as long as you are able and willing to take part in TWO interviews in HANOI between April 17 and July 27, 2019;

- Willing to share your life stories and experiences;

- Examples of Korean TV dramas that you might have watched: Autumn Heart, Winter Sonata, Full House, My Name is Kim Sam Soon, Boys over Flowers, Heartstrings, High Society, Reply 1997, Reply 1994, Reply 1988, I Can Hear Your Voice, W, Descendants of the Sun, Strong Girl Bong-Soon, Something in the Rain, What's Wrong with Secretary Kim, Encounter,..

Travel allowance of VND100,000 will be given to those willing to travel to a preferred location for interviews (within 10km of Hanoi centre). Each interview may last up to 2.5 hours.

\section{Contact me:}

Zalo: Luong Minh Thi, +64-2108782375

Email: thi.luong@vuw.ac.nz

About me: My name is Thi Luong. I am a PhD student at Victoria University of Wellington. This recruitment is for my PhD project "Vietnamese Reception of Soft Masculinity in Korean TV Dramas: Desires, Identifications and Gender." 


\section{Appendix B: Information Sheet}

You are invited to take part in this research. Please read this information before deciding whether or not to take part. If you decide to participate, thank you. If you decide not to participate, thank you for considering this request.

\section{Who am I?}

My name is Thi Minh Thi Luong and I am a doctoral student in Media Studies at Victoria University of Wellington, New Zealand. This research project is work towards my Doctoral dissertation.

\section{What is the aim of this project?}

This project aims to explore how Vietnamese audiences receive the images of men with stereotypically defined feminine characteristics and to connect such reception with their ideals of masculinities. This research has been approved by the Victoria University of Wellington Human Ethics Committee (application reference number 0000026887).

\section{How can you help?}

You have been invited to participate because you met the criteria for my selection of viewers of Korean TV dramas (people aged 26-36 years old, able to attend two separate interviews between April - July 2019, and adequately exposed to Korean TV dramas). If you agree to take part, I will interview you twice on two separate occasions in Hanoi. I will ask you questions about (1) yourself and your background (education, lifestyles, hobbies, etc.), (2) how you view Korean TV dramas and what you feel about male characters in those dramas, (3) your life experiences that involve men, including social, romantic and family relationships, and what you feel about "masculinity". The interview may take two hours each, but there is no requirement for you to commit to this time duration. I will audiorecord the interview with your permission and write it up later. You can choose to not answer any question or stop the interview at any time, without giving a reason. You can withdraw from the study by contacting me at any time before July 30, 2019. If you withdraw, the information you provided will be destroyed or returned to you.

\section{Warning of possible risks}

As the interview involves questions about lived experiences and fantasies, it may, at some moments during the process, cause you emotional discomfort or uneasiness. The interviews may also be emotionally draining in the way that it makes you recall various events and experiences in your life during an expected duration of more than two hours. You are, therefore, advised to consider these risks before you decide to participate. You should only participate if you feel willing and comfortable enough to do so.

\section{What will happen to the information you give?}


- I, the researcher, will listen attentively to the transcripts of two interviews with you and analyse them. Original interview transcripts, summaries and any recordings will be kept securely and destroyed by October 15, 2020.

- $\quad$ There is a possibility that your interviews will be chosen for the review of a case study, which will involve a third party, an academic having access to your interview data (then fully de-identified, which means you cannot be identified through the translated transcripts in English). You may choose to not consent to this possibility in the consent form and your decision will be abided by.

\section{What will the project produce?}

The information from my research will be used in my $\mathrm{PhD}$ dissertation and possibly will be used in my academic publications and conference papers and presentations.

\section{If you accept this invitation, what are your rights as a research participant?}

You do not have to accept this invitation if you don't want to. If you do decide to participate, you have the right to:

- $\quad$ choose not to answer any question;

- $\quad$ ask for the recorder to be turned off at any time during the interview;

- $\quad$ withdraw from the study before July 30, 2019;

- $\quad$ ask any questions about the study at any time;

- $\quad$ receive a copy of your interview transcript if you request it;

- $\quad$ give comments after interviews;

- read any reports of this research by emailing the researcher to request a copy.

How will you be compensated for your time as you agree to participate?

You will receive a voucher worth VND100,000 after the first interview and another worth VND100,000 after the second interview. You will also receive a travel allowance of VND100,000 after the first interview if you attend the interview(s) at a place other than your own house, which you need to travel to.

If you have any questions or problems, who can you contact?

If you have any questions, either now or in the future, please feel free to contact me:

\section{Thi Minh Thi Luong}

Email: Thi.Luong@vuw.ac.nz

Address: School of English, Film, Theatre

and Media Studies

83 Fairlie Terrace, Kelburn campus

Phone +64-4-463 6393

\section{Human Ethics Committee information}

If you have any concerns about the ethical conduct of the research, you may contact the Victoria University HEC Convenor: Dr Judith Loveridge. Email hec@vuw.ac.nz or telephone +64-4-463 6028 . 


\section{Information about support services:}

If you experience any mental issues and need consultation, please consider contacting the following addresses:

- Psyhub: https://www.facebook.com/psyhubhanoi/

- Phòng Tham Vấn và Trị liệu tâm lý Nụ Cười Trái Tim:

https://www.facebook.com/nucuoitraitim/

- Viện Sức Khỏe Tâm Thần, Bệnh Viện Bạch Mai (Mental Health Centre, Bach Mai Hospital, Hanoi)

Tòa nhà T4, T5, T6 Viện Sức khỏe tâm thần - Bệnh viện Bạch Mai, Điện

Thoại: +84.4.35765344 Fax: +84.4.35765346, Email: vskttqg@vnn.vn

- Bệnh Viện Tâm Thần Ban Ngày Mai Hương

Hotline: 043 6275762, miễn phí (free consultation)

Số 4 phố Hồng Mai, phường Bạch Mai, quận Hai Bà Trưng, Hà Nội

Điện thoại: Hotline 043 - 627 - 5762

Email: benhvienmaihuong_89@yahoo.com.vn

Website: www.maihuong.gov.vn 


\section{Appendix C: Consent Form}

This consent form will be held for five years.

Researcher: Thi Thi Minh Luong, School of English, Film, Theatre and Media Studies, Victoria University of Wellington.

- I have read the Information Sheet and the project has been explained to me. My questions have been answered to my satisfaction. I understand that I can ask further questions at any time.

- I agree to take part in an audio recorded interview.

I understand that:

- I will receive a shopping voucher worth VND100,000 after the first interview and another worth VND100,000 after the second interview. I will also receive travel allowance of VND100,000 after the first interview if I attend the interview(s) at a place other than my house/office, which I need to travel to.

- I may withdraw from this study at any point before July 30,2019 , and any information that I have provided will be returned to me or destroyed.

- $\quad$ The identifiable information I have provided will be destroyed on October 15, 2020.

- $\quad$ Any information I provide will be kept confidential by the researcher and her supervisors unless I consent below to allowing my de-identified information to be viewed by another academic.

- I understand that the results might be used for a PhD dissertation, academic publications and/or presented to conferences.

- $\quad$ My name will not be used in reports, nor will any information that would identify me.

- I give my consent to a third party, an academic, to access the data I Yes provided, for review. I understand that that the data to be reviewed by the third party, which include the translated interview transcript (in English) and the researcher's notes and analysis, will be fully de-identified (all identifiable details will be changed or not disclosed).

Participant's consent signature:

Name of participant:

Date:

Contact details:

Signature to confirm acceptance of first shopping voucher:

Signature to confirm acceptance of second shopping voucher:

Signature to confirm acceptance of travel allowance: 


\section{Appendix D: Interview Guide}

\section{(1) Personal background:}

Can you please tell me about yourself and your life?

How did you grow up?

Can you please tell me about your family (including parents and siblings)?

How are your relationships with your parents and siblings?

Tell me about your education and career.

\section{(2) Gender views:}

What do you think an ideal man should be like?

Who are your ideals of masculinity? Who is the ideal man in your opinion? Can you give specific examples?

In your opinion, what are the qualities of an ideal man?

What do you think about gender relations and gender issues in Vietnam?

What do you feel about men in general? (you can talk about foreign and Vietnamese men)

Tell me about your experience with men. Can you share a few stories?

Would you mind telling me a little about your romantic experiences?

What is an ideal romantic relationship in your opinion?

\section{(3) Views regarding Korean dramas and soft masculinities:}

How did you come to watch Korean dramas?

Where do you watch Korean dramas? (online or on television)

Do you watch Korean dramas with subtitles or dubbed versions?

Do you watch Korean dramas with others or on your own?

In your application form, you shared that you had watched and enjoyed [drama name(s)]. Can you tell me your feelings about this/these drama(s)?

Is there any Korean drama that you have watched multiple times?

Who is your favourite K-drama male character? What is it about this character that you like?

Tell me about your favourite scenes in the Korean dramas you have watched.

How do you feel about the way romance is portrayed in Korean dramas?

Have you ever related situations in Korean dramas to your own life? 